\title{
DESIGNING THE BIOMETHANE SUPPLY CHAIN THROUGH AUTOMATED SYNTHESIS \\ Taede Weidenaar
}

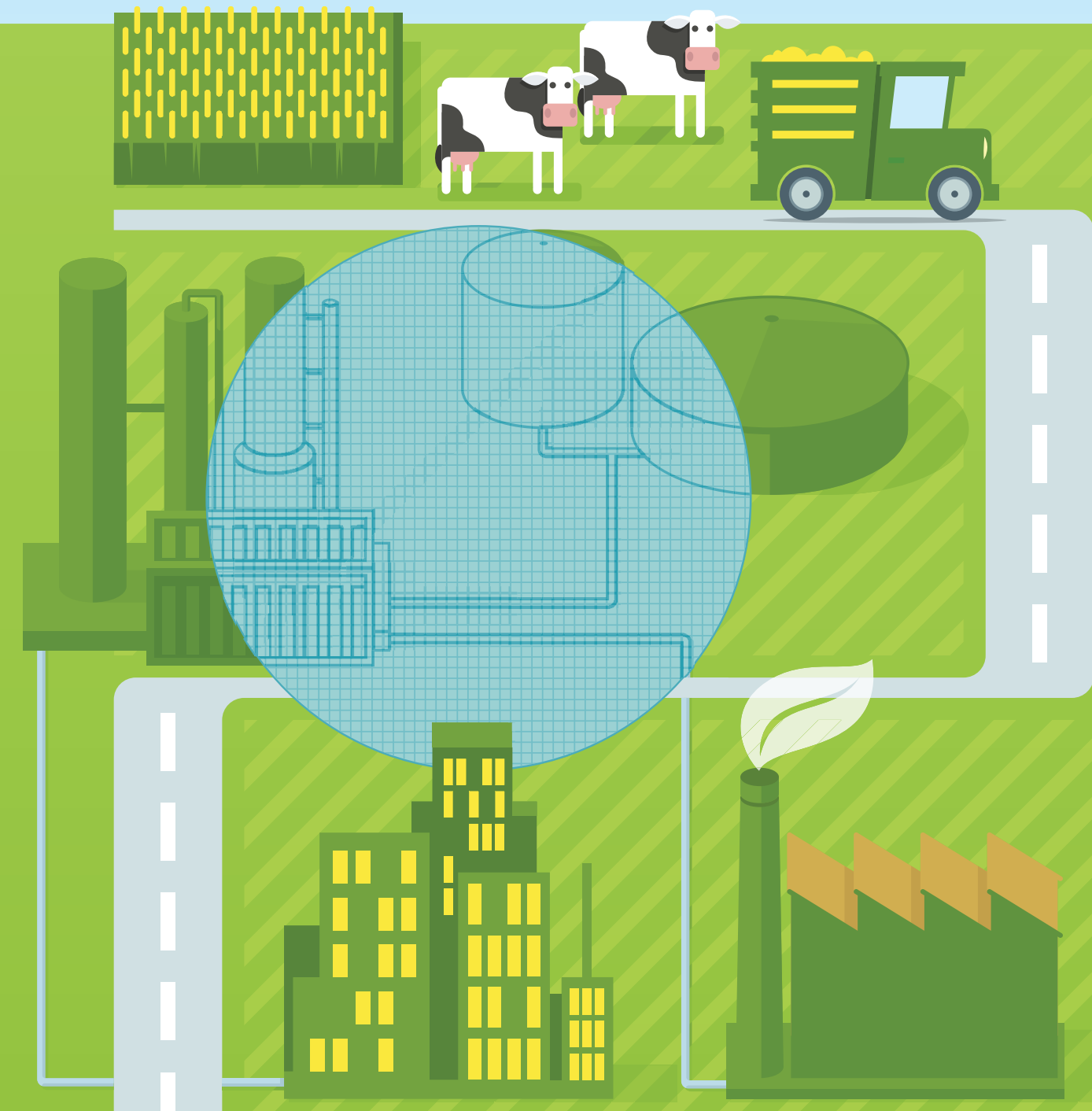




\title{
DESIGNING THE BIOMETHANE SUPPLY CHAIN THROUGH AUTOMATED SYNTHESIS
}

\author{
PROEFSCHRIFT
}

\author{
ter verkrijging van \\ de graad van doctor aan de Universiteit Twente, \\ op gezag van de rector magnificus, \\ prof. dr. H. Brinksma, \\ volgens besluit van het College voor Promoties \\ in het openbaar te verdedigen \\ op donderdag 27 maart 2014 om 14.45 uur
}

door

Taede Durk Weidenaar

geboren op 19 augustus 1984

te Dongeradeel 
Dit proefschrift is goedgekeurd door:

Prof. dr. ir. F.J.A.M. van Houten promotor

Prof. dr. ir. M. Wolters

promotor

Dr. ir. S. Hoekstra

assistent promotor

Dr. ir. J.M. Jauregui Becker

assistent promotor 


\section{DESIGNING THE BIOMETHANE SUPPLY CHAIN THROUGH AUTOMATED SYNTHESIS}

PhD Thesis

By Taede D. Weidenaar at the Faculty of Engineering Technology (CTW) of the University of Twente, Enschede, the Netherlands.

Enschede, 27 March 2014 
De promotiecommissie:

Prof. dr. G.P.M.R. Dewulf Prof. dr. ir. F.J.A.M. van Houten Prof. dr. ir. M. Wolters Dr. ir. S. Hoekstra Prof. dr. ir. J.I.M. Halman Prof. dr. ir. G.J.M. Smit Prof. dr. R. Künneke Prof. dr. A.A. Broekhuis Prof. dr. ir. W. D'haeseleer
Universiteit Twente, voorzitter en secretaris Universiteit Twente, promotor Universiteit Twente, promotor Universiteit Twente, assistent promotor Universiteit Twente Universiteit Twente Technische Universiteit Delft Rijksuniversiteit Groningen Katholieke Universiteit Leuven

This research has been financed by a grant of the Energy Delta Gas Research (EDGaR) program. EDGaR is co-financed by the Northern Netherlands Provinces, the European Fund for Regional Development, the Ministry of Economic Affairs, and the Province of Groningen.

ISBN: $978-90-365-3612-7$

DOI: $10.3990 / 1.9789036536127$

Printed by Ipskamp Drukkers, Enschede

Copyright $($ ) Taede D. Weidenaar, 2014

All rights reserved. 


\section{Summary}

The Dutch gas distribution infrastructure faces several significant changes in the near future. One of these major changes is the production and injection of biomethane into the gas distribution grid. The distribution system operators (DSOs) must invest in the gas distribution grid in order to facilitate the injection of biomethane. Therefore, numerous choices need to be made with respect to the design of the biomethane supply chain and gas distribution grid. The choices made throughout the design process largely depend on the local situation and the DSOs' preferences. In this research, a decision support tool (DST) has been developed that supports the design process of the biomethane supply chain and the gas distribution grid, by creating candidate solutions for a certain region, which consists of biomass locations, gas grids, and gas consumers.

To underline the importance of the DST and to deepen the understanding of the anticipated changes, four scenarios have been developed that describe the role of the gas distribution grid in the Dutch energy system for the year 2050. The scenarios differ from each other in terms of the perceived scarcity of energy resources and the willingness and ability to reduce greenhouse gas emissions. In each future scenario, the gas distribution grid still plays a significant role in the Dutch energy system. In addition, the future gas distribution grid will also perform a few other functions that will become increasingly important: facilitating the injection of biomethane, dealing with gas types other than Groningen gas, as well as balancing supply and demand.

The DST supports the design process for the biomethane supply chain and gas distribution grid by automating the synthesis and analysis task. The DST consists of a design engineering model and a design procedure. The design engineering model that has been developed, is used to create and analyze designs for the biomethane supply chain. The model contains all elements of the biomethane supply chain, ranging from biomass supply to the injection of biomethane into the gas grid, including measures to deal with a temporary surplus of biomethane. The model determines the economic performance, the $\mathrm{CO}_{2}$ emis- 
sion reduction, and the net energy production of each design. Furthermore, the model contains discrete components of the elements and is spatially explicit. In addition, the model allows for different configurations of the biomethane supply chain. Among others, multiple biomass locations can supply biomass to one digester, and multiple digesters can supply biogas to one upgrading plant.

The developed design procedure generates candidate solutions for the design of the biomethane supply chain, with the aid of the design engineering model. The design procedure determines, among others, whether the biomass of a biomass location is digested on-site or at a central location, and into which gas grid the biomethane is injected. By exploring broadly the solution space, a large number of candidate solutions is generated. As such, the design procedure does not result in a single "best" solution, but in a number of candidate solutions, leaving the choice of the preferred solution to the user of the DST.

The DST has been used to determine the design of the biomethane supply chain in each future energy scenario, for three different regions. The regions comprise a rural, an urban, and an intermediate region. It has been established that in the rural region, the DSO may have to invest in measures to deal with a temporary surplus of biomethane. In the intermediate and urban regions, this is less likely. Furthermore, not all biomass may be used in the rural region. This is due to the high availability of biomass and low gas demand in this region. Finally, in each scenario, the design with one or more central digesters has shown the best economic performance.

The impact of changes in the parameters of the model on the economic performance of three design types has been determined by means of a sensitivity analysis. The designs are characterized by (1) local digestion and local upgrading, (2) local digestion and central upgrading, and (3) central digestion and onsite upgrading. For all parameter values, the economic performance of the design with central digestion is superior to the other two designs. Similarly, the economic performance of the design with local digestion and central upgrading is superior to the design with local digestion and local upgrading. Furthermore, the economic performance of the three designs is particularly sensitive to changes in the biogas yield of the biomass and the biomass cost. Other factors, such as pipeline costs, electricity price, and biomass transport cost, only have a minor impact. In addition, the analysis showed that choosing a nearby solution changes the design only slightly.

In conclusion, the DST has been developed successfully. The sensitivity analysis and the analysis of the future biomethane supply chains have demonstrated the usefulness of the DST. The use of the DST can create value for DSOs, other stakeholders and society by (1) reducing the complexity of the design process by providing insight in the available solutions, (2) choosing the preferred solution for society rather than a solution that only optimizes the biomass owner's profits, (3) making strategic investment decisions that look further than the first biomethane producer, and (4) shortening the overall design process. As such, the DST promises to improve the design process of the biomethane supply chain. 


\section{Samenvatting}

Het Nederlandse gasdistributienet staat op de korte termijn enkele ingrijpende veranderingen te wachten. Eén van de grote veranderingen is de productie en invoeding van groen gas in het gasdistributienet. Om de invoeding van groen gas te faciliteren, zullen de regionale netbeheerders (RNB's) in het gasdistributienet moeten investeren. Vele ontwerpkeuzes moeten gemaakt worden voor de groen gasketen en het gasdistributienet. Deze keuzes, welke gemaakt worden in het ontwerpproces, hangen grotendeels af van de lokale situatie en de voorkeuren van de RNB's. In dit onderzoek is een beslissingsondersteuningstool ontwikkeld (BOT) die het ontwerpproces van de groen gasketen en het gasdistributienet ondersteunt, middels het creëren van kandidaat oplossingen voor een bepaald gebied, bestaande uit biomassalocaties, gasnetten en gasverbruikers.

Om het belang van de BOT te benadrukken en het inzicht in de verwachte veranderingen te vergroten, zijn vier scenario's ontwikkeld die de rol beschrijven van het gasdistributienet in het Nederlandse energiesysteem in 2050. De scenario's verschillen van elkaar ten aanzien van de ervaren energie schaarste en ons vermogen en bereidheid tot het reduren van de $\mathrm{CO}_{2}$ uitstoot. Het gasdistributienet speelt in elk van de toekomstscenario's nog steeds een belangrijke rol. Daarnaast zal het gasdistributienet meer functies hebben: het faciliteren van groen gasinvoeding, het distribueren van gassoorten anders dan Groningen-gas en het balanceren van vraag en aanbod.

De BOT ondersteunt het ontwerpproces van de groen gasketen en het gasdistributienet middels het automatiseren van de synthese- en analysetaak. De BOT bestaat uit een ontwerpmodel en een ontwerpprocedure. Het ontwikkelde ontwerpmodel wordt gebruikt voor het genereren en analyseren van ontwerpen voor de groen gasketen. Het model bevat alle onderdelen van de groen gasketen: van biomassa aanbod tot de invoeding van het groen gas in het gasnet, inclusief maatregelen voor een eventueel tijdelijk overschot aan groen gas. Het model berekent de economische prestaties, de $\mathrm{CO}_{2}$ emissiereductie en de netto energieproductie van elk ontwerp. Daarnaast bevat het model discrete componenten 
van de onderdelen van de groen gasketen en is het ruimtelijk expliciet. Ook zijn er verschillende configuraties van de groen gas keten mogelijk. Zo kunnen bijvoorbeeld meerdere biomassalocaties één vergister van biomassa voorzien en kunnen meerdere vergisters één opwerkingsinstallatie van biogas voorzien.

De ontwikkelde ontwerpprocedure genereert oplossingen voor het ontwerp van de groen gasketen, gebruikmakende van het ontwerpmodel. De ontwerpprocedure bepaalt onder andere of de biomassa lokaal of centraal wordt vergist en in welk gasnet het groen gas wordt ingevoed. Middels een brede zoektocht in de oplossingsruimte worden er vele kandidaatoplossingen gegenereerd. Dit resulteert niet in een enkele "beste" oplossing maar in meerdere kandidaatoplossingen, waarbij de keuze voor de uiteindelijke oplossing aan de gebruiker van de BOT wordt overgelaten.

Gebruikmakende van de BOT is voor drie verschillende gebieden in elk toekomstscenario een ontwerp voor de groen gasketen bepaald. De gebieden bestaan uit een landelijk gebied, een stedelijk gebied en een tussengelegen gebied. Het bleek dat de RNB in het landelijk gebied mogelijk moet investeren in maatregelen om een tijdelijk overschot aan groen gas op te lossen. Voor het tussengelegen en stedelijke gebied is dit minder waarschijnlijk. Daarnaast wordt niet alle biomassa gebruikt in het landelijke gebied vanwege de hoge beschikbaarheid van biomassa en de lage gasvraag in dit gebied. Tot slot bleek dat het ontwerp met één of meerdere centrale vergisters economisch het beste presteerde.

Middels een gevoeligheidsanalyse is de impact van veranderende modelparameters op de economische prestaties van drie ontwerptypes bepaald. De ontwerptypes worden gekenmerkt door (1) lokaal vergisten en lokaal opwaarderen, (2) lokaal vergisten en centraal opwaarderen en (3) centraal vergisten en ter plekke opwaarderen. Voor alle waardes van de modelparameters presteert het ontwerp met centrale vergisting economisch gezien het beste. Het ontwerp met lokale vergisting en centrale opwaardering scoort als één na beste. De economische prestaties van de drie ontwerptypes bleken met name gevoelig voor veranderingen in de biomassakosten en de biogasopbrengst. Andere parameters, zoals leidingkosten, elektriciteitskosten en biomassatransportkosten, hadden slechts een beperkte invloed. Ook bleek uit de analyse dat het ontwerp slechts beperkt verandert wanneer een nabijgelegen oplossing wordt gekozen.

De BOT is met succes ontwikkeld. De gevoeligheidsanalyse en de analyse over de toekomstige groen gasketen demonstreerden het nut van de BOT. Het gebruik van de BOT creëert waarde voor RNB's, andere belanghebbenden en de maatschappij, door (1) de complexiteit van het ontwerpproces te verminderen door inzicht te verschaffen in de beschikbare oplossingen, (2) het kiezen van de beste oplossing voor de maatschappij, in plaats van een oplossing die enkel de winst van een biomassaeigenaar maximaliseert, (3) het mogelijk maken van strategische investeringsbeslissingen die verder kijken dan de eerste groen gasproducent en (4) het verkorten van de duur van het ontwerpproces. Zodoende belooft de BOT het ontwerpproces van de groen gasketen te verbeteren. 


\section{Voorwoord}

Tijdens mijn afstudeeropdracht heb ik ervaren dat ik onderzoek doen leuk vind. Toen de vakgroep OPM mij deze promotieopdracht aanbood, hapte ik daarom niet veel later toe. In het begin keek ik op tegen de duur van mijn promotietraject, maar uiteindelijk is het allemaal erg snel gegaan. De vier jaar onderzoek hebben geleid tot dit proefschrift, waar ik trots op ben. Graag wil ik voor de totstandkoming van mijn proefschrift een aantal mensen bedanken.

Allereerst wil ik mijn promotoren Fred van Houten en met name Mannes Wolters noemen. Mannes, jij bent veel bij mijn promotie betrokken geweest. Jij wist mij op de juiste momenten te motiveren, hebt altijd overzicht gehouden en zeker op het laatst enorm veel tijd gestoken in het lezen van mijn proefschrift. Daarnaast wil ik graag mijn dagelijkse begeleiders, Sipke Hoekstra en Juan Juaregui-Becker bedanken. Sipke, bij jou kon ik altijd aankloppen om te discussiëren over mijn onderzoek, wat vaak leidde tot nieuwe inzichten of bevestiging van mijn ideeën. Juan, ik vond het erg leuk en fijn om met jou op een abstract niveau over mijn onderzoek van gedachten te wisselen.

Collega-promovendus Errit Bekkering wil ik bedanken voor onze samenwerking. Errit, ik wens je nog veel succes met het laatste deel van je promotie! Ook wil ik Rosemarie van Eekelen bedanken voor de samenwerking en de leuke discussies samen met Errit in Wientjes. De promovendi van de Hanze Hogeschool ben ik dankbaar voor de nuttige en interessante discussies over groen gas. Daarnaast wil ik de contactpersonen bij de netbeheerders Liander, Stedin en Enexis bedanken voor het ondersteunen van mijn onderzoek: Ben Lambregts, Albert van der Molen, Kirsten van Gorkum, Sybe bij de Leij en Michiel van Dam, bedankt.

Promoveren is natuurlijk niet mogelijk zonder de nodige afleiding. Daarom wil ik graag mijn kamer/lunchgroep-genoten bedanken voor vier hele leuke jaren. Ik ging altijd met plezier naar mijn werk. Wienik, Rick, Boris, Jorge, Adriaan, Martijn, Rob, Krijn en iedereen die ik vergeten ben te noemen: bedankt voor alle koffies/biertjes/mensa-maaltijden/vrijmibo's/wandelingetjes/mtb-tochtjes/ 
zinnige en onzinnige discussies die ik met jullie heb mogen delen!

Mijn familie en vrienden wil ik bedanken voor het bieden van de welkome afleiding naast het promoveren. Heit, mem, Janneke, Roelof, Jorrit en Bettina, ik fyn it hiel moai om regelmatich by jim del te kommen foar de gesellichheid en fansels om spultsjes te dwaan. Jeroen, Justin, Roderick, Kees, Luuk, Niek en Heren 3 en de rest: bedankt voor jullie gezelligheid! Tot slot wil ik mijn lieve en leuke vriendin Judith bedanken. Judith, bedankt voor je steun gedurende mijn promotie. Dankjewel dat je er was en bent voor mij. Ik ben blij met jou als vriendin.

Taede Weidenaar

Enschede, februari 2014 


\section{Table of contents}

Summary V

$\begin{array}{lll}\text { Samenvatting } & \text { VII }\end{array}$

Voorwoord IX IX I

\begin{tabular}{ll} 
Table of contents $\quad$ XI \\
\hline
\end{tabular}

List of abbreviations $\quad$ XV

List of symbols $\quad$ XVII

I Research clarification 1

1 Towards a renewed gas distribution system 3

1.1 The Dutch gas distribution grid .............. 4

1.2 Biomethane production ................ 8

1.3 Options for the design of the biomethane supply chain . . . . . 10

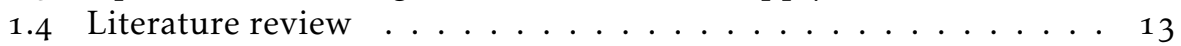

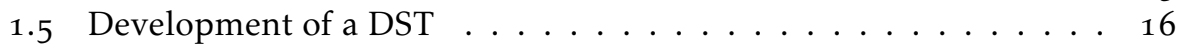

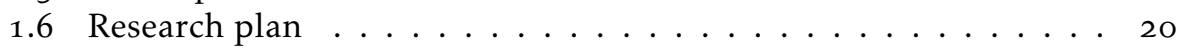

II Descriptive study I 25

2 Scenarios for the Dutch gas distribution infrastructure in $205^{\circ} \quad 27$

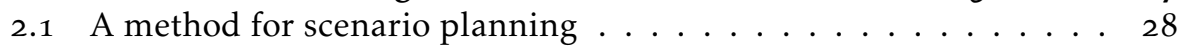

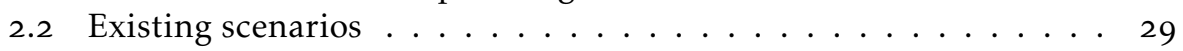

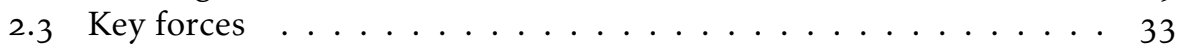




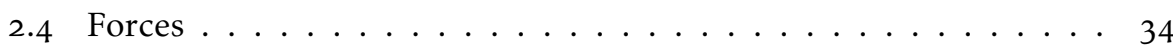

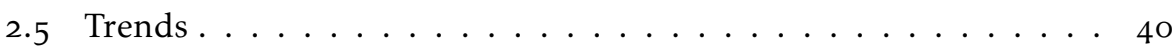

2.6 Scenarios and their narratives ... . . . . . . . . . 41

2.7 Quantification of supply and demand forces . . . . . . . . . . . 44

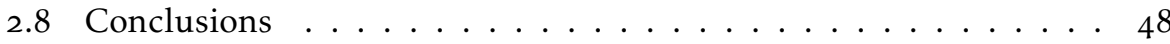

III Prescriptive study $\quad 51$

3 Modeling the biomethane supply chain 53

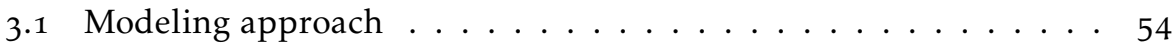

3.2 Literature review on existing models . . . . . . . . . 55

3.3 Elements of the biomethane supply chain and their topological

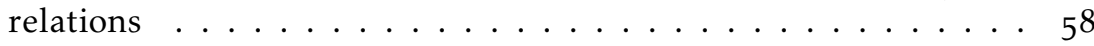

3.4 Scenario parameters . . . . . . . . . . . . . . . 59

3.5 Elements of the biomethane supply chain . . . . . . . . . 61

3.6 Performance indicators . . . . . . . . . . . . . 79

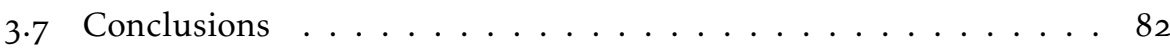

4 Design procedure $\quad 85$

4.1 Design process .......................... 86

4.2 Literature review on existing design procedures . . . . . . . . . 87

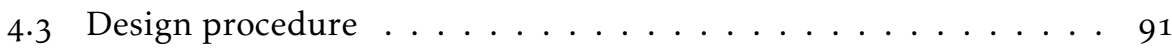

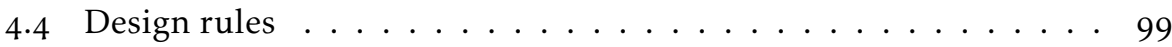

4.5 Choosing a (non-dominated) solution . . . . . . . . . 103

4.6 Verification of the DST . . . . . . . . . . . . 104

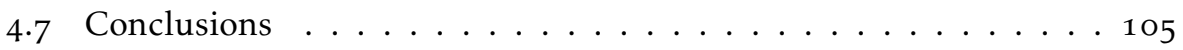

$\begin{array}{ll}\text { IV Descriptive study II } & 107\end{array}$

5 Design of the gas distribution infrastructure in the future scenarios 109

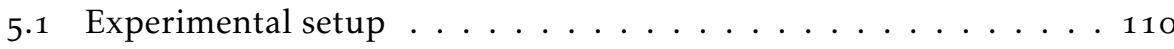

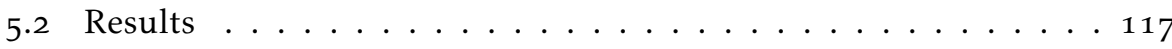

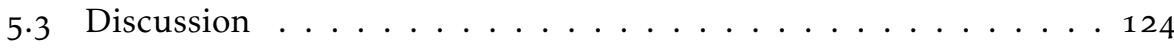

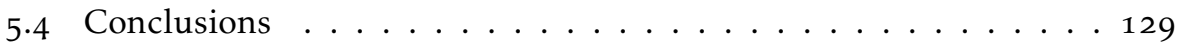

6 Sensitivity analysis 131

6.1 Varying input values of the model . . . . . . . . . . . 132

6.2 Choosing a different solution . . . . . . . . . . . . . 142

6.3 Conclusions .......................... 145 
7 Research valorization 149

7.1 Envisaged use of the DST . . . . . . . . . . . . . . 149

7.2 Limitations . . . . . . . . . . . . . . . . . 153

$7 \cdot 3$ Required development for the DST . . . . . . . . 153

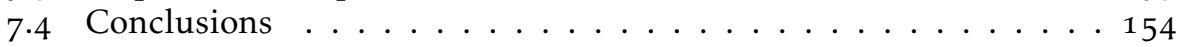

8 Conclusions and recommendations 157

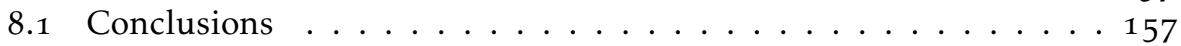

8.2 Directions for future research $\ldots \ldots \ldots \ldots \ldots \ldots$

$\begin{array}{ll}\text { Bibliography } & 163\end{array}$

V Appendices 173

$\begin{array}{ll}\text { A Scenario dependent variables } & 175\end{array}$

B Sensitivity analysis 179

B.1 Factors . . . . . . . . . . . . . . . . . 179

B.2 Sensitivity analysis on the intermediate region $\ldots \ldots \ldots 182$ 



\section{List of abbreviations}

$\begin{array}{ll}\text { AW } & \text { Annual worth } \\ \mathrm{CCS} & \text { Carbon capture and storage } \\ \mathrm{CHP} & \text { Combined heat and power } \\ \mathrm{CO}_{2} & \text { Carbon dioxide } \\ \mathrm{CH}_{4} & \text { Methane } \\ \text { DRM } & \text { Design research methodology } \\ \text { DSO } & \text { Distribution system operator } \\ \text { DST } & \text { Decision support tool } \\ \text { EU } & \text { European Union } \\ \text { G-gas } & \text { Groningen gas } \\ \text { GHG } & \text { Greenhouse gas } \\ \text { GRS } & \text { Gas receiving station } \\ \mathrm{H}_{2} & \text { Hydrogen } \\ \mathrm{H}_{2} \mathrm{O} & \text { Water } \\ \mathrm{H}_{2} \mathrm{~S} & \text { Hydrogen sulfide } \\ \mathrm{HTL} & \text { High-pressure transmission lines } \\ \text { LNG } & \text { Liquefied natural gas } \\ \text { MILP } & \text { Mixed integer linear programming } \\ \text { M\&R station } & \text { Metering and regulation station } \\ \text { NPV } & \text { Net present value } \\ \text { PV } & \text { Photovoltaic } \\ \text { PW } & \text { Present worth } \\ \text { RTL } & \text { Regional transmission lines } \\ \text { SNG } & \text { Synthetic natural gas } \\ \text { TSO } & \text { Transmission system operator } \\ & \end{array}$





\section{List of symbols}

\section{Variables}

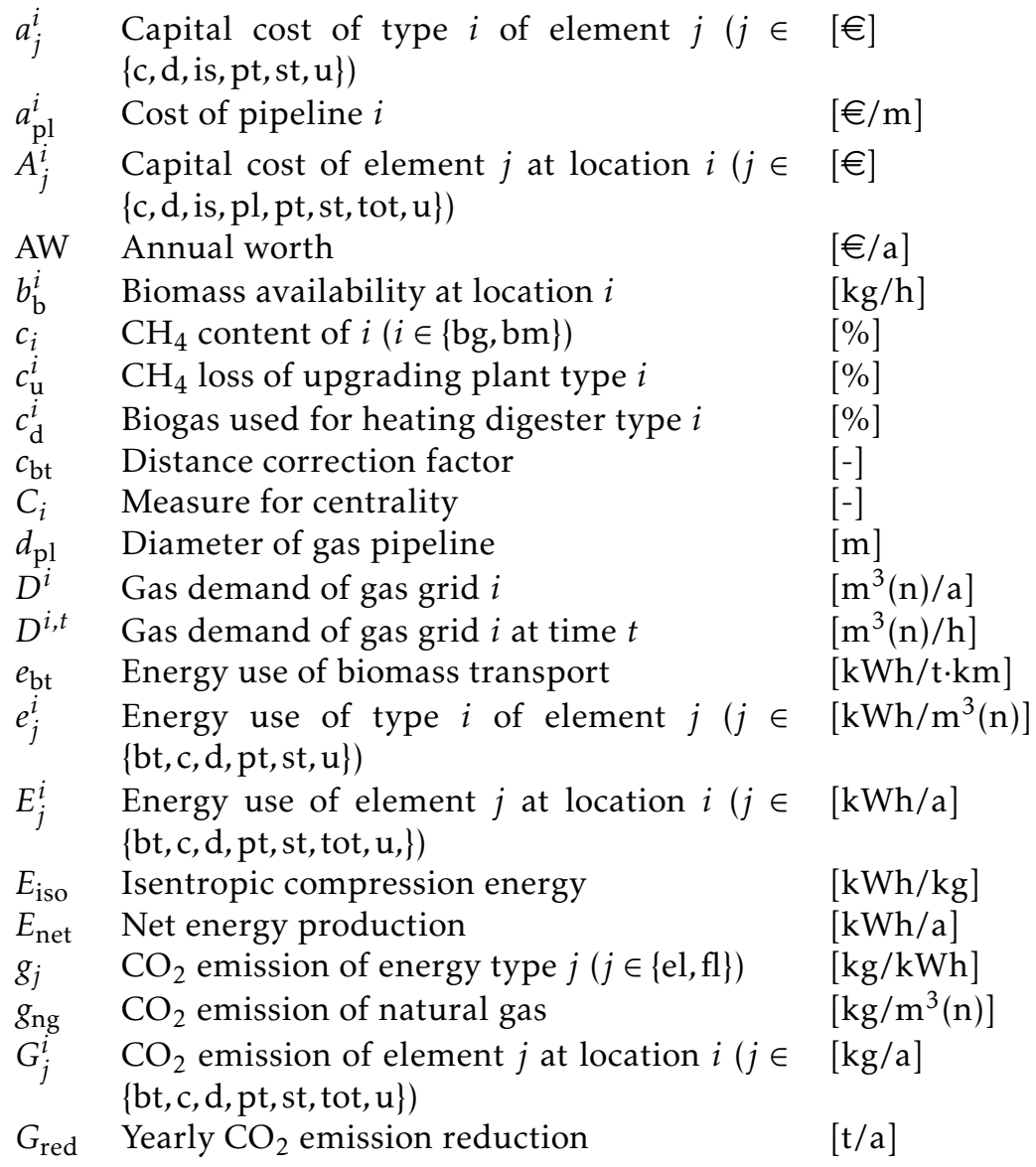




\begin{tabular}{|c|c|c|}
\hline$H$ & Higher heating value & {$\left[\mathrm{J} / \mathrm{m}^{3}(\mathrm{n})\right]$} \\
\hline I & Interest rate & {$[\%]$} \\
\hline$K_{\text {avg }}$ & Compressibility number & {$[-]$} \\
\hline$l^{i}$ & Length of route or segment $i$ & {$[\mathrm{~m}]$} \\
\hline$L$ & Economic life of project & [years] \\
\hline$L_{1}, L_{2}$ & Locations & {$[\mathrm{m}, \mathrm{m}]$} \\
\hline$m_{j}$ & Pipeline laying cost at $j(j \in\{$ rur, urb $\})$ & {$[€ / \mathrm{m}]$} \\
\hline$M$ & Molar mass & {$[\mathrm{g} / \mathrm{mol}]$} \\
\hline$N$ & $\begin{array}{l}\text { Number of steps, runs, locations, or compo- } \\
\text { nents }\end{array}$ & {$[-]$} \\
\hline NPV & Net present value & {$[€]$} \\
\hline$o_{j}^{i}$ & $\begin{array}{l}\text { Operational cost of component type } i \text { of ele- } \\
\text { ment } j(j \in\{c, d, i s, s t, u\})\end{array}$ & {$[€ / \mathrm{a}]$} \\
\hline$o_{\mathrm{pt}}^{i}$ & Operational cost for pre-treatment type $i$ & {$\left[€ / \mathrm{m}^{3}(\mathrm{n})\right]$} \\
\hline$O_{j}^{i}$ & $\begin{array}{l}\text { Operational cost for element } j \text { at location } i \\
(j \in\{\mathrm{b}, \mathrm{bt}, \mathrm{c}, \mathrm{d}, \mathrm{is}, \mathrm{pt}, \mathrm{st}, \mathrm{tot}, \mathrm{u}\})\end{array}$ & {$[€ / \mathrm{a}]$} \\
\hline$O_{\text {inc }}$ & Yearly income & {$[€ / a]$} \\
\hline$p_{i}$ & Energy price $(i \in\{\mathrm{el}, \mathrm{fl}\})$ & {$[€ / \mathrm{kWh}]$} \\
\hline$p_{\text {ng }}$ & Natural gas price & {$\left[€ / \mathrm{m}^{3}(\mathrm{n})\right]$} \\
\hline$p_{\mathrm{bm}}$ & Biomethane subsidy & {$\left[€ / \mathrm{m}^{3}(\mathrm{n})\right]$} \\
\hline$P$ & Pressure & [bar] \\
\hline PW & Present worth & {$[€]$} \\
\hline$q_{\mathrm{bt}}$ & Flat kilometer cost & {$[€ / \mathrm{t} \cdot \mathrm{km}]$} \\
\hline$Q$ & Gas flow & {$\left[\mathrm{m}^{3} / \mathrm{s}\right]$} \\
\hline$r_{i}$ & Probability & {$[-]$} \\
\hline$R$ & Gas constant & {$[\mathrm{J} / \mathrm{mol} \cdot \mathrm{K}]$} \\
\hline$R_{1}, R_{2}$ & Random number $\in[0,1]$ & {$[-]$} \\
\hline $\operatorname{Re}$ & Reynolds number & {$[-]$} \\
\hline$s_{\mathrm{bt}}$ & Loading/unloading cost & {$[€ / t]$} \\
\hline$s_{\mathrm{b}}$ & Biomass cost & {$[€ / \mathrm{kg}]$} \\
\hline$T$ & Temperature & {$[\mathrm{K}]$} \\
\hline$v_{\mathrm{b}}$ & Biogas yield of biomass & {$\left[\mathrm{m}^{3}(\mathrm{n}) / \mathrm{kg}\right]$} \\
\hline$v_{k}^{i}$ & $\begin{array}{l}\text { Volume of gas stored or compressed at loca- } \\
\text { tion } i(k \in\{\mathrm{c}, \mathrm{st}\})\end{array}$ & {$\left[\mathrm{m}^{3}(\mathrm{n}) / \mathrm{a}\right]$} \\
\hline$V_{j}^{i}$ & $\begin{array}{l}\text { (Potential) biogas or biomethane output of } \\
\text { location } i(j \in\{\mathrm{b}, \mathrm{d}, \mathrm{u}\})\end{array}$ & {$\left[\mathrm{m}^{3}(\mathrm{n}) / \mathrm{h}\right]$} \\
\hline$V_{\text {tot }}$ & Total yearly biomethane production & {$\left[\mathrm{m}^{3}(\mathrm{n}) /\right.$} \\
\hline$w_{1}, w_{2}$ & Gas storage and gas compression preference & \\
\hline & Wobbe index & {$\left[\mathrm{J} / \mathrm{m}^{3}(\mathrm{n})\right]$} \\
\hline$x$ & Candidate solution & {$[-]$} \\
\hline$X_{j}^{i}$ & $\begin{array}{l}\text { Decision variable whether to install type } j \text { of } \\
\text { an element at location } i\end{array}$ & {$[-]$} \\
\hline
\end{tabular}


$Y_{j}^{i} \quad$ Number of components of type $j$ of an element that is installed at location $i$

$Z_{j}^{i} \quad$ Variable that indicates whether segment $i$ is $\quad[-]$ of type $k(k \in\{$ rur, urb $\})$

$z \quad$ Compressibility factor

$\epsilon \quad$ Roughness

$[-]$

$\eta \quad$ Efficiency

$\begin{array}{ll}\lambda & \text { Darcy friction factor } \\ \mu & \text { Kinematic viscosity }\end{array}$

$[\mathrm{m}]$

$v \quad$ Fluid velocity

$\rho_{\mathrm{r}} \quad$ Relative density of gas

\section{]}

[-]

$\left[\mathrm{m}^{2} / \mathrm{s}\right]$

$[\mathrm{m} / \mathrm{s}]$

[-]

$\rho \quad$ Gas density

$\theta$ Operational hours

$\left[\mathrm{kg} / \mathrm{m}^{3}(\mathrm{n})\right]$

[hours/a] 


\section{Unit abbreviations}

$\begin{array}{ll}\text { a } & \text { year } \\ \text { bar(a) } & \text { indicates absolute pressure } \\ \text { bar(g) } & \text { indicates gauge pressure } \\ € & \text { euro } \\ \mathrm{g} & \text { gram } \\ \mathrm{h} & \text { hour } \\ \mathrm{J} & \text { Joule } \\ \mathrm{K} & \text { Kelvin } \\ \mathrm{kWh} & \text { kilowatt hour } \\ \mathrm{m} & \text { meter } \\ \mathrm{m}^{3}(\mathrm{n}) & \text { normal cubic meter } \\ \mathrm{s} & \text { second } \\ \mathrm{t} & \text { tonne }(1000 \mathrm{~kg})\end{array}$

\section{SI-prefixes}

$\begin{array}{lll}\mu & \text { micro } & 10^{-6} \\ \mathrm{~m} & \text { milli } & 10^{-3} \\ \mathrm{k} & \text { kilo } & 10^{3} \\ \mathrm{M} & \text { mega } & 10^{6} \\ \mathrm{G} & \text { giga } & 10^{9} \\ \mathrm{~T} & \text { tera } & 10^{12} \\ \mathrm{P} & \text { peta } & 10^{15}\end{array}$

\section{Subscripts}

\begin{tabular}{ll} 
agg & aggregated \\
avg & average \\
b & biomass (location) \\
bg & biogas \\
bm & biomethane \\
bt & biomass transport (route) \\
c & gas compressor (location) \\
cen & central \\
d & digester installation (loca- \\
& tion) \\
el & electricity \\
fl & transport fuel \\
inc & income \\
is & injection station (location) \\
iso & isentropic \\
lp & line pack \\
m & mechanical \\
max & maximum \\
min & minimum \\
$\mathrm{n}$ & normal conditions \\
net & net \\
ng & natural gas \\
opt & optimal \\
pl & pipeline (route) \\
pt & pre-treatment (location) \\
red & reduction \\
rur & rural \\
st & gas storage (location) \\
tot & total \\
$\mathrm{u}$ & upgrading plant (location) \\
urb & urban \\
& \\
\hline
\end{tabular}




\section{Part I}

\section{Research clarification}





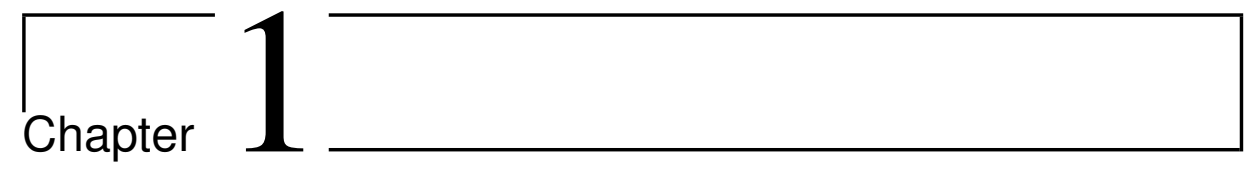

\section{Towards a renewed gas distribution system ${ }^{1}$}

The gas infrastructure forms a crucial part of the Dutch energy system; about half of the primary energy demand is met by natural gas. The gas distribution system, which is part of the gas infrastructure, distributes approximately $20 \mathrm{Gm}^{3}(\mathrm{n})^{2}$ per year. With $98 \%$ of Dutch households connected to the gas distribution grid, the penetration of the gas distribution infrastructure is impressive, as compared to other countries.

The Dutch gas distribution grid is facing a changing gas market. Up to now, the gas distribution grid's sole function is to distribute (one type of) natural gas to gas consumers, and it is merely composed of pipelines, joints and valves. Due to anticipated changes in the gas market, this situation will change in the near future. One of the major changes is the production and injection of biomethane into the gas distribution grid. Biomethane ${ }^{3}$ is gas with burning properties similar to natural gas, but which is produced from renewable sources. The Dutch Distribution System Operators (DSOs), which are responsible for the distribution grids, will have to make investments to assure that the functionality of the gas distribution grid complies with the future requirements of the gas grid. Therefore, research is required on what the needed investments are for the gas distribution grid, in particular with regard to biomethane. Numerous design choices have to be made for the gas distribution grid and biomethane supply chain, and the best choice will depend largely on the specific situation and on the preferences of the DSOs.

Therefore, in this chapter the development of a decision support tool (DST)

\footnotetext{
${ }^{1}$ Parts of this chapter are from [1].

${ }^{2} \mathrm{~m}^{3}(\mathrm{n})$ indicates a normal cubic meter under normal conditions $(\mathrm{T}=273.15 \mathrm{~K}, \mathrm{P}=1.01325 \mathrm{bar})$

${ }^{3}$ In some literature biomethane is referred to as green gas.
} 
is proposed that will aid the design process of the biomethane supply chain and the gas distribution grid. The contribution of our research is the development of a DST that can be applied to different geographical regions and supports the designer in making choices for the design of the biomethane supply chain and gas distribution grid.

This chapter is outlined as follows. Section 1.1 describes the current Dutch gas grid and what changes the gas distribution grid will face in the near future. Since this research focuses on the design options regarding biomethane, section 1.2 elucidates the biomethane supply chain. Next, section 1.3 describes the design options for the biomethane supply chain. Section 1.4 describes a review on literature that addresses the design options for biomethane supply chains. Section 1.5 gives the requirements for the DST that will aid the design process of the biomethane supply chain and gas distribution grid. Finally, section 1.6 describes the research plan, which details the objectives, scope and approach of the research, and the outline of the thesis.

\subsection{The Dutch gas distribution grid}

This section elaborates on the future changes of the gas distribution grid. To get a better grasp of the Dutch gas system, first, the gas grid supply chain, of which the distribution grid is part, is discussed. Then, the anticipated changes for the gas distribution grid are described.

\subsubsection{The present situation}

After the discovery of the Groningen gas field in 1959, with an initial volume of $2.8 \mathrm{Tm}^{3}(\mathrm{n})$ one of the largest gas fields in the world, the Dutch gas sector was shaped and the foundation of the current Dutch gas infrastructure was laid [2].

In Figure 1.1, the gas supply chain in the Netherlands is schematically shown. The high-pressure transmission lines (HTL) grids transport the gas across the country. Two HTL-grids exist in the Netherlands; one HTL-grid transports lowcalorific gas (Groningen gas) and the other transports high-calorific gas. Gas produced from the Dutch gas fields is injected into the HTL grids and the imported or exported gas also enters or leaves the country through the pipelines of these grids. Furthermore, the Dutch gas storage sites are connected to the HTL grids. The HTL grids also supply gas to power stations and large industrial customers. The HTL grid that transports low-calorific gas delivers gas to the metering and regulating (M\&R) stations, which reduce the gas pressure to $40 \mathrm{Oar}(\mathrm{g})^{4}$ and supply gas to several regional transmission lines (RTL) grids. The RTL grids transport the gas further into the country with a finer mesh of pipelines. The

\footnotetext{
${ }^{4} \mathrm{bar}(\mathrm{g})$ indicates the gauge pressure, which is the pressure relative to the ambient pressure. Furthermore, $\operatorname{bar}(\mathrm{a})$ indicates the absolute pressure: 1 bar $(\mathrm{g})=2$ bar $(\mathrm{a})$
} 
RTL grid delivers the gas to gas receiving stations (GRS), which further reduce the gas pressure and supply gas to the distribution grids. The distribution grids are composed of high-pressure distribution grids and low-pressure distribution grids. The high-pressure distribution grids transport the gas over longer distances and are operated at pressures ranging from $1-8 \mathrm{bar}(\mathrm{g})$. In addition, the high-pressure distribution grids feed the natural gas into the low-pressure distribution grids via a district station. The low-pressure distribution grid is operated at pressures ranging from $30-200 \mathrm{mbar}(\mathrm{g})$ and supplies gas to households, commercial buildings, and smaller industry. Transmission system operators (TSOs) are responsible for the RTL and HTL grid and the M\&R stations and GRSs. The DSOs are responsible for the distribution grid and the district stations.

During the past 50 years, the Dutch gas grid has proven to be a robust system and customers could rely on a reliable gas supply5. Recently, the Dutch gas market has been liberalized with the purpose of increasing the competition in the gas market. In this liberalized gas market, customers are given a free choice of gas supplier. Furthermore, the network activities were separated from other activities, in order to safeguard free non-discriminatory access of suppliers to the network. Therefore, since January 2011, by law, gas transport and distribution activities in the Netherlands have to be separated from production and supply activities. The network companies remained 100\% publicly owned. However,

5The yearly downtime of the gas supply for Dutch consumers was on average 64 seconds in the year 2012 [3]. In comparison, the average downtime for electricity was 27 minutes in the same period [4].

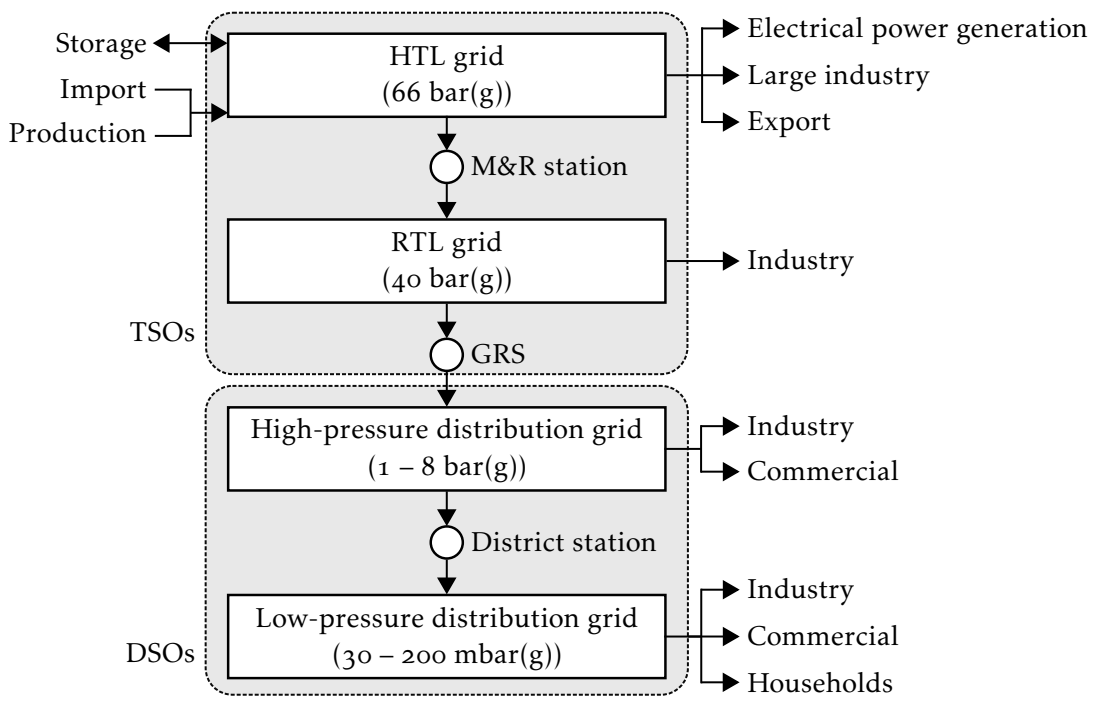

Figure 1.1: Dutch gas grid supply chain 
it should be mentioned that some DSOs went to court to oppose against this law. As a consequence, the European Court of Justice is currently investigating whether the separation is in line with European law.

Besides the liberalization of the gas market, the distribution grid is reaching the end of its economic and technical life, and the distribution grid is facing more changes in the gas market. The expected changes are discussed in the next subsection.

\subsubsection{Foreseen changes for the gas distribution grid}

Table 1.1 lists the anticipated changes in the gas market that will affect the gas distribution grid. As can be seen, the current gas distribution system only supplies one type of gas, namely gas with Groningen gas (G-gas) quality. In the near future it is expected that multiple qualities of gas will flow through the gas distribution grid.

First of all, biomethane will play a more important role in the Dutch gas supply. The Dutch government aims to reduce carbon dioxide $\left(\mathrm{CO}_{2}\right)$ emissions, to increase the amount of renewable energy produced, and to become less dependent on imported energy. Since biomethane reduces $\mathrm{CO}_{2}$ emissions by replacing natural gas, is renewable, and can be produced domestically, its share in the Dutch gas supply is expected to increase. The New Gas Platform, an organization initiated by several Dutch ministries to promote biomethane among parties in the Dutch society, states the ambition of an $8-12 \%$ biomethane share in the gas supply by 2020 and a share of $15-20 \%$ by 2030 [5]. Currently, the biomethane share is only approximately $0.2 \%$ [6] (based on a domestic gas consumption of $\left.4.5 \mathrm{Tm}^{3}(\mathrm{n}) / \mathrm{a}\right)$. With the injection of biomethane in the distribution grid, the top-down gas supply chain will transform into a bi-directional gas supply

\begin{tabular}{ll}
\hline Current situation & Future situation \\
\hline $\begin{array}{l}\text { Mono-gas distribution grid (only } \\
\text { G-gas) }\end{array}$ & $\begin{array}{l}\text { Multi-gas distribution grid (including } \\
\text { biomethane and foreign gases) }\end{array}$ \\
Top-down gas supply chain & Bi-directional gas supply chain \\
$\begin{array}{l}\text { No interaction with other energy } \\
\text { distribution grids }\end{array}$ & $\begin{array}{l}\text { Increased interaction with electricity } \\
\text { distribution grid and heat grids }\end{array}$ \\
Passive grid & $\begin{array}{l}\text { Smart grid, which actively monitors } \\
\text { and controls the quality, flow, and } \\
\text { pressure of gas }\end{array}$ \\
\hline
\end{tabular}

Table 1.1: Foreseen changes for the gas distribution grid 
chain. Gas will not only enter the distribution grid from the GRSs but also from biomethane injection points connected to the high-pressure or low-pressure distribution grid.

Secondly, the Groningen gas field and other smaller Dutch gas fields are in decline and, therefore, the amount of imported natural gas will gradually increase. Increased volumes of gas will be imported from, for example, Norway, Russia, and Algeria by pipeline and by liquefied natural gas (LNG)-tanker and will flow through the Dutch gas distribution grid. These gases have a different quality than that of G-gas, which currently flows in the distribution grid. Hence, the gas will not burn properly in the Dutch gas appliances, which are calibrated for G-gas. Therefore, the gas either has to be converted to G-gas quality or the gas appliances have to be adjusted.

With the introduction of biomethane and foreign gases, the gas distribution grid transforms from a mono-gas system into a multi-gas system. This means that the distribution grid will have to handle more gas qualities. In practice, this could mean that the distribution grid should be able to take care of a wider Wobbe range ${ }^{6}$. In addition, also dedicated distribution grids that distribute a specific gas quality are likely.

Another expected change is the increased interaction of the gas distribution grid with the electricity distribution grid and local heat grids. This is due to two factors. First, due to an expected increase in electricity production from wind and solar photovoltaic (PV), the production of renewable electricity might exceed the consumption at times. By temporarily storing the electricity as hydrogen $\left(\mathrm{H}_{2}\right)$ or methane $\left(\mathrm{CH}_{4}\right)$ in the gas distribution grid (so-called Power-to-gas), this surplus can be dealt with. The electricity will be converted to $\mathrm{H}_{2}$ or $\mathrm{CH}_{4}$ by means of electrolysis and the Sabatier process respectively [7]. Secondly, the rise of gas-fired combined heat and power (CHP) installations, which generate electricity and heat simultaneously, also increases the interaction between the gas distribution grid and electricity grid. These CHP installations could also produce electricity when the electricity production of local solar PVs or windmills is intermittent.

With the introduction of multiple gas qualities, injection of biomethane in the distribution grid, and the increased interaction with the electricity and heat grids, the gas distribution grid is expected to change from a passive grid to an actively controlled smart gas grid $[8,9]$. For example, when injecting biomethane into the gas distribution grid, local gas demand might be insufficient at times to consume all injected biomethane and the pressure of the gas grid will in-

\footnotetext{
${ }^{6}$ The main characteristic for the comparison of gas qualities is the Wobbe index, which is defined as: $W=\frac{H}{\sqrt{\rho_{\mathrm{r}}}}$, where $W$ is the Wobbe index $\left[\mathrm{J} / \mathrm{m}^{3}(\mathrm{n})\right], H$ is the higher heating value $\left[\mathrm{J} / \mathrm{m}^{3}(\mathrm{n})\right]$ of the gas, and $\rho_{\mathrm{r}}$ is the relative density of the gas. G-gas has a Wobbe index that varies between 43.46 and $44.41 \mathrm{MJ} / \mathrm{m}^{3}(\mathrm{n})$
} 
crease. Therefore, the pressure needs to be monitored and appropriate measures are required when the pressure becomes too high. Furthermore, the injection of biomethane requires the monitoring of the quality. Hence, the distribution grid requires monitoring and control of the quality, pressure, and flow of gas in order to maintain the service level $[8,9]$.

The production and injection of biomethane is one of the expected changes that has a large impact on the gas distribution system. In addition, it is a change that will occur on a relatively short term. Therefore, this research will focus on the introduction of biomethane and its impact on the gas distribution grid. The production process of biomethane and the issues concerning injection of biomethane in the distribution grid are described in more detail in section 1.2.

In addition, to get a better understanding of how the future might unfold for the gas distribution grid, a future scenario planning study has been performed. This study resulted in several future scenarios which describe the future role of the gas distribution grid within the Dutch energy system.

\subsection{Biomethane production}

Although two possible options for the production of biomethane can be distinguished, only the production of biomethane from the co-digestion process is considered in this research. This is on the grounds that the other production process, biomethane from gasification, is not yet available for commercial application.

This section first describes the biomethane from co-digestion supply chain, after which the difficulties with respect to the injection of biomethane into the distribution grid are discussed.

\subsubsection{Biomethane from co-digestion supply chain}

Biomethane is produced by digesting wet biomass. Commonly, manure is digested in combination with a co-substrate, for instance, agricultural crops, swill, or other waste products. This process is referred to as co-digestion [10]. In Figure 1.2, the supply chain for biomethane from co-digestion is shown. The feedstock for the co-digestion process is manure and co-substrate. The digestion process produces biogas, consisting of $50-65 \% \mathrm{CH}_{4}[11]$ (for comparison, G-gas consists of $\left.83 \% \mathrm{CH}_{4}\right)$. The upgrading process, removes unwanted components (for instance, $\mathrm{H}_{2} \mathrm{~S}$ and $\mathrm{H}_{2} \mathrm{O}$ ) from the biogas and increases the $\mathrm{CH}_{4}$ content in order to obtain gas with a Wobbe-index similar to that of G-gas. Once the gas is at the desired quality, the gas can be injected into the gas grid. The digestion and upgrading processes are technically robust and commercially proven technologies. 


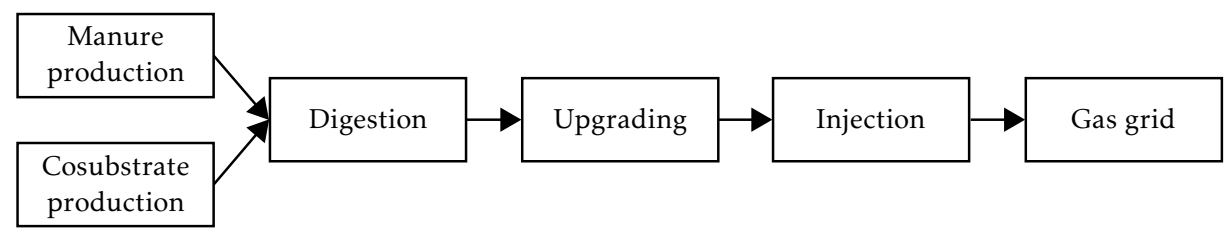

Figure 1.2: Biomethane supply chain [12]

\subsubsection{Biomethane production difficulties}

Biomethane installations using the digestion process to generate biogas are smallscale (the average capacity in the Netherlands is approximately $\left.600 \mathrm{~m}^{3}(\mathrm{n}) / \mathrm{h}[6]\right)$. Therefore, in general, it is economically not feasible to inject the gas into the transportation grid, since the costs for the connection to the transportation pipeline and for compression are too high. Hence, the biomethane will be injected into the distribution grid. The cost for injection of biomethane into the distribution grid are lower since the length of the connection will be shorter (the distribution grid has a finer mesh and therefore, needs usually a shorter connecting pipeline) and compression costs are lower since the distribution grid is operated at a lower pressure than the transportation grid.

However, injection of biomethane into the distribution grid might lead to problems in balancing the gas demand and biomethane supply, since the volume of the gas flow in the distribution grid is significantly lower than in the transportation grid. Therefore, the injection of biomethane can result in congestion in the distribution grid. Furthermore, biomethane production often takes place in rural areas, where gas demand is lower than in urban areas. Finally, due to seasonal fluctuations the gas demand in summer is lower than in winter. The difference between summer and winter demand is about a factor 10, if there are no industrial customers connected to that distribution grid. Since the biomethane production process is very inflexible, and therefore, the volume of produced biomethane can hardly be varied during the year, the gas demand in summer becomes the limiting factor. Since the gas demand in summer is relatively low, it might not always be possible to exploit the full biomethane potential in a certain area.

The next section describes the choices that have to be made during the design process of the biomethane supply chain. In making these choices, the difficulties described here should be kept in mind. 


\subsection{Options for the design of the biomethane supply chain}

During the design process of the biomethane supply chain a number of decisions has to be made, such as where to locate a digester installation and how to deal with a temporary surplus of biomethane. The most important design choices are summarized in Table 1.2 and are discussed in more detail in the remainder of this section.

1 The first choice is whether the available biomass is utilized. From an economic, energetic, or technical perspective it might be unattractive to exploit the biomass potential. The volume of the biomass might be too small to justify the investment in the appropriate equipment or the biomass is available at a too remote location.

2 If the biomass will be used, the question arises where the digestion process takes place. In this respect, two options are possible:

- The digestion process takes place at the biomass location. The advantage of this option is that the biomass does not have to be transported over long distances, which otherwise might result in a negative energy and environmental efficiency of the supply chain. The disadvantage is that the process

\begin{tabular}{|c|c|c|}
\hline & Choice & Options \\
\hline 1 & Use biomass? & $\begin{array}{l}\text {-Yes } \\
\text {-No }\end{array}$ \\
\hline 2 & Location digester installation? & $\begin{array}{l}\text {-On-site } \\
\text {-Central location }\end{array}$ \\
\hline 3 & Location upgrading plant? & $\begin{array}{l}\text {-Adjacent to digester location } \\
\text {-Central location }\end{array}$ \\
\hline 4 & Balancing option? & $\begin{array}{l}\text {-Line-pack flexibility } \\
\text {-Gas storage } \\
\text {-Compression to upstream gas grid } \\
\text {-CHP } \\
\text {-Gas flare } \\
\text {-Connect to other gas grid }\end{array}$ \\
\hline
\end{tabular}

Table 1.2: Development options for the biomethane supply chain 
will be small-scale and therefore the investment and operational cost will be relatively high for the digester installation.

- The digestion process takes place at a central location. On the one hand, this consumes extra energy and gives negative environmental effects, since the biomass has to be transported to this location by road transport. On the other hand, one large digester will have lower operational and investment costs than several smaller digesters. If the collection and digestion process is done centrally, a choice on the optimal size and location of the plant has to be made.

3 For the next step, a choice has to be made with respect to the location where the biogas is upgraded to G-gas quality. Again two options are available:

- The biogas is upgraded at the same location as the digester installation. Advantage of this option is that no costs are incurred for the transport of biogas to a different location.

- The biogas is upgraded at a central location. The biogas of several biogas producers is collected by means of a pipeline, which transports the biogas to the central location (this grid of biogas pipelines is also referred to as biogas hub). At the central location the biogas is upgraded. The advantage of this option is that only one upgrading plant has to be built and operated, and due to advantages of scale this will be cheaper than building and operating several smaller upgrading plants. The disadvantage is the extra costs incurred due to the required biogas pipelines. Furthermore, due to the larger scale of the upgrading plant, the cost for a connection to a gas grid that operates at a higher pressure goes down per $\mathrm{m}^{3}(\mathrm{n})$ biomethane. This option provides extra gas demand capacity, which is caused by larger volumes of gas flow as well as by the reduced fluctuation in gas demand, due to the increased number of industrial customers connected to these gas grids.

Once the location of the upgrading plant is known, a choice has to be made on where to inject the biomethane into the gas grid. First of all, one can inject the biomethane into the gas grid laying closest to the upgrading plant. However, the gas demand of that grid might be too low, and therefore, it might be beneficial to lay a longer gas pipeline that transports the gas to a location in the gas grid where gas demand is higher, consequently the investment costs of these options are higher due to the required pipeline to be built.

Besides upgrading biogas to natural gas quality and injecting it into the gas grid, other utilization options of biogas exist. Depending on the situation, these options might be preferable from an economical, technical, or energy efficiency 
point of view. Among others, the following alternatives are available: (1) Instead of injecting the gas into the gas grid, the biogas can be used as transport fuel (for example in the form of LNG, see [13]). (2) Biogas can be injected into a dedicated biogas grid, to which one or more customers are connected. These customers use gas equipment that is adjusted to the specific gas quality of the biogas. (3) The biogas can be used to fuel a CHP installation, in order to produce electricity and heat. The produced electricity can be utilized locally or be fed to the electricity distribution grid. Or, (4) the biogas could be mixed with natural gas and then injected into the gas grid. If the ratio of biogas and natural gas is sufficiently small the value of the Wobbe index, falls within the allowable Wobbe range (see for example [14]).

4 As mentioned in subsection 1.2.2, balancing issues can occur when the biomethane is injected into the gas grid. This imbalance, caused by a temporary surplus of injected biomethane, can be dealt with in several ways:

- Line-pack flexibility is applied to the gas grid. This means that the pipelines of the gas grid are used as a small buffer, by operating the pressure dynamically.

- A gas storage site is connected to the distribution grid in order to flatten out fluctuations in the gas demand. In times of biomethane surplus, the gas storage site withdraws gas. When biomethane production is insufficient to meet the gas demand, the gas supply can be complemented by natural gas from the gas transport grid or biomethane stored in the local gas storage site.

- By means of a gas compressor, the biomethane is compressed and injected into an upstream gas grid7 with a higher gas demand.

- By means of a CHP installation the surplus of biomethane is converted to electricity and fed to the electricity grid (see, for example [14]).

- The gas grid into which the biomethane is injected is connected to a nearby gas grid with the same operating pressure. As such, the biomethane is consumed by the gas consumers of both grids.

- The surplus of biomethane is flared off. Although, the surplus biomethane is not used, a congestion of gas in the gas grid is prevented.

As can be concluded, many development options for the biomethane supply chain exist. When designing the biomethane supply chain, the designer should

\footnotetext{
${ }^{7} \mathrm{~A}$ gas grid that supplies gas to a grid with a lower operating pressure is the upstream gas grid; the gas grid that is supplied with gas is the downstream gas grid.
} 
consider the available options and determine which one is the best (economically, environmentally, etcetera) for a given situation. Since the solution depends on the specific situation, a DST has been developed. This tool will aid the designer in helping him/her to deal with this large number of possible development options.

\subsection{Literature review}

This section reviews the literature that address the design options for the biomethane supply chain and the subsequent injection in the gas distribution grid. For each article it was determined (1) for which part of the biomethane supply chain the design choices are addressed, (2) if the findings can be applied to different regions, and (3) whether the findings are captured in a method or tool. A summary of the findings of our literature review is given in Table 1.3, and below a more detailed description of the literature is given.

Höhn [15] presents a method that determines suitable biogas plant locations (which consist of a digester installation and upgrading plant) considering the spatial distribution of biomass locations and biomethane demand points. In addition, the method allocates biomass locations to the biogas plants and determines the size of the biogas plant. The method was applied to a case study, comprising three different regions in Finland. The developed method addresses only a part of the biomethane supply chain.

The research presented by van Eekelen [16] made an assessment on the economic performance of three typical biogas hubs. The financial costs of these biogas hubs were compared with an alternative infrastructure where the biomass from the different biomass locations is transported to a central digester and upgrading plant. Furthermore, it was found that the operating pressure has a large influence on the investment cost and, as such, has to be optimized for each case. The developed knowledge is applicable to different regions, but a tool was not developed, and the scope is limited to the biogas hub.

Klocke [17] describes a case study on biogas utilization in a German region. In his techno-economic assessment three layouts for biogas hubs are evaluated. Each layout type comprises several local digesters which supply their biogas to a pre-treatment installation where the biogas is dried, desulphurized, and injected into the biogas hub, which transports it to a central location where the biogas is upgraded and injected into the gas grid. The study by Klocke was done for only one region and limited to three fixed layout types.

For a potential biogas producer in the municipality of Neerijnen in the Netherlands, Smits [18] investigated seven configurations for biogas utilization. The investigated options for biogas utilization are: whether to upgrade the biogas 


\begin{tabular}{|c|c|c|c|}
\hline Source & Q1 & Q2 & Q3 \\
\hline Höhn [15] & $\begin{array}{l}\text { Biomass transport, digester instal- } \\
\text { lation }\end{array}$ & $\begin{array}{l}\text { Multiple re- } \\
\text { gions }\end{array}$ & Yes \\
\hline van Eekelen [16] & Biogas hub & $\begin{array}{l}\text { Generalizable } \\
\text { knowledge }\end{array}$ & No \\
\hline Klocke [17] & Biogas hub & One region & No \\
\hline Smits [18] & $\begin{array}{l}\text { Upgrading plant, where to inject } \\
\text { biomethane, balancing option }\end{array}$ & One region & No \\
\hline Colsen BV [19] & Upgrading plant & One region & No \\
\hline de Veth $[20]$ & Upgrading plant & One region & No \\
\hline Hengeveld [21] & $\begin{array}{l}\text { Digester installation, upgrading } \\
\text { plant }\end{array}$ & $\begin{array}{l}\text { Generalizable } \\
\text { knowledge }\end{array}$ & Yes \\
\hline Pöschl [22] & Upgrading and injection & $\begin{array}{l}\text { Generalizable } \\
\text { knowledge }\end{array}$ & No \\
\hline Bekkering [23] & $\begin{array}{l}\text { Biomass transport, digester instal- } \\
\text { lation, upgrading plant, injection }\end{array}$ & $\begin{array}{l}\text { Generalizable } \\
\text { knowledge }\end{array}$ & Yes \\
\hline Bekkering [24] & $\begin{array}{l}\text { Biomass transport, digester instal- } \\
\text { lation, upgrading plant, balancing }\end{array}$ & $\begin{array}{l}\text { Generalizable } \\
\text { knowledge }\end{array}$ & Yes \\
\hline Gigler [25] & $\begin{array}{l}\text { Biomass transport, digester instal- } \\
\text { lation, upgrading plant, injection, } \\
\text { gas grid }\end{array}$ & $\begin{array}{l}\text { Generalizable } \\
\text { knowledge }\end{array}$ & No \\
\hline Jonkman [26] & Gas grid & One region & No \\
\hline Donders [27] & Gas grid & One region & No \\
\hline Sieverding $[14]$ & Gas grid & $\begin{array}{l}\text { Generalizable } \\
\text { knowledge }\end{array}$ & No \\
\hline
\end{tabular}

Table 1.3: Overview of research that assesses the different development options for the biomethane supply chain. With Q1: Which part of the biomethane supply chain is considered? Q2: Can the findings be applied to different regions or is it limited to a certain region? $Q_{3}$ : Does the research describe a method or tool to find a solution?

(otherwise adjusted gas appliances are required), whether the biomethane is supplied directly to larger customers or injected into the gas grid, and whether a CHP is used to combust a temporary surplus of biomethane. For each configuration the financial costs were determined.

Furthermore, Colsen BV [19] and de Veth [20] describe two studies that investigate how the economic performance of different biomethane supply chains compare with the performance of biogas-to-electricity and biogas-to-heat supply chains for a specific situation in the Netherlands. The biomethane supply chains differ from each other with regard to the upgrading technology used. In addition, Colsen BV [19] also compared the $\mathrm{CO}_{2}$ emission reduction of the alternatives. 
Hengeveld [21] presents a method that was used for an economic and energetic comparison of different biomethane supply chains. They differ from each other with respect to the number of digesters that supply biogas to one central upgrading plant (one, two, four, and eight digesters). For each configuration the energy usage $\left(M J / m^{3}(n)\right)$ and cost is determined $\left(€ / \mathrm{m}^{3}(n)\right)$. Hengeveld found that with increasing number of digesters the biomethane production costs go down. Energetically, no significant differences were found between the configurations.

Pöschl [22] assessed the energy efficiency of different biogas systems, including mono- and co-digestion of multiple biomass types, different biogas utilization options and waste-stream management strategies. The most efficient option for a small-scale biogas plant is CHP generation with heat utilization at relatively short distance. The most efficient option for a large-scale biogas plant is upgrading of biogas and subsequent injection in the gas grid, using a small-scale CHP to provide energy to the process.

Bekkering [23] performed a study on the optimal size of a biomethane supply chain comprising biomass production, biomass transport, biomass storage, one digester installation, one upgrading plant, and the injection into the gas grid. He found that increasing the size of the supply chain is desirable from an economic perspective, since the cost per $\mathrm{m}^{3}(\mathrm{n})$ biomethane decreases with the size of the supply chain. However from a sustainable point of view, a smaller biomethane supply chain is desirable, since the energy required per $\mathrm{m}^{3}(\mathrm{n})$ of biomethane increases with the supply chain's size. Furthermore, for larger scales, the number of biomass transport movements might deteriorate the quality of life for people living near a digester installation, and hence may become a limiting factor for the scale of the digester installation.

In a subsequent research paper, Bekkering [24] analyzed three ways to match the fluctuating gas demand to the (usually) constant biogas production for different scales of the biomethane supply chain and for different demand fluctuations. The three options are: (1) the biogas production of a digester installation is assumed to be variable (by $5 \%$ per week) and, as such, is able to meet the seasonal swing in gas demand; (2) a gas storage is added to the biomethane supply chain to store gas; and (3) a second digester is added to the biomethane supply chain that can be switched on and off during the year. The second option, with gas storage, was found to be the most expensive one by far. Flexible biogas production provides the cheapest option. However, in our research we have not considered this, since it is not sure whether the stability of the digestion process can be guaranteed for this option.

Gigler [25] makes an economic assessment of the following three biomethane supply chain configurations: (1) a configuration with local digestion and local upgrading, (2) a configuration with local digestion and central upgrading, and (3) a configuration with central digestion and on-site upgrading. In his research the second option was found to be the cheapest. In addition, Gigler argues to compress biomethane from the distribution grid to the RTL grid in case of a 
temporary surplus of biomethane. According to Gigler, this is energetically the best solution.

The papers by Jonkman [26] and Donders [27] assess the biomethane injection capacity for the gas distribution grids of NV Rendo and Endinet BV respectively (two Dutch DSOs). Jonkman investigated if the gas distribution grids under investigation can take up 12,20 and $50 \%$ of biomethane of the annual gas consumption. Balancing options investigated were: line-pack flexibility, linking gas grids with similar operating pressure, gas compression, and gas storage. In addition, Donders [27] investigated whether the gas distribution grid of Endinet BV could take up $12 \%$ biomethane of the annual consumption and determined the gas grid costs for the different options. The options investigated were: injection in gas distribution grid, compression to the RTL grid, direct injection in the RTL grid, connecting gas distribution grids, and short-term gas buffering (no longer than 12 hours).

Sieverding [14] proposes two solutions to deal with a temporary surplus of biomethane in a gas grid. For the first option, the upgrading plant is connected to two gas grids, where one connection injects biomethane into the local gas grid when capacity is not a problem. The second connection is connected to a gas grid with higher gas flow and operating pressure, which is activated when gas demand of the local gas grid is insufficient. For the second option, biomethane in the local gas grid is compressed to an upstream gas grid with a higher gas flow.

\section{Research gap}

The described literature addresses in part the issue of the best design for the biomethane supply chain. However, the findings of some research papers is only applicable to one region and does not take into account the whole biomethane supply chain (for instance, Smits [18] and Klocke [17]). The findings of other papers consisted of generalizable knowledge but could not be applied directly to a certain region (for example Bekkering [23] and van Eekelen[16]). In addition, other papers did provide a method, but were limited in the scope of the biomethane supply chain (Höhn [15] and Hengeveld [21]). In conclusion, no research was found that considered the design issues for the whole biomethane supply chain and provides a method or tool that can be applied to different regions. To tackle this problem, the next section describes the development of a DST.

\subsection{Development of a DST}

The contribution of our research is the development of a DST that can be applied to different geographical regions and supports the designer in making choices for the design of the biomethane supply chain (see section 1.3 ). 
Before the characteristics of this tool are described in subsection 1.5.2, first a brief description of design processes in general is given in subsection 1.5.1. Finally, subsection 1.5 .3 gives the storyboard scenario, which describes the intended use of the DST.

\subsubsection{Design process}

In general, the design process can be divided into four main phases [28]: (1) Planning and task clarification, (2) Conceptual design phase, (3) Embodiment design phase, and (4) Detail design phase.

First, the planning and task clarification phase addresses the collection of information regarding requirements and constraints of the design and the planning. For the design of the biomethane supply chain a possible requirement is the amount of biomass that needs to be converted to biomethane and a possible constraint is the maximum size of a digester installation.

Secondly, the conceptual design phase results in a solution principle (or concept), which is obtained by abstracting the essential problems, establishing function structures, searching suitable working principles and then combining these principles in a working structure. A more concrete representation is often required for the assessment of the structure. An example for the design of the biomethane supply chain is the location of the digester installation and upgrading plant, and the gas grid into which the biomethane is injected.

Thirdly, in the embodiment design phase the overall layout is constructed. The definite layout allows the evaluation of the financial and technical viability of the design. Design choices to be made for the embodiment design of the biomethane supply chain are the digester installation type, the routing of the pipelines, etcetera.

Finally, in the detail design phase, the arrangements, forms, and dimensions of all the individual parts are determined. Furthermore, all costs are estimated and all drawings and production documents are produced. The result of the detail design phase is the specification of production. Examples of details included in the design of the biomethane supply chain are the exact route of the pipeline, the location where the pipeline crosses roads and waterways, and the exact outlet pressures of injection stations.

In the conceptual and embodiment design phases the artefact is actually designed. Both phases are accomplished by following four basic design tasks [29]:

1. The synthesis task transforms a set of input requirements into a candidate solution. Synthesis in this thesis, therefore, refers to the generation of candidate solutions.

2. The analysis task calculates the solution's performance. 
3. The evaluation task evaluates the performance of the solution in order to decide whether to modify, reject or accept the candidate solution.

4. The adjustment task is applied when the quality of a candidate solution can be improved by small alterations.

These four tasks are recursively invoked during the design process.

\subsubsection{Characteristics of the DST}

The design options for the biomethane supply chain are already largely known and are listed in section 1.3. However, the preferred solution for the biomethane supply chain depends to a great extent on the specific situation and preferences of the stakeholders involved. This makes the design process a complex and time consuming process. Therefore, we have developed a DST, which generates for each specific situation a number of candidate solutions. Each solution has its own advantages and disadvantages, which are denoted by performance indicators - for instance $\mathrm{CO}_{2}$ emission reduction and net present value (NPV). Showing the performance indicators of each solution, provides the engineer insight in the available solutions and eases the evaluation process and the choice for the eventual solution. In addition, the DST hopefully enables an early involvement of all stakeholders in the design process. Currently, the DSOs become involved in the design process when the biogas producer has already decided on the upgrading plant location, which often turns out to be suboptimal [30].

The DST developed in this research automates the synthesis task. Automating the synthesis task supports the designer by developing candidate solutions at low design efforts [29]. For the automated synthesis, a design procedure and a model of the biomethane supply chain had to be developed. The model can be used to generate and evaluate the design of a biomethane supply chain. The design procedure describes how candidate solutions can be generated for the biomethane supply chain, using the model. In addition, the DST also automates the analysis task. Automating the analysis task enables the designer to calculate the performances of candidate solutions. Moreover, when looking at the different design phases, the DST is focused on the conceptual and embodiment design of the biomethane supply chain.

\subsubsection{Storyboard scenario}

The DST will be used to generate candidate solutions for the biomethane supply chain for a certain region in the Netherlands. The start configuration is defined by the current gas distribution grid and biomass locations with a certain biomass availability. An example of a (simple) start configuration is given in Figure 1.3(a). The depicted start configuration consists of three biomass locations, a low and a high-pressure distribution grid, and five gas consumers. 


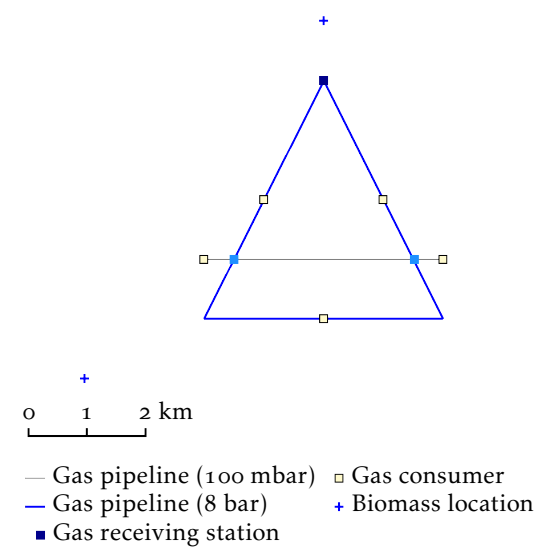

(a) Start configuration

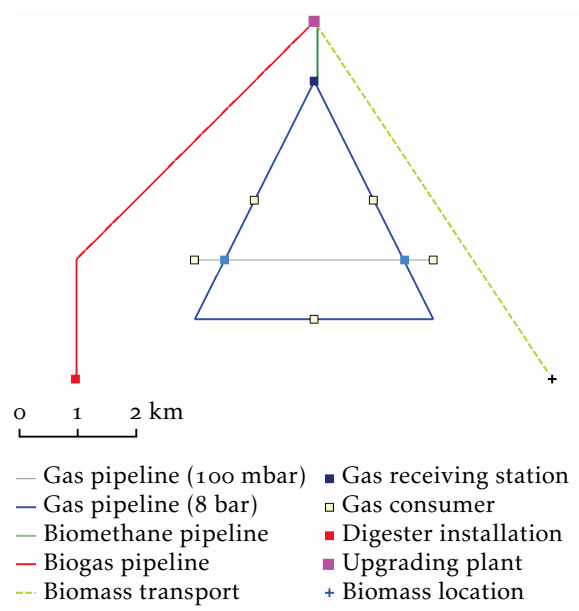

(b) Candidate solution for the biomethane supply chain

Figure 1.3: Example of a start configuration and an example of a biomethane supply chain configuration.

The start configuration is used as input to the DST. The DST's automated generation procedure then generates a number of solutions by adding elements to the start configuration to create biomethane supply chains. These elements are, for instance, digester installations, upgrading plants, pipelines, and gas storages. Decision variables for the DST are, for instance, the location and size of a digester installation, the location and size of an upgrading plant, the route and diameter of a gas pipeline, and the addition of a gas storage.

The DST determines for each generated solution its performance indicators. The user of the DST determines what the important performance indicators are. Examples of performance indicators are biomethane cost, $\mathrm{CO}_{2}$ emission reduction, and net energy production. The performance indicators of the candidate solutions that were generated for the start configuration are shown in Figure 1.4. From the candidate solutions, the user will select the preferred solution. The user can base his choice on the values of the performance indicators, and his personal preferences regarding these performance indicators. In this example the chosen solution is marked white in Figure 1.4.

The design of the chosen solution is shown in Figure 1.3(b). As can be seen, the biomass of all three biomass locations is used; the biomass of the bottom right location is transported to a central digester location located at the top center location; the biomass of the bottom left location is digested locally and its biogas is transported via a biogas pipeline to the central upgrading plant located at the top center location; and the biomethane is injected in the 8 bar $(\mathrm{g})$ grid. 


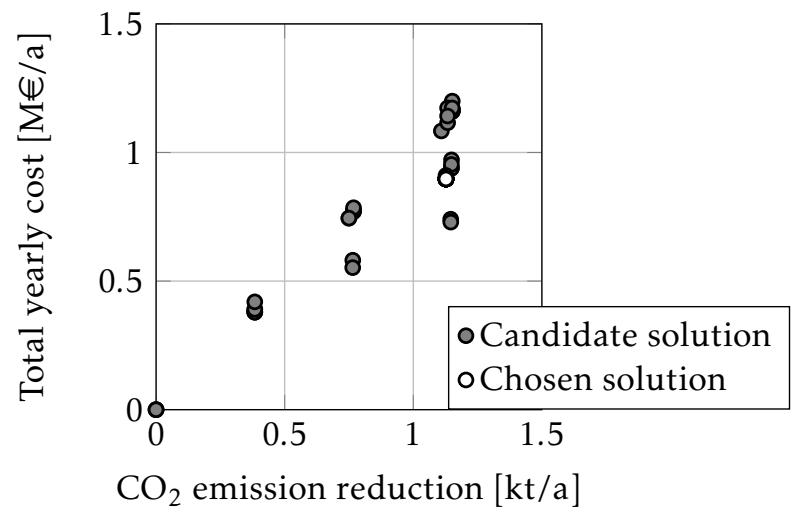

Figure 1.4: Performance indicators of the candidate solutions.

The design shown in Figure 1.3(b) is the embodiment design of the biomethane supply chain. The embodiment design is used to create the detailed design. This last step in the design process is, however, outside the scope of this thesis.

\subsection{Research plan}

This section details the objective and scope of our research, it describes the research method, and it gives the outline of this thesis.

\subsubsection{Research objective and scope}

The main objective of our research was:

To develop a DST that supports the design process of biomethane supply chains, by creating candidate solutions for the design of the biomethane supply chain for a certain region comprising biomass locations, gas grids and gas consumers. The DST should (1) be applicable for multiple regions and take into account the geographical aspects of the region under investigation, (2) consider the different development options for the biomethane supply chain, (3) determine the value of the performance indicators, and (4) allow the user to select the preferred solution.

Before the DST was developed, first four future scenarios were derived that help to determine the role of the gas distribution infrastructure in the Dutch energy system in 2050 and its corresponding functions. The future scenarios captured the potential directions in which the Dutch gas distribution grid might be head- 
ing. The developed scenarios showed that the facilitation of the injection of biomethane will be an important function of the gas distribution grid in the future.

To develop the DST, a design engineering model has been developed that is used to create candidate solutions for the design of the biomethane supply chain, and can be used to determine the values of the performance indicators of the candidate solutions. In addition, a design procedure is needed for the DST. The design procedure describes how the design engineering model is used to create candidate solutions.

The scope of the DST is limited to:

- The biomethane supply chain and measures for the gas grid that deal with a temporary surplus of biomethane.

- The conceptual and embodiment design phases of the design process. Hence, the DST does not provide a detailed design.

- The synthesis and analysis task in the design process. Thus, the evaluation of the solutions and the selection of one solution is left to the user.

The developed DST has been evaluated, to validate whether it actually aids the design process of the biomethane supply chain. Furthermore, the robustness of the candidate solutions generated by the DST was investigated. This was done to find out how sensitive the candidate solutions created by the DST are to changes in the variables of the model.

Moreover, by means of the DST it was investigated what the biomethane supply chain and gas distribution grid will look like in each of the future energy scenarios. This shows the required investments in the gas grid, and the design of the gas distribution grid in each future energy scenario.

Finally, we wanted to know how the developed DST can be used, such that it creates value for DSOs and society.

\subsubsection{Research method}

The aim of our research is to improve the design process of the biomethane supply chain. As such, our research can be considered design research. Although design research applies knowledge from engineering, natural, human, and cultural science, it is not applied science. The methods used in applied sciences cannot be directly applied to design research [31]. Therefore, we chose to use the design research methodology (DRM) (see Blessing [31]) as method for our research. The DRM method was developed to support a more rigorous research approach in design research, and intends to make the research more effective and efficient. The method belonging to DRM is shown in Figure 1.5. As can be seen, it consists of four stages: Research Clarification, Descriptive Study I, Prescriptive Study, and Descriptive Study II. The stages comprise the following [31]: 


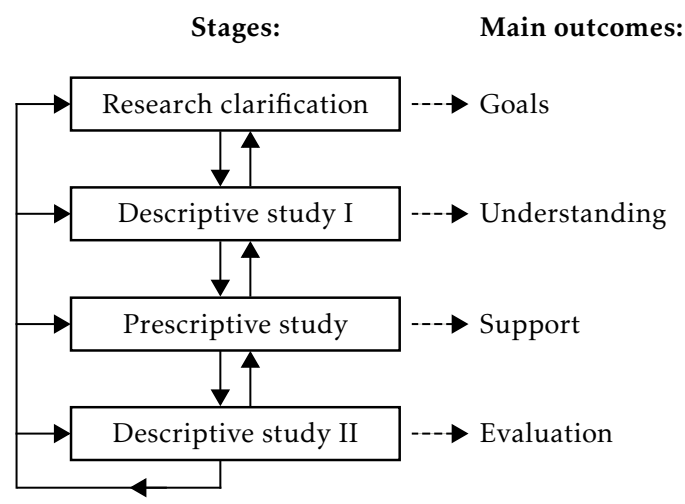

Figure 1.5: DRM framework [31]

Research clarification gives an initial description of the current situation, as well as a description of the desired situation. This step provides an aim in the study, so it helps to define the research goals. Finally, it establishes the criteria against which the outcome of the research is measured.

Descriptive study I aims at increasing the understanding of the design process. Furthermore, it provides a basis for the prescriptive study stage for the effective development of support.

Prescriptive study aims at developing support in a systematic way, taking into account the results of Descriptive study I. This phase attempts to develop the Intended Support, and to realize this to such a level of detail that an evaluation of its effects can take place.

Descriptive study II focuses on the evaluation of support, with regard to the usability and applicability of the actual support and its usefulness. It identifies whether the support can be used for the task for which it is intended.

All four steps were performed in this research.

\subsubsection{Thesis outline}

Figure 1.6 shows the outline of this thesis and in which chapter(s) each stage of the research framework is described. The content of each chapter is described below in more detail.

Chapter 1 provided a description of the choices that have to be made during the design process for the biomethane supply chain (Research clarification). In addition, it described the shortcomings of the current situation, namely that the design process for the biomethane supply chain is a time 


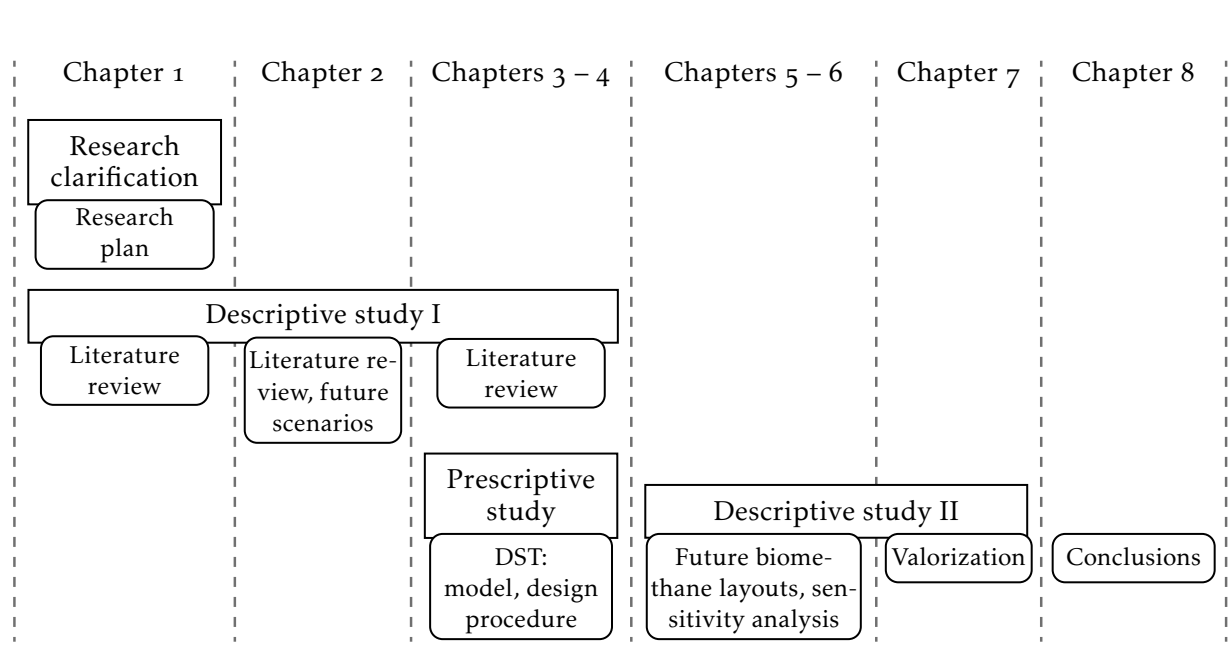

Figure 1.6: Research methodology and outline of this thesis

consuming and complex task. Therefore, this chapter sketched the desired situation. That is to say, a DST should support the design process by providing candidate solutions for the design of the biomethane supply and their performance indicators.

Chapter 2 first gives a literature review on existing future energy scenarios (Descriptive study I). Then, the future scenarios that were developed for the gas distribution system are described (Descriptive study I).

Chapter 3 gives an overview of existing literature on models for (part of) the biomethane supply chain (Descriptive study I). Secondly, it describes the design engineering model that is used in the design process to create and analyze candidate solutions for the biomethane supply chain (Prescriptive study).

Chapter 4 starts with a literature review on existing design procedures for creating energy systems (Descriptive study I). Secondly, it describes the developed design procedure that is used to create candidate solutions for the biomethane supply chain (Prescriptive study), using the design engineering model developed in chapter 2. In addition, it describes the overall design process using the DST.

Chapter 5 describes the possible design for the biomethane supply chain for 3 different regions in the Netherlands in the four future energy scenarios, developed in chapter 2, using the DST. This chapter provides insight in the possible directions that the design of the gas grid is heading. In addition, it also provides a test on the usability of the DST (Descriptive study II). 
Chapter 6 performs a sensitivity analysis on the solutions created by the DST. It shows for three typical designs for the biomethane supply chain how sensitive they are to changes in the parameters of the model and how they perform compared to each other.

Chapter 7 describes the envisaged use of the DST and how its use will improve the current design process of the biomethane supply chain. Furthermore, it describes what steps have to be taken to get from the actual support to the intended support (Descriptive study II).

Chapter 8 draws conclusions on the performed research. It points out what the added value is of our research and how it contributes to the research described in literature. In addition, the limitations of the research are identified. Finally, this chapter indicates possible directions for future research. 


\section{Part II}

\section{Descriptive study I}





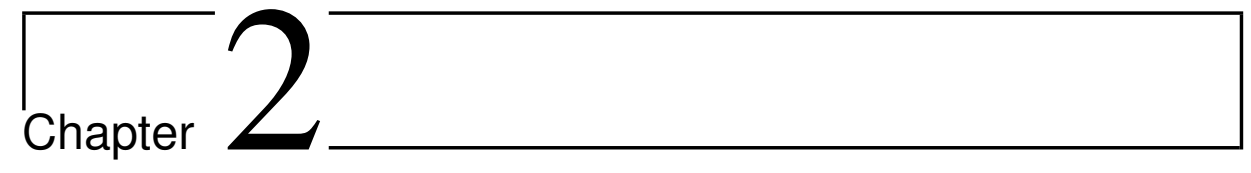

\section{Scenarios for the Dutch gas distribution infrastructure in $2050^{1}$}

The previous chapter briefly discussed the possible changes for the gas distribution grid. As was mentioned, we expect the end of gas production from the Groningen field, an increase in imported gases, an increased share of biomethane, increased interaction between the gas distribution grid and heat and electricity grids, and the end of the economic lifetime of the gas distribution grid. Whether the expected changes will become reality, and to what extent, that is unclear.

What is clear, however, is that the advent of an energy system transition will have a large impact on the gas distribution infrastructure. Therefore, investments in the gas distribution infrastructure are required. With a typical technical lifetime of investments ranging between 40 and 80 years, investment decisions taken now will affect how the system will be shaped by 2050. In the short term, investments are needed to make sure that the infrastructure can cope with future requirements. However, it is not clear what exactly the requirements are. Therefore, it is difficult to determine what to invest in, how much and when. DSOs face a real dilemma. Investing now may enable the energy transition, but it is likely that part of these investments will be unproductive. Postponing investments however, which can be preferable from an investment efficiency point of view, may stifle developments and slow down the transition. This is the DSO's dilemma.

\footnotetext{
${ }^{1}$ This chapter is based on an article [32] that was written by Errit Bekkering, Rosemarie van Eekelen, and Taede Weidenaar.
} 
Therefore, to help in dealing with this dilemma, this chapter describes a study on the possible ways that the future may unfold for the gas distribution grid. Four future scenarios were developed, by building on existing scenarios and largely following a standard scenario planning approach. The scenario planning approach helps the DSOs in coping with their dilemma. In addition, scenario thinking can also be used to derive future system functions. The objective of the scenario planning exercise carried out here was: To develop scenarios that help to determine for the Netherlands the role of the gas distribution infrastructure in the energy system in 2050 and its corresponding functions.

This chapter is intended to further increase the understanding about the possible directions that the gas distribution grid may be heading. Moreover, this chapter forms a basis for subsequent chapters, both by pinpointing at the necessity of the DST and by providing input for the analysis that is done in chapter 5 . As such, this chapter is part of descriptive study I.

The outline of this chapter is as follows. Section 2.1 describes the method that was used to develop the future scenarios. In section 2.2, a literature review on existing future scenarios for energy systems is given. The key forces, forces, and trends, from which the future scenarios were derived are described in sections $2.3-2.5$. The developed scenarios are described in section 2.6. Next, section 2.7 gives some more quantitative details for each of the future scenarios. Finally, in section 2.8 conclusions are drawn on the developed future scenarios.

\subsection{A method for scenario planning}

When carried out properly, scenarios simplify the avalanche of data into a limited number of possible states. Scenario development is not a way to predict the future, but it helps to understand how the future may unfold [33]. Developed scenarios should be plausible, internally consistent and compelling. Dependencies between trends, forces, and key forces need to be considered. A trend is a factor that has an impact and will happen with great certainty. A force has an impact as well, but its outcome is more uncertain than a trend. Finally, a key force has a large impact, but its outcome is very uncertain, see Figure 2.1. Two or three key forces form the basis of the scenarios. For each scenario, an extreme outcome is assigned to each key force. These extreme outcomes form the basis of a scenario, from which the scenarios will be further developed.

To obtain scenarios, some authors suggest adopting a general step-wise approach for scenario planning $[33,34]$. For the scenarios developed here, this approach has largely been followed with a few adaptations. The approach used here is shown in Figure 2.2. The first step was to define the objective and scope, which were already mentioned in the introduction of this chapter. Next, a literature survey was carried out to identify trends, forces, and key forces. Consequently, the here developed scenarios are based on existing scenarios. This is in 


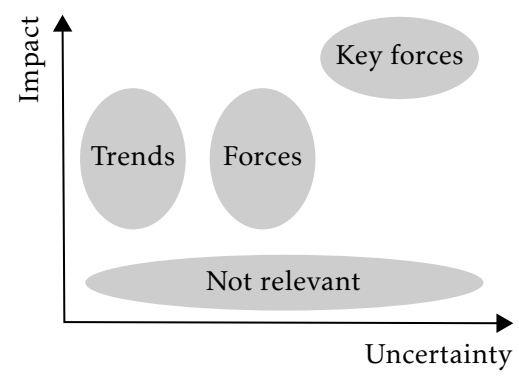

Figure 2.1: Representation of trends, forces and key forces according to their degree of impact and uncertainty

contrast to the approach suggested by Schoemaker [33], who suggests to build the scenarios from scratch. From the two key forces that were identified during the literature survey, four initial scenarios were derived. An expert session was organized to verify the assumptions underlying the initial scenarios. The expert panel consisted of gas distribution experts from the Dutch DSOs, universities and gas knowledge institutes. Once consensus was reached on the initial scenarios, the forces were further quantified. For this quantification the report written by CE Delft [35] was used. This led to the detailed scenarios, which are presented later on in this chapter.

\subsection{Existing scenarios}

The literature survey that was conducted focused on scenarios that are relevant for the energy sector in the Netherlands, and in particular for the gas distribution system, and which are specific enough to help answer the main question. The topics that were of interest are the key forces, how scenarios differ from each other, and which technologies are used in the scenarios. The studies that were examined are summarized in Table 2.1 and are described in more detail below.

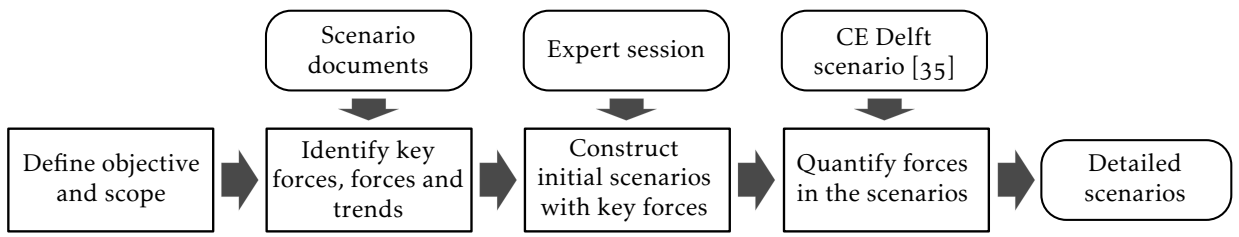

Figure 2.2: Schematic representation of the steps followed in the research approach to obtain detailed scenarios 


\begin{tabular}{|c|c|c|}
\hline Source & $\mathrm{Q}_{1}$ & Q2 \\
\hline CE Delft [35] & $\begin{array}{l}\text { The Nether- } \\
\text { lands }\end{array}$ & $\begin{array}{l}\text { The used energy resources and conversion tech- } \\
\text { nologies \& energy demand. }\end{array}$ \\
\hline $\mathrm{EC}[36]$ & Europe & $\begin{array}{l}\text { The used energy resources and conversion tech- } \\
\text { nologies. }\end{array}$ \\
\hline EGAF [37] & Europe & $\begin{array}{l}\text { The used energy resources and conversion tech- } \\
\text { nologies }\end{array}$ \\
\hline Graabak [38] & Europe & $\begin{array}{l}\text { Development of renewable energy technology \& } \\
\text { attitude of public towards climate change }\end{array}$ \\
\hline Shell [39] & Global & $\begin{array}{l}\text { The ability of the world to find effective answers } \\
\text { to global challenges. }\end{array}$ \\
\hline Keles [40] & Germany & $\begin{array}{l}\text { Whether nuclear energy will be phased out \& } \\
\text { scarcity of energy resources \& the extent of the } \\
\text { GHG emission reduction regime. }\end{array}$ \\
\hline FVEE [41] & Germany & N/A (only one scenario) \\
\hline Lund $[42]$ & Denmark & $\begin{array}{l}\text { The extent to which currently undeveloped re- } \\
\text { newable technologies are used. }\end{array}$ \\
\hline ENA [43] & $\begin{array}{l}\text { United } \\
\text { Kingdom }\end{array}$ & $\begin{array}{l}\text { Further development and commercialization of } \\
\text { CCS \& electricity and heat storage technologies. }\end{array}$ \\
\hline MIT [44] & $\begin{array}{l}\text { United } \\
\text { States }\end{array}$ & $\begin{array}{l}\text { The extent and nature of the GHG emission re- } \\
\text { duction regime. }\end{array}$ \\
\hline
\end{tabular}

Table 2.1: Overview of the future scenarios that were examined. With Q1: To what region do the future scenarios apply? Q2: What are the key forces? Or, if that does not apply, what is the main difference between the developed scenarios?

\section{The Netherlands}

CE Delft [35] has produced scenarios focused on the Dutch energy infrastructure. They start with the $90 \% \mathrm{CO}_{2}$ emission reduction target to develop future scenarios in which a different mix of technologies meets the projected energy demand. The scenarios appear to have a sound technical and quantitative basis (supply and demand) and are largely determined by technology. The three scenarios differ from each other with respect to the energy demand, energy conversion technologies, and central versus distributed energy production. In addition, this report contains useful quantitative information about the energy demand and energy supply in 2050.

\section{Europe}

The European Commission [36] developed several scenarios to achieve $80 \%$ greenhouse gas (GHG) emission reduction in 2050 compared to 1990 . The scenarios differ from each other in the technologies and energy resources used to reduce 
GHG emissions. Technologies include nuclear technology, carbon capture and storage (CCS), and renewable energy technologies. Moreover, in all scenarios saving energy is a priority.

The European Gas Advocacy Forum (EGAF) developed three pathways for the European energy system to achieve 80\% GHG reduction [37]. The scenarios differ from each other in the extent to which various energy sources are employed, which consist of: fossil energy in combination with CCS, nuclear energy, and renewable energy sources.

Graabak [38] developed four future scenarios for the European energy system. The key forces are the technological development of renewable energy technologies, and the attitude of the public towards climate change and environmental issues. All four scenarios use the 20-20-20 targets of the European Union $(\mathrm{EU})^{2}$ as boundary condition and the assumption is that the share of renewable energy will further increase towards 2050. The study also investigated the investments needed in the gas transmission systems for each scenario.

\section{Global}

Two global scenarios, Scramble and Blueprint, are described by Shell [39]. Key uncertainty is the ability of the world to find effective answers to global challenges such as global warming, resource scarcity, and population growth. Orientation of these widely used scenarios is global and geopolitical. The key force is the degree of (international) cooperation.

\section{Germany and Denmark}

Keles [40] examines scenarios that were developed for the German energy market for the year 2030, and tries to identify robust developments and trends from these scenarios. Keles identified four scenario categories within which the developed scenarios can be categorized. Scenario categories identified are: (1) a moderate scenario where the current energy policies and economic framework conditions are continued, especially regarding the current objectives for climate protection and promotion of renewable energies; (2) a scenario that is similar to the moderate scenario, but where nuclear energy is not phased out; (3) a strong GHG emission reduction scenario; and (4) a scenario with fossil energy resource scarcity. All scenarios assume a decrease in population and workforce, and a slight increase in the number of households. In addition, the primary energy demand in all scenarios decreases to some extent. The ForschungsVerbund Erneuerbare Energien (FVEE) [41] also describes an energy system for Germany in the year 2050, which is based on $100 \%$ renewable energy and heavy efficiency improvements, in order to reduce GHG emissions by at least $90 \%$ compared to

\footnotetext{
${ }^{2}$ The aim of the $20-20-20$ targets is to reduce GHG emission with $20 \%$ by 2020 , to reduce energy consumption with $20 \%$ by 2020 , to have a $20 \%$ share of renewable energy in the total energy mix by 2020 , and to have $10 \%$ biofuels in the total consumption of vehicles by 2020 .
} 
1990.

Lund [42] developed three pathways for a $100 \%$ renewable energy system in Denmark in 2050. The main sources of energy supply in the year 2050 are wind and biomass. In addition, energy saving measures and the development of a district heating network to use heat are considered important. The scenarios differ from each other in the extent to which currently undeveloped renewable technologies are used. Moreover, one of the options to buffer large amounts of fluctuating renewable electricity is the use of the gas grid as storage for excess renewable energy.

\section{United Kingdom and United States}

A scenario study has been commissioned by the United Kingdom Energy Networks Association (ENA) [43]. Scenarios focus on the British gas sector. The study makes use of the United Kingdom Department of Energy and Climate Change 2050 Pathways analysis and the United Kingdom Energy Research Council 2050 modeling, and research undertaken for the Committee on Climate Change [45]. These scenarios are oriented on technology. The key forces at play are further development and commercialization of CCS and electricity and heat storage technologies.

An interdisciplinary Massachusetts Institute of Technology (MIT) study [44] examines the role of natural gas in the United States in a carbon-constrained world with a time horizon out to mid-century. The main uncertainty presented in this report is the extent and nature of GHG mitigation measures that will be adopted in the United States and other countries. Various possibilities for the size and production cost of resources, the development of the international gas market (as dictated by economics, geology and geopolitics) and the technology mix (as determined by relative costs of the different technologies) are modeled for a number of GHG policy regimes. The key force is the extent and nature of GHG policy regime.

The scenarios by Shell [39], Keles [40], and MIT [44] pinpoint the ability to find effective answers to reduce GHG emissions as a key force. According to the latter, there is great uncertainty concerning the likely structure of any future international agreement that may emerge to replace the Kyoto Protocol. The absence of a clear international regime for mitigating GHG emissions also raises questions about the likely stringency of national policies over the coming decades.

In contrast, in the scenarios by CE Delft [35], Lund [42], ENA [43], FVEE [41], the EGAF [37], and the European Commission [36], meeting the national or European GHG emission reduction targets for 2050 are taken as a boundary condition. They do not include uncertainty regarding our ability and willingness as a society to adopt measures to tackle this global issue. It is assumed that we will be able to agree on targets and take the necessary measures to meet them. 
Furthermore, one of the key forces in the reports by Shell [39] and Keles [40] is whether the world can find an effective answer to resource scarcity.

None of these existing scenarios could be used directly to find the role of the gas distribution system in the Dutch energy system in 2050. However, elements could be picked out from these scenarios to construct the desired scenarios. In the next sections, the relevant key forces, forces and trends for the here developed scenarios are described.

\subsection{Key forces}

Key forces, which have both a high impact and a high uncertainty, form the basis of the scenarios. The key forces affect and are affected by the forces. Combining information from the scenarios mentioned above, the following two key forces were chosen: (1) perceived energy resource scarcity and (2) willingness and ability to reduce GHG emissions. The key forces, forces, trends, and their interrelations are summarized in Figure 2.3, and are discussed in more detail below.

Perceived energy resource scarcity: Focusing on natural gas, the resource base of natural gas is concentrated in only a handful of countries. Russia, Iran and Qatar account for $55 \%$ of the reserves. Russia, which has by far the largest reserves, could become the dominant supplier of natural gas to the EU. The uncertainty comes from politics. Governments from the EU may not like to rely entirely on Russia. Another important issue that leads to uncertainty is the de-

\begin{tabular}{|c|c|c|}
\hline $\begin{array}{l}\text { Trends } \\
\text { - Depletion of Gronin- } \\
\text { gen field } \\
\text { - Further EU integration } \\
\text { - Aging gas grid } \\
\text { - Decrease in low value } \\
\text { heat demand } \\
\text { - Sharper peak in low } \\
\text { value heat demand } \\
\text { - Increase in electricity } \\
\text { demand } \\
\text { - Increase in number of } \\
\text { households } \\
\text { - Labour force scarcity } \\
\text { - No more cheap oil }\end{array}$ & \begin{tabular}{l}
\multicolumn{2}{c}{ Forces } \\
- Energy demand \\
- Available sources of \\
energy supply \\
- Technological devel- \\
opments \\
- Institutional develop- \\
ments
\end{tabular} & $\begin{array}{l}\text { Key forces } \\
\text { - Perceived energy re- } \\
\text { source scarcity } \\
\text { - Willingness and ability } \\
\text { to reduce GHG emis- } \\
\text { sions }\end{array}$ \\
\hline
\end{tabular}

Figure 2.3: Trends, forces and key forces, and their interrelations 
velopment of the Chinese market, as an alternative destination for Russian gas. This is in contrast to the possible discovery and exploitation of large sources of shale gas in the EU, which will lead to an increase in energy resource availability.

When energy resources are perceived to be scarce, security of energy supply will be more of an issue. Energy conservation measures will become a logical response, in combination with increased local production of electrical wind power, electrical solar power and biomethane. This biomethane will be injected into the gas distribution grid, and a surplus of wind and solar power might be buffered as $\mathrm{CH}_{4}$ in the gas transport and distribution grid. Conversely, in a world with abundant fossil fuels, renewable energy projects will be economically less attractive and energy conservation measures will be less urgent. Hence, the perceived energy resource scarcity is a factor with a large impact on the energy system, including the gas distribution infrastructure.

Willingness and ability to reduce GHG emissions: We regard the reduction targets for GHG emissions that cause the global warming as a factor with a large impact on the development of energy infrastructures and, consequently, on the gas distribution system. A strict GHG reduction regime may mean that local combustion of natural gas is no longer allowed, and that the gas distribution system becomes obsolete in some parts of the country. On the other hand, under this strict regime, it is likely that the gas distribution system has to facilitate the injection and distribution of biomethane. Under a less strict regime, local combustion of gas will still be allowed, and therefore, the gas distribution system will face less rigorous changes. Hence, the reduction of GHG emissions has a large impact on the gas distribution system.

It is however uncertain if society is collectively willing and able to take necessary measures to reach the GHG emission reduction targets. For instance, in the scenarios by Keles [40], Shell [39], and MIT [44] the ability to reduce GHG emissions is a factor with a large degree of uncertainty.

In conclusion, the perceived energy resource scarcity and the willingness and ability to reduce GHG emissions have a large impact on the gas distribution infrastructure, while at the same time there exists uncertainty about their outcome. Therefore, in this study, these factors were chosen as the key forces. As such, they form the basis of the scenarios developed here. From the description of the key forces, it is clear that they are related to the other forces that shape the scenarios. These are described next.

\subsection{Forces}

Energy demand, available sources of energy supply, technological developments and institutional developments were chosen here as forces. The forces are affected by trends and key forces and in turn affect the key forces. In this section 
the forces are described into more detail. Furthermore, it is described how they affect the key forces and the future gas distribution system.

\subsubsection{Energy demand}

As in the reports of CE Delft [35], ENA [43], and DECC [45], the energy demand was divided into four categories:

Low value heat is the energy required for space heating and hot water supply. The largest share of this demand stems currently from households, utility buildings and greenhouse farming. Demand is likely to decrease following the trend line.

High value heat is mostly used in the industry for processes like distillation, refining and separation.

Energy for mobility comprises the energy demand for passenger and freight transport by road, rail and water. It is unclear in what form this energy demand will be met. Will it be met by electricity, gas or liquid fuel?

Energy for lighting and appliances comprises the energy demand for lighting and electrical appliances.

As of 2008, in the Netherlands, the total energy for low value heat amounts to $600 \mathrm{PJ} / \mathrm{a}$, high value heat to $500 \mathrm{PJ} / \mathrm{a}$, energy for mobility to $17 \mathrm{O} \mathrm{PJ} / \mathrm{a}$ and energy for lighting and appliances to $432 \mathrm{PJ} / \mathrm{a}$ [35]. These demand values indicate the demand for end use, not the demand for the energy sources (primary energy demand). The difference in value between the demand for end use and primary energy demand stems from the energy losses incurred during the energy conversion processes. The value for low value heat is of importance, since this demand is at the moment largely met by natural gas. Hence, the value for low value heat determines in part whether the gas grid's capacity should be increased, should remain as it is, or maybe the gas grid should be decommissioned. The demand value per energy demand category was quantified for each scenario, see section 2.7 .

\subsubsection{Available sources of energy supply}

The energy demand will have to be met by one or more energy sources. The available energy sources were divided into several categories along two dimensions. The first dimension is the origin of the energy sources; energy can originate from (1) local or regional sources, (2) national or EU sources, or (3) sources outside of the EU. The second dimension is the type of energy source; the energy sources types that were identified here are (1) renewable energy, (2) nuclear energy and (3) fossil energy. The total overview of the available energy sources is given in Table 2.2 . 


\begin{tabular}{|c|c|c|c|}
\hline & Local and regional & National and EU & Non-EU \\
\hline Renewables: & $\begin{array}{l}\text { - Geothermal } \\
\text { - Biomass } \\
\text { - Wind (on land) } \\
\text { - Solar (solar } \\
\text { panel) }\end{array}$ & $\begin{array}{l}\text { - Biomass } \\
\text { - Wind (at sea) } \\
\text { - Solar (concen- } \\
\text { trated power) }\end{array}$ & $\begin{array}{l}\text { - Solar (concen- } \\
\text { trated power) }\end{array}$ \\
\hline Nuclear: & & - Nuclear & - Nuclear \\
\hline Fossil: & & $\begin{array}{l}\text { - Coal } \\
\text { - G-gas } \\
\text { - Shale gas }\end{array}$ & $\begin{array}{l}\text { - Coal } \\
\text { - Gas from Nor- } \\
\text { way, Algeria and } \\
\text { Russia } \\
\text { - Shale gas } \\
\text { - LNG }\end{array}$ \\
\hline
\end{tabular}

Table 2.2: Sources of energy available to the Netherlands, per category of sources and geographic dispersion

The key forces will play a significant role in the eventual energy mix. As a first example, the share of non-EU energy sources depends largely on the perceived scarcity of energy resources. When energy resources are perceived as scarce, security of supply will become an important issue. One of the ways to secure energy supply will be by increasing the share of local, regional, national and EU sources. Consequently, the share of non-EU resources will be low. With a low perceived energy resource scarcity, security of energy supply will be less of an issue, and there will be no preference for the origin of the energy. Hence, the energy supply mix will be determined by the worldwide energy market and consequently the share of non-EU energy sources will be higher.

As a second example, renewable energy sources will have a high share when the willingness and ability to reduce GHG emissions is high. Economic arguments will play a less important role, and governments will tailor their policies such as to stimulate the use and production of renewable energies in order to reduce GHG emissions.

Besides the key forces, other factors affect the energy mix as well. For instance, for renewable energy, the availability of biomass plays an important role. This is a difficult issue as there are competing claims on biomass: the biomass could be used for the production of gas, electricity, or chemicals and materials. In addition, biomass production might compete with food production for the use of available land [46], which might be undesirable from a societal perspective.

Obviously, the future gas distribution grid will be affected by the eventual energy mix. An energy mix with a minor role for gas might lead to the abandonment of a great part of the gas distribution grid. Furthermore, the origin of the 
natural gas is important, since imported gases have different qualities than Ggas. Therefore, a choice will have to be made whether to keep on converting the foreign gases to G-gas quality (even if the Groningen gas field itself is depleted), or to change to different gas specifications and adjust the gas appliances.

\subsubsection{Technological developments}

Advances in technology will impact the future role of the gas distribution grid as well. Most technologies are still in development and often not yet cost effective. Will they mature and become an economic viable option? The four most important techniques are examined below.

Storage techniques: Development of storage techniques for electricity, heat and gas are expected to have a huge impact on the future energy system in 2050. For bridging longer periods, when supply of renewable energy coming from wind or solar for example is too high or too low, long term storage will be needed. We assumed that the technology and ability to store electricity on a large scale will not become economically and technologically viable, and therefore, the storage of gas remains significantly cheaper than the storage of electricity. A comparison of the different storage technologies is shown in Figure 2.4.

In the scenario with the largest share of renewable electricity, the total yearly production was estimated at $470 \mathrm{PJ}$ or $130 \mathrm{TWh}$ (see section 2.7). If the required buffer capacity would only be $1 \%$ of the yearly production, this would already require a storage capacity of 1.3 TWh. As can be seen in Figure 2.4, the only storage technique that can provide this storage capacity is the conversion of electricity to $\mathrm{H}_{2}$ or $\mathrm{CH}_{4}$ and, subsequently, injecting it into the gas grid. In addition, it can

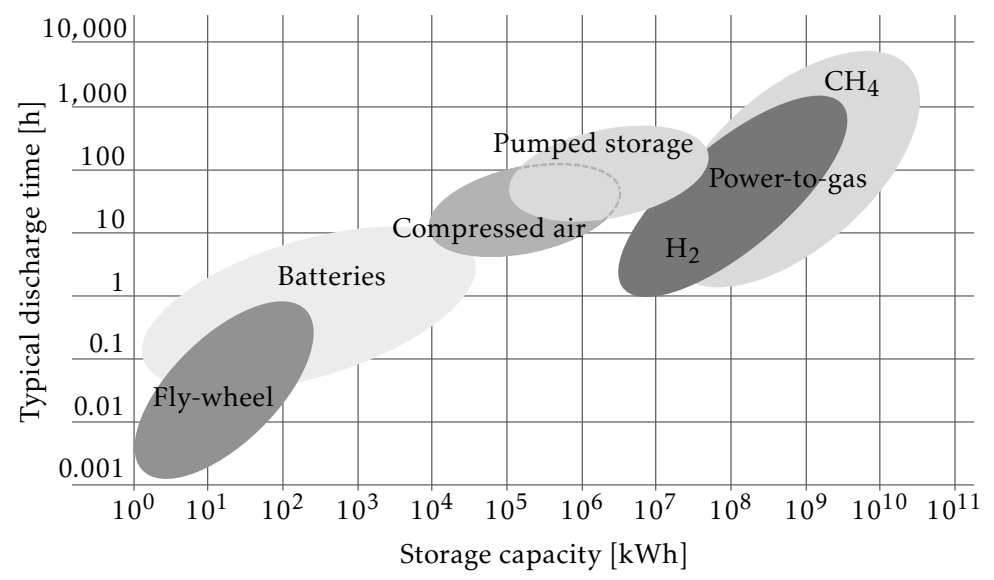

Figure 2.4: Comparison of electricity storage techniques, with typical storage capacity and discharge time $[47,48]$ 
be seen that $\mathrm{H}_{2}$ and $\mathrm{CH}_{4}$ provide the highest storage density compared to other electricity storage techniques - see Figure 2.5. Therefore, in case of an electricity surplus from solar PVs and windmills, the surplus energy will be converted to $\mathrm{H}_{2} / \mathrm{CH}_{4}$ and subsequently be injected into the gas grid (similar to the scenarios developed by Lund [42]). (An elaborate foundation for this assumption has been made elsewhere [49].)

Power-to-gas conversion: As stated above, the conversion of electricity to gas in the form of $\mathrm{H}_{2}$ or $\mathrm{CH}_{4}$ is an important technological development to provide storage for the fluctuating renewable energy supply. The following processes are crucial: electrolysis from electricity and thermal water splitting to produce $\mathrm{H}_{2}$. Furthermore, the produced $\mathrm{H}_{2}$ can be reformed to $\mathrm{CH}_{4}$ by the reaction with $\mathrm{CO}_{2}$ with the Sabatier process. The $\mathrm{CH}_{4}$ will be injected into the gas grid, where the $\mathrm{CH}_{4}$ can be stored in gas storages and can be supplied to producers of electrical power.

We assumed that the conversion of electricity to $\mathrm{H}_{2}$ or $\mathrm{CH}_{4}$ provides the most economic storage solution for surpluses of renewable energy and will become important when the Dutch energy mix consists of a large share of renewable electricity. In the remainder, the $\mathrm{CH}_{4}$ from renewable electricity is referred to as renewable methane.

Gas to electricity and heat: $\mathrm{CHP}$ installations generate both electricity and heat that can be used for heating purposes. CHPs, therefore, increase the energy conversion efficiency considerably. Moreover, CHPs are a cost-effective technology for reducing energy demand and cutting GHG emissions in the energy sector. For individual households or small commercial buildings, the micro-CHP

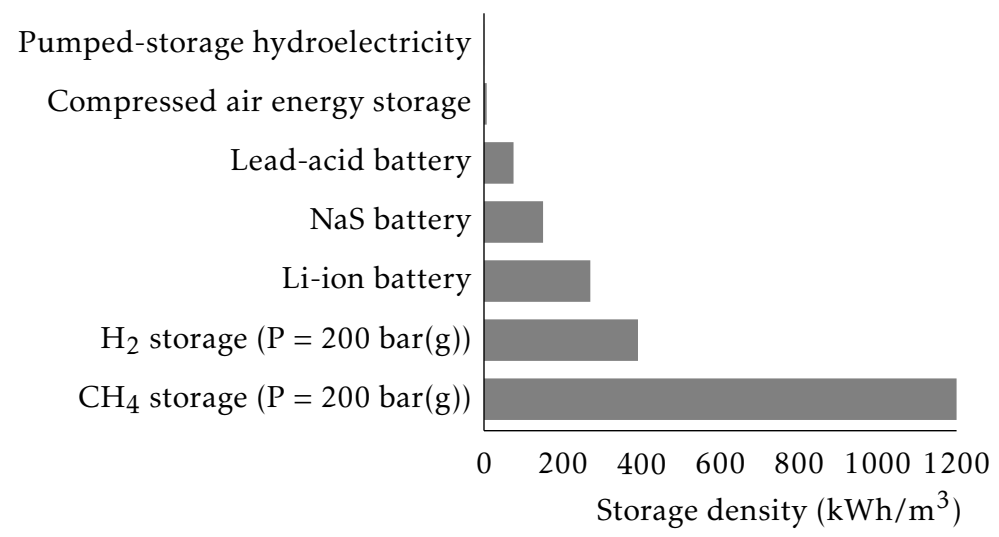

Figure 2.5: Comparison of storage densities $\left[\mathrm{kWh} / \mathrm{m}^{3}\right]$ of energy storage technologies $[50]$. 
has been developed. The market for micro-CHPs will be the replacement of conventional gas central heating boilers, when they reach the end of their useful life. Moreover, (micro-)CHPs are flexible regarding fuel, since natural gas, biogas, biomethane, $\mathrm{H}_{2}$ or $\mathrm{CH}_{4}$ can be used as fuel.

CCS: CCS is the technology that captures $\mathrm{CO}_{2}$ from combustion gases, and subsequently transports it and sequestrates it underground. In view of the associated costs, we assumed that CCS will only play a role when there is a willingness and ability to reduce GHG emissions, and there is a large share of electricity production by means of fossil energy and/or large industry is using fossil energy.

Besides the development of the above mentioned technologies, other technological factors may also have an impact on the gas distribution infrastructure: (1) local versus central use of natural gas, (2) required flexibility, and (3) gas quality.

Whether natural gas can be used locally, partly depends on the extent of the GHG reduction regulations and energy efficiency objectives. The central or local use of the gas can have a considerable impact on the extent of the low-pressure distribution grid [35].

The required flexibility for the gas grid determines to what extent new gas storage sites have to be added to the gas grid. It is also important at which pressure level these gas storage sites are added, that is the national gas grid or the local gas distribution grid.

With the depletion of the Groningen gas field, the quality of the gas flowing through the gas distribution grid is likely to change. Whether this will result in one new national gas quality standard with a broader Wobbe band, in separated regions each with its own specifications, or in a combination of the two options is an issue that requires further research.

\subsubsection{Institutional developments}

The fourth force that impacts the gas distribution system and influences the key forces is the institutional and political developments. Institutions are defined as "the rule of the game" [51]. How the energy system looks and works depends for a large part on the rules we collectively agree on. This pertains both to the degree of government involvement as well as to the level at which governments are involved, whether it is a local, national or supranational entity. For instance, if energy resource scarcity is perceived to be high, then this will be reflected by the institutions. Local self-sufficiency and integration between gas and electricity supply systems will probably be promoted with a clear role for local authorities. Furthermore, GHG reduction efforts will probably go hand in hand with new restrictions and/or incentives both on national and on EU levels. 


\subsection{Trends}

Trends affect the forces and have a relatively low degree of uncertainty. The following nine trends were identified.

Depletion of the Groningen gas field: Of the initial volume of the Groningen gas field, estimated at $2.8 \mathrm{Tm}^{3}(\mathrm{n})$, approximately 1.0 $\mathrm{Tm}^{3}(\mathrm{n})$ remains as of 2010 . The pressure has dropped from 350 bar(a) to around 200 bar(a) in the mid 1990s. Until 2020, the Groningen gas field can provide the necessary swing capacity. After that date, this role will gradually be taken over by underground gas storages [2].

Further EU integration: The stop-and-go process of EU political and economic integration is likely to continue. Organizations such as the Council of European Energy Regulators and the European Commission's formal advisory group of energy regulators will continue to work on the further integration of the EU's national energy markets. Other structures will be designed to manage and regulate the increasingly interlinked and interdependent EU energy system.

Aging gas grid: Parts of the current gas distribution system and many components are approaching their design lifetime. DSOs face important decisions about the replacement or even possible decommissioning of their gas distribution grids. Replacement or renovations of the gas distribution systems will require huge investments in the near future and important decisions about the design of these systems have to be made.

Decrease in low value heat demand: Insulation of buildings is technically simple and economically attractive. Buildings that do not require energy from the grid for heating or cooling already exist. Take-up rate depends on the pace of renovation programs and government rules. The trend that norms get stricter will continue. By 2050, a substantial part of the Dutch stock of houses will be replaced or renovated.

Sharper peak in low heat demand: The peaks in low value heating will become sharper. Due to the ever improving insulation of buildings, low value heating demand decreases, and buildings only require space heating in case of severe cold weather conditions. This means that the base load decreases and the length of the period during which space heating is required becomes shorter. Hence, the low value heat peak demand becomes sharper, though lower in absolute values.

Increase in electricity demand: While demand for low quality heat will go down, demand for electricity will go up. Penetration and use of, for instance, computers, electric appliances and television sets will continue to increase. 
Increase in number of households: The trend of smaller families and more single person households will continue.

Labor force scarcity: Based on the current age profile within the utility companies, an experience drain is foreseen. With the projected shortage of working people in the coming years, internal work processes need to be reviewed and possibly automated.

No more cheap oil: For reasons of cost and availability, oil will be replaced by renewables, coal or nuclear energy for electricity generation. The transport sector will switch either to electricity, liquid bio-fuels or (bio)gas [52].

\subsection{Scenarios and their narratives}

The key forces, forces and trends that have been described were used here to construct four scenarios: Business as Usual, Carbon Constraints, Tight Market, and Renewable Self-sufficiency. For each scenario, an extreme of both key forces was taken, with the variable low or high. In the scenarios with a high willingness and ability to reduce GHG emissions, we are collectively able to implement effective measures to mitigate GHG emission. In the scenarios with a low willingness and ability, we are only to a limited extent able to do this. Furthermore, in the scenarios with a high perceived energy resource scarcity, availability of energy resources may be limited due to political, geological, technical or economic reasons. In the scenarios with a low perceived energy resource scarcity, resources are perceived to be plentiful available. The four scenarios are summarized in Table 2.3 , and are described in more detail below.

\subsubsection{Business as Usual}

This scenario is closest to the current situation, and can be characterized as business as usual. The need for GHG reduction is acknowledged by the public (and with that by politicians), but necessary measures are weighed against other priorities and not implemented at all cost. The practical implementation of measures in the EU stalls, because other goals are conflicting, and because some countries or continents are dragging their feet.

Resources and especially natural gas are not seen as a scarce resource (except for oil), but more as a commodity that is available on the market. Hence, the security of energy supply is not so much an issue in the public debate. Russian gas, possibly EU shale gas plus LNG have replaced G-gas. The market and players in that market determine the energy mix. Economic efficiency is the major consideration.

Local combustion of natural gas is still common practice. Use of the gas distribution infrastructure is comparable to the present use. Renewable energy 
Willingness and ability to reduce GHG emissions

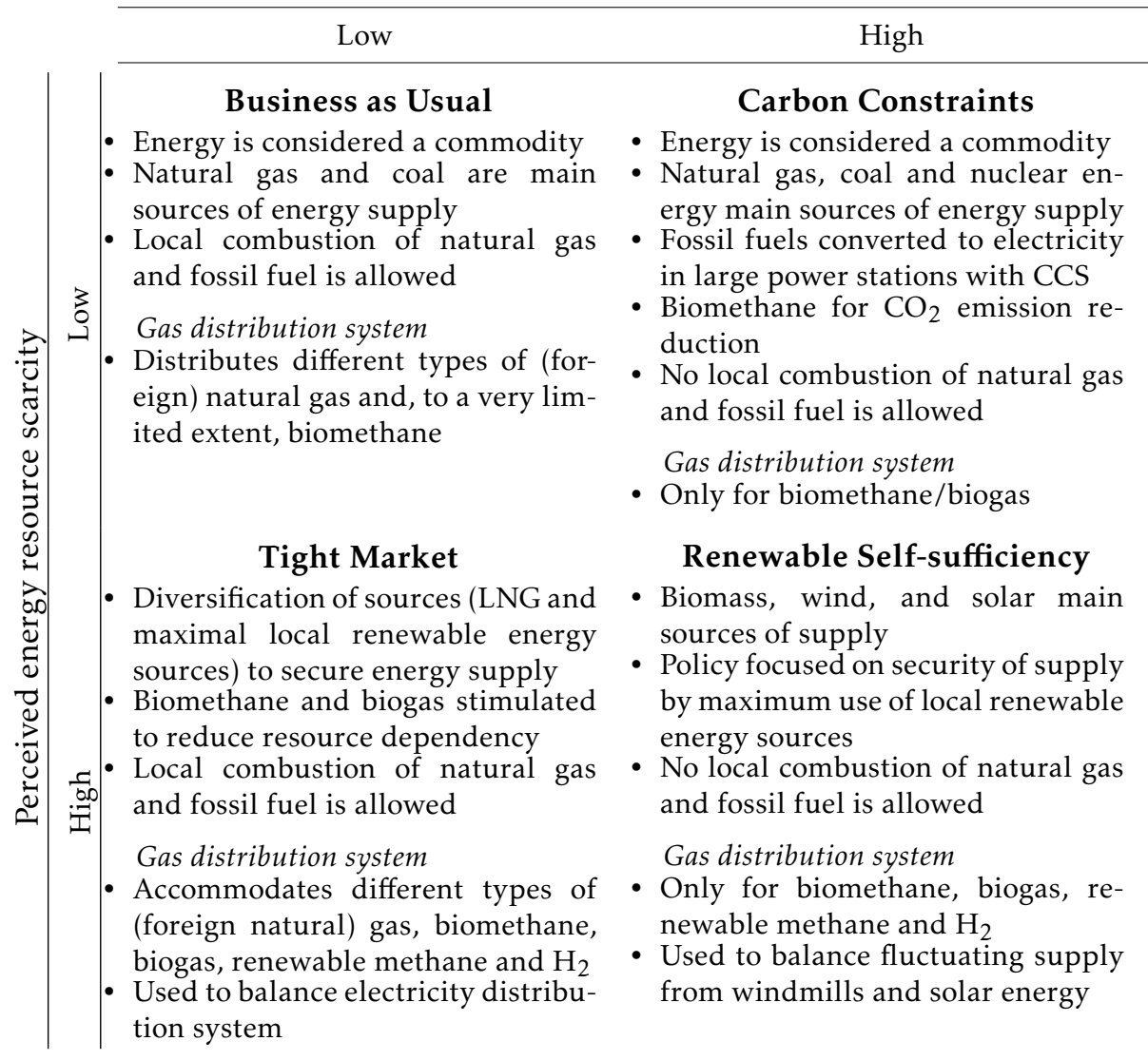

Table 2.3: Scenarios per degree of willingness and ability to reduce GHG emissions and perceived energy resource scarcity

sources compete with fossil sources on price and their share in the energy mix will be significantly lower than the stated ambitions.

\subsubsection{Carbon Constraints}

The ambition of a $90 \%$ reduction in GHG emissions compared to 2008 is considered a boundary condition. Combustion of natural gas is prohibited in households, since it is not possible to capture $\mathrm{CO}_{2}$ locally in an economic way. Instead natural gas is substituted by electricity and heat (from local heat grids). Hence, the gas distribution grid plays a minimal role in this scenario. The gas distribution grid will only remain in use in certain areas where there is sufficient production of biomethane. 
In contrast to the gas distribution grid, the gas transportation grid still has a significant role in the Dutch energy system. Natural gas is transported to large gas-fired power stations to produce electricity in combination with CCS. To transport the $\mathrm{CO}_{2}$ from a power station to a storage facility, a separate infrastructure is needed. Besides natural gas, coal (also in combination with CCS) and nuclear energy have a significant share in the electricity production. In addition, renewable energy sources have a significant share in the energy mix.

Since there is limited perceived energy resource scarcity in this scenario, the gas used to fire the power stations is allowed to be transported from non-EU countries. Therefore, natural gas from a number of large Russian pipelines will compete with natural gas from EU-countries. The energy market and the companies operating in these markets determine the energy mix.

\subsubsection{Tight Market}

In this scenario, there is a perceived scarcity of energy resources. Hence, security of supply is an important issue that is dealt with at national and EU level. A concerted effort is made to diversify energy sources. Renewable energy and energy conservation measures are seen as important and a means to increase security of energy supply.

Due to the high share of electrical renewable energy, such as wind and solar, the fluctuation in these energy sources proves to be a challenge for the balance of supply and demand. Therefore, an important function of the gas system is to provide the needed flexibility to balance demand and supply in the energy system.

Public and politics are aware that reduction of GHG emissions is necessary, but this is low on the political agenda. Implementation of necessary measures proves to be difficult. The slowest implementers, in this case EU, China and the United States, set the pace. The main argument to use renewable energy is to increase the security of energy supply.

\subsubsection{Renewable Self-sufficiency}

Drastic reduction of GHG emissions is a boundary condition in this scenario. It is prohibited to combust natural gas at household level. Therefore, the role of the gas distribution grid is minimal, and natural gas is substituted by electricity and heat (from local heat grids). The gas distribution infrastructure will only remain in use in certain areas where there is sufficient production of biomethane. At a central level, gas can still be combusted in power stations in combination with CCS. A separate $\mathrm{CO}_{2}$ infrastructure is needed for the sequestration of $\mathrm{CO}_{2}$ produced in large power stations.

In this scenario, there is a perceived scarcity of energy sources. Therefore, security of supply is an issue in the public debate, which is dealt with at national and EU level. Preferably, all natural gas (for power stations or large industry) 
will be supplied by domestic or EU suppliers. Moreover, foreign/non-EU gas will be imported as LNG in order not to be too dependent on one supplier. Renewable energy plays an important role and energy conservation measures are seen as important and a means to decrease dependency.

The largest share in the energy supply mix comes from renewable energy. Due to the high share of wind and solar electricity, the balancing of supply and demand becomes challenging. The gas system, both transportation and distribution, is used to balance supply and demand.

\subsection{Quantification of supply and demand forces}

For each scenario, this section gives the values that were quantified for energy demand and energy supply. There is a mismatch between the energy demand values and the energy supply values: the total values for energy supply are higher than for energy demand. This is caused by the fact that the values for energy demand indicate the demand for end use, whereas the values for energy supply indicate the primary energy demand (see also subsection 2.4.1). To convert the end use energy demand to primary energy demand, losses during energy conversion and transport should be taken into account.

\subsubsection{Energy demand}

The energy demand was subdivided previously into low value heat, high value heat, energy for mobility, and energy for lighting and appliances. For the energy demand in the Carbon Constraints, Tight Market, and Renewable Self-sufficiency scenarios the values in the CE Delft report [35] were used. The latter provides recent numbers relevant for the Dutch energy system. CE Delft identifies two scenarios for the demand: the low scenario and the extra low scenario.

For the Renewable Self-sufficiency scenario, we assumed that the demand corresponds to the extra low scenario. In this scenario, energy is perceived to be scarce and the same time the government aims at $90 \%$ GHG emission reduction. There will be a strong incentive for consumers to reduce energy consumption, either by regulation or due to the probably high energy prices. Hence, the demand was chosen to be as low as possible.

The demand values for the Carbon Constraints and Tight Market scenarios correspond to the values for the low scenario in the CE Delft report [35]. In these scenarios, there is a strong incentive to reduce energy consumption (either due to the strict GHG emission regulations or the perceived energy resource scarcity which will increase energy prices). However, the incentive is not as strong as in the Renewable Self-sufficiency scenario, in which the combination of both a perceived energy resource scarcity and strict GHG emission regulations leads to the strongest demand reduction of the four scenarios. 
For the Business as Usual scenario, we assumed that the demand values will be higher than in the Carbon Constraints and Tight Market scenarios, since there is not an incentive for consumers to reduce demand. Therefore, a medium scenario was introduced, which demand values are linearly extrapolated from the low and extra low demand values. The values for the energy demands are shown in Table 2.4.

\subsubsection{Energy supply}

The energy demand will be met by a mix of energy sources. Previously, the energy sources were differentiated according to their geographical origin and their type. The total energy mix and the gas supply mix is described here for each scenario ${ }^{3}$.

Energy supply mix: One main assumption here is that there are no cheap fossil oil reserves left in 2050 [52]. Another assumption is that, although biomass is treated as a limited resource of energy due to competition with its use for materials or other purposes, a part of domestic (and imported) biomass will be available for biomethane and synthetic natural gas (SNG) production.

The energy share values are based on a quantification made in the report by CE Delft [35], and the current energy mix [53]. These values were adapted to fit the main forces and underlying relations in the four scenarios. Table 2.5 shows the energy supply mix per scenario.

For the Business as Usual scenario, gas and coal are the main energy sources. Furthermore, this scenario is the only one in which the total volume of gas increases in comparison to 2008. It has the lowest share of renewables of the four

3 The values for the energy supply mix for Carbon Constraints were derived from CE Delft's scenarios B and C [35]. The values for the energy supply mix for Renewable Self-sufficiency were derived from scenario A of the same study. For the Tight Market scenario, the quantification of the energy supply mix was derived from the extrapolation of the quantities determined for Business as Usual, Carbon Constraints and Tight Market.

\begin{tabular}{llllll}
\hline Demand type & $\begin{array}{l}\text { Lighting } \\
\text { and appli- } \\
\text { ances }\end{array}$ & $\begin{array}{l}\text { Mobi- } \\
\text { lity }\end{array}$ & $\begin{array}{l}\text { High } \\
\text { value } \\
\text { heat }\end{array}$ & $\begin{array}{l}\text { Low } \\
\text { value } \\
\text { heat }\end{array}$ & Total \\
\hline Year 2008 & 432 & 170 & 500 & 600 & 1702 \\
Business as Usual & 630 & 225 & 500 & 500 & 1855 \\
Carbon Constraints & 540 & 200 & 400 & 400 & 1540 \\
Tight Market & 540 & 200 & 400 & 400 & 1540 \\
Renewable Self-sufficiency & 450 & 175 & 300 & 300 & 1225 \\
\hline
\end{tabular}

Table 2.4: Energy demand [PJ] in 2050 per scenario, with year 2008 for comparison 


\begin{tabular}{|c|c|c|c|c|c|c|c|c|c|}
\hline \multirow{2}{*}{\multicolumn{2}{|c|}{ Scenario }} & \multicolumn{2}{|c|}{ Fossil } & \multirow[b]{2}{*}{ Nuclear } & \multicolumn{4}{|c|}{ Renewables } & \multirow{2}{*}{ Total } \\
\hline & & Gas & Coal & & Wind & Solar & Biomass & Other & \\
\hline $\begin{array}{l}\text { Business } \\
\text { Usual }\end{array}$ & as & 2085 & 932 & $6_{5.2}$ & 48.9 & 0.7 & 85 & 5 & 3260 \\
\hline $\begin{array}{l}\text { Carbon } \\
\text { straints }\end{array}$ & Con- & 870 & 660 & 730 & 95 & 20 & 150 & 45 & $257^{\circ}$ \\
\hline \multirow{2}{*}{\multicolumn{2}{|c|}{$\begin{array}{l}\text { Tight Market } \\
\text { Renewable Self- } \\
\text { sufficiency }\end{array}$}} & 1168 & 400 & 100 & 115 & 95 & $15^{\circ}$ & 45 & 2185 \\
\hline & & 300 & $\mathrm{O}$ & $\mathrm{O}$ & 300 & 170 & 915 & 115 & 1800 \\
\hline
\end{tabular}

Table 2.5: Sources of energy supply in 2050 per scenario [PJ]

scenarios. Despite the restrictions on GHG emissions, gas and coal have a large share in the energy mix in the Carbon Constraints scenario. This is acceptable, since the released $\mathrm{CO}_{2}$ will be sequestrated in this scenario. Furthermore, due to the $\mathrm{CO}_{2}$ free electricity production of nuclear power plants, this source of energy has a large share in the energy mix in this scenario. Moreover, renewables do have a significant share as well, but are by far not as significant as in the Renewable Self-sufficiency scenario. Renewables have a significant share in the Tight Market scenario. Focus is on security of supply and the local availability of renewable energies provides this security. In addition, gas and coal have a large share in this scenario, which should preferably originate from domestic or EU sources. The restrictions on GHG emissions and the perceived energy resource scarcity makes that in the Renewable Self-sufficiency scenario, biomass is the dominant source of supply. Other renewables have a significant share in this scenario as well, since renewables provide both security of supply and low GHG emissions. Natural gas only has a minor share in the energy mix in the Renewable Self-sufficiency scenario.

Gas supply mix: The values for the gas supply mix were derived from: the values for the current gas supply mix in the Netherlands, the underlying relations between the forces, and the assumptions about the gas supply mix. The assumptions about the gas supply mix are detailed in Table 2.6.

The key forces determine the share of biomethane, SNG, and shale gas in each scenario. The perceived energy resource scarcity determines the need to secure energy supply by means of locally produced renewable energy (among others, biomethane and SNG ). In addition, the willingness and ability to reduce GHG emissions leads to an increased share of biomethane and SNG in order to reduce GHG emissions. Thus, a high perceived energy resource scarcity, or a high willingness and ability to reduce GHG emissions will lead to an increased share of biomethane and SNG. A high value for both key forces will lead to an even higher share of biomethane and SNG. 


\begin{tabular}{|c|c|c|}
\hline & Renewable gases & Fossil gases \\
\hline 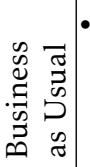 & $\begin{array}{l}\text { - Amount of biomethane and SNG } \\
\text { based on the current situation }\end{array}$ & $\begin{array}{l}\text { - Large sources of shale gas are found } \\
\text { and exploited in the Netherlands } \\
\text { - Russian gas, LNG, and shale gas have } \\
\text { to a large extent replaced g-gas }\end{array}$ \\
\hline 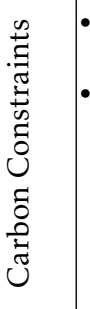 & $\begin{array}{l}\text { - Biomethane and SNG stimulated to } \\
\text { reduce GHG emissions } \\
\text { - The use of agricultural area for en- } \\
\text { ergy crops is not stimulated but also } \\
\text { not prohibited }\end{array}$ & $\begin{array}{l}\text { - Due to strict GHG emission reduc- } \\
\text { tion policy, it is not allowed to burn } \\
\text { natural gas at household level } \\
\text { - Due to environmental concerns and } \\
\text { low gas prices, shale gas sources are } \\
\text { not exploited } \\
\text { - Russian gas and LNG have to a large } \\
\text { extent replaced g-gas }\end{array}$ \\
\hline 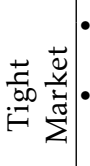 & $\begin{array}{l}\text { - Biomethane and SNG stimulated to } \\
\text { secure energy supply } \\
\text { - Renewable electricity is buffered as } \\
\mathrm{H}_{2} \text { or } \mathrm{CH}_{4}\end{array}$ & $\begin{array}{l}\text { - Large sources of shale gas are found } \\
\text { and exploited in the Netherlands } \\
\text { - Russian gas, LNG and shale gas have } \\
\text { to a large extent replaced g-gas }\end{array}$ \\
\hline 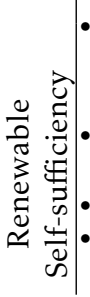 & $\begin{array}{l}\text { - Biomethane and SNG stimulated to } \\
\text { secure energy supply and reduce } \\
\text { GHG emissions } \\
\text { - It is accepted to use agricultural area } \\
\text { for energy crops } \\
\text { - Large-scale import of biomass } \\
\text { Large-scale renewable electricity, } \\
\text { which is buffered as } \mathrm{H}_{2} \text { or } \mathrm{CH}_{4}\end{array}$ & $\begin{array}{l}\text { - Due to strict GHG emission reduc- } \\
\text { tion policy it is not allowed to burn } \\
\text { natural gas at household level } \\
\text { - Due to environmental concerns } \\
\text { shale gas sources are not exploited } \\
\text { at full-scale }\end{array}$ \\
\hline
\end{tabular}

Table 2.6: Assumptions per scenario and type of gas

The perceived energy resource scarcity has a positive effect on the amount of shale gas in the energy mix, since shale gas will increase the security of energy supply. In contrast, the willingness and ability to reduce GHG emissions has a negative effect on the share of shale gas in the gas supply mix, since environmental concerns exist about the exploitation of shale gas.

The quantification of the ratio in the gas supply mix is based on estimations found in literature, our assumptions, and the current gas mix. This leads to a gas supply mix for each scenario, which is summarized in Table 2.7.

In the Business as Usual and the Carbon Constraints scenarios, natural gas and LNG are the primary gas sources. In the Business as Usual scenario, shale gas has gained a medium share in the gas supply mix and biomethane has a negligible role, whereas in the Carbon Constraints scenario, both biomethane and SNG have a minor but important share in the total gas supply mix. Natural gas and LNG have a major share in the Tight Market scenario, but shale gas has the largest 


\begin{tabular}{|c|c|c|c|c|c|c|c|}
\hline \multirow[t]{2}{*}{ Scenario } & \multirow{2}{*}{$\begin{array}{l}\text { Annual } \\
\text { gas de- } \\
\text { mand }\end{array}$} & \multicolumn{3}{|c|}{ Renewables } & \multicolumn{3}{|c|}{ Fossil } \\
\hline & & $\begin{array}{l}\text { Biome- } \\
\text { thane }\end{array}$ & $\mathrm{SNG}$ & $\begin{array}{l}\mathrm{H}_{2} / \mathrm{me}^{-} \\
\text {thane }\end{array}$ & Natural & LNG & Shale \\
\hline $\begin{array}{l}\text { Business as } \\
\text { Usual }\end{array}$ & $65 \cdot 5$ & 0.5 & - & - & 35 & 25 & 10 \\
\hline $\begin{array}{l}\text { Carbon Con- } \\
\text { straints }\end{array}$ & 25 & 2 & 1.5 & - & $11 \cdot 5$ & 10 & - \\
\hline Tight Market & 42 & 2 & 1.5 & 2 & 11.5 & 10 & 15 \\
\hline $\begin{array}{l}\text { Renewable Self- } \\
\text { sufficiency }\end{array}$ & 25 & 4 & 7.8 & 4.2 & 3 & 3 & 3 \\
\hline
\end{tabular}

Table 2.7: Sources of gas supply per scenario $\left[\mathrm{Gm}^{3}(\mathrm{n})\right.$ g-gas equivalents]

share in the gas supply mix. Renewable gases have gained a minor share in the gas supply mix in the Tight Market scenario. Renewable Self-sufficiency is the only scenario where the renewable gases have the major share in the total gas supply mix. However natural gas, LNG and shale gas together still play an important role and represent a third of the total gas supply mix. Furthermore, in the Carbon Constraints and the Renewable Self-sufficiency scenarios, the total annual gas demand is almost half of the gas demand in 2008 and the Business as Usual and Tight market scenarios.

\subsection{Conclusions}

The aim of this chapter was to develop, for the Netherlands, scenarios that help to determine the system functions of the gas distribution infrastructure in the energy system in 2050. For this purpose, four different future scenarios were derived. It was found that in all future scenarios the gas distribution role still plays a significant role, although its role can be more modest compared to today. For example, in the greener scenarios the low-pressure distribution grid is probably abolished and in general the total gas flow will decrease. However, despite a possible reduction in gas flow and abolishment of part of the grid, the gas distribution grid will have an increased number of system functions. In all scenarios (although in the Business as Usual scenario to a lesser extent), the gas distribution infrastructure will have to facilitate the injection of biomethane. Furthermore, in the scenarios with a perceived energy resource scarcity, the gas infrastructure will have to balance the fluctuating electricity supply from windmills and solar energy. And in each scenario, the gas distribution grid has to deal with gas types different than G-gas.

The four future scenarios that were derived differ from future scenarios found in the literature. Unlike in other studies $[35,37,41-43]$, the 80 to $90 \%$ reduction 
in GHG emissions is not taken as a boundary condition in the scenarios developed here. Furthermore, the developed scenarios have a much stronger focus on the gas distribution infrastructure. In addition, the scenarios developed here apply to the Dutch situation, which is different from the aggregate European, German, Danish and United Kingdom situations [37, 41-43]. Therefore, for the Dutch DSOs, the scenarios developed here are of more use than the ones found in literature. By providing scenarios tailored to the Dutch gas distribution infrastructure, we expect to have provided a tool that aids the Dutch DSOs in dealing with their investment dilemma. The developed scenarios can stimulate discussion within the DSOs about which direction the gas distribution may be heading.

As mentioned, the design of the gas distribution grid will be different for each future scenario. In addition, an increase in biomethane can be seen in each future scenario. The increase in biomethane and the different designs for the gas distribution grid underline the importance of the development of the DST, since the DST will support the DSOs in making decisions for the (future) design of the biomethane supply chain and gas distribution system.

The next two chapters describe the model and design procedure of the DST. Moreover, the developed future scenarios formed the basis for the analysis described in chapter 5 . 



\section{Part III}

\section{Prescriptive study}





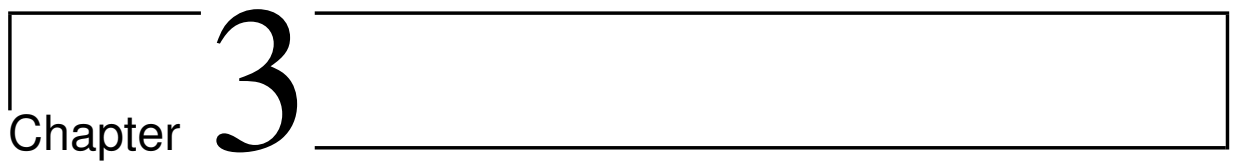

\section{Modeling the biomethane supply chain}

To support the design process for the biomethane supply chain, a model had to be developed that can be used to construct and analyze the design of the biomethane supply chain. This type of model is referred to as a design engineering model. This chapter describes the design engineering model that was developed for the biomethane supply chain. Together with the design procedure, described in chapter 4, the model will support the conceptual and embodiment design phase of the biomethane supply chain, and is used to automate the synthesis task of the design process.

To design a biomethane supply chain for a certain region with specific biomass locations and gas grid, the model had to be spatially explicit. Furthermore, the model had to include all relevant elements of the biomethane supply chain, allow the different biomethane supply chain configurations described in chapter 1 , and determine not only the economic performance of the design, but also the $\mathrm{CO}_{2}$ emission reduction and energy production.

The developed model comprises all process steps in the biomethane supply chain from biomass supply up to injection of biomethane in the gas grid and also includes gas storage. The model describes the design variables for each process step, their possible values, and the analysis required to obtain the performance indicators. Moreover, this chapter reviews literature in which also (part of) the biomethane supply chain has been modeled. The models in literature are compared with the model developed in this chapter.

Thus, the contribution of this chapter is the development of a design engineering model that can be used to generate and analyze candidate solutions for the design of the biomethane supply chain. As such, this chapter forms the first part of the prescriptive study. 
The organization of this chapter is as follows. First, section 3.1 describes the modeling approach for the biomethane supply chain. Then, section 3.2 gives a review of existing literature in which (part of) the biomethane supply chain has been modeled and compares it to our model. Section 3.3 lists the elements of the model and the topological relations between the different elements of the model. Next, section 3.4 introduces the exogenous parameters for the model. In section 3.5 , for each step of the biomethane supply chain a description is given, its design variables are defined, the possible values of the design variables are listed, and the analysis to obtain the performance indicators is given. Section 3.6 gives the overall performance indicators of the supply chain. Finally, section $3 \cdot 7$ draws conclusions on the developed model.

\subsection{Modeling approach}

This section describes the approach that was used to model the biomethane supply chain. Similar to Jauregui-Becker [54], we distinguish the following parts in the model:

Elements: The physical parts of the design, which perform certain (sub)functions of the design, are modeled as elements. For example, a digester installation is one of the elements in the model.

Topological relations: How the different elements of the model can be connected to each other is indicated by the topological relations. For example, a digester element can be connected to an upgrading plant element. But a digester element cannot be connected directly to the gas grid, since the biogas from the digester does not comply with gas quality specifications.

Scenario parameters: The subject under investigation is affected by its environment. Environmental influences in the model are modeled as scenario parameters. For example, in our model, the subsidy given for biomethane is a scenario parameter.

Embodiment variables: The variables that need to be instantiated (that is, are assigned a value) by the design method to obtain a candidate solution are the embodiment variables. For example, the size of the digester installation that is installed at a certain location is an embodiment variable.

Analysis: Analysis entails the equations used to derive the performance indicators of a candidate solution. For example, the equation that determines the energy usage of a digester installation.

Performance indicators: The quality of a candidate solution is indicated by its performance indicators. For example, $\mathrm{CO}_{2}$ emission reduction is one of the performance indicators in our model. 
In our model, the values for the embodiment variables are chosen from a discrete set of possible values. This resembles reality, where, for instance, a farmer that wants to buy a digester, can only choose from a limited number of available types. Furthermore, it allows a designer of the biomethane supply chain to add more digester types to the model. Compared to an embodiment whose values are derived from a continuous energy or cost function, an advantage of the discrete set is that each building block can have its own characteristics. For instance, the set of possible embodiment values of the digester element can consist of a set of digesters that perform well on energy usage which is complemented with another set that scores worse on energy usage but better on economic performance.

The embodiment and scenario parameters were derived from literature that list parameters of elements of the biomethane supply chain, such as capital cost, operational cost, and energy usage.

In my model, the most important performance indicators of the biomethane supply chain are:

- $\mathrm{NPV}[€]$

- Net energy production $[\mathrm{kWh} / \mathrm{a}]$

- Biomethane cost $\left[€ / \mathrm{m}^{3}(\mathrm{n})\right]$

- $\mathrm{CO}_{2}$ emission reduction $[\mathrm{t} / \mathrm{a}]$

- Cost per kilogram of avoided $\mathrm{CO}_{2}$ emission $[€ / \mathrm{kg}]$

These performance indicators are elucidated in section 3.6.

Before the here developed model is described in more detail, first a literature review is given on existing biomethane models.

\subsection{Literature review on existing models}

This section describes a literature review on existing models of (parts of) the biomethane supply chain. The review compares our model with existing ones and is used to see how our model extends the existing models. Aspects that were considered are: (1) which elements are included? (2) what are the performance indicators? (3) is the embodiment instantiated from a continuous or discrete set of values? (4) is it spatially explicit? (5) can the biomass of multiple biomass locations be supplied to a single digester, and can the biogas of multiple digesters be supplied to a single upgrading plant? The findings, which are summarized in Table 3.1, are discussed in the remainder of this section.

Madlener [55] developed a spatially explicit economic model, which incorporates biomass supply, digestion, and conversion of biogas to electricity. The 


\begin{tabular}{llllll}
\hline Source & Q1 & Q2 & Q3 & Q4 & Q5 \\
\hline Madlener [55] & No & $€$ & Yes & Yes & Yes \\
Walla [56] & No & $€$ & No & No & No \\
Börjesson [57] & No & $€$ & N/A & Yes & Yes \\
Bekkering [23] & Almost (no balancing) & $€, \mathrm{kWh}$ & $\mathrm{No}$ & $\mathrm{No}$ & $\mathrm{No}$ \\
Bekkering [24] & Almost (no compres- & $€$ & No & No & No \\
& sion and line-pack flex.) & & & & \\
Blokhina [58] & Almost (no balancing) & $€$ & $\mathrm{~N} / \mathrm{A}$ & Yes & Yes \\
Berglund [59] & No & $\mathrm{kWh}$ & No & No & $\mathrm{N} / A$ \\
Pöschl [22] & Almost (no balancing) & $\mathrm{kWh}$ & Yes & No & No \\
Höhn [15] & No & $\mathrm{km}$ & $\mathrm{No}$ & Yes & Yes \\
\hline Our model & Yes & $€, \mathrm{kWh}, \mathrm{CO}_{2}$ & Yes & Yes & Yes \\
\hline
\end{tabular}

Table 3.1: Comparison of our model with other models from literature that model (part of) the biomethane supply chain. With Q1: Is the whole biomethane supply chain included? Q2: What are the performance indicators? $Q_{3}$ : Is the embodiment modeled discrete? $Q_{4}$ : Is it spatially explicit? $Q_{5}$ : Can the biomass of multiple biomass locations be supplied to a single digester, and can the biogas of multiple digesters be supplied to a single upgrading plant?

model contains three different sizes of digester installations and CHP installations. Thus, the possible values for the embodiment variables are chosen from a discrete set.

Walla [56] describes an economic model that consists of biomass supply, biomass transport, digesters, and CHP installations to produce electricity. The model does not have specific biomass locations and makes use of a continuous function for capital and operational cost of the model elements.

Börjesson [57] developed a spatially-explicit economic model which comprises biomass supply, digestion, upgrading, and three options to use the biomethane: (1) as transport fuel, (2) as fuel for a heat-only boiler, or (3) as fuel for a CHP. Also the option to transport biogas over a certain distance (by pipeline and truck), and injection of biogas in the natural gas grid is considered.

The model presented by Bekkering [23] comprises biomass supply, biomass transport, a digester, an upgrading plant at the same location as the digester, and an injection station. Bekkering assumes that the biomass is available in concentric circles around the farm. Capital cost and operational cost are modeled as a continuous function of the element size. Besides costs, the model also determines the energy performance of the different biomethane supply chains by means of the ratio of the needed energy for the production and injection of one $\mathrm{m}^{3}(\mathrm{n})$ biomethane and the higher heating value of biomethane. This model was extended in [24], by adding to the model: a gas storage (by means of pressurized gas pipes), a digester that can vary its biogas production, and by taking gas 
demand into account.

Blokhina [58] describes an economic model that is spatially explicit. She considers several configurations for optimal biomass use, among which an option to transport biomass from several locations to a central digestion unit. Another option is to digest the biomass locally at each biomass location and transport the produced biogas through pipelines to a central upgrading plant. Hence, the model comprises biomass supply, biomass transport, digester, upgrading, pipelines, and injection elements. To evaluate the economic performance of each configuration, end-use by means of a CHP is assumed. It was not clear whether the embodiment of the elements in Blokhina's model can only be instantiated by a discrete set of values, or that it is derived from a continuous function.

Berglund [59] models the energy performance of part of the biomethane supply chain. She incorporates different kinds of biomass supply, biomass transport, digester installations, upgrading plants, and also digestate handling. The actual injection in the gas grid is not within the scope of the research.

Pöschl [22] modeled the energy performance of the biomethane supply chain, to assess the efficiency of various biogas production and utilization pathways. For the biomethane supply chain in the model, biomass supply, biomass transport, digestion, upgrading, and injection are considered. Pöschl assumes a different energy consumption for small scale digesters and large scale digesters. In addition, different biomass types also lead to a different energy consumption of the digester.

Höhn [15] developed a spatially explicit model that was used to determine the optimal locations and size of biogas plants (consisting of a digester installation and upgrading plant) for three different regions in Finland. This was found by minimizing the transport distances between biomass locations and potential biogas plant locations. The model includes biomass supply and biomass transport, where biomass from multiple locations could be used to supply one digester. Furthermore, embodiment variables are continuous functions.

\section{Research gap}

In conclusion, there already exist numerous models for the biomethane supply chain or parts of it. However, so far, no model exists that (1) comprises the whole biomethane supply chain as presented in the next section; (2) has energy production, $\mathrm{CO}_{2}$ emission reduction, and economics as performance indicators; (3) has a discrete set of embodiment variables; (4) is spatially explicit; and (5) allows for multiple biomass locations for one digester and multiple digesters for one upgrading plant. 


\subsection{Elements of the biomethane supply chain and their topological relations}

The aim of this section is to list the elements of the biomethane supply chain model and to give their topological relations.

Figure 3.1 summarizes the elements of the model and their topological relations. The elements are the physical parts of the biomethane supply chain. All the shown steps have been installed in practice in the Netherlands, with the exception of the gas storage, which has not yet been installed on gas distribution scale. The presented model extends the models discussed in the previous section.

As can be seen in Figure 3.1, there are two options for the available biomass:

1. The biomass can be digested locally at the same site as the biomass.

2. The biomass can be transported by truck to a central location, where biomass of multiple biomass locations is digested.

In the digester, biomass is converted to raw biogas, which consists of 50 to $75 \%$ $\mathrm{CH}_{4}$ [10]. This $\mathrm{CH}_{4}$ content is too low, to allow the biogas to be injected in the gas grid. Therefore, this gas needs to be upgraded to natural gas quality in an upgrading plant. There are two options to get the biogas from the digester to the upgrading plant:

1. The raw biogas can be upgraded locally at the same site as the digester.

2. The raw biogas can be upgraded at a central location, where the biogas of multiple digesters is upgraded. For this option, first some unwanted

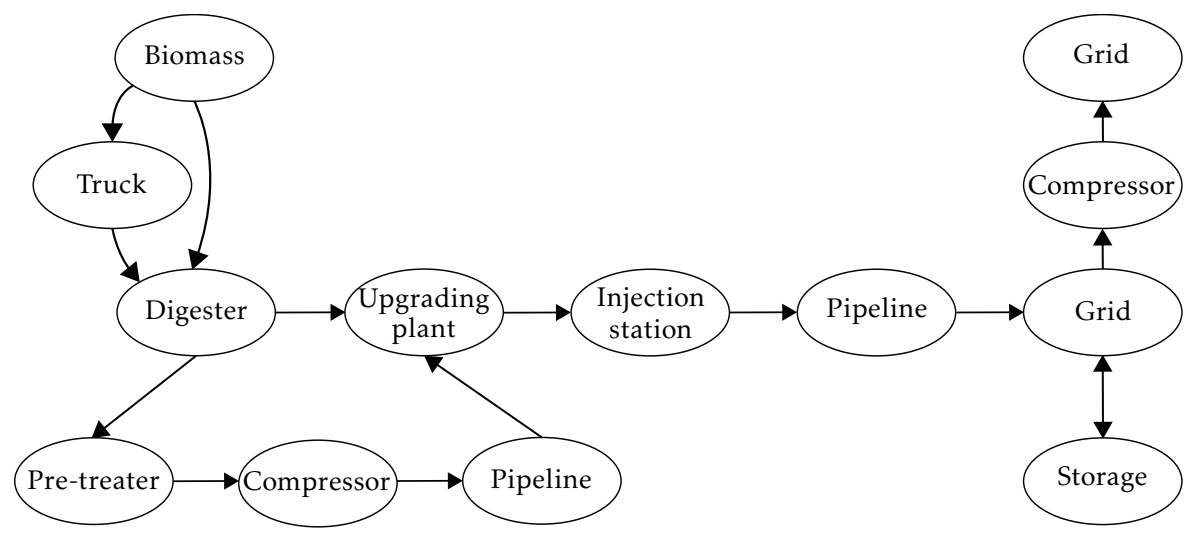

Figure 3.1: Elements of the biomethane supply chain and their topological relations 
components $\left(\mathrm{H}_{2} \mathrm{~S}\right.$ and $\left.\mathrm{H}_{2} \mathrm{O}\right)$ are removed in the pre-treatment step, to prevent corrosion in the next two steps. Next, the compressor compresses the biogas to the right pressure to transport the biogas through a pipeline to the upgrading plant.

In the upgrading plant, some unwanted components are removed, and part of the $\mathrm{CO}_{2}$ is removed such that the $\mathrm{CH}_{4}$ content is increased to $89 \%$ [6o].

After the upgrading step, quality and flow of the biomethane is measured in the injection station. This step also adjusts the biomethane to the right pressure. Finally, through a pipeline, the biomethane is injected in the gas distribution grid.

If the gas demand in the gas grid is always higher than the biomethane production, no further steps are required. If this is not the case, three options exist to deal with this balancing issue:

1. Add a compressor to compress the surplus biomethane to an upstream gas grid, such that the biomethane is also consumed by the gas consumers of this grid.

2. Connect a gas storage to the grid. The gas storage buffers surplus biomethane, and releases it once the gas demand exceeds the biomethane production.

3. A third option, which is not explicitly shown in 3.1 , is using the line-pack flexibility of the gas distribution grid. That is, the pipelines of the grid can be used as a small buffer for excess biomethane, by operating the pressure dynamically.

In short all the elements of the biomethane supply chain and their topological relations were described. These elements and relations are used to build a biomethane supply chain.

\subsection{Scenario parameters}

In this section some general parameters are defined that are part of the model but do not apply to any of the elements in specific, such as depreciation period, interest rate, biomethane subsidy, and electricity price.

The interest rate $I$, economic life of the project $L$, and operational hours $\theta$ were obtained from the report by Lensink [61]. This report was written on behalf of the ministry of economic affairs of the Netherlands and determines the subsidies on renewable energy for the year 2012. 
The interest rate and economic life of the project can be used to convert annual worth (AW) to present worth (PW) [62]. AW $x$ is converted to PW by [62]

$$
f_{\mathrm{PW}}(x)=\frac{(1+I)^{L}-1}{I(1+I)^{L}} \cdot x
$$

Furthermore, $f_{\mathrm{AW}}(x)$ is defined to convert the PW $x$ into the AW [62]

$$
f_{\mathrm{AW}}(x)=\frac{I(1+I)^{L}}{(1+I)^{L}-1} \cdot x
$$

The earnings of producing biomethane consist of the regular gas retail price and on top of this a subsidy for each $\mathrm{m}^{3}(\mathrm{n})$ of biomethane that is injected in the grid. The value for the average retail price in 2012 for natural gas was found in [63], and the biomethane subsidy was derived from [61].

Furthermore, the required $\mathrm{CH}_{4}$ content of biomethane is $89 \%$ [6o] and the $\mathrm{CO}_{2}$ emission of natural gas is $1.78 \mathrm{~kg} / \mathrm{m}^{3}(\mathrm{n})$ [64]. Finally, the higher heating value of natural gas that flows in the Dutch gas distribution system is 9.77 $\mathrm{kWh} / \mathrm{m}^{3}(\mathrm{n})\left[6_{5}\right]$.

For projects that consume more electricity than $50 \mathrm{MWh} / \mathrm{a}$, Lensink [61] uses an average value of $7 € \mathrm{ct} / \mathrm{kWh}$ for the fluctuating electricity price. Since the biomethane supply chains in our model consume significantly more than $50 \mathrm{MWh} / \mathrm{a}$, this is taken as value for the electricity price. Furthermore, to obtain $1 \mathrm{kWh}$ electricity from the grid by the end user, $0.566 \mathrm{~kg} \mathrm{CO}_{2}$ is released into the air [66].

In Table 3.2 the scenario parameters are listed.

\begin{tabular}{llll}
\hline Parameter & Symbol & Value & Unit \\
\hline Interest rate & $I$ & 7.8 & $\%$ \\
Economic life of project & $L$ & 12 & years \\
Operational hours & $\theta$ & 8000 & hours $/ \mathrm{a}$ \\
\hline Gas retail price & $p_{\mathrm{ng}}$ & $24 \cdot 7$ & $€ \mathrm{ct} / \mathrm{m}^{3}(\mathrm{n})$ \\
Biomethane subsidy & $p_{\mathrm{bm}}$ & $47 \cdot 3$ & $€ \mathrm{ct} / \mathrm{m}^{3}(\mathrm{n})$ \\
$\mathrm{CH}_{4}$ content biomethane & $c_{\mathrm{bm}}$ & 89 & $\%$ \\
$\mathrm{CO}_{2}$ emission natural gas & $g_{\mathrm{ng}}$ & 1.78 & $\mathrm{~kg} / \mathrm{m}^{3}(\mathrm{n})$ \\
Higher heating value natural gas & $H_{\mathrm{ng}}$ & $9 \cdot 77$ & $\mathrm{kWh} / \mathrm{m}^{3}(\mathrm{n})$ \\
\hline Electricity price & $p_{\mathrm{el}}$ & 7 & $€ \mathrm{ct} / \mathrm{kWh}$ \\
$\mathrm{CO}_{2}$ emission of electricity & $g_{\mathrm{el}}$ & 0.566 & $\mathrm{~kg} / \mathrm{kWh}$ \\
\hline
\end{tabular}

Table 3.2: Scenario parameters. Sources: $[60,61,64-67]$ 


\subsection{Elements of the biomethane supply chain}

This section describes each element of the biomethane supply chain model. For each element, the embodiment variables, their possible values, and the analysis to obtain the performance indicators are described.

\subsubsection{Biomass}

Biomass is used as feedstock for the digester to produce biogas. A wide range of biomass types can be used to supply the digester, such as animal manure and slurry, agricultural residues and by-products, and digestible organic wastes from food and agro industries [10].

The biogas yield varies strongly between different biomass types. With 0.025 $\mathrm{m}^{3}(\mathrm{n}) / \mathrm{kg}$ [68], cattle manure has one of the lowest biogas yields. While grease, with $0.8 \mathrm{~m}^{3}(\mathrm{n}) / \mathrm{kg}$, has one of the highest biogas yields [68]. If the feedstock of the digester is composed of two or more biomass types, the process is referred to as co-digestion [22].

\section{Values}

For the model, we used the default biomass for co-digestion installations, as defined by Lensink [61]. One tonne of this biomass is composed of 0.5 tonne manure, 0.13 tonne fodder, and 0.37 tonne other biomass (which consists of, among others, glycerin, energy mix, and crop residue). Of the total biomass input about $90 \%$ remains as digestate after digestion. The cost of biomass is 3.1 $€ \mathrm{ct} / \mathrm{kg}$, which includes the cost for removing the digestate [61]. The biogas yield is $0.16 \mathrm{~m}^{3}(\mathrm{n}) / \mathrm{kg}$ biomass, and the biogas contains $56 \% \mathrm{CH}_{4}[61]$.

Table 3.3 summarizes the biomass information.

\begin{tabular}{lll}
\hline Biogas yield & $\mathrm{CH}_{4}$ content biogas & Cost \\
$v_{\mathrm{b}}$ & $c_{\mathrm{bg}}$ & $s_{\mathrm{b}}$ \\
{$\left[\mathrm{m}^{3}(\mathrm{n}) / \mathrm{kg}\right]$} & {$[\%]$} & {$[€ \mathrm{ct} / \mathrm{kg}]$} \\
\hline 0.16 & $5^{6}$ & 3.1 \\
\hline
\end{tabular}

Table 3.3: Parameters for the biomass. Source: [61]

\section{Analysis}

The potential biogas yield $\left[\mathrm{m}^{3}(\mathrm{n}) / \mathrm{h}\right]$ of any biomass location $i$ is given by

$$
V_{\mathrm{b}}^{i}=b_{\mathrm{b}}^{i} \cdot v_{\mathrm{b}}
$$


where $b_{\mathrm{b}}^{i}$ is the biomass availability $[\mathrm{kg} / \mathrm{h}]$ at location $i$, and $v_{\mathrm{b}}$ is the biogas yield of the biomass $\left[\mathrm{m}^{3}(\mathrm{n}) / \mathrm{kg}\right]$.

The biomass cost $[€ / \mathrm{a}]$ for location $i$ is given by

$$
O_{\mathrm{b}}^{i}=b_{\mathrm{b}}^{i} \cdot \theta \cdot s_{\mathrm{b}}
$$

in which $b_{\mathrm{b}}^{i}$ is the biomass availability $[\mathrm{kg} / \mathrm{h}]$ at location $i, \theta$ is the number of operational hours [hours/a], and $s_{\mathrm{b}}$ is the cost of biomass $[€ / \mathrm{kg}]$.

\subsubsection{Biomass transport}

To get biomass from a biomass location to a central digester, biomass is transported over the road.

\section{Embodiment}

The biomass transport costs consist of loading and unloading costs, flat kilometer cost, and fuel cost. The biomass in the model will be transported by a truck. Its energy usage is $0.44 \mathrm{kWh} / \mathrm{t} \cdot \mathrm{km}$, which was taken from Berglund [59] and corresponds to the energy use of a 16 tonne truck transporting manure, digestate, or slaughterhouse waste.

For the flat kilometer cost and loading/unloading cost, we used the information provided by Hamelinck [69], which led to a flat kilometer cost of $5 € \mathrm{ct} / \mathrm{t} \cdot \mathrm{km}$ and loading/unloading cost of $66 € \mathrm{ct} / \mathrm{t}$ [69].

The price (excluding value added tax) of diesel, which is used by the truck as fuel, for the year 2012 was derived from [7o], and the $\mathrm{CO}_{2}$ emission of diesel was found in [64].

Furthermore, the route from the biomass location to the digester is approximated by a straight line in the model. In reality the route will always be longer than this, therefore, the straight line distance is multiplied by a factor to obtain a more realistic road distance. The distance correction factor $c_{\mathrm{bt}}=1.2$, equal to the value used by Ball [71].

Table 3.4 summarizes the biomass transport parameters.

\section{Analysis}

The energy usage $[\mathrm{kWh} / \mathrm{a}]$ of biomass transport route $i$, which transports biomass from biomass location $j$, is

$$
E_{\mathrm{bt}}^{i}=l_{\mathrm{bt}}^{i} \cdot c_{\mathrm{bt}} \cdot b_{\mathrm{b}}^{j} \cdot \theta \cdot e_{\mathrm{bt}}
$$

where $l_{\mathrm{bt}}^{i}$ is the length $[\mathrm{km}]$ of biomass transport route $i, c_{\mathrm{bt}}$ is the distance correction factor, $b_{\mathrm{b}}^{j}$ is the biomass availability $[\mathrm{t} / \mathrm{h}]$ of biomass location $j, \theta$ is the number of operational hours [hours/a], and $e_{\mathrm{bt}}$ is the energy use of biomass 


\begin{tabular}{llll}
\hline Parameter & Symbol & Value & Unit \\
\hline Flat kilometer cost & $q_{\mathrm{bt}}$ & 5 & $€_{\mathrm{ct}} / \mathrm{t} \cdot \mathrm{km}$ \\
Loading/unloading cost & $s_{\mathrm{bt}}$ & 66 & $€_{\mathrm{ct}} / \mathrm{t}$ \\
Cost of transport fuel & $p_{\mathrm{fl}}$ & 12.6 & $€_{\mathrm{ct}} / \mathrm{kWh}$ \\
Energy use biomass transport & $e_{\mathrm{bt}}$ & 0.44 & $\mathrm{kWh} / \mathrm{t} \cdot \mathrm{km}$ \\
$\mathrm{CO}_{2}$ emission of transport fuel & $g_{\mathrm{fl}}$ & 0.267 & $\mathrm{~kg} / \mathrm{kWh}$ \\
Distance correction factor & $c_{\mathrm{bt}}$ & 1.2 & \\
\hline
\end{tabular}

Table 3.4: Biomass transport parameters. Sources: [59, 64, 69-71]

transport $[\mathrm{kWh} / \mathrm{t} \cdot \mathrm{km}]$.

Using equation (3.5), the $\mathrm{CO}_{2}$ emission [kg/a] of biomass transport route $i$ can be found by

$$
G_{\mathrm{bt}}^{i}=E_{\mathrm{bt}}^{i} \cdot g_{\mathrm{fl}}
$$

where $g_{\mathrm{fl}}$ is the $\mathrm{CO}_{2}$ emission $[\mathrm{kg} / \mathrm{kWh}]$ of transport fuel.

Using again equation $(3 \cdot 5)$, the biomass transport cost $[€ / \mathrm{a}]$ of route $i$, transporting biomass from biomass location $j$, is given by

$$
O_{\mathrm{bt}}^{i}=E_{\mathrm{bt}}^{i} \cdot p_{\mathrm{fl}}+b_{\mathrm{b}}^{j} \cdot \theta \cdot s_{\mathrm{bt}}+b_{\mathrm{b}}^{j} \cdot \theta \cdot l_{\mathrm{bt}}^{i} \cdot q_{\mathrm{bt}}
$$

where $p_{\mathrm{fl}}$ is the fuel cost $[€ / \mathrm{kWh}], b_{\mathrm{b}}^{i}$ is the biomass availability $[\mathrm{kg} / \mathrm{h}]$ of biomass location $j, \theta$ is the number of operational hours [hours/a], $s_{\mathrm{bt}}$ is the loading and unloading cost $[€ / \mathrm{t}]$; and $q_{\mathrm{bt}}$ is the flat kilometer cost $[€ / \mathrm{t} \cdot \mathrm{km}]$.

\subsubsection{Digester installation}

In a digester installation, biomass is decomposed under anaerobic conditions by various types of microorganisms into digestate and biogas [10,68]. The biogas consists mainly of $\mathrm{CH}_{4}$ and $\mathrm{CO}_{2}$.

Figure 3.2 shows the general process flow of the digester installation. The pre-storage of biomass is required to buffer seasonal fluctuations in biomass availability. Manure storage requires less volume than solid biomass, since the manure only needs to be stored for a couple of days, while the solid biomass has to be buffered up to a year [10]. After storage, the biomass is mixed and fed quasi-continuously to the digester, in several batches during the day. Inside the digester the biomass is stirred several times a day, in order to mix the new biomass with the existing biomass in the digester.

In the digester, the biomass is decomposed under anaerobic conditions into biogas and digestate, which takes place in four microbiological process steps [10, 
68]. These steps run at the same time and place, in the digester tank. This process can take place at different temperatures. Three temperature ranges are distinguished: (1) psychrophilic, below $20^{\circ} \mathrm{C}$, (2) mesophilic, 30 to $42^{\circ} \mathrm{C}$, and (3) thermophilic, 43 to $55^{\circ} \mathrm{C}$. Modern digesters are usually operated at thermophilic temperatures. One of the most important conditions for stable operation and high biogas yield is a constant operating temperature. Temperature fluctuations lead to imbalance of the anaerobic digestion process and might ultimately lead to complete process failure.

Furthermore, the digestion process can be classified as dry or wet. This is dependent on the dry matter content of the biomass, up to $15 \%$ dry matter is considered wet. Above this value, the process is considered dry [10].

The eventual biogas output rate is to a large extent dependent on the biomass type and volume. However, the operating conditions of the digester are also of importance, such as: constant temperature, $\mathrm{pH}$-value, nutrient supply, stirring intensity, and presence and amount of inhibitors.

\section{Embodiment}

The relevant embodiment variables for the digester installations for the model are biogas output, biomass input, capital cost, operational cost (composed of maintenance cost and labor cost), and energy usage. We found information for these parameters in the reports by Urban [72] and Lensink [61]. We assumed a constant hourly biogas production of the digester installation during the year.

Since the input of the digester installations consists partly of seasonal products (for example maize), a storage is needed to store this biomass during the year. We assumed that only the co-substrate (so not the manure) requires storage, this is in line with the exemplary co-digester installations in the report by Urban [72]. In this report, the capital costs for biomass storage are $184 €$ per (tonne substrate/h). The capital costs for the storages have been added to the capital costs of the digester installations. Furthermore, we assumed that $5 \%$ of the biogas is used for heating the biomass [61].

In Table 3.5 an overview is given of all the used digester installations.

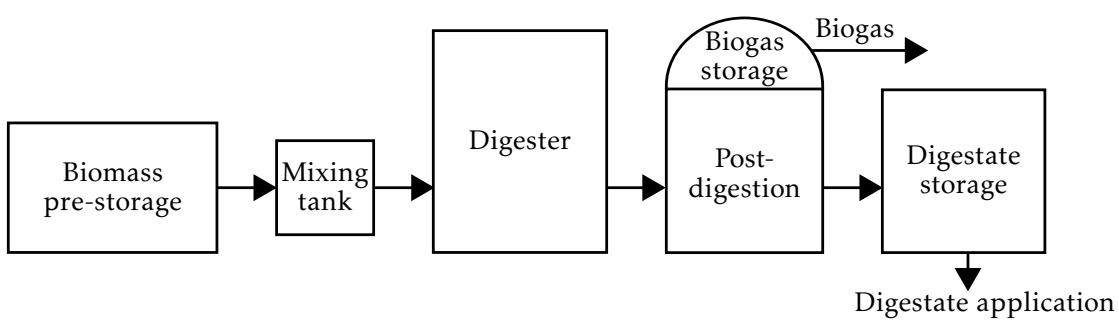

Figure 3.2: Main components and general process flow of biogas production [10]. 


\begin{tabular}{llllll}
\hline Output & $\begin{array}{l}\text { Max bio- } \\
\text { mass input }\end{array}$ & $\begin{array}{l}\text { Capital } \\
\text { cost } \\
a_{\mathrm{d}}^{i} \\
{[\mathrm{k} €]}\end{array}$ & $\begin{array}{l}\text { Operational } \\
\text { cost } \\
o_{\mathrm{d}}^{i} \\
{[\mathrm{k} € / \mathrm{a}]}\end{array}$ & $\begin{array}{l}\text { Energy } \\
\text { age } \\
e_{\mathrm{d}}^{i} \\
{\left[\mathrm{kWh} / \mathrm{m}^{3}(\mathrm{n})\right]}\end{array}$ & $\begin{array}{l}\text { biogas used } \\
\text { for heating } \\
{\left[\begin{array}{c}i \\
{\left[\mathrm{~m}^{3}(\mathrm{n}) / \mathrm{h}\right]}\end{array}\right.}\end{array}$ \\
\hline 100 & 625 & 594 & 51.3 & 0.11 & 5 \\
150 & 938 & 832 & 61.6 & 0.11 & 5 \\
230 & 1,438 & 1,187 & $77 \cdot 9$ & 0.11 & 5 \\
360 & 2,250 & 1,725 & 104.5 & 0.11 & 5 \\
550 & 3,438 & 2,459 & 143.3 & 0.11 & 5 \\
850 & 5,313 & 3,541 & 204.6 & 0.11 & 5 \\
1,300 & 8,125 & 5,059 & 296.5 & 0.11 & 5 \\
2,000 & 12,500 & 7,269 & 439.5 & 0.11 & 5 \\
\hline
\end{tabular}

Table 3.5: Digester installation information. Sources: [61, 72]

\section{Analysis}

By using $(3 \cdot 3)$, the biogas output $\left[\mathrm{m}^{3}(\mathrm{n}) / \mathrm{h}\right]$ of digester installation location $i$ can be found by

$$
V_{\mathrm{d}}^{i}=\sum_{k \in K} V_{\mathrm{b}}^{k} \cdot\left(1-\sum_{j \in J}\left(X_{j}^{i} c_{\mathrm{d}}^{j}\right)\right)
$$

in which $K$ is the set of biomass locations that provide biomass to digester installation location $i, V_{\mathrm{b}}^{k}$ is the potential biogas yield $\left[\mathrm{m}^{3}(\mathrm{n}) / \mathrm{h}\right]$ of biomass location $k, J$ is the set of available digester installations, $X_{j}^{i}$ is the decision variable whether to install digestion installation type $j$ at location $i$, and $c_{\mathrm{d}}^{j}$ is the ratio [\%] of the produced biogas that is used for heating the digester.

The energy usage $[\mathrm{kWh} / \mathrm{a}]$ of digester installation location $i$ is

$$
E_{\mathrm{d}}^{i}=\sum_{k \in K} V_{\mathrm{b}}^{k} \cdot \theta \cdot \sum_{j \in J}\left(X_{j}^{i} \cdot e_{\mathrm{d}}^{j}\right)
$$

where $K$ is the set of biomass locations that provide biomass to digester installation location $i, V_{\mathrm{b}}^{k}$ is the potential biogas yield $\left[\mathrm{m}^{3}(\mathrm{n}) / \mathrm{h}\right]$ of biomass location $k, J$ is the set of available digester installations, $\theta$ the number of operational hours [hours/a], and $e_{\mathrm{d}}^{j}$ the energy usage $\left[\mathrm{kWh} / \mathrm{m}^{3}(\mathrm{n})\right]$ of digester installation type $j$.

Using (3.9), the $\mathbf{C O}_{2}$ emission [ $\left.\mathrm{kg} / \mathrm{a}\right]$ of digester installation location $i$ is 


$$
G_{\mathrm{d}}^{i}=E_{\mathrm{d}}^{i} \cdot g_{\mathrm{el}}
$$

where $g_{\text {el }}$ is the $\mathrm{CO}_{2}$ emission $[\mathrm{kg} / \mathrm{kWh}]$ of electricity.

For the remaining elements to be discussed, the $\mathrm{CO}_{2}$ emission is found analogous to (3.10) - unless otherwise stated. That is, the element's $\mathrm{CO}_{2}$ emission is found by multiplying its yearly electricity consumption with the $\mathrm{CO}_{2}$ emission of electricity.

Using (3.9), the operational cost $[€ /$ a $]$ of digester installation location $i$ can be found by

$$
O_{\mathrm{d}}^{i}=\sum_{j \in J}\left(Y_{j}^{i} o_{\mathrm{d}}^{j}\right)+E_{\mathrm{d}}^{i} \cdot p_{\mathrm{el}}
$$

where $J$ is the set of available digester installations, $Y_{j}^{i}$ is the number of digester installations of type $j$ that are installed at location $i$, for only one $j$ is $Y_{j}^{i}>0$ (that is, only one type of digester is assigned to digester location $i$ ); $o_{\mathrm{d}}^{j}$ is the operational cost $[€ / \mathrm{a}]$ of digester installation $j$; and $p_{\mathrm{el}}$ is the electricity price $[€ / \mathrm{kWh}]$.

The capital cost $[€]$ of digester installation location $i$ is

$$
A_{\mathrm{d}}^{i}=\sum_{j \in J}\left(Y_{j}^{i} a_{\mathrm{d}}^{j}\right)
$$

where $J$ is the set of available digester installations, $Y_{j}^{i}$ is the number of digester installations of type $j$ that are installed at location $i$, for only one $j$ is $Y_{j}^{i}>0$ (that is, only one type of digester is assigned to digester location $i$ ); and $a_{\mathrm{d}}^{j}$ is the capital cost $[€]$ of digester installation $j$.

For the remaining elements to be discussed, the operational and capital costs of the element at location $i$ are determined analogously to (3.11) and (3.12) respectively - unless otherwise stated. That is, the operational cost of the element at location $i$ is determined by summation of the operational cost of all instances allocated to location $i$, plus the yearly electricity costs. The capital cost of the element at location $i$ is found by summing the capital cost of each instance allocated to location $i$.

\subsubsection{Pre-treatment of raw biogas}

The raw biogas leaving the digester installation is saturated with $\mathrm{H}_{2} \mathrm{O}$ and contains $\mathrm{H}_{2} \mathrm{~S} . \mathrm{H}_{2} \mathrm{~S}$ in combination with $\mathrm{H}_{2} \mathrm{O}$ is corrosive and can damage among 
others pipelines, compressors and valves [10]. Therefore, if the raw biogas is not directly upgraded in an upgrading plant it needs to be desulphurized and dried.

\section{Desulphurization}

Desulphurization is the process of removing $\mathrm{H}_{2} \mathrm{~S}$ from the raw biogas. Several options exist to remove the $\mathrm{H}_{2} \mathrm{~S}$. First, the $\mathrm{H}_{2} \mathrm{~S}$ can be biologically oxidized, which is based on injecting a small amount of air into the biogas (2-8\%) [10]. Secondly, the $\mathrm{H}_{2} \mathrm{~S}$ can be removed by adding a chemical substance to the feedstock mixture, which binds the sulphur chemically during the anaerobic digestion process [10]. A third option is to add ferrous material to the digester, which binds the sulphur [10]. The latter process is the process used in the model.

\section{Drying}

In the drying process, $\mathrm{H}_{2} \mathrm{O}$ is removed from the raw biogas. The two options that exist for drying, both use the fact that the $\mathrm{H}_{2} \mathrm{O}$ content in the biogas depends on the temperature. The first method cools down the biogas by transporting it in pipelines, which are preferably below the ground, for cooler temperature. The $\mathrm{H}_{2} \mathrm{O}$ in the biogas then condensates to the pipeline walls, and can be collected in condensation separators $[10,73]$. The second method, actively cools the biogas by electrically powered gas coolers at temperatures below $10^{\circ} \mathrm{C}[10,73]$. The second option is used in the model.

\section{Embodiment}

The possible values for the embodiment variables for the desulphurization step are obtained from Urban [72]. For this method, Iron is added to the digester, which will react with $\mathrm{H}_{2} \mathrm{~S}$. The main cost is material cost for iron(iii) oxidehydroxide, which is estimated at $500 € / \mathrm{t}\left[7_{2}\right]$. We assumed that the biogas contains $1000 \mathrm{ppmv} \mathrm{H}_{2} \mathrm{~S}$, which leads to a cost of $1.04 € \mathrm{ct} / \mathrm{m}^{3}(\mathrm{n})$. The capital cost for desulphurization is negligible compared to the operational cost [72] and is, therefore, not taken into account.

The information for drying the biogas is obtained from Häring [73]. The relevant embodiment variables for drying are capital cost and energy usage.

The information for the drying and desulphurization are listed in Table 3.6.

\section{Analysis}

Using (3.8), the energy usage $[\mathrm{kWh} / \mathrm{a}]$ of pre-treatment location $i$ is

$$
E_{\mathrm{pt}}^{i}=V_{\mathrm{d}}^{i} \cdot \theta \cdot \sum_{j \in J}\left(X_{j}^{i} e_{\mathrm{pt}}^{j}\right)
$$




\begin{tabular}{llll}
\hline Max biogas input & $\begin{array}{l}\text { Capital cost } \\
a_{\mathrm{pt}}^{i} \\
{[\mathrm{k} €]}\end{array}$ & $\begin{array}{l}\text { Operational cost } \\
o_{\mathrm{pt}}^{i} \\
{\left[€ \mathrm{ct} / \mathrm{m}^{3}(\mathrm{n})\right]}\end{array}$ & $\begin{array}{l}\text { Energy usage } \\
e_{\mathrm{pt}}^{i} \\
{\left[\mathrm{Wh} / \mathrm{m}^{3}(\mathrm{n})\right]}\end{array}$ \\
\hline 100 & 17 & 1.04 & 0.98 \\
150 & 17 & 1.04 & 0.98 \\
230 & 19 & 1.04 & 0.98 \\
360 & 21 & 1.04 & 0.98 \\
550 & 25 & 1.04 & 0.98 \\
850 & 30 & 1.04 & 0.98 \\
1,300 & 38 & 1.04 & 0.98 \\
2,000 & 51 & 1.04 & 0.98 \\
\hline
\end{tabular}

Table 3.6: Desulphurization and drying information. Sources: [72, 73]

where $J$ is the set of available pre-treatment installations, $V_{\mathrm{d}}^{i}$ is the raw biogas output rate $\left[\mathrm{m}^{3}(\mathrm{n}) / \mathrm{h}\right]$ of the digester located at location $i, \theta$ is the number of operational hours [hours/a], $X_{j}^{i}$ is the decision variable whether to allocate pretreatment type $j$ to location $i$, and $e_{\mathrm{pt}}^{j}$ is the energy usage of pre-treatment type $j$.

Furthermore, the $\mathbf{C O}_{2}$ emission $G_{\mathrm{pt}}^{i}$ of pre-treatment location $i$ is found analogously to (3.10).

Using (3.13) and (3.8), the operational cost $[€ / a]$ of pre-treatment location $i$ is

$$
O_{\mathrm{pt}}^{i}=\sum_{j \in J}\left(Y_{j}^{i} \cdot o_{\mathrm{pt}}^{j}\right) \cdot V_{\mathrm{d}}^{i} \cdot \theta+E_{\mathrm{pt}}^{i} \cdot p_{\mathrm{el}}
$$

where $J$ is the set of available pre-treatment installations, $Y_{j}^{i}$ is the number of pre-treatment installations of type $j$ that are installed at location $i$, for only one $j$ can $Y_{j}^{i}$ be larger than zero; $o_{\mathrm{pt}}^{j}$ is the operational cost $\left[€ / \mathrm{m}^{3}(\mathrm{n})\right]$ of pre-treatment installation $j ; V_{\mathrm{d}}^{i}$ is the raw biogas output $\left[\mathrm{m}^{3}(\mathrm{n}) / \mathrm{h}\right]$ of the digester located at location $i$; and $p_{\mathrm{el}}$ is the electricity price $[€ / \mathrm{kWh}]$.

The capital cost $A_{\mathrm{pt}}^{i}$ of pre-treatment location $i$ is found analogously to (3.12).

\subsubsection{Gas compressor}

In the biomethane supply chain a compressor is needed for two occasions: (1) to transport biogas via a pipeline from a digester installation to an upgrading plant, and (2) to compress biomethane or natural gas to an upstream gas grid when gas demand in the grid is too low to consume all biomethane. 


\section{Embodiment}

Information regarding capital cost and operational cost was obtained from Holstein [74] and Zondag [75]. These reports list both screw and reciprocating compressors. Compression in the model is limited to compression with an inlet pressure range of 1 to 5 bar(a) and outlet pressure range of 2 to 9 bar(a), which requires one compression stage [75]. Relevant embodiment variables for the compressors are capital cost, operational cost (which are maintenance costs), in- and outlet pressure, and energy usage. We assumed that the yearly operational cost is $5 \%$ of the capital cost.

In Table $3 \cdot 7$ an overview is given of all the compressors used.

\begin{tabular}{|c|c|c|c|c|}
\hline $\begin{array}{l}\text { Compressic } \\
\text { rate } \\
{\left[\mathrm{m}^{3}(\mathrm{n}) / \mathrm{h}\right]}\end{array}$ & $\begin{array}{l}\text { Inlet } \\
\text { pressure } \\
P_{1}^{i} \\
{[\text { bar }(\mathrm{a})]}\end{array}$ & $\begin{array}{l}\text { Outlet } \\
\text { pressure } \\
P_{2}^{i} \\
{[\operatorname{bar}(\mathrm{a})]}\end{array}$ & $\begin{array}{l}\text { Capital } \\
\text { cost } \\
a_{\mathrm{c}}^{j} \\
{[\mathrm{k} €]}\end{array}$ & $\begin{array}{l}\text { Operational } \\
\text { cost } \\
o_{\mathrm{c}}^{i} \\
{[\mathrm{k} \in / \mathrm{a}]}\end{array}$ \\
\hline 100 & $1-5$ & $2-9$ & 86 & $4 \cdot 3$ \\
\hline 150 & $1-5$ & $2-9$ & 90 & $4 \cdot 5$ \\
\hline 230 & $1-5$ & $2-9$ & 96 & 4.8 \\
\hline 360 & $1-5$ & $2-9$ & 106 & $5 \cdot 3$ \\
\hline $55^{\circ}$ & $1-5$ & $2-9$ & 120 & 6.0 \\
\hline 850 & $1-5$ & $2-9$ & 143 & $7 \cdot 2$ \\
\hline 1,300 & $1-5$ & $2-9$ & 178 & 8.9 \\
\hline 2,000 & $1-5$ & $2-9$ & 231 & 11.6 \\
\hline
\end{tabular}

Table 3.7: Gas compressor information. Sources: $[74,75]$

\section{Analysis}

To obtain the energy consumed by the gas compressor, first the isentropic compression energy needs to be calculated [76], which is given by

$$
E_{\text {iso }}=\frac{z R T}{M} \cdot \frac{N \gamma}{\gamma-1} \cdot\left(\left(\frac{P_{2}}{P_{1}}\right)^{\frac{\gamma-1}{N \gamma}}-1\right)
$$

Energy consumption $\left[\mathrm{kWh} / \mathrm{m}^{3}(\mathrm{n})\right]$ of the compressor can then be found by $[74$, 76]

$$
e_{\mathrm{c}}=\frac{E_{\mathrm{iso}} \cdot \rho}{3600 \cdot \eta_{\mathrm{iso}} \eta_{\mathrm{m}} \eta_{\mathrm{el}}},
$$


where:

$z:$ compressibility factor $=0.994$

$R:$ gas constant $=8.31 \mathrm{~J} / \mathrm{mol} \cdot \mathrm{K}$

$T:$ gas temperature $=288.15 \mathrm{~K}$

$M:$ molar mass $=28.35 \mathrm{~g} / \mathrm{mol}$ for biogas, and $20.51 \mathrm{~g} / \mathrm{mol}$ for natural gas

$N$ : number of compression steps $=1$

$\gamma:$ specific heat ratio $=1.3$

$P_{1}, P_{2}$ : inlet and outlet pressure respectively [bar(a)]

$\eta_{\text {iso }}:$ isentropic efficiency $=0.8$

$\eta_{\mathrm{m}}:$ mechanical efficiency $=0.85$

$\eta_{\mathrm{el}}$ : electrical efficiency $=0.9$

$\rho$ : gas density $=1.16 \mathrm{~kg} / \mathrm{m}^{3}(\mathrm{n})$ for biogas, and $0.84 \mathrm{~kg} / \mathrm{m}^{3}(\mathrm{n})$ for natural gas

When filling in all the known coefficients [74], the energy consumption for both biogas and natural gas is

$$
e_{\mathrm{c}}=0.192 \cdot\left(\left(\frac{P_{2}}{P_{1}}\right)^{0.231}-1\right)
$$

From $(3.17)$ the energy consumption $[\mathrm{kWh} / \mathrm{a}]$ of compressor location $i$ can be derived

$$
E_{\mathrm{c}}^{i}=v_{\mathrm{c}}^{i} \cdot 0.192 \cdot\left(\left(\frac{P_{2}^{i}}{P_{1}^{i}}\right)^{0.231}-1\right)
$$

where $v_{\mathrm{c}}^{i}$ is the yearly volume of compressed gas $\left[\mathrm{m}^{3}(\mathrm{n}) / \mathrm{a}\right]$ of the gas compressor, $P_{1}^{i}$ and $P_{2}^{i}$ are the inlet and outlet pressure [bar(a)] respectively of location $i$.

From (3.18), the yearly $\mathbf{C O}_{2}$ emission $G_{\mathrm{c}}^{i}$ of gas compressor location $i$ can be found analogously to equation (3.10).

Furthermore, using (3.18), the operational cost $O_{\mathrm{c}}^{i}$ of gas compressor location $i$ is determined analogously to equation (3.11). In addition, the capital cost $A_{\mathrm{c}}^{i}$ of gas compressor location $i$ is found analogously to equation (3.12).

\subsubsection{Gas pipeline}

Gas pipelines are used to transport gas over a certain distance. In the model gas pipelines are used in two cases: (1) to transport biogas from a digester installation to a central upgrading plant, and (2) to transport biomethane from an injection station to the gas grid. 


\section{Embodiment}

The pipeline costs in the model are broken down into material costs and laying costs. The cost for laying pipelines depends on the area. Laying pipelines in a densely populated area will be more expensive than in a rural area. In our model two areas are distinguished: (1) a rural area and (2) an urban area.

Laying a pipeline in a rural area and in an urban area costs 62 and $122 € / \mathrm{m}$ respectively, which was derived from information provided by Enexis (Kirsten van Gorkum, innovator at Enexis, personal communication, 2011) - see Table 3.8.

\begin{tabular}{lll}
\hline Rural area $[€ / \mathrm{m}]$ & $m_{\text {rur }}$ & 62 \\
Urban area $[€ / \mathrm{m}]$ & $m_{\text {urb }}$ & $\mathbf{1 1 2}$ \\
\hline
\end{tabular}

Table 3.8: Pipeline laying cost.

Information about gas pipeline material is obtained from Te Riele [77] and Enexis (Kirsten van Gorkum, innovator at Enexis, personal communication, 2011). Information about the inner diameter of the pipeline, maximum operating pressure, material cost, and roughness can be found in Table 3.9.

\begin{tabular}{|c|c|c|c|}
\hline $\begin{array}{l}\text { Diameter } \\
d_{\mathrm{pl}}^{i} \\
{[\mathrm{~mm}]}\end{array}$ & $\begin{array}{l}\text { Max pressure } \\
{[\operatorname{bar}(\mathrm{g})]}\end{array}$ & $\begin{array}{l}\text { Cost } \\
a_{\mathrm{pl}}^{i} \\
{[€ / \mathrm{m}]}\end{array}$ & $\begin{array}{l}\text { Roughness } \\
\epsilon \\
{[\mu \mathrm{m}]}\end{array}$ \\
\hline $5^{2}$ & 8 & 6 & 1 \\
\hline 61 & 8 & 8.5 & 1 \\
\hline 90 & 8 & 18 & 1 \\
\hline 131 & 8 & 38 & 1 \\
\hline 164 & 8 & 60 & 1 \\
\hline 205 & 8 & 93 & 1 \\
\hline 258 & 8 & 148 & 1 \\
\hline
\end{tabular}

Table 3.9: Gas pipeline information. Source: [77]

\section{Analysis}

When gas is transported over a distance through a gas pipe, the pressure at the beginning of the pipeline, $P_{1}[\operatorname{bar}(\mathrm{a})]$, will decrease over the length of the pipeline. Hence, the pressure at the end of the pipeline, $P_{2}[\operatorname{bar}(a)]$, will be lower than the initial pressure. The difference between these two pressures can be found by $\left[7^{6}\right]$ 


$$
P_{1}^{2}-P_{2}^{2}=\lambda \cdot \frac{l_{\mathrm{pl}}}{d_{\mathrm{pl}}} \cdot \rho_{\mathrm{n}} \cdot v^{2} \cdot \frac{T}{T_{\mathrm{n}}} \cdot P_{\mathrm{n}} \cdot z,
$$

where:

$\lambda$ : the Darcy friction factor

$l_{\mathrm{pl}}:$ the length of the gas pipeline $[\mathrm{m}]$

$d_{\mathrm{pl}}:$ the diameter of the pipeline $[\mathrm{m}]$

$\rho_{\mathrm{n}}$ : the gas density $\left[\mathrm{kg} / \mathrm{m}^{3}(\mathrm{n})\right]$ under normal conditions

$v:$ the fluid velocity $[\mathrm{m} / \mathrm{s}]$

$T:$ the temperature of the gas $[\mathrm{K}]$

$T_{\mathrm{n}}$ : the reference temperature under normal conditions $=273.15 \mathrm{~K}$

$P_{\mathrm{n}}:$ the reference pressure under normal conditions $=1.01325$ bar $(\mathrm{a})$

$z:$ the compressibility factor $=0.9977$

Fluid velocity $v[\mathrm{~m} / \mathrm{s}]$ is defined by

$$
v=\frac{Q}{\frac{1}{4} \pi \cdot d_{\mathrm{pl}}^{2}}
$$

where $Q$ is the gas flow in the pipeline $\left[\mathrm{m}^{3} / \mathrm{s}\right]$, and $d_{\mathrm{pl}}$ is the inner diameter $[\mathrm{m}]$ of the pipeline.

Furthermore, by means of the Colebrook equation, the value for the Darcy friction factor $\lambda$ can be defined by $[76$, p124]

$$
\frac{1}{\sqrt{\lambda}}=-2 \log \left(\frac{2.51}{\operatorname{Re} \cdot \sqrt{\lambda}}+\frac{\epsilon}{3.71 \cdot d_{\mathrm{pl}}}\right)
$$

where Re is the Reynolds number, and $\epsilon$ is the roughness [m].

The Reynolds number is defined as $[76, \mathrm{p} 121]$

$$
\operatorname{Re}=\frac{v \cdot d_{\mathrm{pl}}}{\mu}
$$

where $v$ is the flow velocity $[\mathrm{m} / \mathrm{s}]$ of the gas, $d_{\mathrm{pl}}$ is the inner diameter $[\mathrm{m}]$ of the pipeline, and $\mu$ the kinematic viscosity $\left[\mathrm{m}^{2} / \mathrm{s}\right]$. For biogas the kinematic viscosity is $\mu=1.08 \mathrm{e}-5$ and for biomethane, $\mu=1.37 \mathrm{e}-5$. Knowing the pressure drop in a pipeline, allows the tool to find an appropriate pipeline for a given gas flow and pipeline length - see Chapter 4 .

The capital cost $[€]$ of pipeline segment $i$ is

$$
A_{\mathrm{pl}}^{i}=l_{\mathrm{pl}}^{i}\left(\sum_{j \in J}\left(X_{j}^{i} a_{\mathrm{pl}}^{j}\right)+\sum_{k \in K}\left(Z_{k}^{i} \cdot m_{k}\right)\right)
$$


where $l_{\mathrm{pl}}^{i}$ is the length [m] of pipeline segment $i$; $J$ is the set of available pipelines; $X_{j}^{i}$ is the decision variable whether to install pipeline $j$ at segment $i$; $a_{\mathrm{pl}}^{j}$ is the material cost $[€ / \mathrm{m}]$ of pipeline $j ; K$ is the set of area types; $Z_{k}^{i}$ is the variable that indicates whether segment $i$ is of area type $k$; and $m_{k}$ is the laying cost $[€ / \mathrm{m}]$ for area type $k$.

\subsubsection{Upgrading plant}

The upgrading plant removes part of the $\mathrm{CO}_{2}$ from the (raw) biogas. As such the $\mathrm{CH}_{4}$ content will be increased up to $89 \%$. In addition $\mathrm{H}_{2} \mathrm{~S}$ is also removed from the (raw) biogas. Some of the upgrading plants available in the market today are [78]: pressure swing adsorption, amine scrubbing, water scrubbing, physical scrubbing with organic solvents, and membrane separation. A less proven technology is cryogenic technology.

All technologies except the water scrubber require pre-treatment of the raw biogas to remove $\mathrm{H}_{2} \mathrm{~S}$, which will otherwise damage the adsorber bed, the amines and the membranes.

We take water scrubbing as technique for the upgrading plants in our model, since this is the most widely used and most matured technology. Furthermore, the water scrubber is the upgrading method that is least sensitive to impurities. This technique is now described in more detail. Figure 3.3 shows a schematic illustration of a water scrubber.

As can be seen in Figure 3.3, the raw biogas is compressed and injected into the bottom of the absorption column and water is injected to the top of the column. The water leaving the absorption column has been equilibrated with the

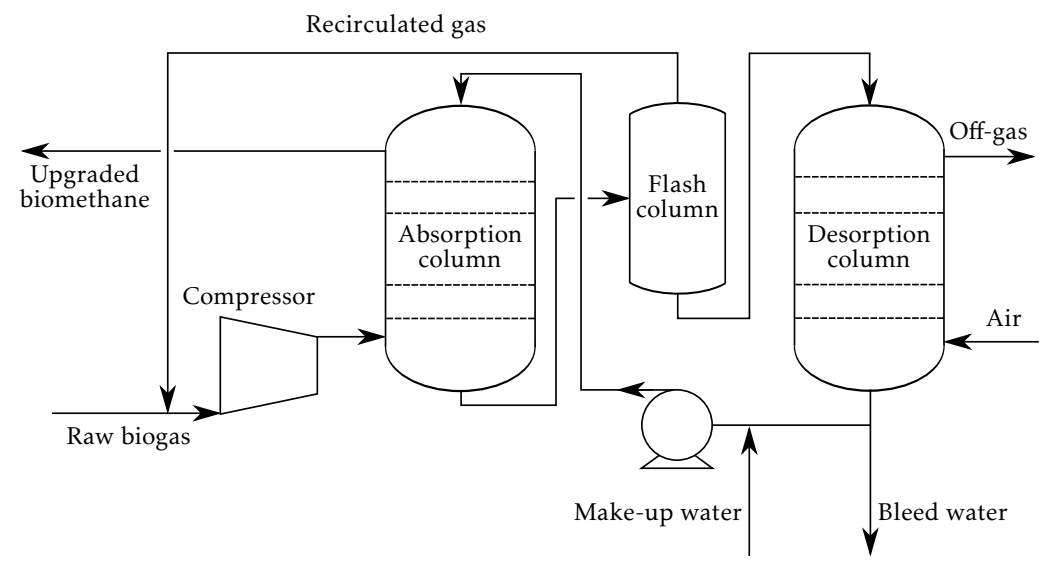

Figure 3.3: Schematic illustration of a water scrubber [78]. 
highest partial pressure of $\mathrm{CO}_{2}$ and the lowest partial pressure of $\mathrm{CH}_{4}$. This results in water that contains as much $\mathrm{CO}_{2}$ as possible and as little $\mathrm{CH}_{4}$ as possible. The height of the column determines the purity of the biogas, while the width of the bed column determines the capacity. In the flash column the pressure is decreased to around 2.5-3.5 bar(a), to release the $\mathrm{CH}_{4}$ absorbed in the water. Some of the $\mathrm{CO}_{2}$ as well as the main part of the $\mathrm{CH}_{4}$ is released from the water and circulated back to the compressor. The gas stream that is recirculated back to the gas compressor is about 20 to $30 \%$ of the incoming raw gas flow. The water transported to the desorption column will contain the main part of the $\mathrm{CO}_{2}$ but less than $1 \%$ of the $\mathrm{CH}_{4}$ in the raw biogas. The water enters the top of the desorption column, while air is entering at the bottom. The water leaving the desorption column is virtually free from $\mathrm{CO}_{2}$ and is pumped back into the top of the absorption column. $\mathrm{H}_{2} \mathrm{~S}$ is absorbed by the water during the absorption and released during the desorption process. Oxygen and nitrogen in the raw biogas will not be separated in the water scrubber [78].

Water scrubbing is considered a mature technology and large changes in investment cost are not expected.

\section{Embodiment}

The information for the water scrubbers is obtained from Bauer [78], Urban [72], and TU Wien [79]. The embodiment variables for the upgrading plant are capital cost, operational cost (consisting of maintance cost, labor cost, water cost, and thermal treatment of the offgas), energy usage, and $\mathrm{CH}_{4}$ loss. An overview of the upgrading plants used for the model is given in Table 3.10.

\begin{tabular}{|c|c|c|c|c|}
\hline $\begin{array}{l}\text { Biogas } \\
\text { input } \\
{\left[\mathrm{m}^{3}(\mathrm{n}) / \mathrm{h}\right]}\end{array}$ & $\begin{array}{l}\text { Capital cost } \\
a_{\mathrm{u}}^{i} \\
{[\mathrm{k} €]}\end{array}$ & $\begin{array}{l}\text { Operational } \\
\text { cost } \\
o_{\mathrm{u}}^{i} \\
{[\mathrm{k} € / \mathrm{a}]}\end{array}$ & $\begin{array}{l}\text { Energy us- } \\
\text { age } \\
e_{\mathrm{u}}^{i} \\
{\left[\mathrm{kWh} / \mathrm{m}^{3}(\mathrm{n})\right]}\end{array}$ & $\begin{array}{l}\mathrm{CH}_{4} \text { loss } \\
c_{\mathrm{u}}^{i} \\
{[\%]}\end{array}$ \\
\hline 100 & 640 & 34 & 0.24 & 1.5 \\
\hline $15^{\circ}$ & 773 & 35 & 0.24 & 1.5 \\
\hline 230 & 944 & 36 & 0.24 & 1.5 \\
\hline 360 & 1164 & 38 & 0.24 & 1.5 \\
\hline $55^{\circ}$ & 1419 & 41 & 0.24 & 1.5 \\
\hline 850 & 1739 & 46 & 0.24 & 1.5 \\
\hline 1,300 & 2121 & 53 & 0.24 & 1.5 \\
\hline 2,000 & 2595 & 65 & 0.24 & 1.5 \\
\hline
\end{tabular}

Table 3.10: Upgrading plant information. Sources: $[72,78,79]$ 


\section{Analysis}

Using (3.8), the biomethane output $\left[\mathrm{m}^{3}(\mathrm{n}) / \mathrm{h}\right]$ of upgrading plant location $i$ is

$$
V_{\mathrm{u}}^{i}=\sum_{k \in K} V_{\mathrm{d}}^{k} \cdot \frac{c_{\mathrm{bg}}}{c_{\mathrm{bm}}} \cdot\left(1-\sum_{j \in J}\left(X_{j}^{i} c_{\mathrm{u}}^{j}\right)\right)
$$

in which $K$ is the set of digester installations that supply biogas to upgrading plant location $i, V_{\mathrm{d}}^{k}$ is the biogas output $\left[\mathrm{m}^{3}(\mathrm{n}) / \mathrm{h}\right]$ of digester location $k, c_{\mathrm{bg}}$ is the $\mathrm{CH}_{4}$ content [\%] of biogas, $c_{\mathrm{bm}}$ is the required $\mathrm{CH}_{4}$ content [\%] of biomethane, $J$ is the set of available upgrading plants, $X_{j}^{i}$ is the decision variable whether upgrading plant type $j$ should be installed at location $i$, and $c_{\mathrm{u}}^{j}$ is the $\mathrm{CH}_{4}$ loss [\%] of upgrading plant type $j$.

Using (3.8), the energy usage $[\mathrm{kWh} / \mathrm{a}]$ of upgrading plant location $i$ is

$$
E_{\mathrm{u}}^{i}=\sum_{k \in K} V_{\mathrm{d}}^{k} \cdot \theta \cdot \sum_{j \in J}\left(X_{j}^{i} \cdot e_{\mathrm{u}}^{j}\right)
$$

where $K$ is the set of digester installations that supply biogas to upgrading plant location $i, V_{\mathrm{d}}^{k}$ is the biogas output $\left[\mathrm{m}^{3}(\mathrm{n}) / \mathrm{h}\right]$ of location $k, \theta$ is the number of operational hours [hours/a], $J$ is the set of available upgrading plants, $X_{j}^{i}$ is the decision variable whether upgrading plant type $j$ should be installed at location $i$, and $e_{\mathrm{u}}^{j}$ is the energy usage $\left[\mathrm{kWh} / \mathrm{m}^{3}(\mathrm{n})\right]$ of upgrading plant type $j$.

Using (3.25), the yearly $\mathbf{C O}_{2}$ emission $G_{\mathrm{u}}^{i}$ of upgrading plant location $i$ is found analogously with (3.10).

Using (3.25), the operational cost $O_{\mathrm{u}}^{i}$ of upgrading plant location $i$ is determined analogously to (3.11). Furthermore, the capital cost $A_{\mathrm{u}}^{i}$ of upgrading plant location $i$ is determined analogously to equation (3.12).

\subsubsection{Injection station}

Once the biogas has been upgraded to biomethane, it is supplied to the injection station. The injection station takes care of injecting the biomethane into the gas grid. It has a number of functions: (1) it measures gas quality (among others Wobbe index, $\mathrm{H}_{2} \mathrm{~S}$ content, and $\mathrm{H}_{2} \mathrm{O}$ content), (2) it measures gas flow, (3) if the biomethane quality complies with the regulations it injects the biomethane at the right pressure into the gas grid, and (4) it adds odorant to the biomethane that is injected into the gas grid. 


\section{Embodiment}

The injection station in the model consists of a valve to regulate the pressure, gas quality measurement, odorization, a switch box, and a grid connection (excluding the costs for the pipeline from the injection station to the grid). Information for the injection station is obtained from de Veth [20], and Stedin (Wim van Erp, Personal communication, March 15, 2013), and Lensink [61].

We assume that the outlet pressure of the gas upgrading plant is $8 \mathrm{bar}(\mathrm{g})$, therefore, the inlet pressure of the injection station is $8 \mathrm{bar}(\mathrm{g})$. This means that for gas grids that are operated at 8 bar $(\mathrm{g})$ or lower no energy is used.

Table 3.11 shows the relevant information for the injection station.

\begin{tabular}{llll}
\hline Max output rate & Outlet pressure & $\begin{array}{l}\text { Capital cost } \\
a_{\mathrm{is}}^{i}\end{array}$ & $\begin{array}{l}\text { Operational cost } \\
o_{\mathrm{is}}^{i}\end{array}$ \\
{$\left[\mathrm{~m}^{3}(\mathrm{n}) / \mathrm{h}\right]$} & {$[\operatorname{bar}(\mathrm{g})]$} & {$[\mathrm{k} €]$} & {$[\mathrm{k} € / \mathrm{a}]$} \\
\hline $2, \mathrm{OOO}$ & $\leq 8$ & 135 & 6.0 \\
\hline
\end{tabular}

Table 3.11: Injection station information. Sources: [20, 61]

\section{Analysis}

The operational cost $[€ / a]$ of injection station location $i$ is

$$
O_{\mathrm{is}}^{i}=\sum_{j \in J}\left(Y_{j}^{i} \cdot o_{\mathrm{is}}^{j}\right)
$$

where $J$ is the set of available injection stations, $Y_{j}^{i}$ is the number of injection stations of type $j$ that are installed at location $i$, for only one $j$ can $Y_{j}^{i}$ be larger than zero; and $o_{\text {is }}^{j}$ is the operational cost $[€ / \mathrm{a}]$ of injection station $j$.

The capital cost $A_{\mathrm{is}}^{i}$ of injection station location $i$ is determined analogously to equation (3.12).

\subsubsection{Gas storage}

When at certain periods in the year, more biomethane is injected in the gas grid than is consumed, a gas storage can be used to buffer the surplus biomethane. The stored biomethane will be released again when gas demand is higher than the biomethane injection rate. Although gas storage is common practice at the high-pressure national grid, no gas storages are connected to the gas distribution grid at the moment in the Netherlands. 


\section{Embodiment}

Information about gas storages was obtained from Bärnthaler [8o] - see Table 3.12. Of the listed gas storage technologies, we will only use storage by pressurized pipe, which is operated at a maximum pressure of 100 bar(a). The gas storage mentioned in Bärnthaler [8o] is designed for natural gas. We assume that the stored biomethane is dry, and that the $\mathrm{CO}_{2}$ that is present in the biomethane does not have any undesirable effects on the gas storage material. As such, the gas storage is also suitable for biomethane.

The model uses the same storage volumes as those that are listed in Bärnthaler [8o]. Furthermore, the operational cost of the gas storages are $2 \%$ of the capital cost [8o]. The energy consumption ranges from $0.3 \mathrm{kWh} / \mathrm{m}^{3}(\mathrm{n})$ to 0.4 $\mathrm{kWh} / \mathrm{m}^{3}(\mathrm{n})$. We take $0.4 \mathrm{kWh} / \mathrm{m}^{3}(\mathrm{n})$ as the energy consumption required for the storage connected to the grid operated at 3 bar $(\mathrm{g})$ or lower, since here the most compression energy is required. Furthermore, $0.35 \mathrm{kWh} / \mathrm{m}^{3}(\mathrm{n})$ and 0.3 $\mathrm{kWh} / \mathrm{m}^{3}(\mathrm{n})$ are taken as energy consumption for the gas storages connected to the 4 and 8 bar(g) grid respectively.

\begin{tabular}{lllll}
\hline $\begin{array}{l}\text { Storage vol- } \\
\text { ume }\end{array}$ & $\begin{array}{l}\text { In- and out- } \\
\text { let pressure }\end{array}$ & $\begin{array}{l}\text { Capital cost } \\
a_{\text {st }}^{i}\end{array}$ & $\begin{array}{l}\text { Operational } \\
\text { cost } \\
o_{\text {st }}^{i} \\
{[\mathrm{k} € / \mathrm{a}]}\end{array}$ & $\begin{array}{l}\text { Charge energy } \\
\text { consumption } \\
e_{\text {st }}^{i}\end{array}$ \\
\hline 60 & $\left.\leq \mathrm{kWh} / \mathrm{km}^{3}(\mathrm{n})\right]$ & 40 & 0.4 \\
125 & $\leq 3$ & 2.00 & 46 & 0.4 \\
250 & $\leq 3$ & 3.80 & 76 & 0.4 \\
60 & 4 & 6.80 & 136 & 0.35 \\
125 & 4 & 2.00 & 40 & 0.35 \\
250 & 4 & 3.80 & 76 & 0.35 \\
60 & 8 & 6.80 & 136 & 0.3 \\
125 & 8 & 2.00 & 40 & 0.3 \\
250 & 8 & 3.80 & 76 & 0.3 \\
\hline
\end{tabular}

Table 3.12: Gas storage information. Sources: [8o]

\section{Analysis}

Energy consumption $[\mathrm{kWh} / \mathrm{a}]$ of gas storage location $i$ is

$$
E_{\mathrm{st}}^{i}=v_{\mathrm{st}}^{i} \cdot \sum_{j \in J}\left(X_{j}^{i} \cdot e_{\mathrm{st}}^{j}\right)
$$

where $J$ is the set of available gas storages, $v_{\text {st }}^{i}$ the volume of gas stored in a year $\left[\mathrm{m}^{3}(\mathrm{n}) / \mathrm{a}\right]$ at gas storage location $i, X_{j}^{i}$ the decision variable whether to in- 
stall gas storage type $j$ at location $i$, and $e_{\mathrm{st}}^{j}$ the energy consumption $\left[\mathrm{kWh} / \mathrm{m}^{3}(\mathrm{n})\right]$ of gas storage type $j$.

Using (3.27), the yearly $\mathbf{C O}_{2}$ emission $G_{\mathrm{st}}^{i}$ of gas storage location $i$ is found analogously to $(3.10)$.

Using (3.27), the operational cost $O_{\text {st }}^{i}$ of gas storage location $i$ is determined analogously to equation (3.11). In addition, the capital cost $A_{\mathrm{st}}^{i}$ of gas storage location $i$ is found analogously to $(3.12)$.

\subsubsection{Line-pack flexibility}

Another way to provide storage capacity is by using the line pack flexibility of the gas grid. Keyaerts [81] defines line-pack flexibility as "the amount of gas that can be managed flexibly by controlling the operation pressure levels between a minimal and a maximal level". By lowering the operating pressure in a grid, a certain pressure range becomes available that can be used to store gas for a certain period. This could be especially useful for situations where the supply of biomethane exceeds the demand of gas in the grid during a certain period of the day. By using the line-pack flexibility of the gas grid the excess of biomethane can be stored for several hours until the demand for gas exceeds the supply of biomethane again.

\section{Analysis}

The available line pack flexibility $\left[\mathrm{m}^{3}(\mathrm{n})\right]$ is $[76]$

$$
V_{\mathrm{lp}}=V_{\mathrm{pl}}\left(\frac{P_{\mathrm{avg}}}{K_{\mathrm{avg}}}-\frac{P_{\mathrm{avg}^{\prime}}}{K_{\mathrm{avg} g^{\prime}}}\right) \cdot \frac{1}{P_{\mathrm{n}}} \cdot \frac{T_{\mathrm{n}}}{T}
$$

where $V_{\mathrm{pl}}$ is the volume $\left[\mathrm{m}^{3}\right]$ of the pipeline, $P_{\mathrm{avg}}$ is the higher average pressure [bar(a)], $P_{\text {avg' }}$ is the lower average pressure [bar(a)], $K_{\text {avg }}$ and $K_{\text {avg' }}$ are dimensionless compressibility numbers corresponding to $P_{\text {avg }}$ and $P_{\text {avg' }}$.

Line-pack flexibility will only be used in summer, which means that the gas flow in the gas grid will be really low. Therefore, we assumed that average higher pressure $P_{\text {avg }}$ and average lower pressure $P_{\text {avg' }}$ are equal to the maximum pressure $P_{\max }$ and minimum operating pressure $P_{\min }$ respectively. The minimum operating pressure is found by: $P_{\min }=0.4 \cdot P_{\max }$. Furthermore, the value for $K_{\text {avg }}$ and $K_{\text {avg' }}$ is defined as

$$
K_{\mathrm{avg}}=1-\frac{P_{\mathrm{avg}}}{450 \mathrm{bar}(\mathrm{a})}
$$

Since the highest possible value for $P_{\text {avg }}=9$ bar(a), for which $K_{\mathrm{avg}}=0.98$, its value is approximated by $K_{\mathrm{avg}} \approx 1$. Furthermore, by assuming $T=T_{\mathrm{n}}$, the line- 
pack flexibility of pipeline section $i$ with pipeline type $j$ can be approximated by

$$
V_{\mathrm{lp}}=\frac{l_{\mathrm{pl}}^{i} \pi\left(d_{\mathrm{pl}}^{j}\right)^{2}}{4} \cdot \frac{0.6 \cdot P_{\mathrm{max}}^{i}}{1 \operatorname{bar}(\mathrm{a})}
$$

where $l_{\mathrm{pl}}^{i}$ is the length $[\mathrm{m}]$ of pipeline section $i, d_{\mathrm{pl}}^{j}$ is the inner diameter $[\mathrm{m}]$ of pipeline type $j$, and $P_{\max }^{i}$ is the maximum operating pressure [bar(a)] of pipeline section $i$.

Applying line-pack flexibility to a gas grid would not require much more work than adjusting the outlet pressure of the GRSs twice a year. Therefore, we assumed that the costs involved with line-pack flexibility are negligible. Furthermore, we assumed that applying line-pack flexibility to a gas grid consumes no energy.

\subsubsection{Gas distribution grid}

This section describes two components of the gas grid which were not shown in Figure 3.1, but are part of the gas distribution grid, namely the GRS and gas consumer.

\section{GRS/district station}

The GRS receives gas from the RTL grid, which is operated at 40 bar $(\mathrm{g})$. The GRS reduces the pressure from $40 \mathrm{bar}(\mathrm{g})$ to usually $8 \mathrm{bar}(\mathrm{g})$ and then feeds it to the gas distribution grid.

The district station has a similar function as the GRS, with the exception that it receives gas from the high-pressure distribution grid and feeds the gas to the low-pressure distribution grid.

\section{Gas consumer}

Gas consumers, consume gas. In our model, to each gas consumer an hourly gas demand is assigned. This value is important because it tells whether all biomethane that is injected into the grid will be consumed.

\subsection{Performance indicators}

Now that all elements have been defined, the general performance indicators for the biomethane supply chain can be defined, which are (1) NPV, (2) net energy production, (3) biomethane cost, (4) $\mathrm{CO}_{2}$ emission reduction, and (5) $\mathrm{CO}_{2}$ cost. 
To obtain the general performance indicators, first the expenses are defined. The total capital cost $[€]$ for the biomethane supply chain can be found by

$$
A_{\mathrm{tot}}=\sum_{k \in K} A_{\mathrm{d}}^{k}+\sum_{l \in L} A_{\mathrm{c}}^{l}+\sum_{m \in M} A_{\mathrm{pt}}^{m}+\sum_{n \in N} A_{\mathrm{pl}}^{n}+\sum_{o \in O} A_{\mathrm{u}}^{o}+\sum_{p \in P} A_{\mathrm{is}}^{p}+\sum_{q \in \mathrm{Q}} A_{\mathrm{st}}^{q}
$$

and total operational cost $[€ / a]$ for the biomethane supply chain can be found by

$$
O_{\mathrm{tot}}=\sum_{i \in I} O_{\mathrm{b}}^{i}+\sum_{j \in J} O_{\mathrm{bt}}^{j}+\sum_{k \in K} O_{\mathrm{d}}^{k}+\sum_{l \in L} O_{\mathrm{c}}^{l}+\sum_{m \in M} O_{\mathrm{pt}}^{m}+\sum_{n \in N} O_{\mathrm{u}}^{n}+\sum_{p \in P} O_{\mathrm{is}}^{p}+\sum_{q \in \mathrm{Q}} O_{\mathrm{st}}^{q}
$$

where the definitions of $I, J, K, L, M, N, O, P$, and $Q$ can be found in Table 3.13 .

Income is generated by the compensation for each $\mathrm{m}^{3}(\mathrm{n})$ of biomethane that is injected in the gas grid. Total yearly biomethane production is

$$
V_{\mathrm{tot}}=\sum_{o \in O} V_{\mathrm{u}}^{o} \cdot \theta
$$

where $V_{\mathrm{u}}^{o}$ is the biomethane output $\left[\mathrm{m}^{3}(\mathrm{n}) / \mathrm{h}\right]$ of upgrading plant location $o$, $\theta$ is the number of operational hours [hours/a], and for $O$ see Table 3.13.

The compensation consists of the gas retail price $p_{\mathrm{ng}}$ and the biomethane subsidy $p_{\text {bm }}$. Using $(3.33)$, the income $O_{\text {inc }}[€ / \mathrm{a}]$ is defined by

$$
O_{\text {inc }}=V_{\text {tot }} \cdot\left(p_{\text {ng }}+p_{\mathrm{bm}}\right)
$$

\begin{tabular}{l}
$I:$ the set of all biomass locations \\
$J:$ the set of all biomass transport routes \\
$K:$ the set of all digester installation locations \\
$L:$ the set of all gas compressor locations \\
$M:$ the set of all pre-treatment locations \\
$N:$ the set of all pipeline segments \\
$O:$ the set of all upgrading plants \\
$P:$ the set of all injection stations \\
$Q:$ the set of all gas storage locations \\
\hline
\end{tabular}

Table 3.13: List with the sets that are used in section 3.6 


\section{NPV}

The NPV consists of all annual costs, present costs, and income generated by the biomethane supply chain, which are converted to present costs.

Using (3.1), the NPV of the biomethane supply chain is

$$
\mathrm{NPV}=-A_{\text {tot }}+f_{\mathrm{PW}}\left(O_{\text {inc }}-O_{\text {tot }}\right)
$$

\section{Net energy production}

The total net energy production is found by subtracting the yearly energy consumption from the total produced energy. Total energy consumption [kWh/a], both fuel and electricity, is

$$
E_{\mathrm{tot}}=\sum_{j \in J} E_{\mathrm{bt}}^{j}+\sum_{k \in K} E_{\mathrm{d}}^{k}+\sum_{l \in L} E_{\mathrm{c}}^{l}+\sum_{m \in M} E_{\mathrm{pt}}^{m}+\sum_{o \in O} E_{\mathrm{u}}^{o}+\sum_{q \in Q} E_{\mathrm{st}}^{q}
$$

where the definitions of $J, K, L, M, O$, and $Q$ can be found in Table 3.13. Using (3.33), the total net energy production $[\mathrm{kWh} / \mathrm{a}]$ is

$$
E_{\text {net }}=V_{\text {tot }} \cdot H_{\text {ng }}-E_{\text {tot }}
$$

where $H_{\mathrm{ng}}$ is the higher heating value $\left[\mathrm{kWh} / \mathrm{m}^{3}(\mathrm{n})\right]$ of natural gas.

\section{Biomethane cost}

The biomethane cost $\left[€ / \mathrm{m}^{3}(\mathrm{n})\right]$ is determined by adding all costs made during the lifetime of the biomethane project and then dividing it by the amount of biomethane produced in this period. Using (3.2), the biomethane cost can be found by

$$
\text { Biomethane cost }=\frac{f_{\mathrm{AW}}\left(A_{\mathrm{tot}}\right)+O_{\mathrm{tot}}}{V_{\mathrm{tot}}}
$$

\section{$\mathrm{CO}_{2}$ emission reduction}

The biomethane supply chain abates $\mathrm{CO}_{2}$ emissions by replacing natural gas with biomethane. However, $\mathrm{CO}_{2}$ is also released into the air due the electricity and fuel consumption of the biomethane supply chain. Hence, the total $\mathrm{CO}_{2}$ emission reduction can be found by subtracting the produced $\mathrm{CO}_{2}$ emission from the abated $\mathrm{CO}_{2}$ emissions.

Total $\mathrm{CO}_{2}$ emission [t/a] due to electricity consumption and fuel use is

$$
G_{\mathrm{tot}}=\sum_{j \in J} G_{\mathrm{bt}}^{j}+\sum_{k \in K} G_{\mathrm{d}}^{k}+\sum_{l \in L} G_{\mathrm{c}}^{l}+\sum_{m \in M} G_{\mathrm{pt}}^{m}+\sum_{o \in O} G_{\mathrm{u}}^{o}+\sum_{q \in Q} G_{\mathrm{st}}^{q}
$$

where the definitions of $J, K, L, M, O$, and $Q$ can be found in Table 3.13. 
Hence, yearly $\mathrm{CO}_{2}$ emission reduction $[\mathrm{t} / \mathrm{a}]$ is

$$
G_{\text {red }}=V_{\text {tot }} \cdot g_{\text {ng }} / 1000-G_{\text {tot }}
$$

where $g_{\mathrm{ng}}$ is the $\mathrm{CO}_{2}$ emission of natural gas $\left[\mathrm{kg} / \mathrm{m}^{3}(\mathrm{n})\right]$.

$\mathrm{CO}_{2}$ cost

The cost of $\mathrm{CO}_{2}[€ / \mathrm{kg}]$ is found by dividing the total yearly cost by the total yearly $\mathrm{CO}_{2}$ emission reduction. Thus

$$
\mathrm{CO}_{2} \operatorname{cost}=\frac{f_{\mathrm{AW}}\left(A_{\mathrm{tot}}\right)+O_{\mathrm{tot}}}{G_{\mathrm{red}}}
$$

\subsection{Conclusions}

This chapter described the design engineering model for the biomethane supply chain. The design engineering model can be used to create and subsequently analyze the biomethane supply chain. The different elements of the biomethane supply chain model were defined. Where applicable, the equations to derive energy use, $\mathrm{CO}_{2}$ emission, operational cost, and capital cost of the elements were defined. From these equations the NPV, biomethane cost, net energy production, $\mathrm{CO}_{2}$ emission reduction, and $\mathrm{CO}_{2}$ cost for the whole supply chain were derived.

The literature review in this chapter showed that the developed model extends the existing models by means of five aspects:

1. The elements that are taken into account by the model. For example, besides our model, only Bekkering [24] considered a potential imbalance between biomethane supply and gas demand. In addition, this model extends the model in [24] by considering line-pack flexibility and compressing gas to an upstream gas grid as options to solve the imbalance.

2. The model analyzes $\mathrm{CO}_{2}$ emission reduction, net energy production, and economic performance, whereas the reviewed literature analyzed no more than two of these performance indicators.

3. The model is spatially explicit. This in contrast to the models developed by, for example, Bekkering [23], Berglund [59], and Walla [56].

4. Where most models assume continuous cost functions (for example Börjesson [57] and Walla [56]), the model described in this chapter uses a discrete set of possible values, each with specific operational and capital cost. 
5. Multiple biomass locations can supply biomass to one digester installation, and multiple digester installations can supply biogas to one upgrading plant. This is in contrast with the single supply chain's developed by, for instance, Pöschl [22] and Walla [56].

Now that the individual elements and their topological relations have been defined, the next chapter prescribes how to construct solutions from a given start configuration, using the developed design engineering model. It also discusses how the performance indicators are used to choose one specific solution among all the generated solutions. 



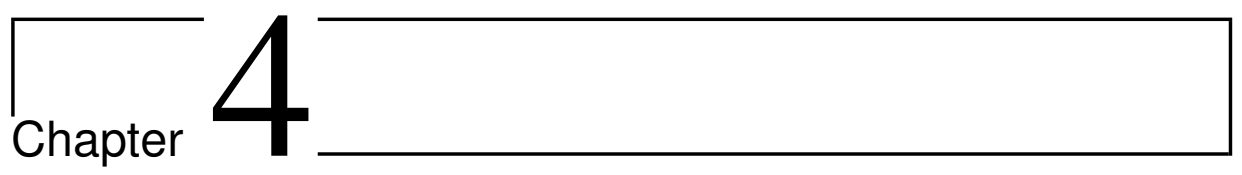

\section{Design procedure}

A design procedure has been developed that is used to generate candidate solutions for the design of the biomethane supply chain. To create candidate solutions, the design procedure uses the design engineering model described in the previous chapter. The design procedure determines, among others, whether the biomass of a biomass location is digested on-site or at a central digester location, whether the biogas from a digester is upgraded on-site or at a central upgrading plant, and into which gas grid the biomethane is injected. Furthermore, the developed design procedure does not result in a single "best" solution, but in a number of candidate solutions. The choice for the preferred solution is left to the user. Besides the design procedure, also the design rules are described in this chapter. Where the design procedure describes the overall strategy to come to a solution, the design rules describe how certain elements are assigned a value. The design rules determine, among others, which specific pipeline, digester installation, or upgrading plant is used at a certain location and also the operating pressure of a biogas pipeline.

Thus, the contribution of this chapter is the development of a design procedure that generates various solutions for the design of the biomethane supply chain and lets the user choose the preferred solution. As such, this chapter forms the second part of the prescriptive study.

This chapter is outlined as follows. First, section 4.1 gives a broad description of the design process, starting with a configuration that consists of biomass locations and one or more gas grids, and ending with a preferred design for the biomethane supply chain. Next in section 4.2, design procedures available in literature that also generate a design for an energy system are reviewed. Section $4 \cdot 3$ describes the design procedure that is used to synthesize a large number of candidate designs for the biomethane supply chain. Next, section 4.4 describes the 
design rules. Section 4.5 points out how the large number of generated solutions are evaluated by the user. In section 4.6 , it is described how the developed design engineering model, design procedure and design rules were verified. Finally, section 4.7 draws conclusions on the developed design procedure.

\subsection{Design process}

The design problem that has to be solved can be characterized as a routine design problem [82]. In routine design, knowledge is available about (1) the elements that can be used to generate candidate solutions, (2) the topological relations of the elements, and (3) relations and constraints that relate parameters and elements to functional requirements.

Obtaining a candidate solution for the design problem is done by a synthesis process [82]. Synthesis processes in routine design are performed by two types of tasks:

1. Generating networks of elements.

2. Assigning values to unknown parameters.

The network of elements refers to the number of elements that have to be instantiated and the topological relations that have to be determined. For the biomethane supply chain this refers to, for example, which and how many digesters supply their biogas to which upgrading plant, and into which gas grid the biomethane of an upgrading plant is injected. Assigning values to unknown parameters, means that the embodiments of the elements have to be instantiated. For the biomethane supply chain, this is, for example, assigning values to the location variables of a digester, or determining the pressure of a biogas pipeline.

The general flow of the design process is shown in Figure 4.1. In our model, the requirements and constraints for the design of the biomethane supply chain are captured in a so-called start configuration. A start configuration consists of (1) one or more gas grids, (2) gas consumers (with a certain gas demand) connected to these gas grids, and (3) one or more biomass locations with a certain biomass type and availability. In Figure 1.3(a), an example of a start configuration was given. In addition, the elements of the biomethane supply chain need to be defined. For example, one or more digester installations have to be defined, which can be used to convert the biomass to biogas. These elements were defined in the previous chapter.

By means of the start configuration and the elements defined in chapter 3 , the DST generates the candidate solutions. First the design procedure generates networks of elements (see section $4 \cdot 3$ ) and then the design rules assign values to the unknown parameters (see section 4.4). 


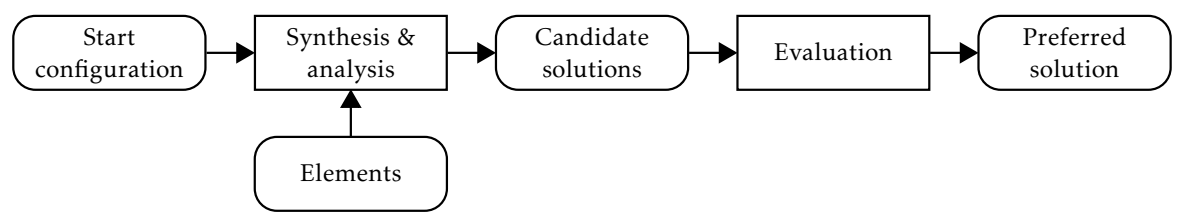

Figure 4.1: General flow of the design process

For each generated solution, the performance indicators are determined. The choice for the preferred solution from the candidate solutions is left to the user, who will base this choice on his/her preferences regarding the performance indicators (see section 4.5). The chosen solution is the embodiment design for the biomethane supply chain. This design indicates, for example, where digesters are located, the route of biogas pipelines, the location of the upgrading plant, and into which gas grid the biomethane is injected. In Figure 1.3(b), an example solution was shown.

To generate the candidate solutions for the design of the biomethane supply chain, a design procedure was developed. The requirements for the design procedure are: (1) the design procedure has to consider all the design choices, mentioned in section 1.3, (2) since the number of elements and topological relations can vary during the generation process, the design procedure should be able to handle a varying number of constraints and equations in time, (3) it has to allow for multiple objectives, (4) it should not choose a single best solution, but let the user choose the solution from a set of candidate solutions, and (5) it should explore a large part of the solution space and not steer the solution towards a certain performance.

Before the design procedure and design rules are described, first a literature review of design procedures for generating energy systems is presented.

\subsection{Literature review on existing design procedures}

This section describes a review on research papers where design procedures are described that generate solutions for the design of an energy system. First the scope of the research was limited to biomethane and biogas infrastructures. Since this survey resulted in a very limited number of design procedures, the scope of the research was expanded to other energy infrastructures: $\mathrm{H}_{2}$ infrastructures, supply chains for refueling stations, heat infrastructures, and electricity infrastructures. So a broad literature survey was performed. The requirements for our design procedure were compared with the characteristics of the design procedures found in literature. This section, therefore, describes how our design procedure compares with the design procedures found in literature. Aspects that were considered, in this respect, are: (1) Can the design procedure 
handle a varying number of constraints and equations in time? (2) Is the design procedure single or multi-objective? (3) Is the choice for the preferred solution made by the design procedure or by the user? (4) Does the design procedure steer the solution towards a certain optimum or does it provide a more broad exploration of the solution space?

Table 4.1 summarizes the most interesting research papers found. The research papers that are included in this table are the ones that comply with at least one of the requirements mentioned in the previous section. The research papers listed in Table 4.1 and a few additional research papers are described in more detail in the remainder of this section.

\section{Biogas/biomethane infrastructures}

When looking at design procedures for a biogas or biomethane infrastructure, not any research paper was found that satisfies more than one of the mentioned constraints. Höhn [15], for example, uses optimization to create one optimal biogas infrastructure. Höhn did this by allocating biomass sources to biogas plants through minimization of the transport distance.

Madlener [55] describes a multi-agent simulation model, where each actor uses an investment decision flowchart to create a biogas infrastructure. The decisions that are made are the location and size of biogas plants. This algorithm is able to handle a varying number of equations and constraints in time. However, the algorithms in both papers were not multi-objective, nor was the eventual

\begin{tabular}{lllll}
\hline Source & Q1 & Q2 & Q3 & Q4 \\
\hline Madlener [55] & Yes & Single & Algorithm & Optimization \\
Hugo [83] & No & Multi & User & Optimization \\
Kuby [84] & Yes & Single & Algorithm & Optimization \\
Bapna [85] & No & Multi & User & Optimization \\
Zamboni [86] & No & Multi & User & Optimization \\
Molyneaux [87] & Yes & Multi & User & Optimization \\
Voll [88] & Yes & Single & User & Optimization \\
Celli [89] & No & Multi & User & Optimization \\
Carrano [90] & Yes & Multi & User & Optimization \\
\hline Our design procedure & Yes & Multi & User & Exploration \\
\hline
\end{tabular}

Table 4.1: Comparison of our design procedure with other design procedures from literature that create energy systems. With Q1: Can the design procedure handle a varying number of constraints and equations in time? Q2: Is the algorithm single or multiobjective? $Q_{3}$ : Is the choice for the preferred solution made by the algorithm or by the user? $Q_{4}$ : Does it steer the solution towards a certain optimum or does it provide a more broad exploration of the solution space? 
choice for the configuration made by the user, nor do they explore the solution space.

\section{$\mathrm{H}_{2}$ infrastructures}

In literature in which $\mathrm{H}_{2}$ infrastructures are created, there is a significant number of papers in which a single optimal solution is found through optimization (in particular, the use of Mixed Integer Linear Programming (MILP) models is very common). For instance, Ball [71] describes a MILP model that finds the cost-optimal way for constructing and implementing a $\mathrm{H}_{2}$ production and distribution infrastructure. In addition, Johnson [91] also developed a MILP model that minimizes cost for a $\mathrm{H}_{2}$ network (consisting of pipelines and production locations) given a certain spatially distributed $\mathrm{H}_{2}$ demand.

The design procedure described by Hugo [83] also steers its solutions towards an optimum, but the design procedure is multi-objective, and the procedure allows the user to make the final decision with respect to the preferred solution. The objectives are NPV and GHG emission reduction. The algorithm looks for the ideal supply of $\mathrm{H}_{2}$ refueling stations with $\mathrm{H}_{2}$. Decision variables are: which primary energy feedstock to use, which conversion technology to use, which intermediate energy carrier to use, which distribution technology to use, and which refueling technology to use.

\section{Refueling station infrastructure}

Kuby [84] describes a design procedure that generates $\mathrm{H}_{2}$ refueling infrastructures. The procedure locates $\mathrm{H}_{2}$ refueling stations through a greedy substitution algorithm that adds one facility at a time at the site that increases the objective function the most, and allows the model to swap unused candidate sites for chosen candidate sites at each iteration. As such, the design procedure allows for a varying number of constraints and equations in time. Performance indicator is (1) the number of trips that can potentially be refueled or (2) the vehiclemiles traveled that can potentially be refueled. Kuby's algorithm is, however, single-objective, does not let the user choose the eventual solution, and steers the solution towards an optimum.

The design procedure described by Bapna [85] does not allow for a varying number of constraints and equations in time, but it is multi-objective and lets the user choose the preferred solution. Bapna's algorithm locates gas stations on certain roads and locates the gas stations such that a maximum number of people can access them. The multi-objective problem is dealt with by using an adjustable weight for the two performance indicators, minimizing cost and maximizing coverage of people that can access the gas stations. For each value of the weight a different single-objective optimization problem has to be solved.

The design procedure described by Zamboni [86] generates solutions by means of an MILP algorithm, but it is multi-objective and lets the user choose the even- 
tual solution. The design procedure, which supports the design process for the supply chain for biofuel systems, minimizes financial cost and GHG emissions. Decision variables are the location and scale of biomass production for each site, supply mode for the produced biomass, location and scale of the biofuel production facility, and distribution mode for the biofuel to the blending plants.

\section{Heat infrastructures}

Molyneaux [87] describes a design procedure that assigns several energy conversion technologies to a distribution heating network in order to satisfy consumer demands. The objectives are $\mathrm{CO}_{2}$ emission and financial cost. Solutions are generated by using an evolutionary algorithm. That is to say, new solutions are created by making a combination of previous generated solutions. The user chooses the preferred solution from the generated solutions and the design procedure allows the number of constraints and equations to vary in time.

Voll [88] describes an algorithm that generates solutions for heating and cooling networks. Optimization variable is the NPV and the decision variables are which type of energy conversion technology (boilers, CHP engines, absorption chillers, and turbo-chillers) should be installed, and between which nodes should a pipe be laid. The algorithm generates a set of near-optimal solutions for the heating and cooling network. Instead of taking the optimal solution as a blue print for the eventual solution, Voll looked at similarities between the ten best solutions and recommends to base the solution on these similarities.

\section{Electricity infrastructures}

Celli [89] describes a multi-objective algorithm that sites and sizes electrical generators into the existing electricity distribution grid. Solutions are found through optimization, and the performance indicators that have to be minimized are: cost of energy losses, the cost of service interruptions, the cost of network upgrading, and the cost of energy purchased.

Carrano [9o] describes a multi-objective genetic algorithm that generates a set of multi-objective solutions, which are potential designs of an electrical distribution network. Decision variables are the possible connections between the nodes (paths where the conductors can be placed). The objectives are financial costs and system failure costs. The user chooses the preferred solution from the non-dominated solutions. The design procedure allows for a varying number of constraints and equations in time, but does steer the solution towards an optimum.

\section{Research gap}

When looking at literature on biogas and biomethane infrastructures, none of the research papers described a design procedure that allows for multiple ob- 
jects, lets the user choose the preferred solution from a set of candidate solutions, and accomodates a broad exploration of the solution space.

When looking at other energy infrastructures, we found that in most literature one or more solutions were created by means of optimization. However, there were also some algorithms (for example, Molyneaux [87] and Carrano [9o]) that allowed the number of constraints and equations to vary in time, are multiobjective, and allow the users to choose the eventual solution. As such, the design procedures by Carrano [9o] and Molyneaux [87] have potential to be used as design procedure to generate solutions for the biomethane supply chain. Their procedures were, however, not used for our design procedure, as they steered the solutions towards a certain optimum. However, in future research, when it is desired to navigate the solutions more directly towards a certain optimum, it might be interesting to implement their procedures.

In conclusion, there was no design procedure in literature available that complied with the requirements mentioned in the previous section. Therefore, in the next section, a design procedure is described that generates candidate solutions for the biomethane supply chain that complies with the aforementioned requirements.

\subsection{Design procedure}

The overall design procedure is graphically displayed in Figure 4.2. The shown steps are described in more detail in subsections 4.3.1 - 4.3.4

To obtain the solutions, the design procedure randomly assigns values to the decision variables. The reason that we do not use a design procedure that is more defined, is that a more defined method would search a smaller part of the solution space. This is unwanted since the performance indicators and the embodiment elements are not known beforehand (for example, the performance indicators are chosen by the user, and component types for an element can be added or removed). Therefore, it is not sure beforehand to which part of the solution space the solutions should be confined. Hence, we defined a design procedure that randomly assigns the decision variables, in order not to steer the solution generation process and confine the solution space too much. When in a later stage more certainty exists about the desired performance indicators and embodiment elements, and more knowledge has been developed about fruitful solution generation directions, the design procedure can be more defined to steer the solution generation process towards a certain part of the solution space.

As Figure 4.2 shows, the algorithm is run for a pre-defined number of times $N$. Each run starts for each biomass location with the decision whether to utilize the biomass or not. Then, for all the locations that use their biomass, the procedure decides whether the biomass will be digested locally or at a central digester installation. If the biomass will be digested at a central location, a biomass route is 
constructed. Next, for each digester installation it is decided whether its biogas will be upgraded locally or centrally, and the upgrading plant is assigned. In addition, for the central upgrading plant the biogas hub is created. ${ }^{1}$ For each upgrading plant, the design procedure then decides into which gas grid its biomethane will be injected. The injection station and pipeline are placed in this step. Finally, the biomethane injection rate in a gas grid may be higher than the gas demand of its gas consumers during certain periods in a year. This is an undesirable situation, and therefore, the design procedure checks whether this imbalance occurs and, if needed, solves this problem. Subsections $4 \cdot 3 \cdot 1-4 \cdot 3 \cdot 4$ describe the steps of the design procedure in more detail.

\footnotetext{
${ }^{1}$ Due to environmental and safety regulations, not all biomass locations will be suitable as location for a digester installation or upgrading plant. This depends on the size of the installation, the type of biomass used, and whether the installation is at an appropriate distance from other objects to ensure that there will be no smell nuisance, noise nuisance or safety risk. In our model, it is assumed that the digester installation and upgrading plant can be located at any biomass location. When the DST is developed further in a subsequent research, the model could incorporate certain restrictions regarding the location of digester installations and upgrading plants.
}

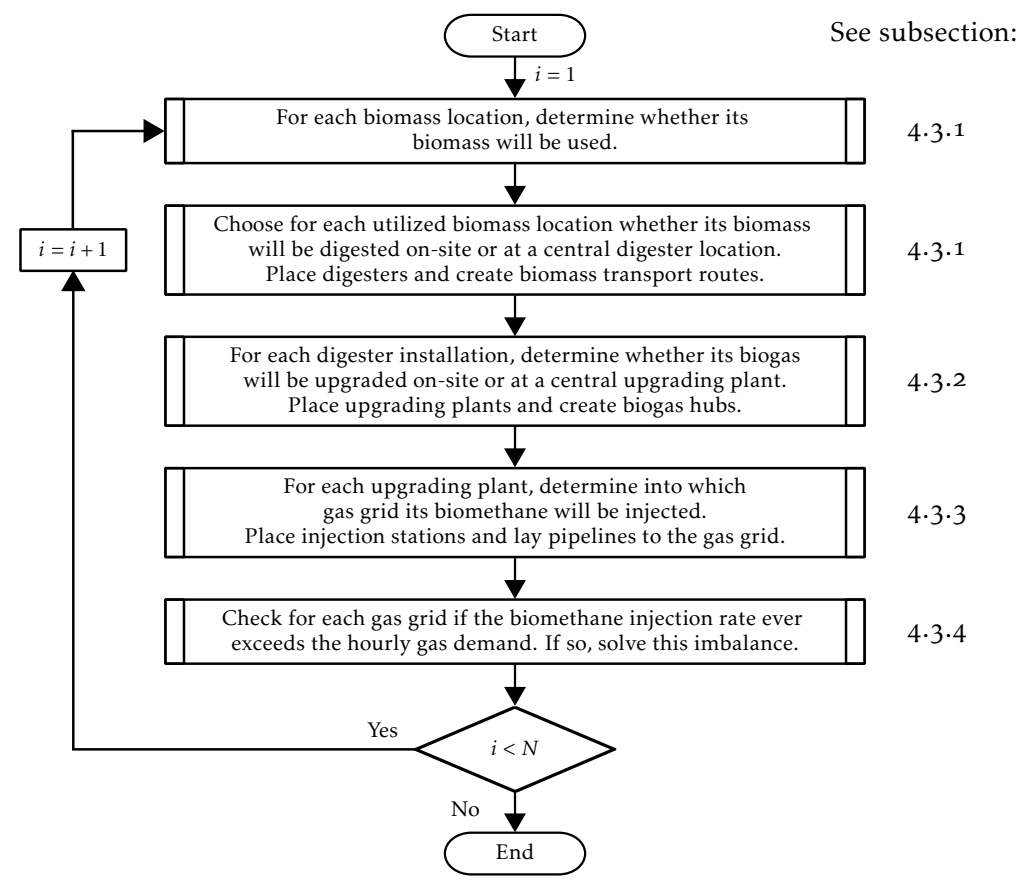

Figure 4.2: Flow chart of the overall design procedure 


\subsubsection{Biomass utilization options}

The design procedure starts with a loop over all biomass locations - see Figure 4.3. For each biomass location, the design procedure decides whether the biomass will be used for biomethane production. This decision is made randomly by the procedure, and the chance that the biomass will be used is $r_{1} \in$ $[0,1]$, which value is defined by the user. The value that is chosen for $r_{1}$ has a large influence on the decisions made by the DST. Therefore, the value for $r_{1}$ (and also $r_{2}$ and $r_{3}$, which are described below) should be chosen carefully. Moreover, the design procedure allows the value of $r_{1}$ (and $r_{2}$ and $r_{3}$ ) to vary during the generation of $N$ solutions. The user can define a lower boundary value and a higher boundary value for $r_{1}$ and the number of intermediate values in between. The value for $r_{1}$ then increases incrementally from the lower value to the higher value during the generation of $N$ solutions. This enables a broader exploration of the design space.

Next, if the biomass at location $i$ will be used for biomethane production, the design procedure decides whether the biomass will be digested on-site or at a central location. This decision is again made randomly, and the chance that the biomass will be digested centrally is $r_{2} \in[0,1]$, which is defined by the user. If this is the case, then location $i$ is added to the group of locations which biomass will be digested centrally. If it is not the case, then a digester installation will be placed on-site and scaled according to the available biomass. This is repeated until all biomass locations are allocated.

After this, from the group of centrally to be digested biomass locations, the procedure chooses at which biomass locations a central digester installation will be located. In addition, the procedure determines the number and which biomass locations will transport their biomass to the central digester locations. To do a broad exploration of the solution space, the number of locations that transport biomass to a central digester and the location of the central digester are chosen randomly by the procedure. This is done by means of the following algorithm:

1. Initialize: $N=$ number of biomass locations which biomass is digested centrally.

2. Generate random integer $R_{1}$ between 1 and $N$, and random integer $R_{2}$ between 0 and $N-1$.

3. Allocate a digester installation to the $R_{1}^{\text {th }}$ biomass location.

4. Select the $R_{2}$ biomass locations that are closest to the $R_{1}^{\text {th }}$ biomass location, and create a biomass transport route between the $R_{2}$ biomass locations and the $R_{1}^{\text {th }}$ biomass location.

5. Update: $N=N-R_{2}-1$.

6. If $N>0$, go to step 2. Else, end algorithm. 


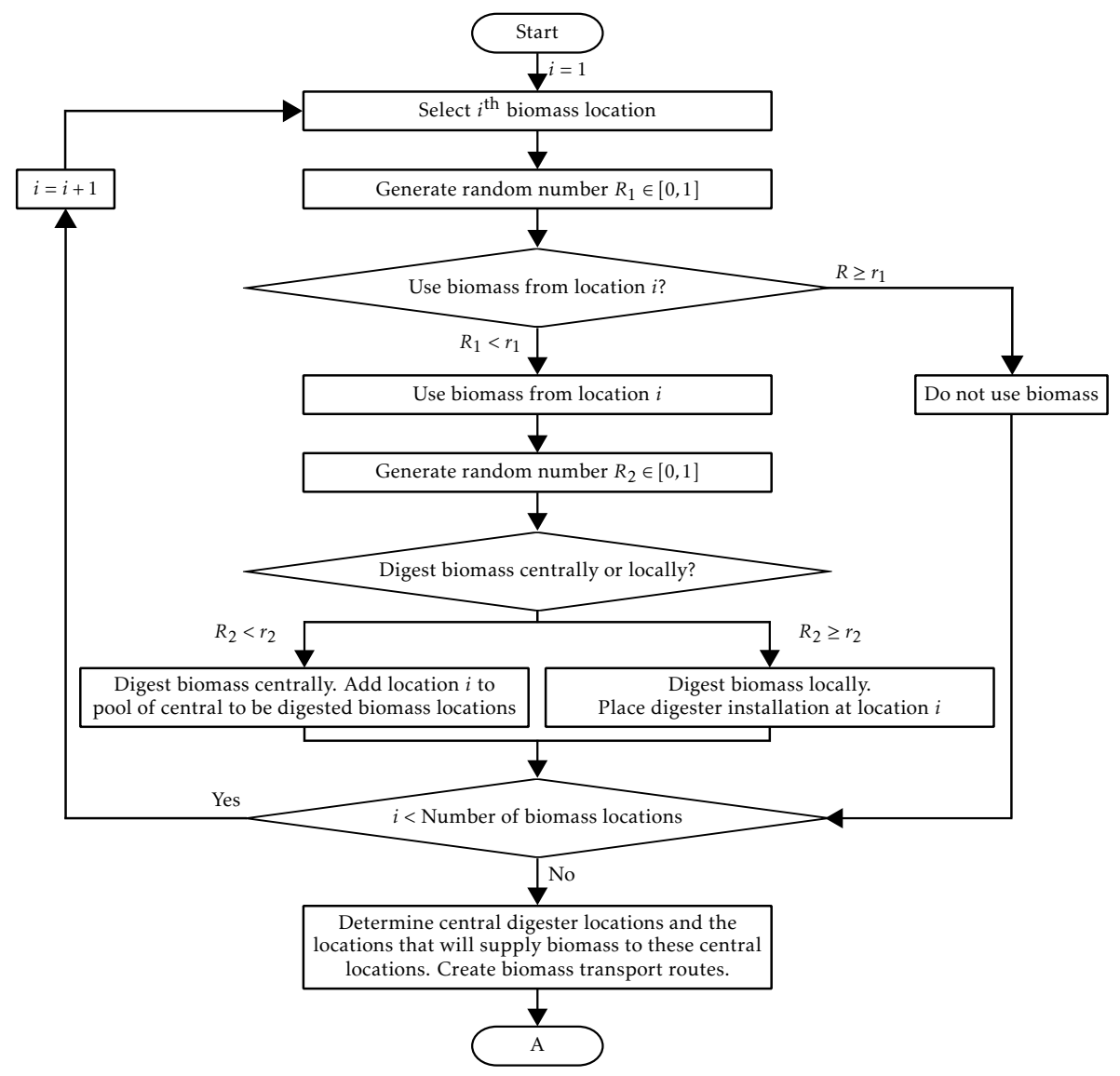

Figure 4.3: First part of the design procedure. Should the biomass be used? And is the used biomass digested centrally or locally?

\subsubsection{Upgrading the biogas}

At this point, the digester installations and biomass transport routes have been defined. Next, the design procedure decides for each digester installation whether its biogas will be upgraded on-site or at a central location - see Figure 4.4. This decision is again made randomly, and the chance that the biogas will be upgraded centrally is $r_{3} \in[0,1]$, which is defined by the user. If the biogas is upgraded centrally, the procedure adds the digester location to the group with other digester locations which biogas will be upgraded centrally. If the biogas will be upgraded on-site, then an upgrading plant is allocated at the digester location.

Next, from the group of digester locations which biogas will be digested cen- 


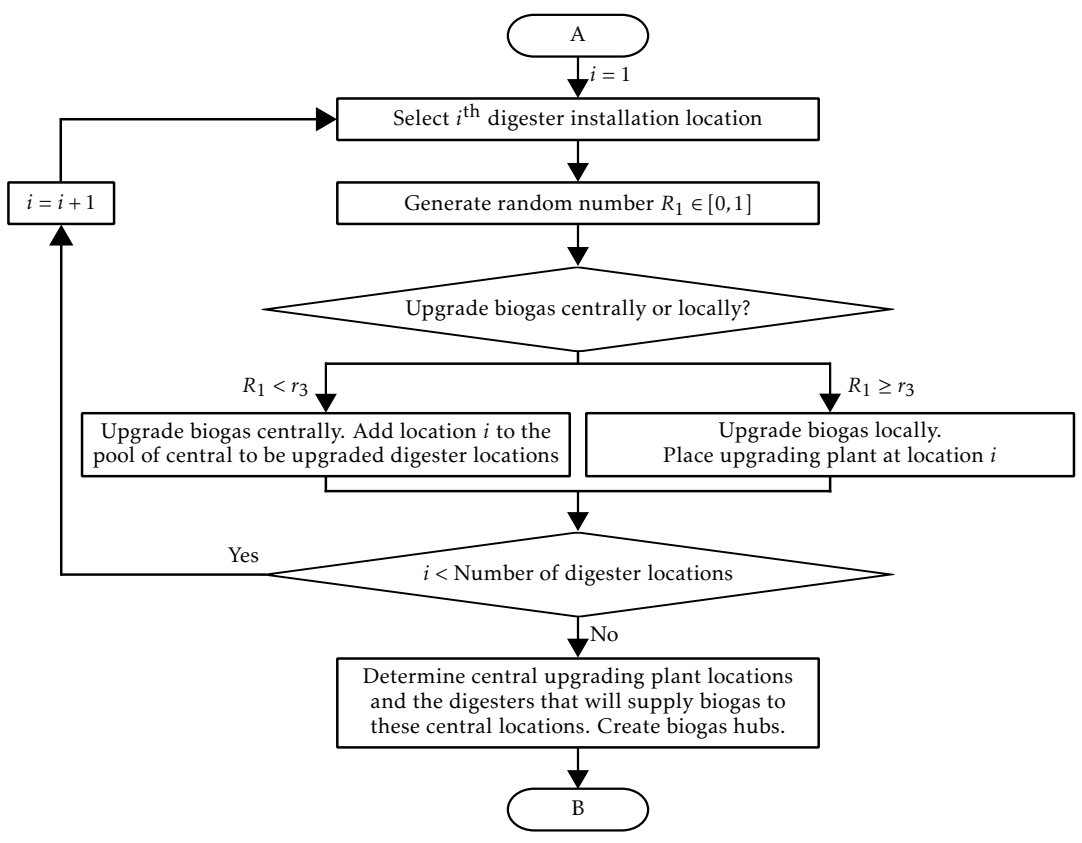

Figure 4.4: Second part of the design procedure. Is the biogas upgraded at a central location or on-site?

trally, the design procedure chooses at which locations a central upgrading plant will be allocated. In addition, the procedure determines the number and which digester locations will supply their biogas to the central upgrading plants. To do a broad exploration of the solution space, the number of digester locations that supply biogas to a central upgrading plant and the location of the central upgrading plant are chosen randomly by the procedure. This is done by means of the following algorithm:

1. Initialize: $N=$ number of digester installation which biogas is upgraded centrally.

2. Generate random integer $R_{1}$ between 1 and $N$, and random integer $R_{2}$ between 0 and $N-1$.

3. Allocate an upgrading plant to the $R_{1}^{\text {th }}$ digester installation location.

4. Create biogas hub for the $R_{2}$ digester installations that are closest to the $R_{1}^{\text {th }}$ digester installation - subsection 4.4.4 describes how a biogas hub is created.

5. Update: $N=N-R_{2}-1$. 
6. If $N>0$, go to step 2. Else, end algorithm.

\subsubsection{Injection of biomethane in a gas grid}

Now all upgrading plants have been allocated, the design procedure has to decide for each upgrading plant into which of the $N$ gas grids the biomethane will be injected. The higher the gas demand of a gas grid, the larger the chance that it will be selected as gas grid into which the biomethane is injected. See Figure 4.5 for a schematic representation of this decision process.

To determine into which gas grid the biomethane is injected, first the total yearly gas demand $D^{k}$ of each gas grid and the total gas demand of all gas grids $D_{\text {tot }}=\sum_{j=1}^{N} D^{j}$ are determined. Then, the $i^{\text {th }}$ upgrading plant is selected; and a random number $R_{1} \in[0,1]$ is generated. The following boolean determines whether the biomethane of upgrading plant $i$ will be injected into gas grid $k$ :

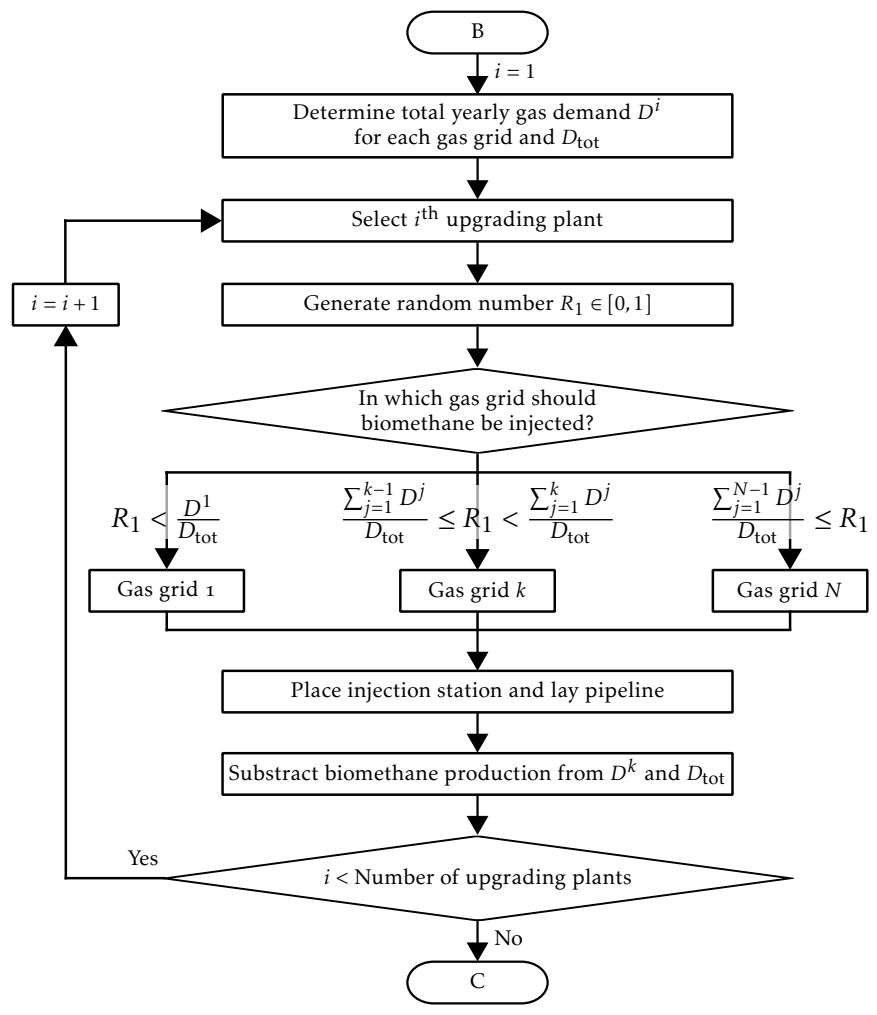

Figure 4.5: Third part of the design procedure. In which gas grid is the biomethane injected? 


$$
\frac{D^{k-1}+D^{k-2}+\ldots+D^{0}}{D_{\text {tot }}} \leq R_{1}<\frac{D^{k}+D^{k-1}+\ldots+D^{0}}{D_{\text {tot }}}
$$

where $D^{0}=0$ and $k$ is a positive integer that identifies each gas grid. As can be seen in (4.1), the larger the total yearly gas demand $D^{k}$ of gas grid $k$, the larger the chance that the boolean is true. And thus, the larger the chance that the biomethane of upgrading plant $i$ will be injected into gas grid $k$.

When (4.1) is true, the biomethane from upgrading plant location $i$ will be injected into gas grid $k$. An injection station will be located at location $i$ and a gas pipeline is laid from the injection station to gas grid $k$-subsection 4.4 .2 describes how a pipeline is laid.

Finally, the yearly biomethane production of upgrading plant location $i$ is subtracted from $D^{k}$ and $D_{\text {tot }}$. These updated values are used to decide into which gas grid the biomethane of the $(i+1)^{\text {th }}$ upgrading plant is injected.

\subsubsection{Dealing with a biomethane surplus}

In the final step, the design procedure checks whether the gas demand in each gas grid is sufficient to consume the injected biomethane at all times. If this is not the case, this has to be solved by either applying line-pack flexibility, adding a gas storage to the gas grid, or compressing surplus gas to the upstream gas grid. Figure 4.6 shows a schematic representation of this decision process.

The design procedure loops over all the gas grids, and starts with the most downstream gas grid and ends with the most upstream gas grid. For gas grid $i$, first the aggregated hourly gas demand is determined. The aggregated gas demand comprises ( 1 ) addition of the gas demand from gas consumers connected to gas grid $i,(2)$ substraction of biomethane injected in gas grid $i$, and (3) addition of the aggregated gas demand of downstream gas grids. Mathematically the aggregated gas demand $D_{\text {agg }}^{i, t}$ of gas grid $i$ at time $t$ is defined as

$$
D_{\text {agg }}^{i, t}=D^{i, t}-\sum_{k \in K} V_{\mathrm{u}}^{k}+\sum_{j \in J} D_{\mathrm{agg}}^{j, t}
$$

where $D^{i, t}$ is the gas demand $\left[\mathrm{m}^{3}(\mathrm{n}) / \mathrm{h}\right]$ of gas grid $i$ at time $t, K$ is the set of upgrading plants that inject biomethane into gas grid $i, V_{\mathrm{u}}^{k}$ is the biomethane output $\left[\mathrm{m}^{3}(\mathrm{n}) / \mathrm{h}\right]$ of upgrading plant $k$, and $J$ is the set of all gas grids that are one level downstream of gas grid $i$.

Next, the procedure checks whether the aggregated gas demand $D_{\text {agg }}^{i, t}$ of gas grid $i$ is always positive:

$$
D_{\text {agg }}^{i, t}>0, \forall t \in T
$$

where $T=[1,8760]$ is the set comprising all hours during a year. If the aggregated gas demand is indeed always positive, no further action is required, 


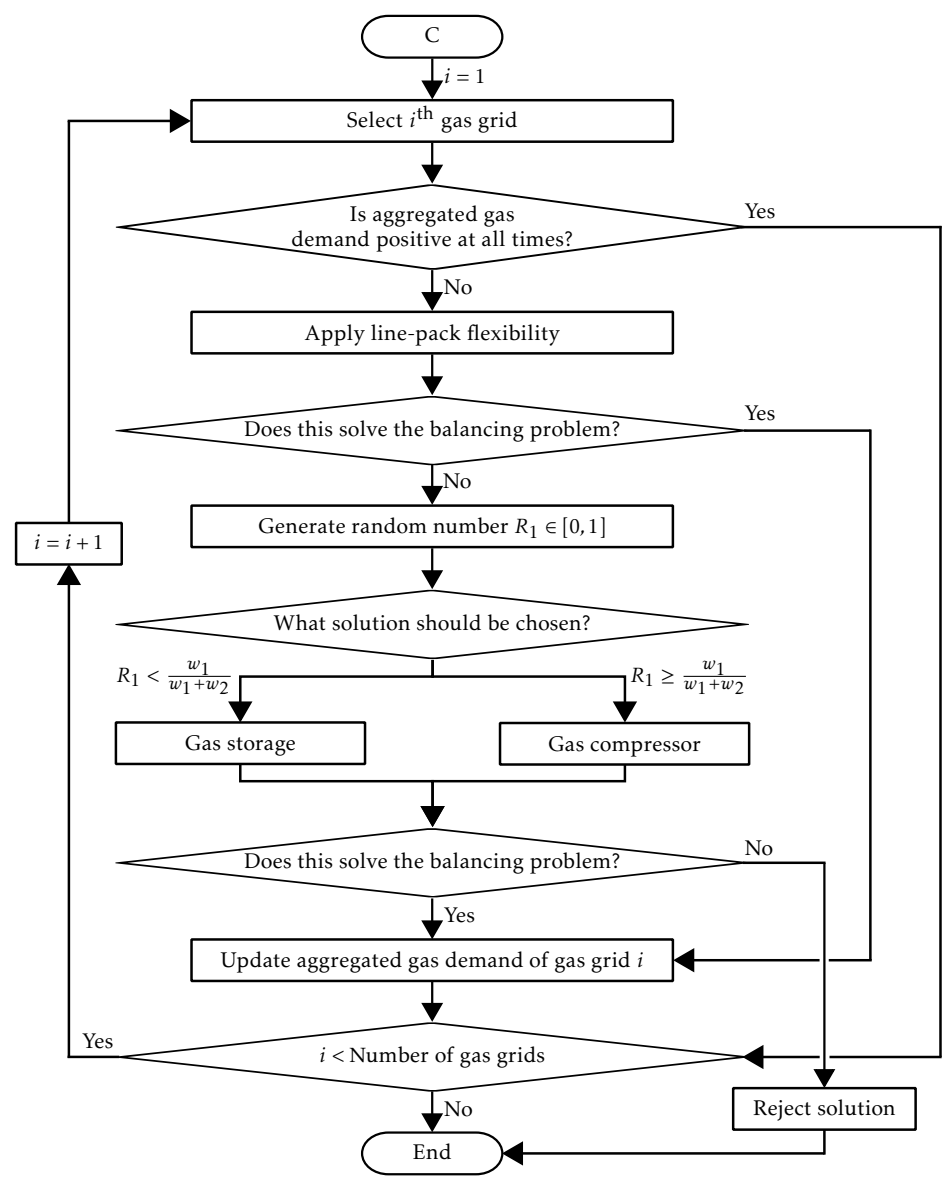

Figure 4.6: Fourth part of the design procedure. Is there a balancing problem? And which technology is used to deal with this balancing problem?

and the design procedure moves on to the next gas grid. If the aggregated gas demand is, however, negative for some $t$, then a solution to fix the imbalance has to be found.

Since line-pack flexibility is a potential solution to the balancing problem which is free of cost, this is tried first. If this solves the problem, the aggregated gas demand $D_{\text {agg }}^{i, t}$ is updated, and the procedure moves on to the next gas grid.

When applying line-pack flexibility does not suffice, two other options are available to solve the balancing problem: (1) adding a gas storage to gas grid $i$, and (2) adding a gas compressor to gas grid $i$ to compress the surplus biomethane to the upstream gas grid. Based on the random generated number $R_{1} \in[0,1]$ and 
the preference weighs $w_{1} \in \mathbb{R}$ and $w_{2} \in \mathbb{R}$ for gas storage and gas compression respectively, the choice between these two options is made:

1. When

$$
R_{1}<\frac{w_{1}}{w_{1}+w_{2}}
$$

a gas storage is added to gas grid $i$. Based on the aggregated gas demand $D_{\text {agg, }}^{i, t}$, the procedure determines the required storage volume, and allocates a gas storage to gas grid $i$. If the yearly volume of injected biomethane exceeds the yearly gas demand of gas grid $i$ and its downstream grids, adding a gas storage will not solve the balancing problem. In this case, the solution will be rejected. Otherwise, the aggregated gas demand $D_{\text {agg }}^{i, t}$ of gas grid $i$ is updated and the design procedure moves on to the next gas grid.

2. When

$$
R_{1} \geq \frac{w_{1}}{w_{1}+w_{2}}
$$

a gas compressor is added to gas grid $i$. Based on the aggregated gas demand $D_{\text {agg, }}^{i, t}$ the scale of the gas compressor is determined, and subsequently a gas compressor is allocated to gas grid $i$. If it is prohibited to inject gas into the upstream grid (for example, it might be prohibited to inject biomethane in the RTL grid), then the solution is rejected. Otherwise the aggregated gas demand $D_{\text {agg }}^{i, t}$ of gas grid $i$ is updated and the design procedure moves on to the next gas grid.

\subsection{Design rules}

Design rules determine how certain elements of the biomethane supply chain are instantiated. The design rules are described in this section.

Subsection 4.4.1 describes how the biomass transport routes are assigned. Biomass transport is the only element that is assigned a value from a continuous function. Next, subsection 4.4.2 describes how pipelines are assigned. Then, a general description of the instantiation of the remaining elements is given in $4 \cdot 4 \cdot 3$. Finally, $4 \cdot 4 \cdot 4$ describes how a biogas hub is created.

\subsubsection{Creating a biomass transport route}

The design procedure, described in section $4 \cdot 3$, determined from which biomass locations the biomass will be transported to a central digester location. For each biomass location for which biomass is transported to a central location, a separate biomass transport route is created.

Biomass transport route $i$ represents the transportation of biomass from biomass location $L_{j}$ to central digester location $L_{k}$. The biomass availability $b_{\mathrm{b}}^{j}$ is 
known and the length $l_{\mathrm{bt}}^{i}$ of the biomass transport route can be calculated from the locations of $L_{j}$ and $L_{k}$.

Using the equations described in $3 \cdot 5 \cdot 2$, the energy usage $E_{\mathrm{bt}}^{i}, \mathrm{CO}_{2}$ emission $G_{\mathrm{bt}}^{i}$, and the cost $O_{\mathrm{bt}}^{i}$ of biomass transport route $i$ can be determined.

\subsubsection{Assigning a pipeline route and pipeline type}

When laying a pipeline, the laying costs depend on the area type. Laying a pipeline is more expensive in an urban area than in a rural area (see Table 3.8 for the area specific costs). Therefore, when the route for a pipeline has to be determined, given a start and end point, a straight line through the city might be more expensive than laying a longer pipeline around the city through the surrounding rural area.

To account for these differences in laying cost, the start configuration contains information regarding the area type. A grid of points indicates whether a certain location is a rural or urban area. A pipeline route is created by connecting the points between the start and end point. The laying costs are derived from the points that are connected. We used the $\mathrm{A}^{*}$ algorithm (see, for instance, Lee [92]) to find the cost minimal pipeline route for a given start and end point.

Now that the route, and thus the length, of the pipeline is known, a pipeline has to be chosen. The pressure $P_{2}$ at the end of the pipeline should not drop below the minimum pressure $P_{\min }$. Hence, the diameter $d_{\mathrm{pl}}$ of the pipeline should be large enough; yet, larger diameters come at a higher cost. Therefore, the pipeline is chosen that has the smallest diameter for which the pressure at the end of the pipeline is higher than the minimum pressure, $P_{2}>P_{\min }$.

The heuristic to determine the pipeline is as follows:

1. Initialize: $N=$ number of pipelines; the smallest diameter so far is $d_{\mathrm{opt}}=$ inf, counter $i=1$, and determine the minimum pressure $P_{\min }$ and maximum pressure $P_{\max }$ for the pipeline.

2. Select pipeline $i$.

3. Given the roughness $\epsilon$ of pipeline $i$, the gas density $\rho_{\mathrm{n}}$ and kinematic viscosity $\mu$ of the gas, the gas flow $v$ and the length $L$ of the pipeline, use (3.19) to determine $P_{1}^{2}-P_{2}^{2}$

4. If $P_{1}^{2}-P_{2}^{2}<P_{\max }^{2}-P_{\min }^{2}$, and $d^{i}<d_{\mathrm{opt}}$, choose pipeline $i$ as the best pipeline so far, and set $d_{\mathrm{opt}}=d^{i}$.

5. Update: $i=i+1$.

6. If $i \leq N$, go to step 2. Else, go to step 7 .

7. Allocate the pipeline corresponding to the optimal diameter $d_{\text {opt }}$. 


\subsubsection{Assigning a component type to a location}

When an element is allocated to a certain location, the corresponding embodiment has to be instantiated. For example, for a given biomass availability, a specific digester has to be allocated to a certain location. The digester type that is chosen, is the one that is able to digest the required amount of biomass and which results in the lowest financial cost. In addition, to increase the digestion capacity, multiple digesters can be allocated to a digester location.

The heuristic described here is used to choose the best component type for a location. The heuristic applies to (1) digester installations, (2) pre-treatment installations, (3) gas compressors, (4) upgrading plants, (5) injection stations, and (6) gas storages.

The heuristic is defined as follows:

1. Initialize: $N=$ number of component types available for this element; counter $i=1$; and the best economic performance so far is $\mathrm{AW}_{\mathrm{opt}}=\mathrm{inf}$.

2. Determine the number $N_{i}$ of components required for component type $i$, based on the requirements for that location. For instance, the amount of biomass that has to be digested.

3. (a) Determine capital cost $A$ for component type $i$.

(b) Determine operational cost $O$ for component type $i$.

(c) Using equation (3.2), define $\mathrm{AW}_{i}=f_{\mathrm{AW}}(A)+O$.

4. If $\mathrm{AW}_{i}<\mathrm{AW}_{\mathrm{opt}}$, choose this as the best option so far; and define $\mathrm{AW}_{\mathrm{opt}}=$ $\mathrm{AW}_{i}$.

5. Update: $i=i+1$.

6. If $i \leq N$, go to step 2. Else, go to step 7 .

7. Allocate the required number of components $N_{\text {opt }}$ of the type corresponding to $\mathrm{AW}_{\text {opt }}$.

As can be noted, only one component type is allocated to a certain location.

\subsubsection{Creating a biogas hub}

A biogas hub consists of two or more digester locations that share one central upgrading plant. The upgrading plant is located at the site of one of the digester installations. The design procedure has decided where the upgrading plant will be located and which digester installations will supply biogas to this central upgrading plant.

The heuristic is given a set of digester locations of which one is designated as the site for the upgrading plant. The heuristic is split in two steps. First, the 
topological relations between the digesters are determined. That is, the heuristic determines from which digester to which digester a pipeline will be laid. Secondly the heuristic determines the optimal operating pressure for the biogas hub.

The following heuristic is used to determine the topological relations between the digester installations:

1. Initialize: $S$ is the group of digester locations that have to be connected to the upgrading plant by means of a biogas pipeline. Location $L_{1}$ is initialized by assigning it to the location of the upgrading plant.

2. Define $L_{2}$ as the digester location that lies closest to $L_{1}$, where $L_{2} \in S$.

3. Define $L_{1}$ as the digester location that lies closest to $L_{2}$, where $L_{1} \in S$.

4. Between $L_{1}$ and $L_{2}$ a pipeline will be laid. Remove $L_{2}$ from $S$

5. If the number of digester locations in $S>1$, go to step 2. Else, end the heuristic.

Now that the topological relations are known, the heuristic has to determine which gas compressors and gas pipelines will be allocated. An important decision in this respect is the operating pressure of the biogas pipelines. With a higher operating pressure, the compression costs go up, but the pipeline costs will go down, since a smaller diameter suffices to transport the biogas, and vice versa. Hence, the operating pressure has to be chosen such that the cheapest combination of gas compressors and gas pipelines is chosen. In the model, the operating pressure of the biogas hub can lie between $1 \mathrm{bar}(\mathrm{g})$ and $8 \mathrm{bar}(\mathrm{g})$. In addition, for this heuristic, the possible values for the operating pressure are limited to integer values, in order to limit the computational burden.

The following heuristic determines the optimal operating pressure for the biogas hub:

1. Initialize: operating pressure $P=0$ bar $(\mathrm{g})$, the lowest $\mathrm{AW}$ of the biogas hub so far $\mathrm{AW}_{\mathrm{opt}}=\mathrm{inf}$, and the optimal operating pressure $P_{\mathrm{opt}}=0 \mathrm{bar}(\mathrm{g})$.

2. $P=P+1$ bar $(\mathrm{a})$.

3. For operating pressure $P$ and compression rate $v_{c}$ determine the capital cost $A_{\mathrm{c}}$ and operational cost $O_{\mathrm{c}}$ for the compressors, using the equations defined in section 3.5.5.

4. For operating pressure $P$ and biogas flow $V$, determine which pipelines will be allocated and determine the corresponding capital cost $A_{\mathrm{pl}}$, using equation (3.23). 
5. Determine the combined $\mathrm{AW}$ of the compressor and pipelines: $\mathrm{AW}_{\text {tot }}=$ $f_{\mathrm{AW}}\left(A_{\mathrm{c}}+A_{\mathrm{pl}}\right)+\mathrm{O}_{\mathrm{c}}$

6. If $\mathrm{AW}_{\text {tot }}<\mathrm{AW}_{\mathrm{opt}}$, this is the cheapest solution so far and: $\mathrm{AW}_{\mathrm{opt}}=\mathrm{AW}_{\text {tot }}$, $P_{\mathrm{opt}}=P$.

7. If $P<8$ bar(g), go to step 2. Else, go to step 8 .

8. Create the biogas hub, by allocating the pipelines and compressors corresponding to the optimal operating pressure $P_{\mathrm{opt}}$

\subsection{Choosing a (non-dominated) solution}

Creating solutions using the design procedure described in this chapter for a given start configuration, results in $N$ solutions. $N$ is probably a large number, in order to explore a large part of the solution space.

The user has defined several performance indicators on which his/her choice for the eventual solution will be based. However, selecting one solution from the $N$ generated solutions is a cumbersome task for the user. To reduce the number of solutions to choose from, the user can limit him/herself to the non-dominated solutions. Here a non-dominated solution is defined as follows:

Having $M$ performance indicators, a solution $x_{1}$ dominates solution $x_{2}$ when it satisfies the following two conditions [93]:

1. For all $M$ performance indicators, solution $x_{1}$ is not worse than $x_{2}$.

2. For at least one performance indicator, solution $x_{1}$ is better than $x_{2}$.

When $x_{1}$ dominates $x_{2}$, one can also say that $x_{1}$ is non-dominated by $x_{2}$ [93]. As such, the set of non-dominated solutions is that set of solutions that are not dominated by any of the $N$ solutions [93]. The example below illustrates the idea of dominance.

Example. Figure 4.7 shows the performance indicators, $f_{1}$ and $f_{2}$, of several solutions. As can be seen, solution 1 is a dominated solution, since solutions exist that score better on both $f_{1}$ and $f_{2}$. For example the values for $f_{1}$ and $f_{2}$ of solution 2 are both higher than of solution 1. Furthermore, solution 2 is a non-dominated solution since there is no solution that improves both $f_{1}$ and $f_{2}$. For instance, choosing a solution that has a higher value for $f_{2}$ results in a lower value for $f_{1}$.

The user can limit his/her choice for the preferred solution to the non-dominated solutions. Which non-dominated solution the user will choose, depends on his/her preferences.

Finally, the non-dominated solutions of the entire feasible solution space are referred to as Pareto-optimal solutions [93]. 


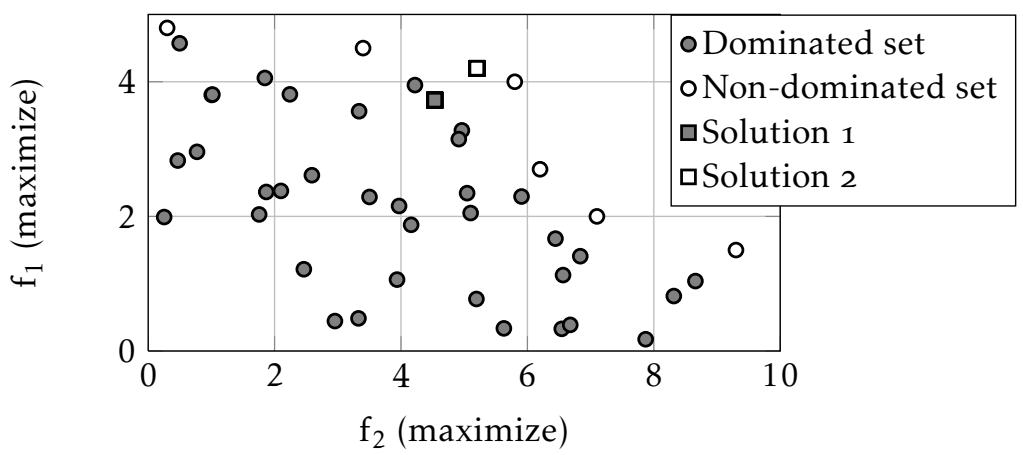

Figure 4.7: Example of a dominated and a non-dominated solution set, having two performance indicators $f_{1}$ and $f_{2}$.

\subsection{Verification of the DST}

The developed DST (which consists of the design engineering model, the design procedure, and the design rules) was verified. The verification was done to check whether (1) the solution space is explored properly by the design procedure and (2) the design engineering model was correctly implemented in the DST.

To check whether the solution space is properly explored by the design procedure, we performed two tests. The start configuration used for these two tests was a relatively simple one. As a result, we could determine the optimal solution (for example, the solution with the highest $\mathrm{CO}_{2}$ emission reduction) with common sense. Due to the number of biomass locations, the solution space was still significant for the DST. The first test showed that the DST generates the optimal solution when maximizing $\mathrm{CO}_{2}$ reduction, maximizing net energy production, or minimizing total costs. Although the focus of the DST is on exploring the solution space, rather than finding the Pareto-optimal solutions, finding the Pareto-optimal solutions provided a good indication that other parts of the solution space are also explored. The second test showed that the non-dominated solutions found by the DST are diverse. A diverse set of solutions represents a set of solutions that covers the entire Pareto-optimal region uniformly [93].

To verify the design engineering model, we performed again two tests. For the first test, we calculated the values for the performance indicators for several simple biomethane supply chains by hand and compared these with the values calculated by the DST. For the second test, we performed an extreme value test. For several parameters, we significantly increased or decreased their values. In the next step, the DST generates a large number of solutions. Afterwards, the solution that has the best value for a certain performance indicator was compared with what was expected to be the best solution. To give an example, we varied the value for energy usage for biomass transport (the low value was 0.1 $\mathrm{kWh} / \mathrm{t} \cdot \mathrm{km}$ and the high value was $10 \mathrm{kWh} / \mathrm{t} \cdot \mathrm{km})$. For both values, the DST 
generated a large number of solutions and the one with the highest net energy production was chosen. For the low value for energy usage, the best solution was the solution with a central digester to which biomass is transported from other biomass locations by means of trucks. For the high value for energy usage, the solution where the biomass of each biomass location is digested locally came out as best solution. These results were as expected. Both the first and second test gave a positive result.

In conclusion, the verification showed that (1) the DST explores the solutions space properly and (2) the design engineering model was correctly implemented in the DST.

\section{$4 \cdot 7$ Conclusions}

A design procedure was developed that generates designs for the biomethane supply chain, given a start configuration with a number of biomass locations and gas distribution grids. The design procedure determines if the biomass is used, where the biomass is digested, where the biogas is upgraded, in which gas grid the biomethane is injected, and which technology will deal with a surplus of biomethane. With this design procedure a large number of solutions can be created. Moreover, the DST does not choose a single best solution, but lets the user to choose the solution from the generated (non-dominated) solutions. The user bases his/her choice for the preferred solution on the performance indicators and possibly also other characteristics of the biomethane supply chain, which are not reflected in the performance indicators.

The developed design procedure extends the procedures described in literature, by (1) being able to handle a varying number of constraints and equations in time, (2) being multi-objective, (3) letting the user to choose the preferred solution, and (4) providing a broad exploration of the solution space.

The DST, consisting of the model described in Chapter 3 and the design procedure described in this chapter, was implemented in the programming language C\#. The software environment used for this was Visual C\# 2010 Express [94].

In chapters 5 and 6 , the DST is used to generate candidate solutions for the biomethane supply chain for certain regions in the Netherlands. 



\section{Part IV}

\section{Descriptive study II}





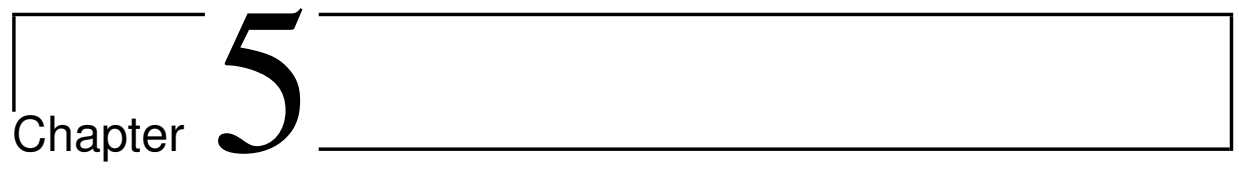

\section{Design of the gas distribution infrastructure in the future scenarios $^{1}$}

In chapter 2, four scenarios were derived for the Dutch energy system in the year 2050. If one of these scenarios will become reality, the gas distribution infrastructure is likely to be shaped differently compared to today. Therefore, in this chapter, it was determined how the gas distribution infrastructure will be shaped in each of the scenarios for three different geographical regions in the Netherlands. More specifically, for each scenario and region, the design of the biomethane supply chain and the corresponding performance indicators were determined.

The three regions used for this research are actual regions in the Netherlands. Furthermore, the gas distribution grid, hourly gas demand patterns, and biomass locations corresponding to these three regions were used. As such, the analysis presented in this chapter also demonstrated the usefulness of the DST for three real situations. Hence, it forms the first part of Descriptive Study II.

Thus, the contribution of this chapter is firstly, determining the design ofand investments in the biomethane supply chain for the different scenarios and regions, and secondly demonstrating the use of the DST for three real situations.

This chapter is organized as follows. First, in section 5.1 , the experimental setup is given. It describes the three regions and how the future scenarios were translated to model parameters and optimization objectives that can be used by the DST. Then in section 5.2 , the results are described. In particular, the design of

\footnotetext{
${ }^{1}$ Parts of this chapter are from [95]
} 


\section{Chapter 5 Design of the gas distribution infrastructure in the future scenarios}

the biomethane supply chain and the corresponding investments for different scenarios and regions are given. These results are discussed in more detail in section 5.3. Finally, section 5.4 draws conclusions on the performed analysis.

\subsection{Experimental setup}

In order to determine how the future scenarios will influence the design of the gas distribution infrastructure, the scenarios had to be translated to useable input for the DST. Three start configurations were needed, consisting of biomass locations, one or more gas distribution grids, and hourly gas demand of the connected gas consumers. These start configurations form a cross section of the Netherlands when considering biomethane potential and gas demand. Furthermore, statements in the scenarios about, for instance, the development of future energy prices, increase or decrease in the total Dutch energy demand, and potential biomass availability in the Netherlands needed to be translated to useful input for the DST. This resulted in concrete electricity and fuel prices, biomass locations with biomass availability in the start configurations, and hourly gas demand profiles for each gas consumer in the start configurations. In addition, to know on what performance indicators the choice for the preferred solution should be based, the key forces of the future scenarios were translated to optimization goals.

Note that the scope of this research is smaller than that of the scenario development exercise. For instance, in this chapter we assumed that only biomethane and G-gas will flow through the gas distribution grid. Therefore, other gases mentioned in Chapter 2 (such as $\mathrm{H}_{2}$ or $\mathrm{CH}_{4}$ produced from a surplus of renewable electricity) were not taken into account.

In this section, in 5.1.1 it is first discussed why these three regions were chosen, what their characteristics are, and how they were translated to start configurations useable for the DST. This subsection describes the nominal situation. Secondly, in 5.1.2 it is discussed how some characteristics of the nominal start configuration (such as biomass availability) were adjusted to the specific scenarios. Furthermore, in this subsection, some parameters of the DST (such as the fuel and electricity price) were also adjusted according to the future scenarios. Thirdly, in 5.1.3 it is described how the key forces of the future scenarios were translated to optimization goals for the DST.

\subsubsection{Three nominal start configurations}

In order for the results in this chapter to be as applicable as possible for gas distribution infrastructures in general in the Netherlands, we chose to use three representative regions that can be considered a cross section of the Netherlands. This selection of representative regions was based on (1) biomass availability, 
which determines the potential volume of biomethane production, and (2) population density, which determines the volume of the gas demand. This is shown in Figure 5.1(a), having: a rural region, which is typified by a high availability of biomass and a low population density; an intermediate region, which has a medium availability of biomass and a medium population density; and an urban region, which has a low availability of biomass and a high population density. The three regions that were chosen coincide with three of the forty COROP regions defined by the Dutch national institute of statistics (CBS) [96].

The three chosen regions are listed below and their location in the Netherlands is shown in Figure 5.1(b):

- Rural region: Noord-Drenthe, consisting of the municipalities: Assen, Midden-Drenthe, and Aa en Hunze.

- Intermediate region: Arnhem/Nijmegen, consisting of the municipalities: Arnhem, Beuningen, Druten, Duiven, Groesbeek, Heumen, Lingewaard, Millingen aan de Rijn, Nijmegen, Overbetuwe, Renkum, Rijnwaarden, Rozendaal, Ubbergen, Westervoort, Wijchen, and Zevenaar.

- Urban region: The Hague, consisting of the municipalities: The Hague, Leidschendam-Voorburg, Pijnacker-Nootdorp, Rijswijk, and Zoetermeer.

Next, the three regions should be translated to three start configurations that can be used by the DST.

The maximum potential of biomethane production in the Netherlands was estimated at $2 \mathrm{Gm}^{3}(\mathrm{n}) / \mathrm{a}$, which is based on the available biomass in the Nether-

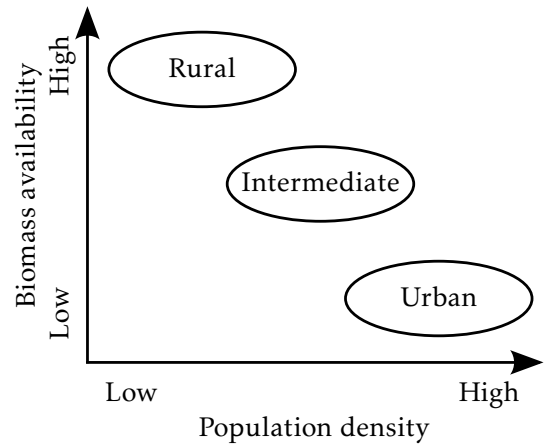

(a) Characterization of the three regions

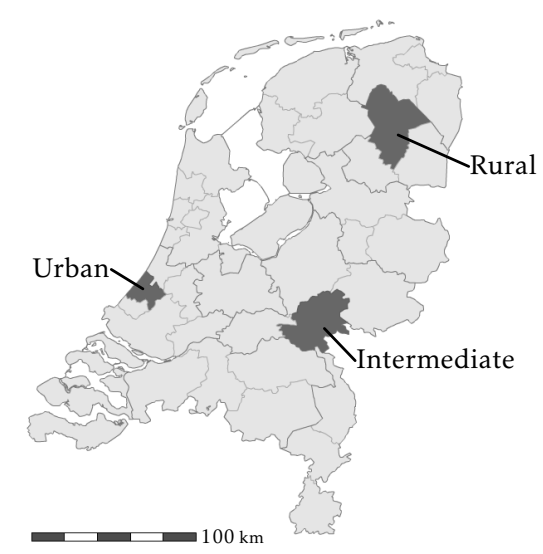

(b) Location of the three chosen regions [97]

Figure 5.1: Characterization and location of the three regions 


\section{Chapter 5 Design of the gas distribution infrastructure in the future scenarios}

lands $[5,98,99]$. To define the biomass locations for the three start configurations, we assumed that all biomethane is produced from biomass as defined by ECN, which consists of $50 \%$ manure and $50 \%$ other co-substrate [61]. To produce the biomethane potential of $2 \mathrm{Gm}^{3}(\mathrm{n}) / \mathrm{a}$, only a fifth of the cattle manure available in the Netherlands is required [100]. Therefore, 1 in 5 farms located in the three regions were added as biomass locations to the corresponding start configurations. The choice of which farm to add and which not was made randomly. The dairy farmers' manure production was based on the average manure production of all dairy farmers located in their municipality for the year 2010 [100]. Furthermore, for each farmer in the start configuration, we assumed that their co-substrate availability is equal to their manure availability.

The current layout of each gas distribution grid in the three regions was provided by the DSOs. In the research presented in this chapter only the layout of the high-pressure distribution grid, whose operating pressure is higher than $200 \operatorname{mbar}(\mathrm{g})$, was used. The low-pressure distribution grid, whose operating pressure is equal to or lower than $200 \operatorname{mbar}(\mathrm{g})$, was omitted from this research. Since it has a low transport capacity and low hourly gas demand, we assumed this grid is not suitable as an injection point for biomethane. The district stations that supply gas from the high-pressure distribution grid to the low-pressure distribution grid were not omitted, and instead represent gas consumers in this research.

The hourly gas throughput of the GRSs was used to define the hourly gas demand profile of the district stations/gas consumers. This was done by evenly spreading the hourly gas throughput of the GRSs over the downstream gas consumers. As an example, in the case where a GRS has four downstream district stations, the gas throughput of each district station at a certain point in time will be a fourth of the gas throughput of the GRS at that point in time.

The resulting start configurations of the rural, intermediate, and urban region are shown in Figure 5.2, 5.3, and 5.4 respectively. Furthermore, in Table 5.1, some characteristics of the three start configurations are shown. Note that the intermediate region has a higher biomethane potential than the rural region. This is due to the larger size of this region.

\subsubsection{Scenario dependent variables}

Energy prices will go up when there is a perceived scarcity of energy. Similarly, subsidy for biomethane will be higher when there is a willingness to reduce $\mathrm{CO}_{2}$ emissions or when there is a perceived energy scarcity. As a consequence, some of the variables that were defined in Chapter 3 will have different values in the four future scenarios. In addition, when there is a perceived energy scarcity, the hourly gas demand is likely to be lower than currently the case, and also more biomass resources are likely to become available to produce renewable energy. 


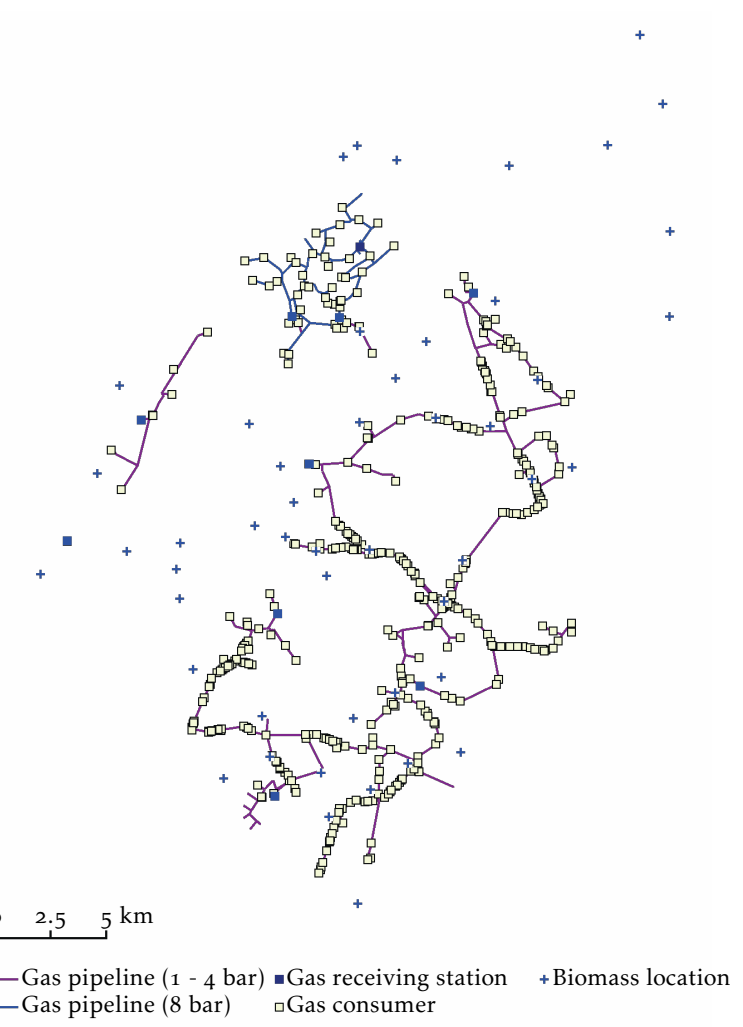

Figure 5.2: Start configuration of the rural region.

\begin{tabular}{llll}
\hline & Rural & Intermediate & Urban \\
\hline Total gas demand in 2012 $\left[\mathrm{Gm}^{3}(\mathrm{n}) / \mathrm{a}\right]$ & 0.13 & 0.70 & 1.08 \\
Mean biomass supply per location $[\mathrm{kg} / \mathrm{h}]$ & 779 & 777 & 562 \\
Number of biomass locations & 49 & 55 & 10 \\
Biomethane potential $\left[\mathrm{Mm}^{3}(\mathrm{n}) / \mathrm{a}\right]$ & 32 & 35 & 4.4 \\
Potential biomethane share $[\%]$ & $24 \cdot 3$ & 5.0 & 0.4 \\
\hline
\end{tabular}

Table 5.1: Characteristics of the three start configurations 


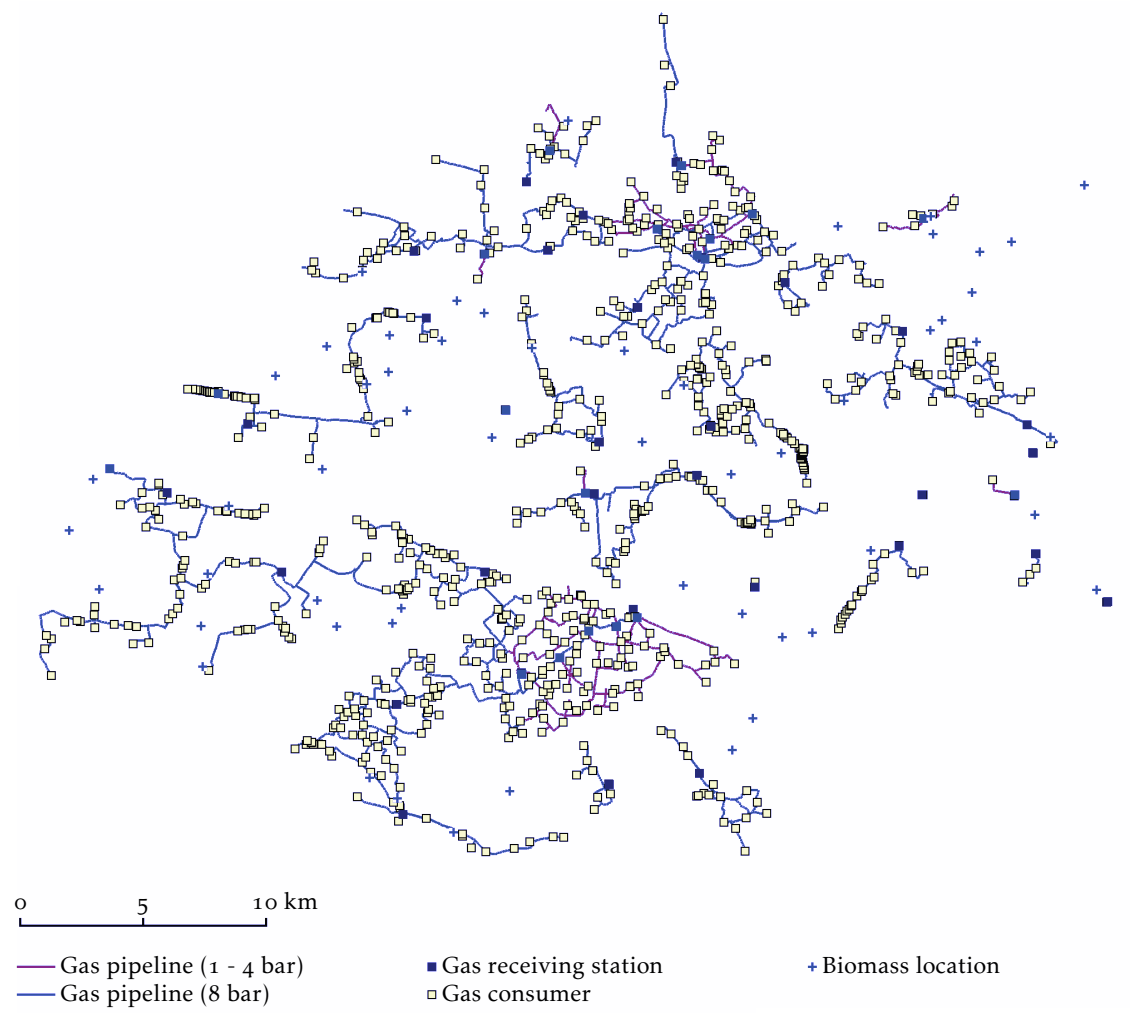

Figure 5.3: Start configuration of the intermediate region.

Hence, depending on the four scenarios, the values for biomass availability and hourly gas demand in the three nominal start configurations presented in the previous subsection are subject to change.

The values for these scenario dependent variables are listed in Table 5.2.

As can be seen in Table 5.2, in the Business as Usual scenario, biomass availability is only $25 \%$ of the nominal situation. We assumed that in this scenario only one fourth of the farmers that have biomass available in the nominal situation want to use their biomass for biogas production. This was achieved by omitting 3 out of 4 biomass locations from the nominal start configuration, which was done randomly. Furthermore, biomass availability in the Renewable Selfsufficiency scenario is double that of the nominal situation. This availability was achieved by letting the farmers have $25 \%$ extra biomass available. The remaining $75 \%$ extra biomass comes from 1 or 2 biomass centers that have imported biomass available. These are located near harbors. Finally, biomass availability in the Carbon Constraints and Tight Market scenarios is equal to the nominal sit- 


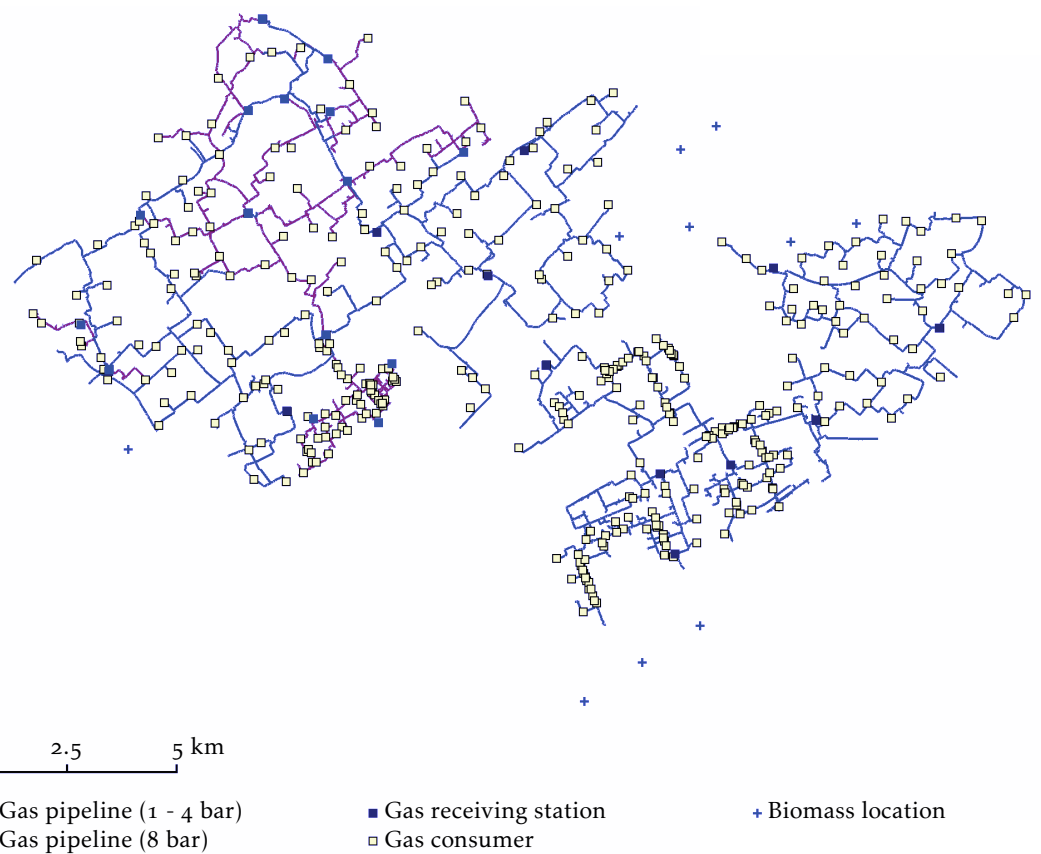

Figure 5.4: Start configuration of the urban region.

\begin{tabular}{llllll}
\hline & $\begin{array}{l}\text { Nominal } \\
\text { value }\end{array}$ & $\begin{array}{l}\text { Business } \\
\text { as Usual }\end{array}$ & $\begin{array}{l}\text { Carbon } \\
\text { Con- } \\
\text { straints }\end{array}$ & $\begin{array}{l}\text { Tight } \\
\text { Market }\end{array}$ & $\begin{array}{l}\text { Rene- } \\
\text { wable } \\
\text { Self-suf- } \\
\text { ficiency }\end{array}$ \\
\hline $\begin{array}{l}\text { Biomass avail- } \\
\text { ability factor }\end{array}$ & 1 & 0.25 & 1 & 1 & 2 \\
$\begin{array}{l}\text { Gas demand fac- } \\
\text { tor }\end{array}$ & 1 & 0.83 & 0.67 & 0.67 & 0.5 \\
$\begin{array}{l}\text { Biomethane sub- } \\
\left.\text { sidy [€ct/m }{ }^{3}(\mathrm{n})\right]\end{array}$ & 47.3 & 0 & 47.3 & 47.3 & 94.6 \\
$\begin{array}{l}\text { Gas retail price } \\
{\left[€ \mathrm{Ect} / \mathrm{m}^{3}(\mathrm{n})\right]}\end{array}$ & 24.7 & 24.7 & 24.7 & 49.4 & 49.4 \\
$\begin{array}{l}\text { Electricity price } \\
{[€ \mathrm{ct} / \mathrm{kWh} \text { ) }}\end{array}$ & 7 & 7 & 7 & 14 & 14 \\
$\begin{array}{l}\text { Transport fuel } \\
\text { price [€ct/kWh] }\end{array}$ & 12.6 & 2.53 & 2.53 & 5.06 & 5.06 \\
\hline
\end{tabular}

Table 5.2: Values of the scenario dependent variables 


\section{Chapter 5 Design of the gas distribution infrastructure in the future scenarios}

uation. So biomass-wise the start configuration for these scenarios is identical to the nominal start configuration.

The hourly gas demand in 2050 for each future scenario is found by multiplying the nominal hourly gas demand by the gas demand factor, which is given in Table $5 \cdot 2$.

Finally, in the Carbon constraints and Renewable Self-sufficiency scenarios, the gas grid is adjusted to biogas quality - see Chapter 2. So no upgrading of the biogas is needed. In the DST this will be simulated by setting the cost for upgrading at zero.

In Appendix A, a more detailed description of the scenario dependent variables can be found.

\subsubsection{Solution generation settings}

This section describes the experimental settings. First, the chances of biomass utilization, local digestion and local upgrading were defined - see Chapter 4 . We let the chances for local digestion and upgrading vary between zero and one, and did this in 5 steps. Since it was not interesting for this study to have no biomass utilization at all, the chance of biomass utilization started at 0.01. In five steps the chance of biomass utilization increased to 1 . By varying the chances, instead of choosing a fixed configuration, a larger part of the solution space was explored. For each configuration of chances, 80 runs were executed, which resulted in a total of 10,000 runs. These settings are summarized in Table 5.3.

Furthermore, the optimization goals had to be chosen. The ambitions for $\mathrm{CO}_{2}$ emission reduction and perceived energy resource scarcity in the future scenarios determined these goals. If there is a drive to reduce GHG emissions, $\mathrm{CO}_{2}$ emission reduction was an optimization goal. If energy resources are perceived to be scarce, net energy production was one of the optimization goals. Finally, the NPV was always optimized. Table 5.4 summarizes the optimization goals per scenario.

Finally, we had to define how the potential surplus of biomethane should be

\begin{tabular}{llll}
\hline & Lower value & Upper value & Number of steps \\
\hline Chance of biomass utilization & o.o1 & 1 & 5 \\
Chance of local digestion & o & 1 & 5 \\
Chance of local upgrading & o & 1 & 5 \\
Runs per step & 80 & & \\
\hline
\end{tabular}

Table 5.3: The solution generating settings, which resulted in 10,0oo solutions 


\begin{tabular}{llll}
\hline & $\mathrm{NPV}$ & $\begin{array}{l}\text { Net energy pro- } \\
\text { duction }\end{array}$ & $\begin{array}{l}\mathrm{CO}_{2} \text { emission re- } \\
\text { duction }\end{array}$ \\
\hline Business as Usual & $\mathrm{X}$ & & $\mathrm{X}$ \\
Carbon Constraints & $\mathrm{X}$ & & \\
Tight Market & $\mathrm{X}$ & $\mathrm{X}$ & $\mathrm{X}$ \\
Renewable Self-sufficiency & $\mathrm{X}$ & $\mathrm{X}$ & $\mathrm{X}$ \\
\hline
\end{tabular}

Table 5·4: Optimization goals per scenario

dealt with. We allowed gas to be compressed to an upstream gas grid (although not to the RTL grid), gas to be stored in a gas storage, and gas to be buffered by means of line pack.

\subsection{Results}

For each scenario and each region, 10,000 candidate solutions were generated. To make a choice among the 10 ,ooo solutions, only the non-dominated solutions were considered. In this way, the set of candidate solutions became much smaller. In addition, we have only selected solutions with a positive NPV. Finally, if net energy production or $\mathrm{CO}_{2}$ emission reduction was one of the objectives, we selected the solution with the highest net energy production or $\mathrm{CO}_{2}$ emission reduction respectively - but with a positive NPV.

In this section, the results are discussed per region. For the rural region, the results per scenario are described in subsection 5.2.1. The results for the intermediate and urban region are discussed in 5.2.2 and 5.2.3 respectively.

\subsubsection{Rural region}

\section{Business as Usual}

None of the 10,000 solutions generated for the Business as Usual scenario had a positive NPV. So the best solution is the start configuration, with an NPV of zero. Hence, in this scenario, there will be no biomethane production and the gas distribution infrastructure remains as it is.

\section{Carbon Constraints}

Figure $5 \cdot 5(\mathrm{a})$ shows the NPV and $\mathrm{CO}_{2}$ emission reduction of the non-dominated solutions in the Carbon Constraints scenario. The design of the preferred solution is shown in Figure 5.6. It has four digestion centers that are supplied with biomass from other locations by means of trucks. Each digester installation has its own upgrading plant. As can be seen, of only a limited number of locations 
the biomass is used. This is due to the low hourly gas demand in this region, which requires expensive gas balancing measures to further increase the biomethane production. Already, there are two gas storages in operation that buffer the biomethane in times of surplus. However, adding more storage capacity would result in a negative NPV.

\section{Tight Market}

Figure $5 \cdot 5$ (b) shows NPV and net energy production of the non-dominated solutions in the Tight Market scenario. The design of the preferred solution is shown in Figure 5.7. This solution has five digester installations, of which three are central digesters to which biomass is transported from other locations. Each digester installation has an upgrading plant on site. Compared to the preferred solution in the Carbon Constraints scenario, more biomass is used. This is due to the higher compensation for biomethane in the Tight Market scenario: the biomethane subsidy is the same but the gas retail price is double that of the Carbon Constraints scenario. Furthermore, since more biomass is used, also more gas needs to be stored in this scenario.

\section{Renewable Self-sufficiency}

$\mathrm{NPV}$, net energy production, and $\mathrm{CO}_{2}$ emission reduction of the non-dominated solutions in the Renewable Self-sufficiency scenario are shown in Figure 5.8. Of

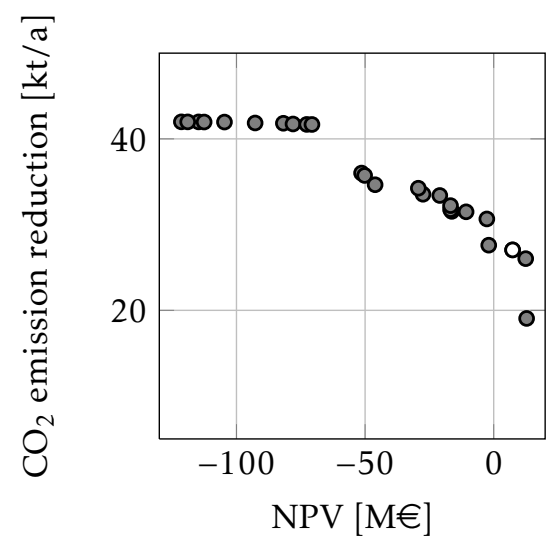

(a) Carbon Constraints

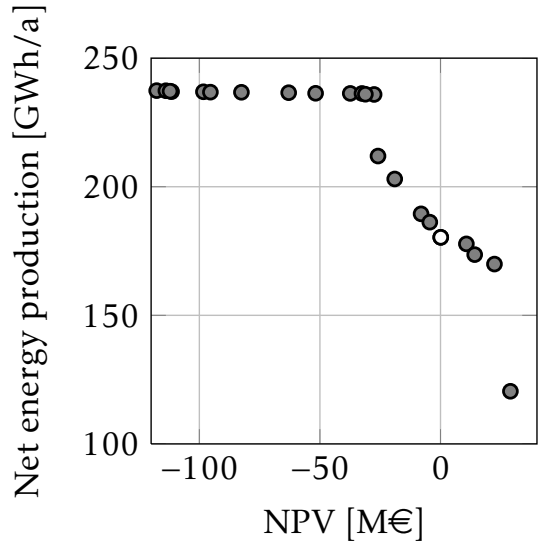

(b) Tight Market

Figure 5.5: Performance indicators of the non-dominated solutions in the Carbon Constraints and Tight Market scenarios. The chosen solutions are marked white. (Rural region) 


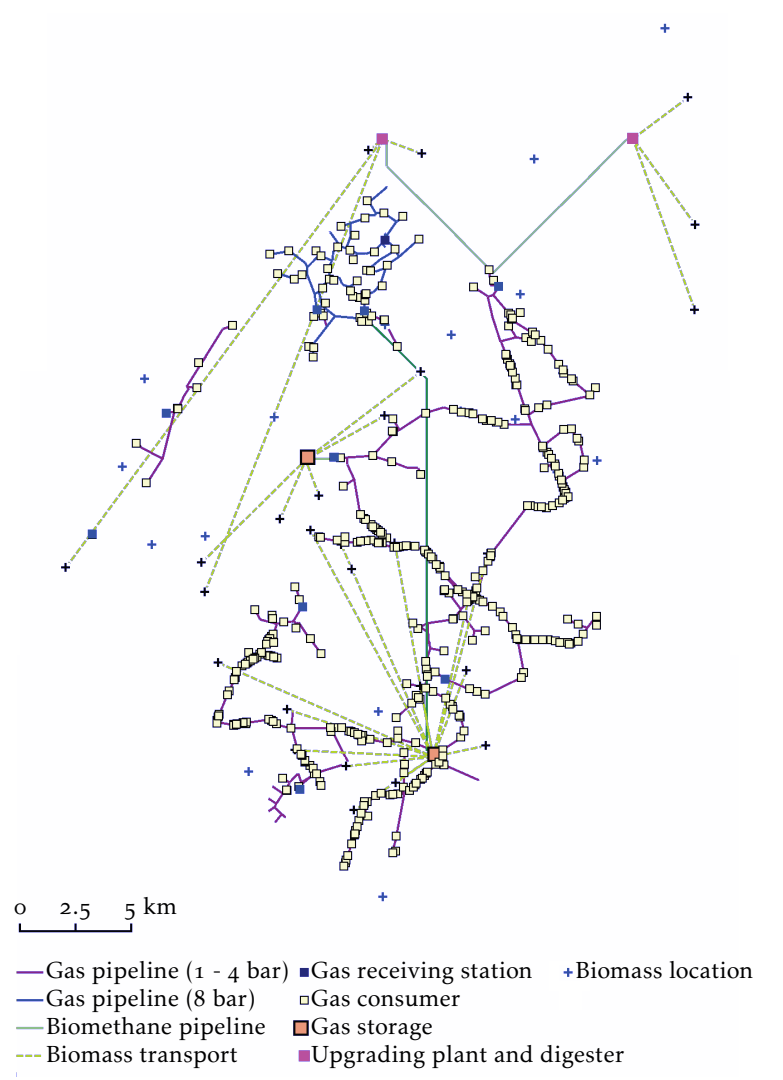

Figure 5.6: Design of the chosen solution in the Carbon Constraints scenario. (Rural region)

the solutions with a positive NPV, we chose the one that has both the highest $\mathrm{CO}_{2}$ emission reduction and highest net energy production. Its design is shown in Figure 5.9. In this solution more biomethane is produced than in the preferred solutions in the Tight Market and Carbon Constraints scenarios. However, even in the Renewable Self-sufficiency scenario, which has the highest incentive to produce biomethane, not all biomass is used. The biomass from the biomass center is not used either.

\subsubsection{Intermediate region}

\section{Business as Usual}

Just as for the rural region, none of the solutions in the Business as Usual scenario had a positive NPV. The best solution is, therefore, the start configuration with 


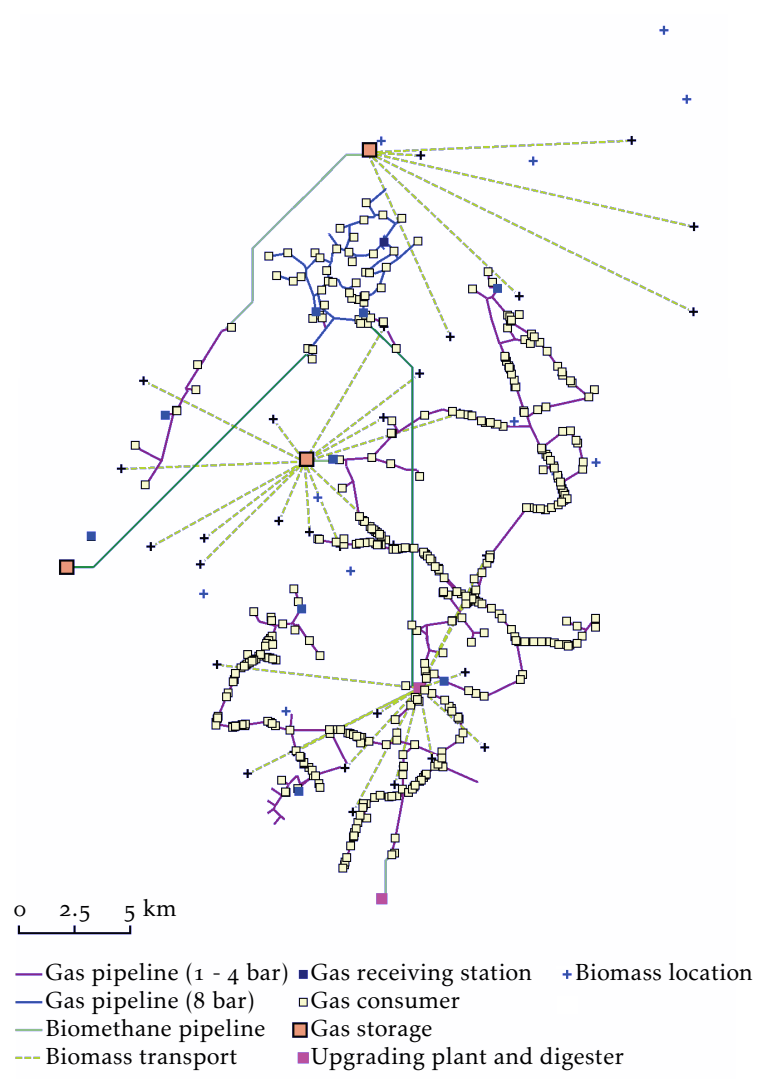

Figure 5.7: Design of the chosen solution in the Tight Market scenario. (Rural region)

an NPV of zero. Hence, the gas distribution infrastructure remains as it is in this scenario.

\section{Carbon Constraints and Tight Market}

The NPV and net energy production of the non-dominated solutions in the Tight Market scenario are shown in Figure 5.10. No significant difference in net energy production exists among the solutions (the difference is about $1 \%$ between the highest and the lowest value). Hence, the solution with the highest NPV was chosen. Its design, shown in Figure 5.11, is comparable to the solution for this region in the Carbon Constraints scenario. In both designs, all biomass is used; three digester installations are installed, each with their own upgrading plant; two gas distribution grids use line-pack for buffering; and no gas storage is needed. The locations of the digester installations, however, differ. This is an indication that not the entire solution space is explored and that the found 


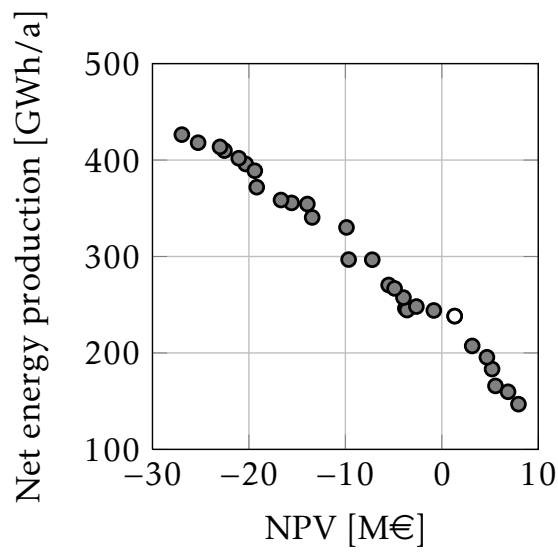

(a)

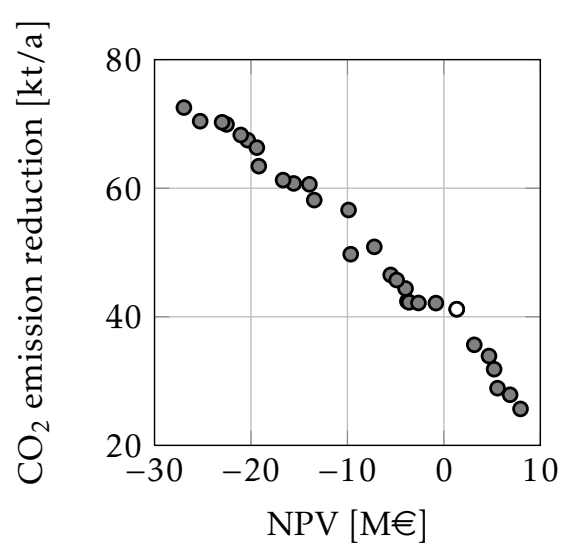

(b)

Figure 5.8: Performance indicators of the non-dominated solutions in the Renewable Self-sufficiency scenario. The chosen solution is marked white. (Rural region)

solutions are not per se optimal.

\section{Renewable Self-sufficiency}

In Figure 5.12, the performance indicators of the non-dominated solutions are shown for the Renewable Self-sufficiency scenario. Since there is again not much difference in net energy production and $\mathrm{CO}_{2}$ emission reduction, we chose the solution with the highest NPV. Its design is shown in Figure 5.13. All biomass, including the biomass from the biomass centers, is used. Due to the increase in biomethane production, and the decrease in hourly gas demand, storage of gas is needed in this solution. Hence the DST added five gas storages to this region. In addition, the gas grids into which biomethane is injected, but no gas storage is connected, apply line-pack for buffering. Furthermore, this design has 17 biomethane producers, which is by far the highest of all design discussed in this chapter. This high number is in part caused by the number of gas grids to which biomethane can be injected. By injecting the biomethane into a larger number of gas distribution grids, the hourly gas demand of more grids is available to consume the produced biomethane, and as a consequence less biomethane needs to be stored. 


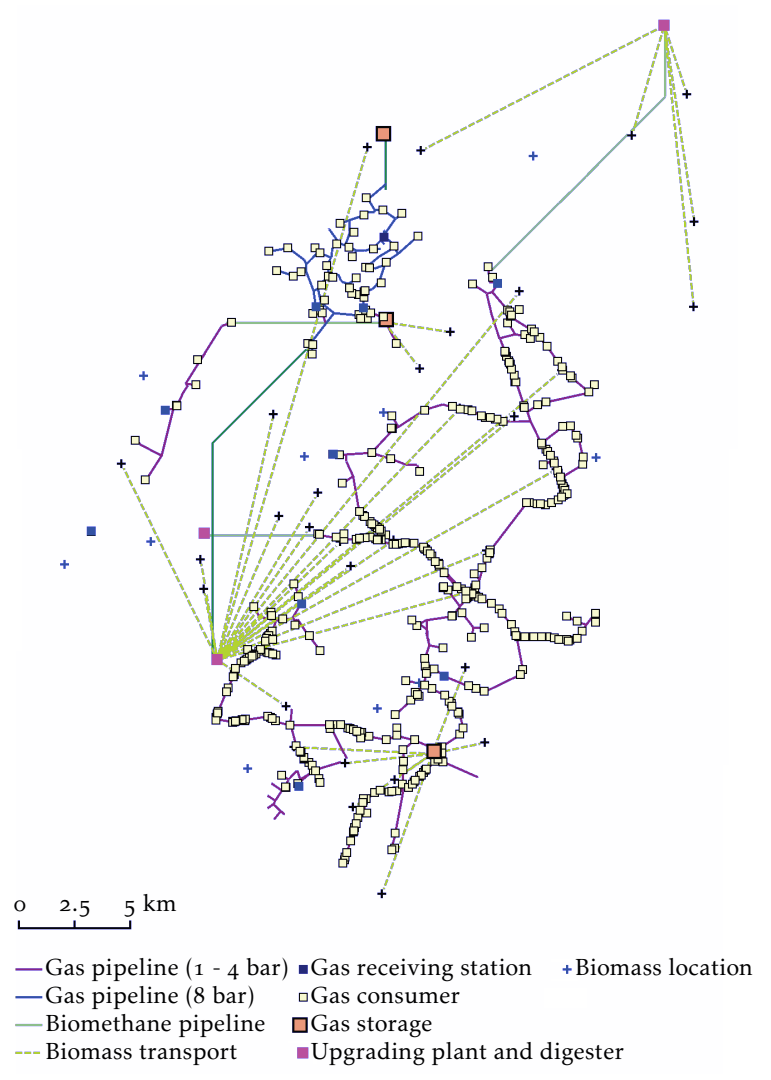

Figure 5.9: Design of the chosen solution in the Renewable Self-sufficiency scenario. (Rural region)

\subsubsection{Urban region}

\section{Business as Usual}

Just as for the other two regions, none of the generated solutions had a positive NPV in the Business as Usual scenario. So, again the gas distribution infrastructure stays as it is.

\section{Carbon Constraints}

The NPV and $\mathrm{CO}_{2}$ emission reduction of the non-dominated solutions in the Carbon Constraints scenario are shown in Figure 5.14. Ten solutions have a positive NPV. Apart from the solution with the highest NPV, there is not much difference in $\mathrm{CO}_{2}$ emission reduction performance among the solutions. From the $\mathrm{CO}_{2}$ emission reduction plateau, we chose the one with the highest NPV, since other 


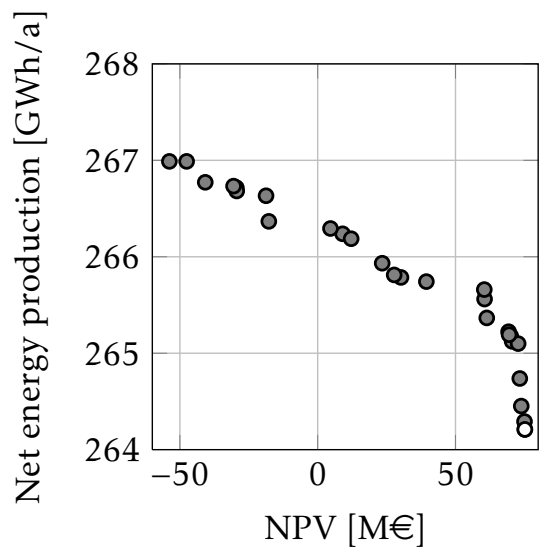

Figure 5.10: Performance indicators of the non-dominated solutions in the Tight Market scenario. The chosen solution is marked white. (Intermediate region)

solutions do not result in a significant improvement of $\mathrm{CO}_{2}$ emission reduction, but do result in a significant lower NPV. Its design, shown in Figure 5.15, has one local digester installation, and one central digester installation to which biomass is transported from the other locations. In contrast to the rural region, all biomass is used in this scenario and only line-pack is applied to buffer the biomethane. This is a result of higher hourly gas demand and lower biomass availability compared to the rural region.

\section{Tight Market}

The design of the preferred solution in the Tight Market scenario is quite similar to the solution in the Carbon Constraints scenario. It also has one central digester installation and one local digester installation. The central digester installation is located at the same site and digests biomass from the same number of biomass locations as in the Carbon Constraints scenario. Biomethane production is also equal.

\section{Renewable Self-sufficiency}

In the solution chosen for the Renewable Self-sufficiency scenario, again all biomass, including the biomass center, is used. Just as the previous two designs that were mentioned, this design is also typified by central digestion, on-site upgrading, and only line-pack for buffering.

Table 5.5 lists the performance indicators of the solutions whose design was shown in this chapter. This table and the other results presented in this section 


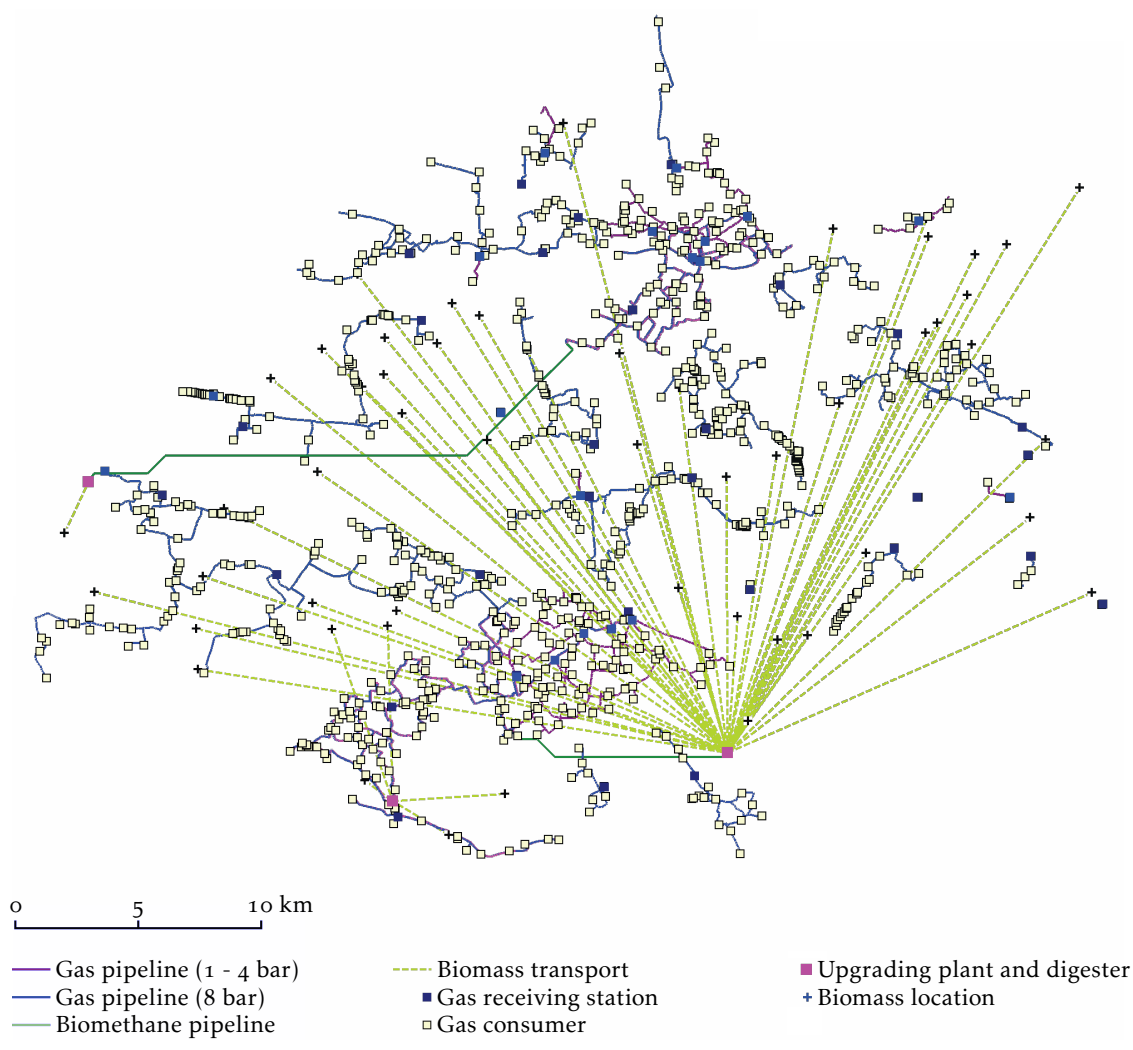

Figure 5.11: Design of the chosen solution in the Tight Market scenario. (Intermediate region)

are discussed in more detail in the next section.

\section{$5 \cdot 3$ Discussion}

Regardless of the scenario, the solutions with the highest NPV favor large central digester installations with on-site upgrading plants. This is due to the advantage of scale with digester installations and upgrading plants in relation with relatively low transport costs. Furthermore, in none of the chosen solutions there were pipelines that transport biogas. Also, there were hardly any local digester installations.

When looking at biomethane share in Table 5.5, the rural region had the highest biomethane share of the three regions, namely $24 \%$ in the Carbon Constraints scenario, $28 \%$ in the Tight Market scenario, and $50 \%$ in the Renewable Self-sufficiency 


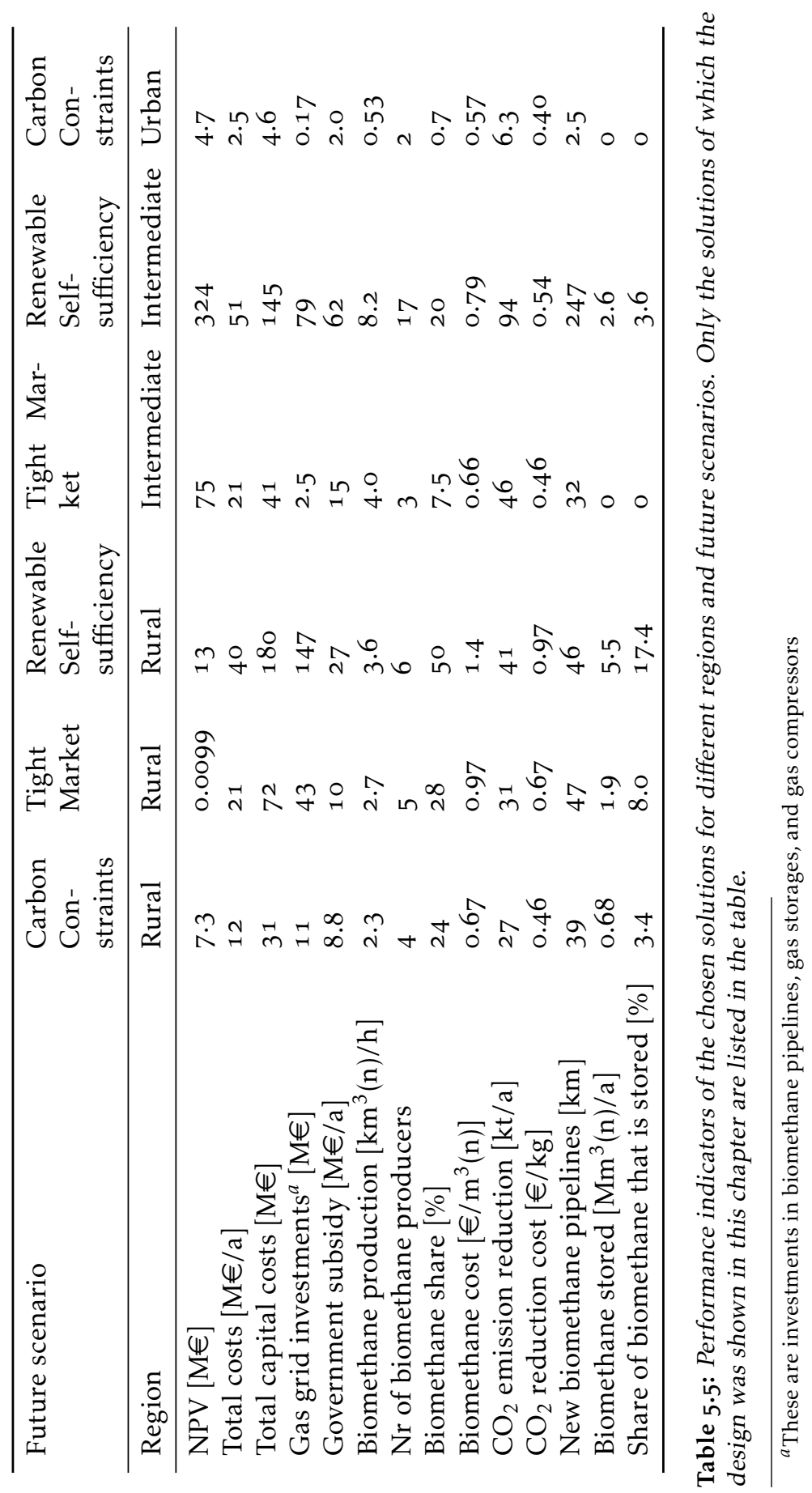




\section{Chapter 5 Design of the gas distribution infrastructure in the future scenarios}

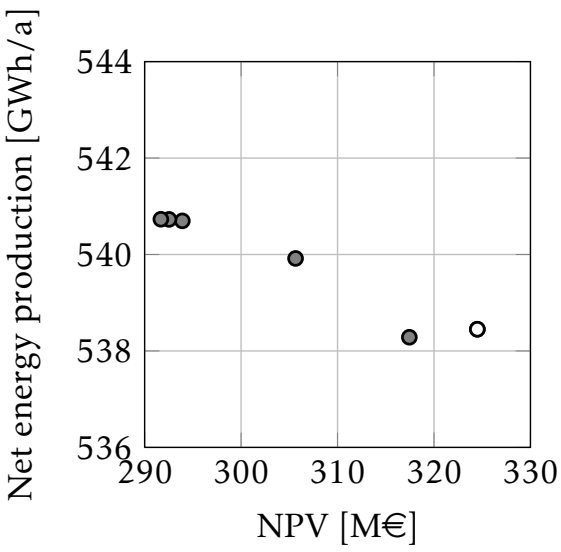

(a)

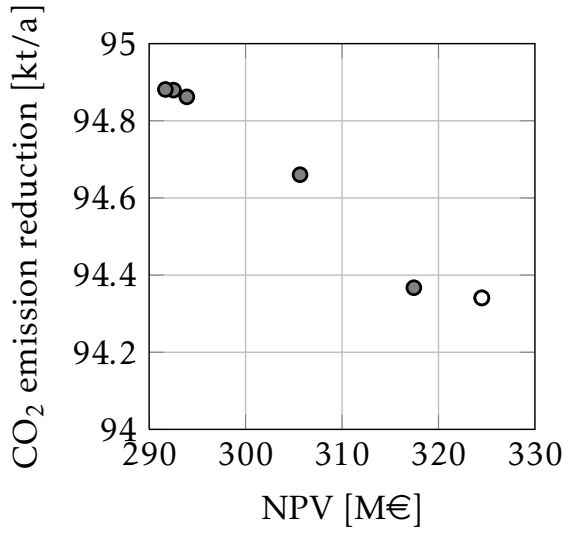

(b)

Figure 5.12: Performance indicators of the non-dominated solutions in the Renewable Self-sufficiency scenario. The chosen solution is marked white. (Intermediate region)

scenario. As can be seen in Table 5.5, biomethane cost rises with an increase in biomethane share. This is in part due to an increase in gas storage costs. Another explanation for the increase are the higher electricity and fuel prices in the Tight Market and Renewable Self-sufficiency scenarios.

For the intermediate region, the biomethane share in the Carbon Constraints and Tight Market scenario is about $7.5 \%$, and $20 \%$ for the Renewable Self-sufficiency scenario. Only in the latter scenario, gas storage is needed. This is reflected in the biomethane cost, which is $11 €$ ct higher than in the Tight Market scenario.

The urban region has by far the lowest biomethane share, not exceeding $1.9 \%$. The hourly gas demand was always sufficient to consume the biomethane and only line-pack was required to guarantee sufficient hourly gas demand throughout the year. This is in contrast with the rural region, where the combination of high biomass availability and low hourly gas demand made that not all biomass can be used without storage of gas. In none of the solutions chosen for the rural region was all biomass used. The surplus biomass will not necessarily be unused, since it can also be used for the production of electricity, heat, or transport fuel see also section 1.3. Furthermore, for the rural region, storage of gas was needed in all scenarios, except for the Business as Usual scenario. For the intermediate region, gas storage was only needed in the Renewable Self-sufficiency scenario.

Table 5.5 shows that the share of total capital cost that is invested in the gas grid varies strongly. It varies from only $4 \%$ for the urban region in the Carbon Constraints scenario, to $82 \%$ for the rural region in the Renewable Self-sufficiency scenario. This share rises strongly when gas storages are added to the gas infras- 


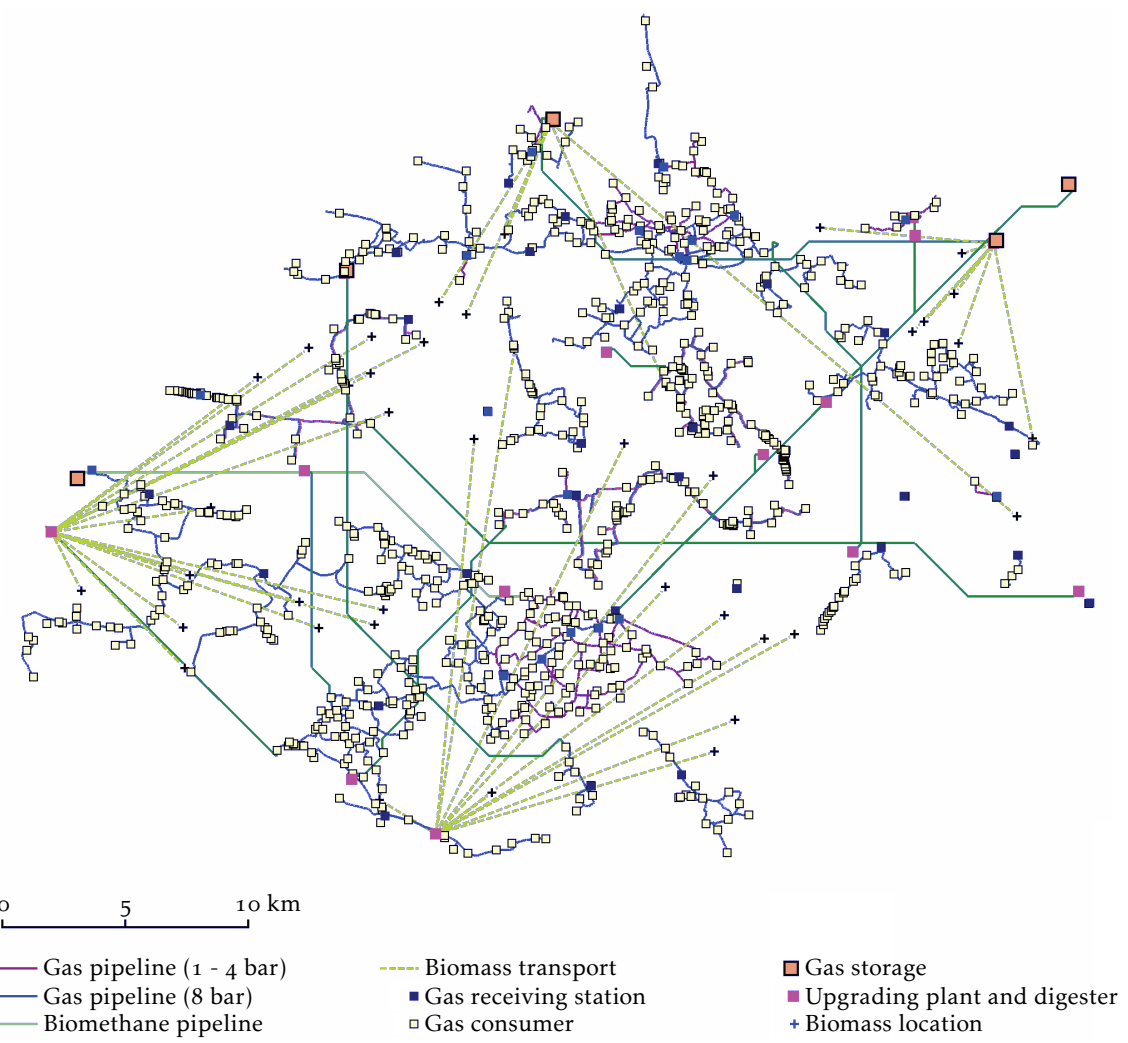

Figure 5.13: Design of the chosen solution in the Renewable Self-sufficiency scenario. (Intermediate region)

tructure. To be specific, the share of total capital cost invested in the gas grid in the two solutions with no gas storage ranges from $4 \%$ to $6 \%$, while for the four solutions with gas storage the share ranges from $35 \%$ to $82 \%$.

Furthermore, once utilization of all biomass resulted in a positive NPV, there was not much to choose from a $\mathrm{CO}_{2}$ emission reduction and net energy production point of view. Leaving the user of the DST not much choice but to pick the solution with the highest NPV. However, if the user of the DST uses a different set of building blocks - for instance multiple types of upgrading plants, instead of only water washers - this will probably be different. 


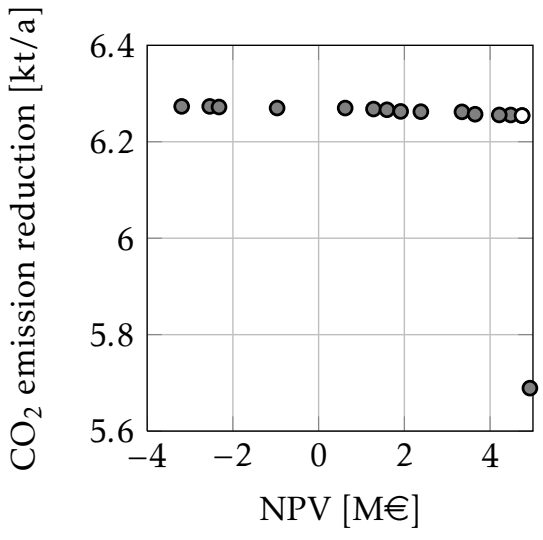

Figure 5.14: Performance indicators of the non-dominated solutions in the Carbon Constraints scenario. The chosen solution is marked white. (Urban region)
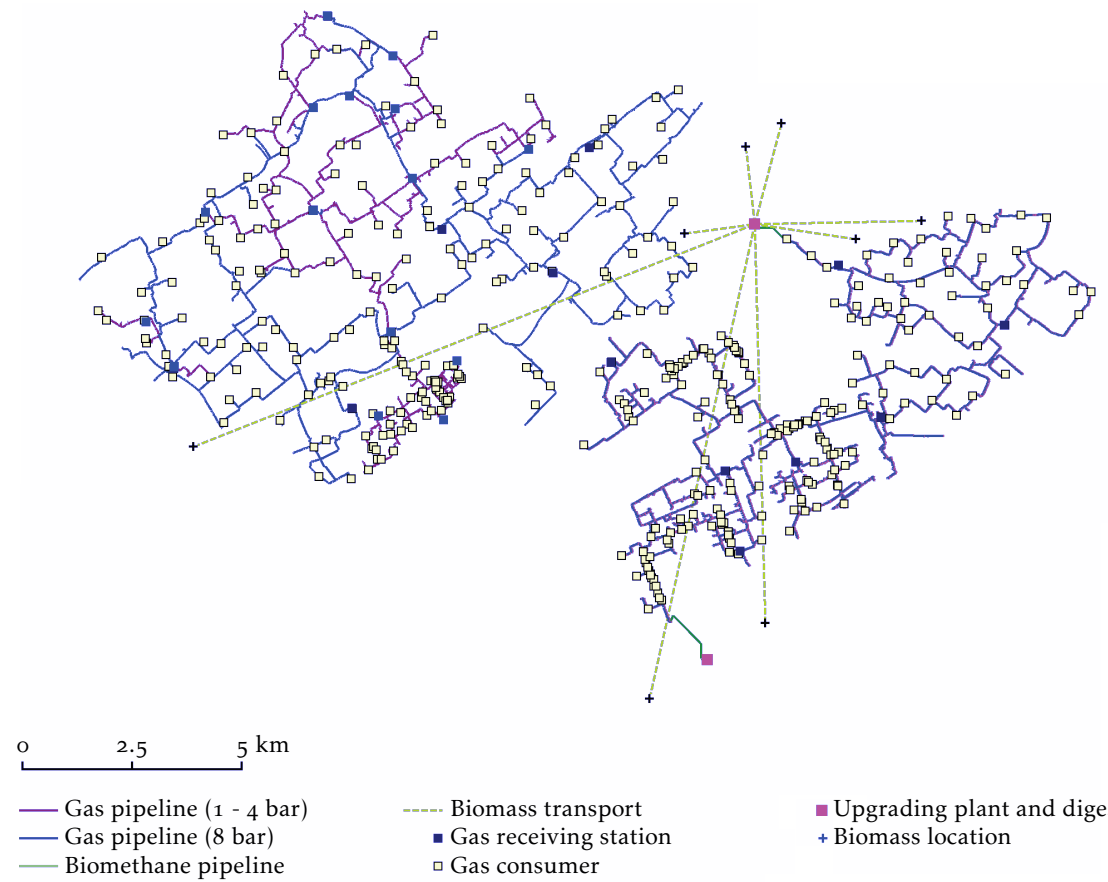

n Upgrading plant and digester + Biomass location

Figure 5.15: Design of the chosen solution in the Carbon Constraints scenario. (Urban region) 


\section{$5 \cdot 4$ Conclusions}

For three different regions in the Netherlands, the design of the biomethane supply chain was determined for four different future energy scenarios.

It was found that in rural regions, DSOs might have to invest in balancing measures. In this research, this meant most of the time that gas storages had to be installed. But they could also choose to compress the surplus biomethane to the RTL grid to buffer the gas there. DSOs operating in intermediate areas are less likely to have to invest in balancing measures, and for DSOs operating in urban areas it is not likely at all.

It was also found that in the rural region, not all biomass will be used, even in the future scenario that has the highest incentive to utilize all biomass. This means that the Dutch biomethane potential of $2 \mathrm{Gm}^{3}(\mathrm{n}) / \mathrm{a}\left(\right.$ or $4 \mathrm{Gm}^{3}(\mathrm{n}) / \mathrm{a}$ in the Renewable Self-sufficiency scenario) might not be achieved due to limited hourly gas demand in regions with a high availability of biomass.

If biomass transport is allowed, large central digester installations with an on-site upgrading plant proved to be the most economic way to produce biomethane. Biogas pipelines did not show up in any of the chosen solutions. Also, local digester installations with an on-site upgrading plant were hardly present in the chosen solutions.

In the Business as Usual scenario there was no biomethane production for any region. So, biomethane will not be produced without subsidy.

The findings in this chapter are of course very dependent on the defined values for cost and energy use of the different components in the model. These values might differ from the current situation, or from the estimated values for the future situation, and result in different types of design. In addition, a different trade-off between the performance indicators, made by the user of the DST, will result in a different design as well. Therefore, the next chapter describes a sensitivity analysis, in order to see how the performance and design of the preferred solutions are affected by the modeling assumptions and the trade-off made by the user of the DST.

When looking at the usefulness of the DST, one of the aims of this chapter, the DST has shown to be able to handle large areas. In general, the DST gave sensible results for the three regions. There were, however, some minor optimizations that might be made.

The intermediate region was the most challenging for the DST. This region has the largest number of biomass locations and largest number of gas grids to which biomethane can be injected, which resulted in a large solution space. The eventual "best" solution found for this region can be further improved. To further optimize the solutions, more calculation time should be allowed, or the number of biomass locations and gas grids should be reduced in order to reduce the size of the solution space, or an improved algorithm should be implemented 
to better deal with large numbers of biomass locations and gas grids.

Furthermore, the preparation time for the start configurations was around two days per region. Whether this is acceptable or not is something of concern if the DST is valorized (see Chapter 7). 


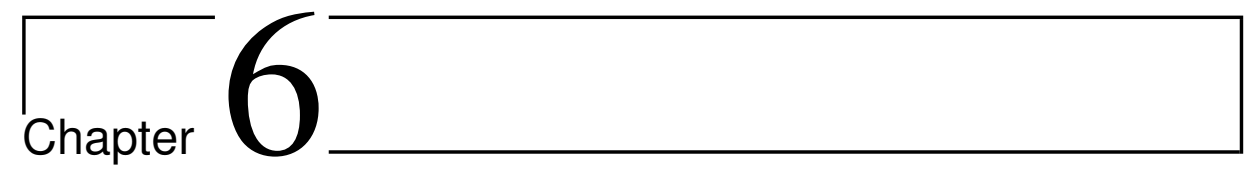

\section{Sensitivity analysis}

In the previous chapter, for each scenario one solution was selected from a set of non-dominated solutions. This choice was made considering two aspects: (1) the solutions' performance indicators and (2) the trade-off that we made between these performance indicators. The values of the performance indicators depend on the values that were determined for the parameters of the model, see Chapter 3. In this sense, different parameter values will lead to different values for the performance indicators. Furthermore, if a different trade-off would be made between the performance indicators, this would result in a different design. So a change in parameter value or a change in the trade-off that a user makes will have an impact on the eventual design and its performance indicators. To assess this impact, in this chapter an analysis is presented that determined how sensitive the solutions of the model are to these two aspects.

Thus, the contribution of this chapter is firstly, determining the sensitivity of the performance indicators of a design to changes in the parameter values. Secondly, it was assessed how the choice made by the user of the DST affects the design of the biomethane supply chain. This chapter forms the second part of descriptive study II.

This chapter is outlined as follows. In section 6.1, the analysis is presented that varied the values of the model's parameters to see how this affects the performance indicators for three typical designs. Section 6.2 describes the analysis that determined to what extent the design changes when choosing a different solution. Finally, section 6.3 draws conclusions on the performed analysis. 


\subsection{Varying input values of the model}

In Chapter 5, for all future scenarios a solution was chosen that was characterized by central digestion of biomass and on-site upgrading of biogas. This type of design came out as the preferred solution based on the values of the parameters in the model. If these values would change, the chosen design might no longer be the preferred option. This would have significant consequences for the eventual investment decisions. Therefore, in this section it is determined how sensitive the performance indicators of several typical designs are to changes in the parameter values of the model. Three designs were examined that can be considered "extreme" types of designs for the biomethane supply chain: (1) a design characterized by central digestion and on-site upgrading of biogas, which is quite similar to the designs found in the previous chapter; (2) a design characterized by local digestion and on-site upgrading; and (3) a design characterized by local digestion and central upgrading.

This section is outlined as follows. Subsection 6.1.1 describes the performance metrics used for the sensitivity analysis. Next, in 6.1.2, the factors that were varied are given. Then, in 6.1.3 the three designs that were analyzed are described. The method for the sensitivity analysis is explained in 6.1.4, and finally, in 6.1.5, the results of the analysis are presented and discussed.

\subsubsection{Performance indicators}

In this sensitivity analysis, the performance of a design was determined by the following two performance indicators:

- $\mathrm{NPV}[€]$

- Biomethane cost $\left[€ / \mathrm{m}^{3}(\mathrm{n})\right]$

In Chapter 5 , also net energy production and yearly $\mathrm{CO}_{2}$ emission reduction were used as performance indicators. However, the factors that were varied in the analysis in this section (except one factor) do not affect these two performance indicators and were, therefore, not investigated. Furthermore, we assumed that the factors that influence $\mathrm{CO}_{2}$ emission reduction (such as the values for the $\mathrm{CO}_{2}$ emission of natural gas and transport fuel) will not change much in reality. In addition, we assumed that the energy use of the different components (for instance, gas compressors and upgrading plants) will probably not change much either. Hence, the factors that influence the $\mathrm{CO}_{2}$ emission reduction and net energy production were not varied in this sensitivity analysis.

\subsubsection{Factors}

Table 6.1 lists all the factors that have been varied, including their nominal, low, and high value. The variation of each factor is symmetrical, and the absolute 
value of the variation was determined by evaluating what a realistic variation would be. Therefore, in terms of percentage, the variation of the factor values was not the same for all factors.

When the economic life of the project (factor $\mathrm{C}$ ) was varied, the biomethane subsidy period was changed accordingly. Furthermore, in Table 6.1, the values for factors $D, G, H$, and I indicate the relative change of the underlying costs. Varying the pipeline costs (D), means that both material and laying costs are varied. Furthermore, the cost of biomass transport $(\mathrm{G})$ consists of flat kilometer cost, loading/unloading cost, and transport fuel cost. Finally, when varying the digester installation costs $(\mathrm{H})$ (or upgrading plant costs $(\mathrm{I})$ ), the capital and operational costs of the different digester installations (or upgrading plants) are varied relative to their nominal values.

In Appendix B, the chosen factors and their values are described in more detail.

\subsubsection{Biomethane supply chain design types}

For the sensitivity analysis, the start configurations of the intermediate and urban region, presented in Chapter 5, were used. The results for the urban region are discussed in this chapter, while the results for the intermediate region are discussed in Appendix B.

In this analysis, we were interested in the economic performance of different design types, which differ from each other with regard to whether the biomass is digested locally or centrally, and whether the biogas is upgraded locally or centrally. Since any required balancing measures (for example a gas storage) would distort this economic comparison, we did not regard these measures. This is the reason that the sensitivity analysis has not been performed on the rural region. Due to the high biomass availability and low gas demand in this region, balanc-

\begin{tabular}{lllll}
\hline & Factor & $\begin{array}{l}\text { Nominal } \\
\text { value }\end{array}$ & $\begin{array}{l}\text { Low } \\
\text { value }\end{array}$ & $\begin{array}{l}\text { High } \\
\text { value }\end{array}$ \\
\hline A & Biomass cost $[€ \mathrm{ct} / \mathrm{kg}]$ & 3.1 & 1.5 & 4.5 \\
$\mathrm{~B}$ & Biogas yield $\left[\mathrm{m}^{3}(\mathrm{n}) / \mathrm{kg}\right]$ & 0.16 & 0.08 & 0.24 \\
$\mathrm{C}$ & Economic life of project [years] & 12 & 9 & 15 \\
$\mathrm{D}$ & Pipeline costs & 1 & 0.8 & 1.2 \\
E & Natural gas price + subsidy [€ct $\left./ \mathrm{m}^{3}(\mathrm{n})\right]$ & 72 & 64.8 & 79.2 \\
$\mathrm{~F}$ & Electricity price [€ct $/ \mathrm{kWh}]$ & 7 & 5 & 9 \\
$\mathrm{G}$ & Biomass transport costs & 1 & 0.8 & 1.2 \\
$\mathrm{H}$ & Digester installation costs & 1 & 0.8 & 1.2 \\
$\mathrm{I}$ & Upgrading plant costs & 1 & 0.8 & 1.2 \\
\hline
\end{tabular}

Table 6.1: Factors that were varied and their nominal, low, and high value 
ing measures would be required.

Figure 5.4 shows the start configuration for the urban region. The biomass availability is similar to the nominal situation in Chapter 5 - see subsection 5.1.1. The three design types that were used for the sensitivity analysis are:

1. The Local for local design, which is characterized by local digestion of biomass and local upgrading of biogas. The Local for local design is shown in Figure 6.1.

2. The Biogas hub design, which is characterized by local digestion of biomass and central upgrading of biogas. Biogas pipelines are needed in this design to transport biogas from one or more digester installations to a central upgrading plant. The Biogas hub design is shown in Figure 6.2.

3. The Biomass transport design, which is characterized by central digestion of biomass and central upgrading of biogas. In this design, biomass is transported from several biomass locations to a central digester installation. The Biomass transport design is shown in Figure 6.3.

All three designs, have a total biomethane production of $529 \mathrm{~m}^{3}(\mathrm{n}) / \mathrm{h}$. Furthermore, the performance indicators of the three designs in the nominal situation are given in Table 6.2. As can be seen, in the nominal situation, the Biomass transport design has the highest NPV as well as lowest biomethane cost, the Biogas hub design ranks second, and the Local for local design scores worst.

Table 6.3 shows the breakdown of the biomethane costs for each design. It can be seen that biomass costs and digestion costs contribute significantly to the biomethane costs of all three designs. Furthermore, upgrading costs for the Biomass transport design is only a third of the upgrading costs for the Local for local design. It can also be seen that biomass transport costs only makes a minor contribution to the biomethane costs of the Biomass transport design. Finally, the Biomass transport design has the lowest operational cost as well as the lowest capital cost.

\subsubsection{Method}

In the sensitivity analysis, we wanted to determine how the performance indicators are affected when the values of the factors, defined in 6.1.2, are varied. This

\begin{tabular}{llll}
\hline & Local for local & Biogas hub & Biomass transport \\
\hline NPV $[\mathrm{M} €]$ & -11.7 & -7.3 & 1.0 \\
Biomethane cost $\left[€ / \mathrm{m}^{3}(\mathrm{n})\right]$ & 1.08 & 0.95 & 0.69 \\
\hline
\end{tabular}

Table 6.2: Performance indicators for the design types with nominal values. (Urban region) 

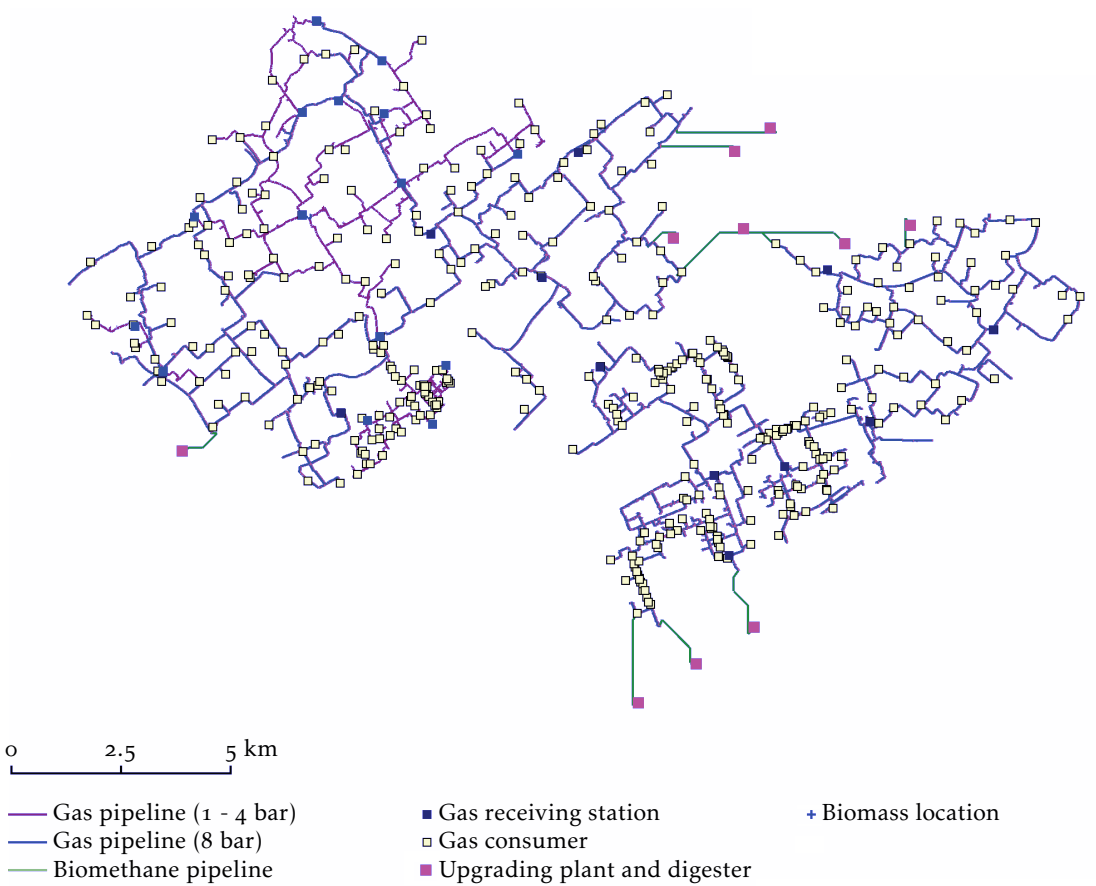

- Gas receiving station

$\square$ Gas consumer

- Upgrading plant and digester

+ Biomass location

Figure 6.1: The Local for local design is characterized by local digestion and local upgrading. (Urban region)

\begin{tabular}{llll}
\hline & Local for local & Biogas hub & Biomass transport \\
\hline Biomass & 32.9 & 32.9 & 32.9 \\
Biomass transport & $\mathrm{O}$ & $\mathrm{O}$ & 1.3 \\
Digestion & 33.8 & 33.8 & 23.3 \\
Biogas treatment & $\mathrm{O}$ & 2.2 & $\mathrm{O}$ \\
Biogas compression & $\mathrm{O}$ & 3.9 & $\mathrm{O}$ \\
Biogas pipelines & $\mathrm{O}$ & $7 \cdot 7$ & $\mathrm{O}$ \\
Upgrading & 31.5 & 12.6 & 10.5 \\
Injection & 5.6 & 1.1 & 0.6 \\
Biomethane pipelines & 4.4 & 0.5 & 0.2 \\
\hline Capital cost & 49.2 & 39.6 & 22.4 \\
Operational cost & 59.0 & 55.2 & 46.4 \\
\hline Total & 108.3 & 94.8 & 68.9 \\
\hline
\end{tabular}

Table 6.3: Breakdown of the biomethane costs for the three biomethane supply chain designs $\left[€ c t / \mathrm{m}^{3}(\mathrm{n})\right]$. (Urban region) 

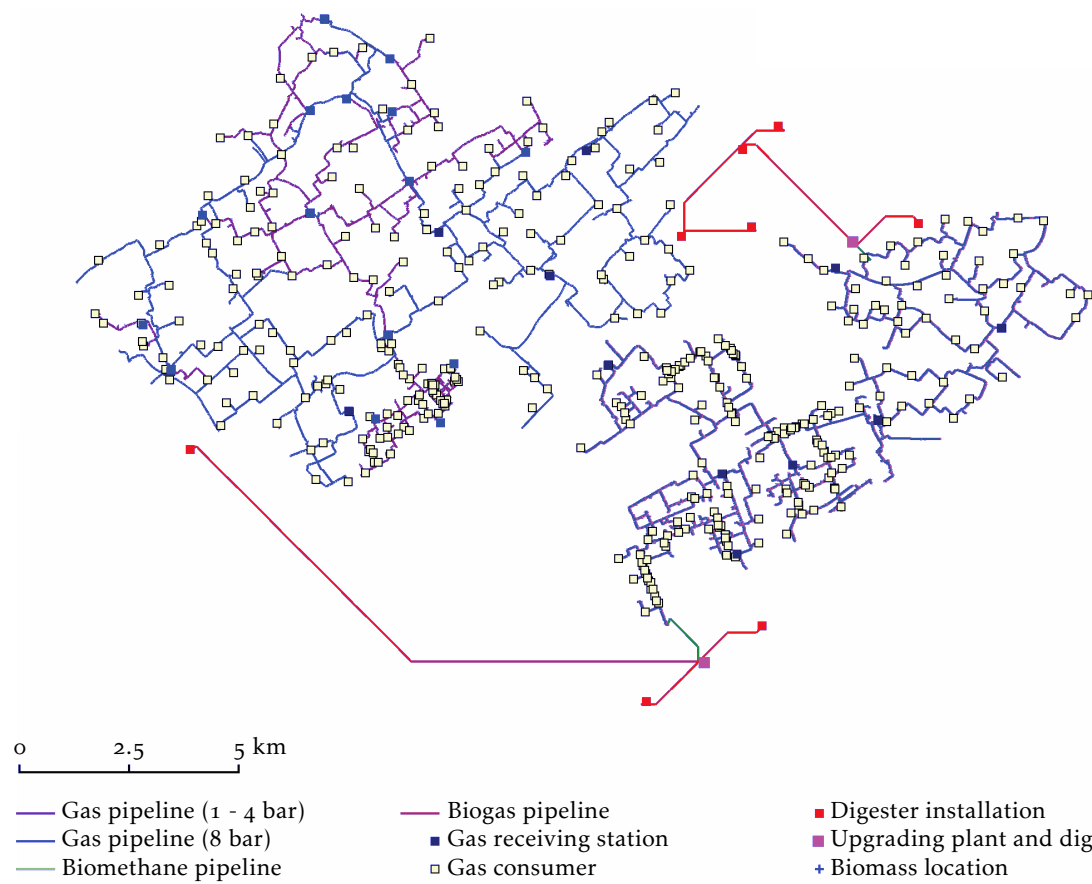

- Digester installation

- Upgrading plant and digester

+ Biomass location

Figure 6.2: The Biogas hub design is characterized by local digestion and central upgrading. Pipelines transport biogas from local digester installations to several central upgrading plants. (Urban region)

was done by adjusting the value of one factor to their high or low value, defined in Table 6.1, while keeping the other factors at their nominal values.

In addition, where possible, we determined the factor value for which the NPV or biomethane cost of two designs are equal. For example, we determined for which value of biomass transport costs, the NPV of the Biomass transport and Biogas hub design are equal.

In the following subsection the results of the experiments are described.

\subsubsection{Results and discussion}

For the high and low value of each factor, the NPV and biomethane cost were determined for the 3 typical designs. The NPV values for these three designs are listed in Table 6.4 and are graphically displayed in Figure 6.4. The biomethane costs are listed in Table 6.5 and are graphically displayed in Figure 6.5. 

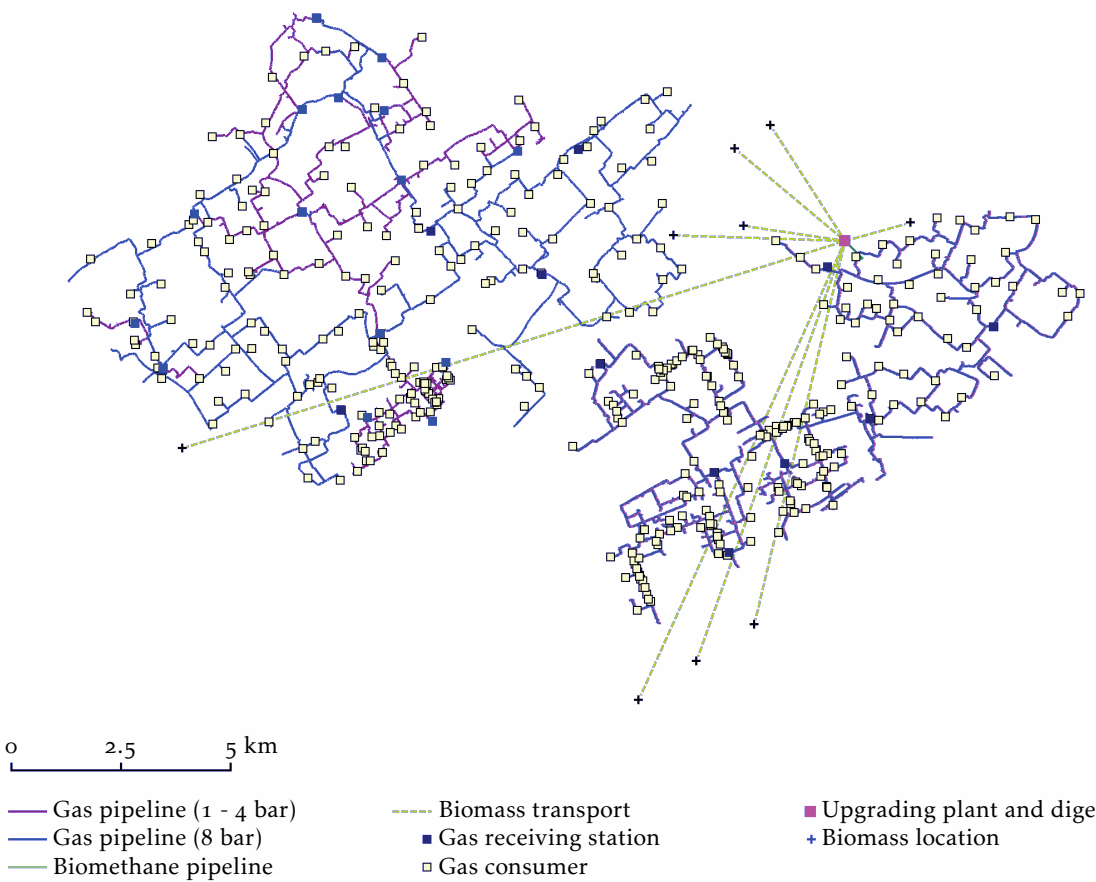

Biomass transport

- Gas receiving station

$\square$ Gas consumer - Upgrading plant and digester
+ Biomass location

Figure 6.3: The Biomass transport design is characterized by central digestion and central upgrading. Trucks transport biomass to the central digester installations. (Urban region)

\begin{tabular}{llllllll}
\hline Factor & \multicolumn{2}{c}{ Local for local } & \multicolumn{2}{c}{ Biogas hub } & \multicolumn{2}{c}{ Biomass } \\
& & low & high & low & high & low & high \\
\hline A & Biomass cost & -6.2 & -16.5 & -1.9 & -12.1 & 6.5 & -3.8 \\
B & Biomass yield & -21.7 & -5.7 & -16.6 & -1.1 & -5.6 & 9.0 \\
C & Economic life of project & -12.4 & -11.1 & -8.3 & -6.6 & -0.4 & 2.1 \\
D & Pipeline costs & -11.4 & -12.0 & -6.8 & -7.9 & 1.0 & 1.0 \\
E & Gas retail price \& subsidy & -14.0 & -9.4 & -9.7 & -5.0 & -1.3 & 3.3 \\
F & Electricity price & -11.3 & -12.1 & -6.9 & -7.8 & 1.4 & 0.6 \\
G & Biomass transport costs & -11.7 & -11.7 & -7.3 & -7.3 & 1.1 & 0.9 \\
H & Digester installation costs & -9.6 & -13.8 & -5.2 & -9.4 & 2.4 & -0.4 \\
I & Upgrading plant costs & -9.8 & -13.5 & -6.7 & -8.0 & 1.5 & 0.5 \\
\hline
\end{tabular}

Table 6.4: NPV [M€] of the 3 designs for the high and low values of the factors. (Urban region) 


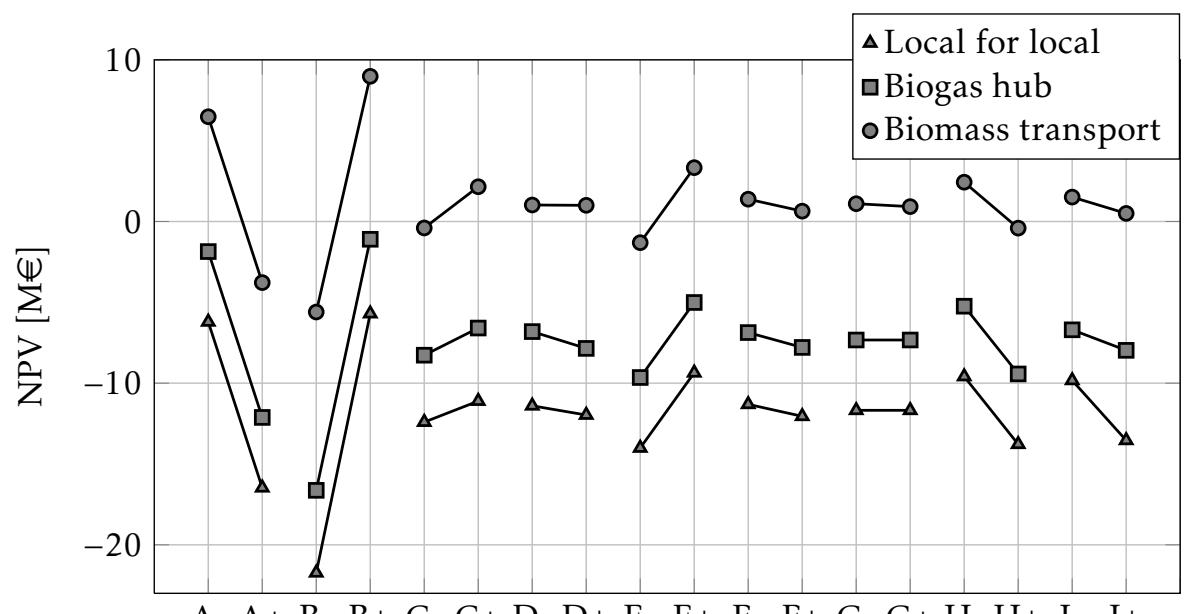

A- A+B- B+C-C+D-D+E- E+ F- F+ G- G+ H- H+ I- I+

Figure 6.4: NPV for the low and high values of the factors. (Urban region)

\begin{tabular}{llcccccc}
\hline Factor & \multicolumn{3}{c}{ Local for local } & \multicolumn{2}{c}{ Biogas hub } & \multicolumn{2}{c}{ Biomass } \\
& & low & high & low & high & low & high \\
\hline A & Biomass cost & 0.91 & 1.23 & 0.78 & 1.10 & 0.52 & 0.84 \\
B & Biomass yield & 2.07 & 0.84 & 1.75 & 0.74 & 1.07 & 0.53 \\
C & Economic life of project & 1.19 & 1.02 & 1.03 & 0.90 & 0.74 & 0.66 \\
D & Pipeline costs & 1.07 & 1.09 & 0.93 & 0.96 & 0.69 & 0.69 \\
E & Gas retail price \& subsidy & 1.08 & 1.08 & 0.95 & 0.95 & 0.69 & 0.69 \\
F & Electricity price & 1.07 & 1.09 & 0.93 & 0.96 & 0.68 & 0.70 \\
G & Biomass transport costs & 1.08 & 1.08 & 0.95 & 0.95 & 0.69 & 0.69 \\
H & Digester installation costs & 1.02 & 1.15 & 0.88 & 1.01 & 0.64 & 0.73 \\
I & Upgrading plant costs & 1.03 & 1.14 & 0.93 & 0.97 & 0.67 & 0.70 \\
\hline
\end{tabular}

Table 6.5: Biomethane cost $\left[€ / \mathrm{m}^{3}(\mathrm{n})\right]$ of the 3 designs for the high and low values of the factors. (Urban region) 


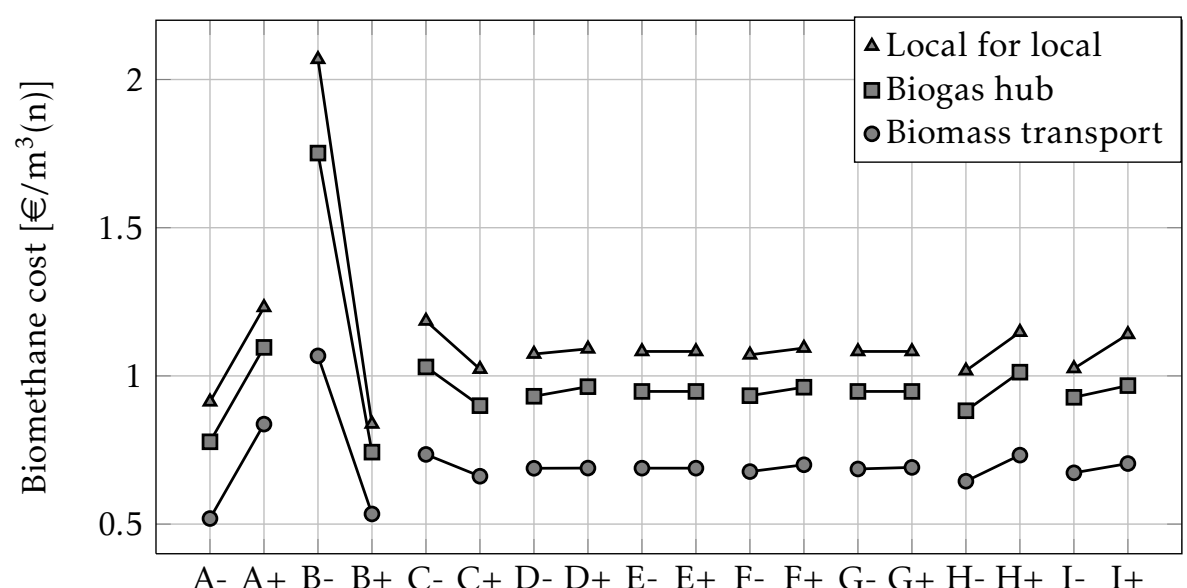

Figure 6.5: Biomethane cost for the low and high values of the factors. (Urban region)

\section{Biomass cost (A)}

As can be seen in Figure 6.4 and Figure 6.5, varying the biomass cost strongly varies the NPV and biomethane cost of the 3 designs. The high value of the biomass cost results in a negative NPV for the Biomass transport design. The NPV of the Local for local and Biogas hub design is negative for both values of the biomass cost.

In Table 6.3, it can be seen that all three designs make the same costs for biomass $\left(32.9 € \mathrm{ct} / \mathrm{m}^{3}(\mathrm{n})\right)$. When changing the value of the biomass cost factor, the cost incurred for biomass changes, but there is still no difference in biomass cost between the three designs. Therefore, a change in biomass cost will not result in a different hierarchy of the designs based on NPV or biomethane costs.

\section{Biogas yield (B)}

Increasing (or decreasing) the biogas yield results in a higher (or lower) biogas and biomethane production. As can be seen, biogas yield has a large impact on NPV and biomethane cost. Especially, the Local for local design benefits from an increase in biogas yield. Due to the small size of the local upgrading plants, the Local for local design benefits more from an increase in scale than the Biogas hub design and Biomass transport design. The upgrading plants of the latter two designs were already larger; hence, less gain in price can be achieved by increasing the size of the upgrading plant. Similarly, due to the small size of the digester installations in the Local for local and Biogas hub design, these designs gain more from an increase in biogas yield than the Biomass transport design, which has one large digester.

The smallest digester installation is the one with an output of $100 \mathrm{~m}^{3}(\mathrm{n}) / \mathrm{h}$, 
which leads to a disadvantage for the Local for local and Biogas hub design. That is, if due to a decreasing biogas yield, the biogas production drops significantly below this $100 \mathrm{~m}^{3}(\mathrm{n}) / \mathrm{h}$, the digester installation will be underutilized. This is of course very uneconomic, since with underutilization the total cost for digestion hardly decreases. For the central digester installation, in the Biomass transport design, this is only to a lesser extent the case.

\section{Economic life of project $(C)$}

Increasing the economic life of the project, slightly increases the NPV of the three designs. This makes sense, since investments can be depreciated over a longer period. Furthermore, an economic life of nine years results in a negative NPV for the Biomass transport design.

Since the Biomass transport design has both the lowest operational cost as well as the lowest capital cost, its NPV remains the highest of the three designs, regardless of economic life. The Biogas hub design's operational and capital cost are lower than the Local for local design's. Therefore, regardless of the economic life of the project, the NPV of the Biogas hub design will be higher than the NPV of the Local for local design.

\section{Pipeline costs (D)}

The NPV of the Local for local and Biogas hub designs slightly decreases when increasing the pipeline costs. The Biomass transport design's NPV does not change. For the Biomass transport design, this stems from the small total length of pipelines; it only has one short pipeline.

An increase in pipeline costs, reduces the gap in NPV between the Local for local and Biogas hub design. However, in order to make their NPVs equal, the pipeline costs would have to increase with a factor 4.6 , which is not very likely.

\section{Natural gas price \& subsidy (E)}

Increasing the natural gas price and biomethane subsidy results in a higher NPV. The impact on the NPV is similar for the three designs.

The NPV of the Local for local and Biogas hub design will become positive when the subsidy would increase to $83.6 € \mathrm{ct} / \mathrm{m}^{3}(\mathrm{n})$ and $70.1 € \mathrm{ct} / \mathrm{m}^{3}(\mathrm{n}) \mathrm{respec}-$ tively.

\section{Electricity price $(\mathrm{F})$}

Increasing the electricity price results in a lower NPV and higher biomethane cost. The increase from $7 € \mathrm{ct} / \mathrm{kWh}$ to $9 € \mathrm{ct} / \mathrm{kWh}$ slightly reduces the gap in NPV between the Local for local design and the Biogas hub design. 


\section{Biomass transport costs $(\mathrm{G})$}

Since no biomass transport takes place in the Local for local and Biogas hub designs, varying the transport costs has no effect on their NPVs and biomethane cost. Surprisingly, the NPV and biomethane cost of the Biomass transport design are also hardly affected by a change in transport costs. This is caused by the low costs of biomass transport; in the nominal situation, biomass transport constitutes only $1.9 \%$ of the biomethane cost.

Furthermore, for the Biogas hub design's NPV to be higher than the Biomass transport design's NPV would require an increase in biomass transport costs of a factor 22. For the Local for local design this number is even higher, namely 30.

\section{Digester installation costs $(\mathrm{H})$ and upgrading plant costs (I)}

Increasing digester installation costs and upgrading plant costs results in a lower NPV and higher biomethane cost. Varying digester installation costs, results in a difference in biomethane cost of 13 €ct for the Local for local design and Biogas hub design. For the Biomass transport design, the difference is only $9 €$ ct. This is due to a difference in size of the digester installations. All three designs have to digest the same amount of biomass, but the digester installations in the Local for local and Biogas hub design are much smaller than the central digester installation in the Biomass transport design. Hence, the cost for digestion is much higher in the first two designs $\left(33.8 € \mathrm{ct} / \mathrm{m}^{3}(\mathrm{n})\right)$ than for the Biomass transport design $\left(23.3 € \mathrm{ct} / \mathrm{m}^{3}(\mathrm{n})\right)$. Therefore, changing the digester installation costs will have a larger effect on the biomethane cost and NPV of the Local for local and Biogas hub design than on the Biomass transport design.

Similarly, changing upgrading plant costs has a large impact on the Local for local design (which has several small local upgrading plants); it results in a difference in biomethane cost of $11 €$ ct. While the impact on biomethane cost of the Biogas hub and Biomass transport designs (which have 1 or 2 larger central upgrading plants) is limited; it changes biomethane cost with $4 €_{\text {ct }}$ and $3 €_{\text {ct }}$ respectively.

To conclude, it can be seen in Figure 6.4 and Figure 6.5 that the Biomass transport design's NPV and biomethane cost always outperforms the Biogas hub and Local for local designs'. For only some of the factors does the NPV of the Biomass transport design become negative. Furthermore, the Biogas hub design always outperforms the Local for local design's NPV and biomethane cost.

Furthermore, for all low and high values of the factors, the NPV of the Local for local and Biogas hub design is negative. For these two design types to have a positive NPV would require an increase in locally available biomass. Such that larger digester installations - and upgrading plants in case of the Local for local design - are required. Per $\mathrm{m}^{3}(\mathrm{n})$ of produced biomethane these installations cost less than their smaller counterparts. As a consequence biomethane cost will 
decrease, and with this the NPV will increase.

\subsection{Choosing a different solution}

This section describes another sensitivity analysis that was performed. The approach of this sensitivity analysis differed from the one described in the previous section. In the previous section, we kept the design fixed, changed the value of the parameters and saw how this affects the performance indicators. We now kept the values of the parameters fixed, chose a different set of performance indicators from the solutions, and saw how this affects the design.

$\mathrm{NPV}$ and $\mathrm{CO}_{2}$ emission reduction were used as performance indicators. The start configuration was similar to the one used in the previous section, see 6.1.3.

Subsection 6.2.1 describes how the three design types, used in the previous section, can be quantified. Next, subsection 6.2.2 shows how the design changes when choosing a different solution for two situations: (1) choosing a different non-dominated solution, and (2) choosing a dominated solution instead of a nondominated solution.

\subsubsection{Quantifying the type of design}

Suppose a trade-off has to be made between NPV and $\mathrm{CO}_{2}$ emission reduction; to what extent will a shift from one solution to another solution affect the design? To answer this question, we used the three designs defined in the previous section as a starting point. When characterizing a design, we wanted to know to which extent it can be characterized as Local for local, as Biogas hub, or as Biomass transport design. To quantify this, two measures were used, namely (1) centrality of digestion and (2) centrality of upgrading.

First, centrality of digestion is the measure that defines to which extent biomass is digested centrally. It is obtained by dividing the number of locations that digest their biomass at a central location by the total number of biomass locations. Mathematically it is defined as follows:

$$
C_{\mathrm{d}}=\frac{N_{\text {cen, }}}{N_{\text {tot, } \mathrm{d}}}
$$

With $C_{\mathrm{d}}$, centrality of digestion; $N_{\text {cen,d }}$, the number of biomass locations whose biomass is digested at a central location; and $N_{\text {tot,d }}$, the total number of biomass locations whose biomass is digested. If $C_{\mathrm{d}}=1$, this indicates a Biomass transport design. If $C_{\mathrm{d}}=0$ this might indicate a Biogas hub, or a Local for local design.

Secondly, centrality of upgrading, $C_{\mathrm{u}}$, defines to what extent biogas from a digester installation is upgraded at a central location. It is determined by dividing 
the number of digesters whose biogas is upgraded at a central upgrading plant by the total number of digesters, or mathematically:

$$
C_{\mathrm{u}}=\frac{N_{\text {cen,upg }}}{N_{\text {tot,upg }}}
$$

With $N_{\text {cen,upg, }}$ the number of digester installations whose biogas is upgraded at a central upgrading plant; and $N_{\text {tot,upg }}$ the total number of digester installations. If $C_{\mathrm{u}}=1$, this indicates a Biogas hub design. If $C_{\mathrm{u}}=0$ this can indicate a Local for local or a Biomass transport design.

Table 6.6 characterizes the three designs by means of $C_{\mathrm{d}}$ and $C_{\mathrm{u}}$.

\subsubsection{Results and discussion}

\section{Choosing a different non-dominated solution}

The run that generated 10,000 candidate solutions, resulted in 28 non-dominated solutions. The NPV and $\mathrm{CO}_{2}$ emission reduction of the non-dominated solutions are shown in Figure 6.6.

As can be seen, there is a significant variation in NPV between the 28 solutions. The $\mathrm{CO}_{2}$ emission reduction, however, only varies slightly among the solutions.

For all non-dominated solutions the values of $C_{\mathrm{d}}$ and $C_{\mathrm{u}}$ were determined. The value of $C_{\mathrm{u}}$ for all solutions was zero. Therefore, no Biogas hub element is present in any of the non-dominated solutions.

The values of $C_{d}$ are shown in Figure 6.6 next to the points. As can be seen the value with the lowest NPV has a "pure" Local for local design, since $C_{d}=0$. With increasing NPV, the value of $C_{d}$ increases intermittently to 1 . That $C_{d}$ is not equal to 1 , for the solution with the highest NPV, has to do with the specific sizes of the available digester installations. That is, if in the solution with the highest NPV, all biomass would be digested at a central location, the central digester installation would have to be one size larger. This is more expensive than the current design with one small local digester and the large central digester installation - which is one size smaller than when all biomass would be

\begin{tabular}{lll}
\hline & $C_{\mathrm{d}}$ & $C_{\mathrm{u}}$ \\
\hline Local for local & $\mathrm{O}$ & $\mathrm{O}$ \\
Biogas hub & $\mathrm{O}$ & $\mathbf{1}$ \\
Biomass transport & 1 & $\mathrm{O}$ \\
\hline
\end{tabular}

Table 6.6: Quantification of the design types 


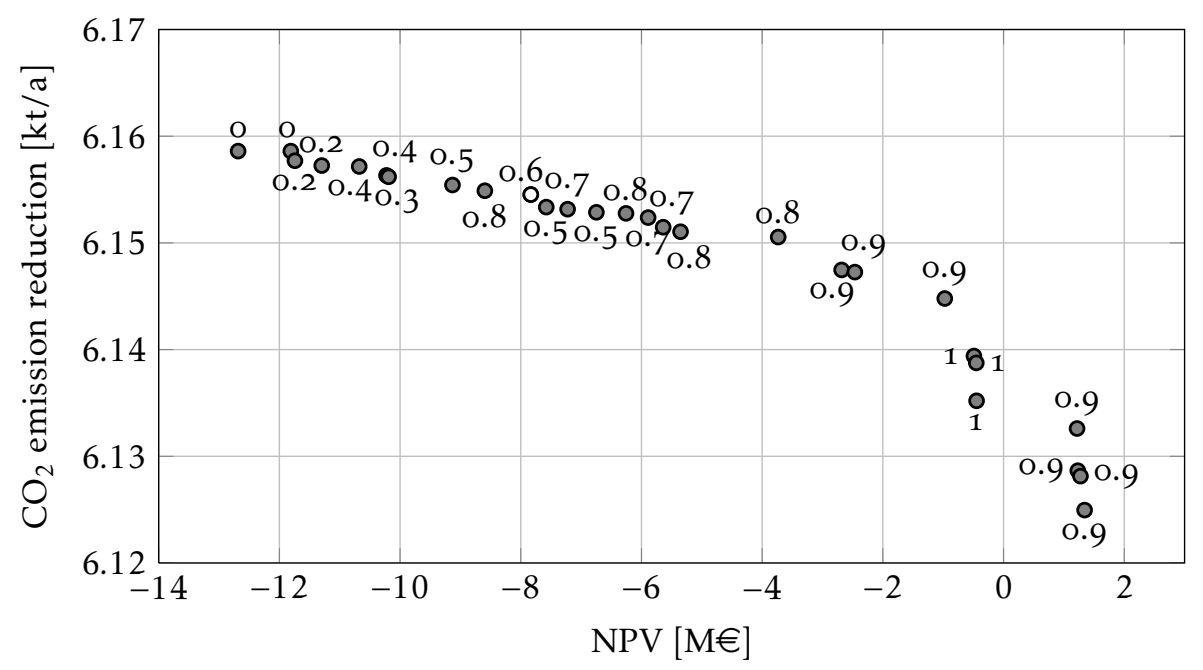

Figure 6.6: $\mathrm{NPV}$ and $\mathrm{CO}_{2}$ emission reduction of the non-dominated solutions. The centrality of digestion $C_{\mathrm{d}}$ is indicated with each dot. (Urban region)

digested here. With a continuous set of digester installations, the values of $C_{d}$ would continuously increase from o to 1 with increasing NPV.

As an example, Figure 6.7 shows the design with $C_{\mathrm{d}}=0.6$, which is marked white in Figure 6.6. The design is a blend of Local for local and Biomass transport. It has four locations that digest their biomass locally, and six locations that digest their biomass centrally.

\section{Choosing a different dominated solution}

Next, we wanted to see how the design changes if a dominated solution is chosen, instead of a non-dominated solution. The difference in performance can be quite small between dominated and non-dominated solutions. Therefore, it might be interesting to have a look at some dominated solutions as well. Especially if you consider that in modeling there are always some small errors. As a consequence, in reality, a dominated solution may have a better performance than a non-dominated solution.

To see to what extent the design of the dominated solutions differ from the non-dominated solutions' design, we zoomed in on the solutions with a positive NPV. In Figure 6.8, the NPV and $\mathrm{CO}_{2}$ emission reduction of all designs with a positive NPV is shown. The centrality of digestion $C_{\mathrm{d}}$ is indicated around each dot. As can be seen, the value for $C_{\mathrm{d}}$ is either 0.9 or 1 for all dominated solutions with a positive NPV. Furthermore, only one solution has a Biogas hub element $\left(C_{\mathrm{u}}=1\right)$. So again, also for the dominated solutions, no dramatic change in 


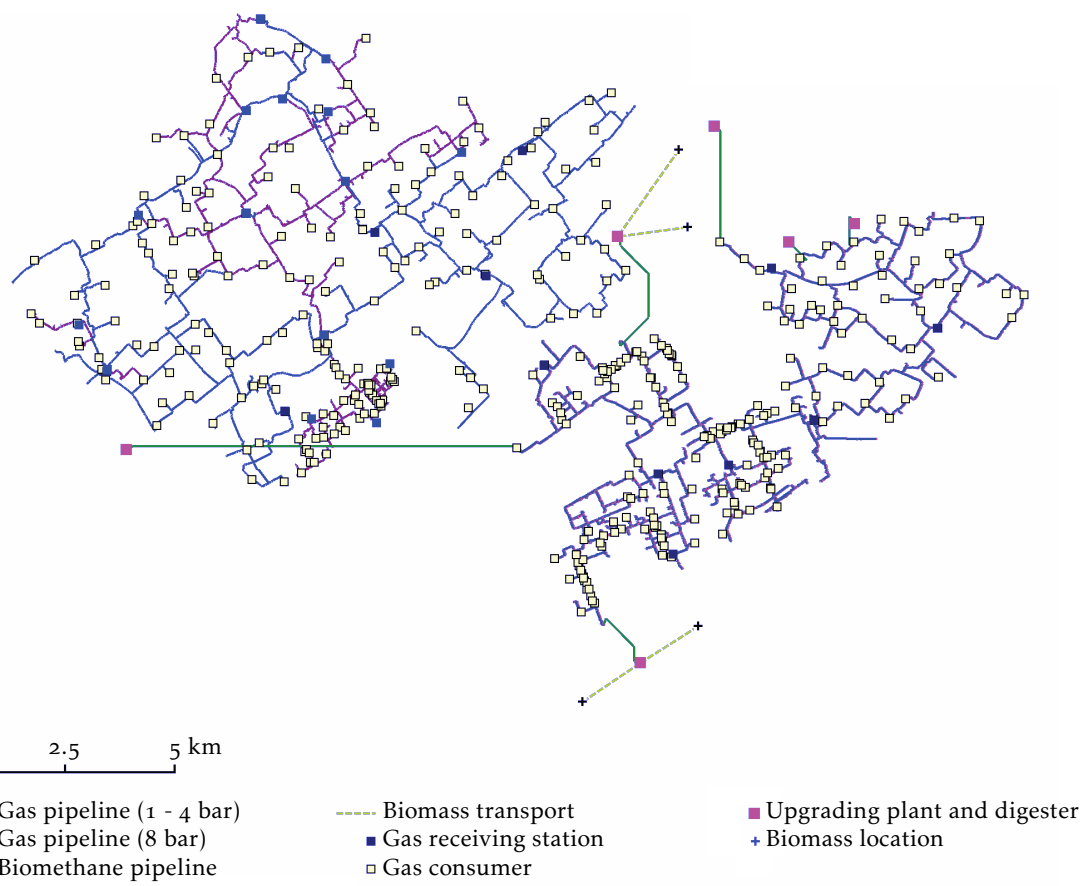

Figure 6.7: Design that is a blend of a Local for local and a Biomass transport design. $C_{\mathrm{d}}=0.6$ (Urban region)

design will occur when choosing a solution with a slightly different performance.

\subsection{Conclusions}

This chapter described two types of sensitivity analyses on the model. The first examined how much the performance indicators of three typical designs are affected when changing the model's parameters. The second test examined to what extent the design changes when we made a different trade-off between two performance indicators.

The first test showed, that for all values of the parameters, the Biomass transport design's economic performance is superior to the other two designs. Just as the Biogas hub design's economic performance is superior to the Local for local design. Therefore, the choice for a type of design based on its NPV or biomethane cost is quite robust.

The economic superiority of the Biomass transport design is a result of the size of the central digester installation and central upgrading plant, which both 


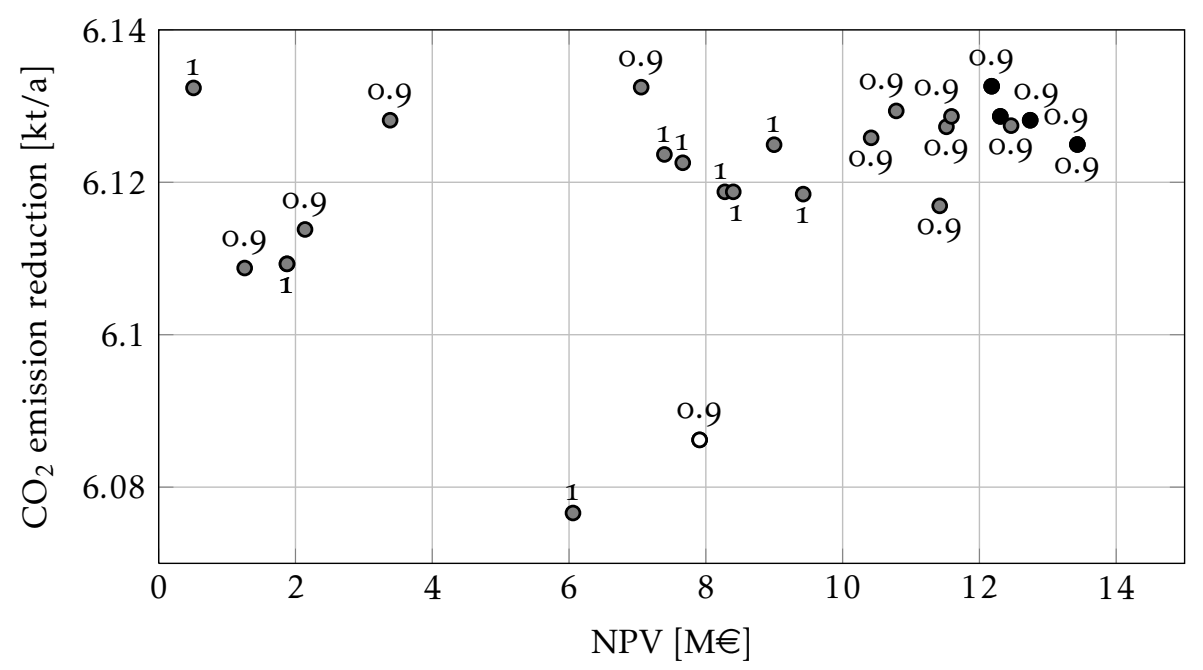

Figure 6.8: $\mathrm{NPV}$ and $\mathrm{CO}_{2}$ emission reduction of the solutions with positive NPV. Dominated solutions are marked grey, non-dominated solutions are marked black, and the solution with a Biogas hub element is marked white. The centrality of digestion is indicated with each dot. (Urban region)

have the advantage of economy of scale. Whereas the Biogas hub has 1o local digester installations, which are smaller of scale and therefore, per cubic meter of biomethane more expensive. The Local for local design has both local digester installations and local upgrading plants, incurring twice the economic disadvantage of small-scale. The latter two designs' NPV was negative for all values of the model's parameters. These two designs will have a positive NPV when the amount of biomass that is locally available will increase significantly.

In addition, the impact of the biomass cost and biogas yield is very significant. A small change in biomass cost or biogas yield can make the difference between a positive and a negative NPV. Other factors, such as pipeline costs, electricity price, and biomass transport costs, only had a minor impact on the NPV and biomethane cost of the three designs.

The results for the sensitivity analysis on the intermediate region, described in Appendix B, confirm the findings in this chapter. The same hierarchy of designs based on their economic performance was found. In addition, the impact of the factors on the economic performance of the designs is also comparable.

In the second test, it was found that when optimizing NPV and $\mathrm{CO}_{2}$ emission reduction of the solutions for the urban region, there was no Biogas hub element present in any of the non-dominated solutions. In addition, by increasing the NPV, the solution changed gradually from an all Local for local design to a Bio- 
mass transport design. This means that if the choice for the preferred solution shifts, the design changes only slightly. Furthermore, when looking at the dominated solutions, all solutions with a positive NPV were almost the same as their non-dominated counterparts with a positive NPV. So the solution choice made by the user of the DST is also robust.

It should be kept in mind that the choice for a type of design does not solely depend on this techno-economic optimization. Other societal and institutional aspects might play an important role as well. It might, for instance, be undesirable to transport large amounts of biomass over the road, and thus central digester installations could be prohibited. Furthermore, jointly owning an upgrading plant in the Biogas $h u b$ case, or a digester installation in the Biomass transport case makes things harder to organize. As a consequence, despite its poor techno-economic performance, the Local for local design might be preferred over the other two designs. 



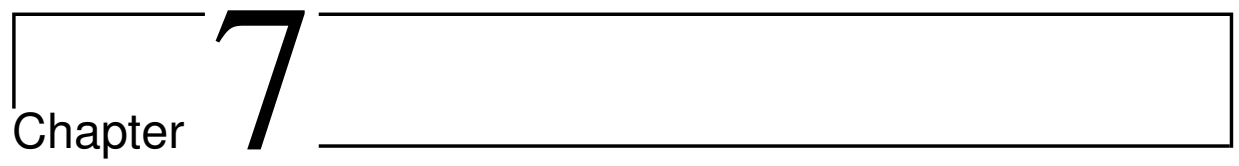

\section{Research valorization}

Chapters 5 and 6 illustrated how the DST can be used to create a design for the biomethane supply chain for a certain region. It is, however, not yet described how the use of the DST can provide value for the DSOs and other stakeholders.

The contribution of this chapter is, therefore, to explain how the DST can be used such that it creates value for the DSOs, other stakeholders and society.

The outline of this chapter is as follows. Section 7.1 explains how the DST can create value for the DSOs, other stakeholders, and society by describing its envisaged use. Next, in section 7.2 the limitations of the DST are described. Section 7.3 lists the improvements for the DST that are needed to enable the envisaged use. Finally, section 7.4 draws conclusions on the proposed valorization of the DST.

\subsection{Envisaged use of the DST}

\section{Current practice}

At present, when one or more biomass owners want to use their biomass, they will first consider (usually, a consulting company supports them) several biomass utilization options, such as electricity production and biomethane production. Next, if biomethane production comes out as the best option for the biomass owners, they have to decide on the design of part of the biomethane supply chain. When looking at Figure 3.1, this part of the supply chain comprises all steps from biomass supply up to and including upgrading plant. After this stage, they will involve the DSO in the design process.

Thus, usually no earlier than when the biomass owners have decided on the location and size of the upgrading plant, is the DSO included in the design pro- 
cess. At this stage, the biomass owners will ask the DSO how they can inject the biomethane into the gas grid, given the location and biomethane output of the upgrading plant. The DSO's contribution to the process is deciding on the most suitable gas grid to inject the biomethane, taking extra balancing measures if required, and deciding on the best route for the pipelines that will connect the upgrading plant to the gas grid. Looking at Figure 3.1, the DSO has influence on the design of that part of the biomethane supply chain that comprises the injection station up to and including the gas grid (and balancing measures).

This approach, with relatively minimal involvement of the DSO, might lead to suboptimal solutions, since the design of the first part of the supply chain (up to and including the upgrading plant) did not consider investments in the gas distribution grid. As such, the solution that optimizes profit for the biomass owner might not be the solution that provides the lowest societal cost. Furthermore, the design process of a biomethane supply chain can be quite lengthy, especially when a larger number of biomass owners is involved. The latter is due to two factors: (1) with an increasing number of biomass owners comes an increasing number of design options, which makes the design process more complex, and (2) with the increasing number of biomass owners also the number of stakeholders, and thus potentially conflicting interests increases.

The above description is a generalization of the most common practice. For some cases, the design process might deviate from the above description.

\section{Envisioned practice}

We envisage that the DST will be used (1) for cases where one or more biomass owners want to use their biomass for biomethane production and (2) for making strategic decisions on the future biomethane infrastructure, without immediate interest from biomass owners.

For the first option, several biomass owners are interested in producing biomethane and injecting it into the gas grid of the DSO. Several other stakeholders are also involved in the design process, such as DSOs, municipalities, and citizens living near the biomethane production location.

When preparing the DST for a certain case, first the available elements have to be added to the DST, biomass locations have to be defined, and from existing files available to the DSOs the gas distribution grid and gas consumption have to be loaded. Next, the performance indicators which are of interest for the stakeholders are chosen, and are used to determine the non-dominated solutions. Performance indicators of interest are, for instance, the profit of a biomass owner, investments in the gas grid, and the number of biomass transport movements. Next, using the DST, a large number of solutions are generated and their performance indicators are determined. The performance indicators give insight into the available solutions and allow stakeholders to make trade-offs between 
different options. The example below illustrates this.

Example. For the rural region (see section 5.1.1) in the nominal situation, 1, ooo solutions were generated. Four performance indicators were defined, namely the investments in the gas grid, biomethane production rate, and the profit of farmers 1 and 2 (the profit of other farmers involved in this project is not regarded). The non-dominated solutions are shown in Figure 7.1.

Considering the profit of farmers 1 and 2 (see Figure 7.1(b)), they will have a strong preference for solution 1, since this option will maximize their profit. However, when looking at Figure 7.1(a), solution 1 is not the solution that yields the highest biomethane production nor is it the one with the lowest investments in the gas grid. Instead, when looking at the performance indicators in Figure 7.1(a), one might argue that solution 2 should be the preferred option. Its biomethane production is almost maximal and the investments in the gas grid are relatively low. But choosing for solution 2 would cause farmer 1 and 2 to lose half of their profit compared to solution 1 .

Therefore, when designing biomethane supply chains, trade-offs have to be made between conflicting interests. It might be possible that the DSO finances part of the investments of farmer 1 and 2 as compensation for choosing a solution that does not maximize their profit.

Providing insight in the trade-offs that have to be made, increases understanding and consensus among stakeholders for the solution that is eventually chosen. It will help them to realize that compromises have to be made in order not to disadvantage one stakeholder disproportionately. The chosen solution will be a trade-off between the conflicting interests of different stakeholders. Furthermore, once the DST is configured for the case at hand, the DST can be used to quickly generate a large number of solutions. This will significantly shorten the

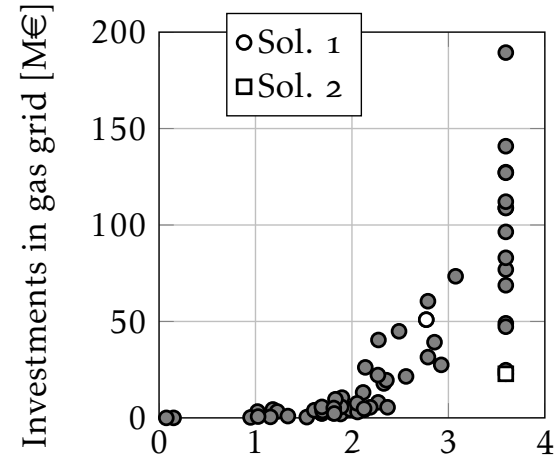

Biomethane prod. $\left[\mathrm{km}^{3}(\mathrm{n}) / \mathrm{h}\right]$

(a)

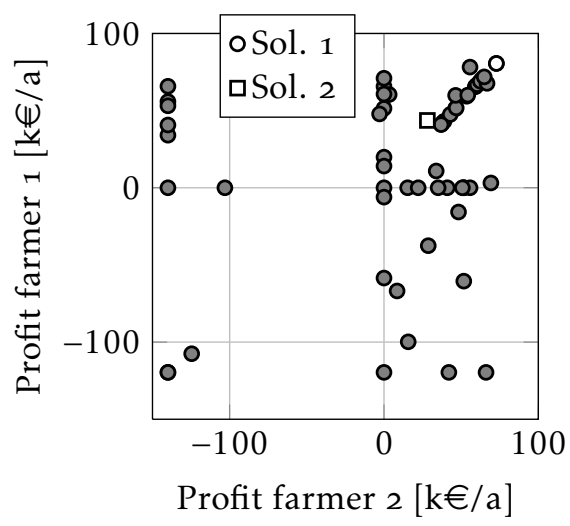

(b)

Figure 7.1: Performance indicators of the non-dominated solutions for the Rural region in the nominal situation. 
time needed for the design process of the biomethane supply chain.

For the second option, the DST is used to make strategic decisions on the future biomethane supply chain. This option gives the DSOs insight in what the consequences will be when biomass owners in a certain region want to use their biomass to produce biomethane in the coming years. This allows DSOs to see ahead, and make investment decisions that look beyond the first biomass owner that knocks on the DSO's door to inject biomethane.

As such, the solution chosen for the first biomass owner(s) that wants to inject its biomethane into the gas grid might not seem the best or cheapest option. But this solution might prove to be a good option when subsequent biomass owners also want to inject their biomethane into the gas distribution grid. The example below illustrates this.

Example. The DST was used to determine the preferred design for the biomethane supply chain for the possible future situation in which all farmers use their biomass to produce biomethane. This design is shown in Figure 7.2(a). As can be seen, the biogas is produced locally at the farmers' sites. Furthermore, the biogas is transported to the leftmost farm, where it is upgraded to biomethane. Finally, the produced biomethane is injected into the high-pressure distribution grid.

At some point in time, the two leftmost farmers actually want to use their biomass. The preferred design for this situation is shown in Figure 7.2(b). In this design, the produced biomethane is injected in the low-pressure distribution grid. This design may seem a good solution. However, when at a later point in time, the rightmost farmer also wants to use its biomass to produce biomethane, the ideal solution from Figure 7.2(a) is no longer possible. This is caused by the fact that the biogas pipeline connecting the two
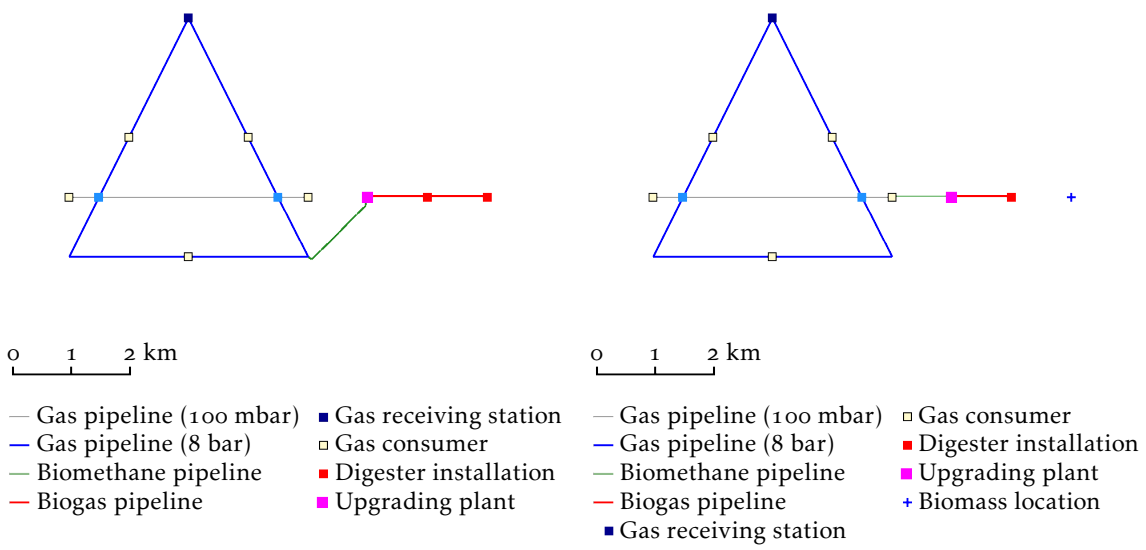

(a) Preferred design when all farmers use their (b) Preferred design when only the two biomass. leftmost farmers use their biomass

Figure 7.2: Example of how the DST can be used to make strategic decisions. 
leftmost farmers is too small to transport the extra biogas from the third farmer. Furthermore, the gas demand in the low-pressure distribution grid is too low to consume the biomethane of all three farmers. Instead, for the rightmost farmer, the digestion and upgrading steps will have to be performed locally, and the biomethane will have to be injected into the high-pressure distribution grid. This solution is much more expensive than the one shown in Figure 7.2(a).

Therefore, when the first two farmers want to produce biomethane, it may be a good choice to lay a biogas pipeline that is larger than necessary at that point in time, and to inject the biomethane in the high-pressure distribution grid instead of the low-pressure distribution grid. Even though these design choices are more expensive at first, it may turn out to be cheaper when later on the third farmer also wants to produce biomethane.

\subsection{Limitations}

The use of the DST, as illustrated in the previous section, has some limitations.

First of all, the DST only considers the gas grid. The DST gives the best solution when the biomass is used as biomethane. It does, however, not consider whether it might be more attractive to convert it to electricity and supply it to the electricity grid, or convert it to heat and use it locally or in a heat grid.

Secondly, the DST provides the embodiment design of the biomethane supply chain. Once a choice is made on the preferred solution, a detail design still has to be made, for which the DST is not suited.

Thirdly, of the potential future changes, mentioned in chapter 2, only the injection of biomethane is incorporated in the DST. Other potential changes for the gas distribution grid are not included in the tool. These changes can be: (1) a changing gas quality, due to an increased share of foreign gases, (2) the use of dedicated biogas grids, where its gas appliances are tailored to biogas quality, or (3) the injection of $\mathrm{H}_{2} / \mathrm{CH}_{4}$ from surplus wind or solar energy.

Finally, for the DST to be used in practice, it needs further improvements. The investments required to develop the DST are worthwhile when the share of biomethane increases significantly. Therefore, if the number of biomethane producers is limited to only one or two per year, it might not be worthwhile to invest in the development of the DST.

\subsection{Required development for the DST}

In order to enable the envisaged use of the DST, some improvements to the DST are required, such as:

Integration with existing files. The DSOs have thoroughly documented their gas distribution grids. These files are used to analyze the capacity of the gas distribution grid. The files contain information regarding the location, diameter, and material type of each pipeline; the location and consumption 
of gas consumers; and the location and capacity of district stations and GRSs. Moreover, a lot of effort is invested in keeping the files up-to-date. Therefore, a DST that is able to use that information, will have the most recent information at its disposal. Also, the DSOs do not have to maintain two separate files for the same region.

Automation of tasks. As mentioned in chapter 5 , it took me around two days to prepare a start configuration for a region. Someone unfamiliar with the DST might encounter difficulties in preparing a start configuration, and as a result the preparation time might increase significantly. In our opinion, even with this extra preparation time, it is still worthwhile to use the DST, since its use will shorten the design process significantly. However, to increase user acceptance, it might be worthwhile to automate certain cumbersome tasks.

One can think of linking a map of the area to the start configuration, which can be used to designate certain locations as biomass production locations by clicking on the map. This will make the process of assigning biomass locations to the start configuration more easy.

Improved exploration of the solution space. Allow users to filter certain solutions. For instance, let them limit the size of the digesters, or limit the total transport distances. In this way, solutions can be filtered that are economically interesting but are for other reasons undesirable. (In case of the two examples the nasty smells of a large digester or nuisance due to the amount of trucks passing by are reasons why an economically interesting solution might be undesirable.)

\section{$7 \cdot 4$ Conclusions}

The DST has the potential to create value for the DSOs, other stakeholders and society. First, the DST reduces the complexity of the design process. It allows the user to choose its own performance indicators and these performance indicators again give insight in the solution space. As such, it increases acceptance among different stakeholders for the chosen design, by showing the advantages and disadvantages of each solution. Ultimately, this improves the quality of the chosen solution.

Secondly, society benefits, since solutions can be chosen that no longer only optimize the profit of the biomass owner. Instead, a solution can be chosen that is most beneficial for society (for example, lowest societal cost).

Thirdly, the strategic use of the DST allows the DSOs to look further than the first biomass owner when investing in the gas grid. Later on, these higher initial investments might prove cost-effective when subsequent biomass owners also want to inject their biomethane. 
Finally, by reducing the time to come to an embodiment design of the biomethane supply chain, the DST shortens the overall design process. It does this, by automating several tasks. For instance, it allows easy addition of new values for elements of the biomethane supply chain and it can quickly generate a large number of solutions. Integrating the DST with existing files further reduces the time to come to a design for the biomethane supply chain. 



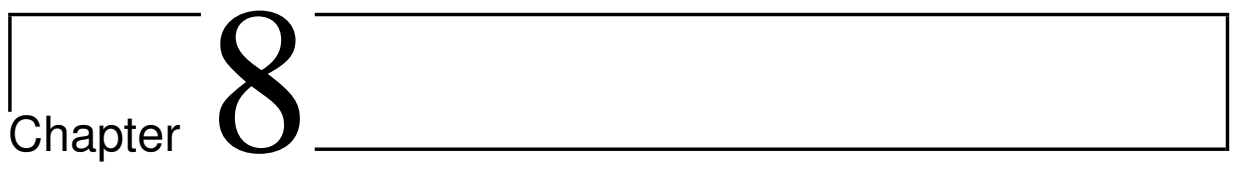

\section{Conclusions and recommendations}

\subsection{Conclusions}

The main objective of this thesis was to develop a DST that supports the design process of the biomethane supply chain, by creating candidate solutions for the design of the biomethane supply chain for a certain geographical region comprising biomass locations, gas grids and gas consumers.

Below the main findings, added value for society, contributions to scientific literature, and limitations of the performed research are listed.

\section{Future energy scenarios}

In chapter 2, four future energy scenarios were developed that describe the possible ways the future might unfold for the Dutch gas distribution grid. It was found that in all scenarios the gas distribution grid still plays a significant role for the Dutch energy system, although its role might be more modest compared to today. For example, in the greener scenarios the low-pressure distribution grid is probably abolished and in general the total gas flow within the gas distribution grid will decrease. The gas distribution grid will have an increased number of system functions. In all future scenarios, the gas distribution grid will have to deal with more gas types. In particular, the production and injection of biomethane will increase. Furthermore, due to injection of biomethane, biogas, $\mathrm{H}_{2}$ or renewable methane balancing of supply and demand will become increasingly important. Since the developed scenarios were tailored to the Dutch gas distribution grid, we expect that they will help the Dutch DSOs to deal with their dilemma of when and what to invest in. 


\section{DST}

A DST was developed that supports the design process for the biomethane supply chain. More specifically, the DST automates the synthesis task of the design process. As part of the DST, a design engineering model of the biomethane supply chain was developed in chapter 3 . Furthermore, in chapter 4 , a design procedure was developed that describes how the design engineering model is used to create solutions for the biomethane supply chain. The contribution of the described research is the formalization of the design engineering model, the design procedure, and the design rules required for the design of a biomethane supply chain. Secondly, the automation of the synthesis task of the design process is also a novelty.

More specifically, the developed design engineering model can be used to create solutions for the design of the biomethane supply chain. When comparing our model with other models described in literature, our model has several characteristics that these models do not have: first, in the scope of the biomethane supply chain, which ranges from biomass supply to injection in the gas grid and dealing with a temporary surplus of biomethane. Secondly, it can be used to determine the $\mathrm{CO}_{2}$ emission reduction, net energy production, and economic performance. Thirdly, the model is spatially explicit. Fourthly, it makes use of discrete components of the biomethane supply chain. And fifthly, the model allows to have multiple biomass locations to supply one digester installation, and multiple digester installations to supply one upgrading plant.

The developed design procedure generates candidate solutions for the biomethane supply chain, using the design engineering model. With the design procedure a large number of candidate solutions can be created, which allows for a good exploration of the solution space. In synthesizing the candidate solutions, the design procedure considers all the development options mentioned in chapter 1 . That is, the design procedure determines if the biomass is used, where the biomass is digested, where the biogas is upgraded, in which gas grid the biomethane is injected, and which technology will deal with a temporary surplus of biomethane. The developed design procedure has a combination of characteristics that was not found in other design procedures described in literature. First, the design procedure is able to handle a varying number of constraints and equations in time. Secondly, it allows for multiple objectives. Thirdly, the user him/herself is allowed to evaluate and choose the eventual solution. And fourthly, the design procedures accommodates a broad exploration of the solution space.

The design procedure uses a random decision making process, which enables a broad exploration of the solution space. This procedure does not guarantee optimal solutions, and it can unfortunately be time consuming to find optimal or near-optimal solutions. However, the design procedure enables flexibility with respect to the elements that the user can add, and the performance indicators that the user can choose. Furthermore, although the DST was only applied to 
regions in the Netherlands in this thesis, the DST can in principle be applied to any region in any country.

\section{Future designs of the biomethane supply chain and sensitivity analysis}

In chapter 5 , the DST was used to obtain the design of the biomethane supply chain in each future energy scenario, for three different regions. The outcomes of this research showed what the biomethane supply chain and gas distribution grid will look like for each of the three regions. As such, this research further details the future energy scenarios and gives the DSOs and other stakeholders a better grasp of the directions that the gas distribution grid might be heading.

It was found that in rural regions the DSOs may have to invest in balancing measures, for instance gas storage, to deal with a temporary surplus of biomethane. For DSOs that operate in intermediate or urban regions, it is less likely that they have to invest in balancing measures. Furthermore, the biomass potential in a rural region might not be fully utilized. This is due to the high availability of biomass and low gas demand, therefore, costly balancing measures are required to fully utilize the biomass potential. Finally, the design with one or more central digesters was found to be the most economic way to produce biomethane.

Chapter 6 described the sensitivity analysis that was performed on the design engineering model. The first part of the sensitivity analysis investigated how sensitive the performance indicators of three design types are to changes in the parameters of the model. The three typical designs are characterized by (1) local digestion and local upgrading; (2) local digestion and central upgrading; and (3) central digestion and on-site upgrading respectively. Regardless of the value for the parameters, the economic performance of the design with central digestion is superior to the other two designs. Similarly, the economic performance of the design with local digestion and central upgrading is superior to the design with local digestion and local upgrading.

Furthermore, the sensitivity analysis showed that the economic performance of the three designs is in particular sensitive to changes in the biogas yield of the biomass, and the biomass cost. Other factors, such as pipeline costs, electricity price, and biomass transport cost, have only a minor impact on the economic performance.

The second part of the sensitivity analysis showed that when choosing a different non-dominated solution, the design only changes gradually when moving along the different solutions. As such, the choice made by the user can also be considered quite robust.

Furthermore, the research on the future design of the biomethane supply chain and the sensitivity analysis showed that the DST can be used for different regions, and that it is able to handle regions of such size. Therefore, it provides a 
good indication that the DST will improve the design process of the biomethane supply chain.

A limitation in both researches was the optimization towards overall goals, while the economic attractiveness of a solution for the individual biomass owners was not taken into account. As a result, a solution might be chosen that has a positive NPV for the overall project, but in which one or more biomass owners make a nett loss. In real life, it is not very likely that a biomass owner wants to produce biomethane when he/she will make a loss.

\section{Overall research}

The goal of our research was to improve the design process of the biomethane supply chain. To improve this design process, a DST was developed, consisting of a design engineering model and design procedure. The DST automates the synthesis and analysis phase of the design process, while leaving the choice for the preferred candidate solution to the user. The DST supports the design process by generating candidate solutions for the embodiment design of the biomethane supply chain and determining their performance indicators.

The developed DST was evaluated by performing the research on the future design for the biomethane supply chain and the sensitivity analysis. Moreover, interviews with and demonstrations for the employees of the DSOs were given on the use and usefulness of the DST. These provided a good indication that the DST will improve the design process of the biomethane supply chain.

In conclusion, the DST was successfully developed. The DST can be used to aid the design process for biomethane supply chains. Although further evaluation of the DST is needed, it promises to be of use for the DSOs and other stakeholders involved in the design process of the biomethane supply chain.

\subsection{Directions for future research}

The DST was already evaluated by doing the analyses described in this thesis, and interviews with employees of the DSOs also pointed out the usefulness of the DST. However, for an ultimate evaluation of the DST, the DST should be used in an actual design process and be used by the envisioned users. This evaluation of the DST will show how much the design process will improve by using the DST.

The design procedure uses several random decisions to create candidate solutions, in order not to steer the direction of the solution generation. The design procedure lets the user decide on the performance indicators. The Pareto optimal solutions will eventually be found, as long as sufficient solutions are gen- 
erated. However, this approach requires a lot of candidate solutions and a lot of time, to obtain a solution that is somewhat near the Pareto front. Therefore, a more defined design procedure would be recommendable. One could implement more specific design rules, which are based on design knowledge regarding the biomethane supply chain. In addition, one could think of implementing, for example, greedy or genetic algorithms.

As indicated by the future energy scenarios, besides an increased share in biomethane, the gas distribution grid also has to deal with other novel types of gas, such as natural gas from Russia or Norway, and renewable methane from surplus electricity. In addition, the gas quality of the gas distribution grid might be adjusted to, for example, biogas quality. In future research, it may, therefore, be interesting to expand functionality of the DST to assess the impact of these new gas types on the gas distribution grid.

The solutions created for the research in chapters 5 and 6 were evaluated based on the overall performance of the biomethane supply chain. As such, solutions in which a biomass owner would make a loss could be chosen, since the NPV of the overall biomethane supply chain was positive. This is not a realistic situation, and therefore, it is recommendable that future research should also take into account the interests of these individual stakeholders.

Moreover, instead of looking only at the "final" design of the biomethane supply chain, it may be interesting to investigate how the gas grid (1) should or (2) may evolve over time. The first option shows what the design of the biomethane supply chain should look like in the intermediate steps, in order to obtain the desired final design. The second option shows whether short-term optimizations of the design, in subsequent time periods, may result in a final design that deviates from the desired design. 



\section{Bibliography}

[1] T. D. Weidenaar, S. Hoekstra, and M. Wolters. Development options for the Dutch gas distribution grid in a changing gas market. In Proceedings of the 2011 IEEE International Conference on Networking, Sensing and Control, pages 32-37, Delft, 2011.

[2] J. Schenk. Groningen-gasveld vijftig jaar: kloppend hart van de Nederlandse gasvoorziening. Boom, Amsterdam, 2009.

[3] A. Hendriks. Storingsrapportage gasdistributienetten 2012 - Inclusief gasonderbrekingen t.g.v. geplande werkzaamheden. Netbeheer Nederland, Apeldoorn, 2013. www.netbeheernederland.nl/publicaties/onderzoek. Accessed at 12-2-2014.

[4] T. Bogaert and L. Derksen. Betrouwbaarheid van elektriciteitsnetten in Nederland - Resultaten 2012. Netbeheer Nederland, Utrecht, 2013. www.netbeheernederland.nl/publicaties/onderzoek. Accessed at 12-22014.

[5] J. Wempe and M. Dumont. Let's give full gas! The role of green gas in the Dutch energy management system. SenterNovem, Utrecht, 2007. www.biowho.nl/files/file/Let's\%2ogive\%2oFull\%2oGas.pdf?phpMyAdmin

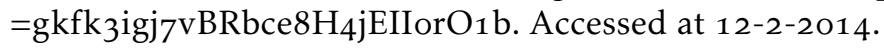

[6] AgentschapNL. www.b-i-o.nl. Accessed at 5-11-2013.

[7] G. Müller-Syring, M. Henel, H. Rasmusson, H. Mlaker, W. Köppel, T. Höcher, and M. Sterner. Power to Gas: Untersuchungen im Rahmen der DVGW-Innovationsoffensive zur Energiespeicherung. Energie/wasserpraxis, (04):72-77, 2011.

[8] M. Wolters. Requirements of future gas distribution networks. In World Gas Conference, Amsterdam, 2006. 
[9] G. Müller-Syring and T. G. Theisen. Smart Gas Grids. Energie/wasserpraxis, (11):34-37, 2010.

[10] T. Al Seadi, D. Rutz, H. Prassl, M. Köttner, T. Finsterwalder, S. Volk, and R. Janssen. Biogas handbook. University of Southern Denmark Esbjerg, Esbjerg, 2008.

[11] J. H. Welink, M. Dumont, and K. Kwant. Gas van aardgaskwaliteit uit biomassa - Update van de studie uit 2004. SenterNovem, Utrecht, 2007. http://refman.et-model.com/publications/39/download/SenterNovem _ 200701_Gas\%2ovan\%2oaardgaskwaliteit\%2ouit\%2obiomassa.pdf?1297827 073. Accessed at 12-2-2014.

[12] J. Bekkering, A. A. Broekhuis, and W. J. T. van Gemert. Optimisation of a green gas supply chain - A review. Bioresource technology, 101(2):450, 2010.

[13] P. van der Gaag, N. Sapulette, and E. Stenhuis. Productie en inzetbaarheid van Bio-LNG in de Nederlandse transportsector. Holland Innovation Team, 20o8. www.changemagazine.nl/doc/productie-en-inzetbaarheid-van-biolng.pdf. Accessed at 12-2-2014.

[14] M. Sieverding. Biogaseinspeiseprojekte bei RWE. gwf-Gas/Erdgas, (november):798-801, 2010.

[15] J. Höhn, E. Lehtonen, S. Rasi, and J. Rintala. A Geographical Information System (GIS) based methodology for determination of potential biomasses and sites for biogas plants in southern Finland. Applied Energy, 113:1-10, 2014 .

[16] R. N. van Eekelen, E. A. Polman, H. A. Ophoff, and M. van der Laan. New networks for biogas. Kiwa NV, Apeldoorn, 2012. www.sgc.se/ckfinder/userfiles/files/SGC264_English.pdf. Accessed at 122-2014.

[17] B. Klocke and H. Pflaum. Kooperationsvorhaben Nachhaltiges Biogas am Niederrhein - Nachhaltige Planung für ein innovatives Biogaseinspeisesystem. gwf-Gas/Erdgas, (November):786-793, 2010.

[18] I. Smits, P. Latta, S. Velders, G. V. Heijster, J. V. Wijnkoop, and S. Brussel. Haalbaarheidsstudie Groen Gas Haaften. Alliander, Arnhem, 2010. http://groengas.nl/report/haalbaarheidsstudie-groen-gas-haaften. Accessed at 12-2-2014.

[19] ColsenBV. Haalbaarheidsstudie Groen Gas Rilland. SenterNovem, Utrecht, 2009. http://www.biogas.nl/downloads/0428haalbaarheidsstudie-groengas-rilland.pdf. Accessed at 12-2-2014. 
[20] J. de Veth and J. Uenk. Haalbaarheid Groen Gas. Casus Sint-Oedenrode. SenterNovem, Nijmegen, 2008. www.rvo.nl/sites/default/files/bijlagen/Haalbaarheid\%2oGroen\%2oGas\% 20-\%20Casus\%2oSint-Oedenrode.pdf. Accessed at 12-2-2014.

[21] E. J. Hengeveld. Groen gas, uit centraal of decentraal geproduceerd biogas? - modelberekeningen voor een biogas-hub. Presentation at Flexigas Symposium, Groningen, 2013.

[22] M. Pöschl, S. Ward, and P. Owende. Evaluation of energy efficiency of various biogas production and utilization pathways. Applied Energy, $87(11): 3305-3321,2010$.

[23] J. Bekkering, A. A. Broekhuis, and W. J. T. van Gemert. Operational modeling of a sustainable gas supply chain. Engineering in Life Sciences, 10(6):585-594, 2010.

[24] J. Bekkering, A. A. Broekhuis, W. J. T. van Gemert, and E. J. Hengeveld. Balancing gas supply and demand with a sustainable gas supply chain A study based on field data. Applied Energy, 111:842-852, 2013.

[25] J. Gigler, T. van Wingerden, and H. Vlap. Challenges for Green Gas injection into the Natural Gas Grid. In International Gas Union Research conference, Seoul, 2011.

[26] J. N. R. Jonkman. Verkenning mogelijkheden invoeding groengas op het aardgasnetwerk van NV RENDO. NV Rendo, Meppel, 2011. www.rendonetwerken.nl/bestanden/documenten/327-onderzoekgroengasinjectie-totale-rendo-netwerk-definitief.pdf. Accessed at 12-22014 .

[27] R. Donders, E. van der Putten, and H. Holstein. Groen Gas Invoeding in het Gasnet. Endinet B.V. \& KEMA Nederland B.V., Eindhoven, 2010. http://groengas.nl/wp-content/uploads/2013/o1/2010-11o8-Groen-Gas-Invoeding-in-het-Gasnet-Scenario-Ontwikkeling.pdf. Accessed at 12-2-2014.

[28] G. Pahl, W. Beitz, J. Feldhusen, and H. Grote. Engineering Design - A systematic approach. Springer, Berlin, 3rd edition, 2007.

[29] J. M. Jauregui-Becker and W. W. Wits. A Template for Design for eXcellence ( DfX ) Methods. In Smart Product Engineering - Proceedings of the 23rd CIRP Design Conference, Bochum, Germany, March 11th - 13th, 2013, pages $33-42,2013$.

[30] C. Aretz and O. Donner. Biogas: Eine wichtige Komponente im Energiekonzept der Stadtwerke. gwf-Gas/Erdgas, (November):794-796, 2010. 
[31] L. T. Blessing and A. Chakrabarti. DRM, a Design Research Methodology. Springer London, London, 2009.

[32] T. D. Weidenaar, E. Bekkering, and R. van Eekelen. Scenarios for the Dutch gas distribution infrastructure in 2050. Working Papers of the Energy Delta Gas Research, ISSN 2213-6169, Groningen, 2012.

[33] P. J. Schoemaker. Scenario Planning: A Tool for Strategic Thinking. Sloan Management Review, 36(2):25-40, 1995.

[34] P. Schwartz. The Art of the Long View. Double Day, New York, 1991.

[35] CE Delft and Netbeheer Nederland. Net voor de Toekomst - een verkenning. Netbeheer Nederland, Arnhem, 2011. www.netbeheernederland.nl/Content/Files/373-3200o8-

Rapport $\% 20$ Net $\% 20$ voor $\% 20 d e \% 20$ Toekomst.pdf. Accessed at 12-22014.

[36] EC. Energy Roadmap 2050. European Commission, Brussels, 2011. http://ec.europa.eu/energy/energy2020/roadmap/doc/ com_2011_8852_en.pdf. Accessed at 12-2-2014.

[37] European Gas Advocacy Forum. Making the Green Journey Work - Optimised pathways to reach 2050 abatement targets with lower costs and improved feasibility. 2011. www.centrica.com/files/pdf/making_the_green_journey_work.pdf. Accessed at 12-2-2014.

[38] I. Graabak and B. H. Bakken. Scenarios for integration of large shares of renewable energy in Europe up to 2050. In IEEE PowerTech, pages 1-8, Trondheim, 2011.

[39] Shell. Shell energy scenarios to 2050. Shell, The Hague, 2008. www.shell.com/global/future-energy/scenarios/2050. Accessed at 12-22014.

[40] D. Keles, D. Möst, and W. Fichtner. The development of the German energy market until $2030-$ A critical survey of selected scenarios. Energy Policy, 39(2):812-825, 2011.

[41] ForschungVerbund Erneuerbare Energien. Energy Concept 2050 for Germany with a European and Global Perspective. Berlin, 2010. www.fvee.de/fileadmin/publikationen/Politische_Papiere_FVEE/ 10.06.Energy_Concept_2050/EK2010_EN.pdf. Accessed at 12-2-2014.

[42] H. Lund, F. Hvelplund, B. V. Mathiesen, P. A. Ostergaard, P. Christensen, D. Connolly, E. Schaltz, J. R. Pillay, M. Pagh Nielsen, C. Felby, N. Scott Bentsen, N. I. Meyer, D. Tonini, T. Astrup, 
K. Heussen, P. E. Morthorst, F. M. Andersen, M. Münster, L.L. P. Hansen, H. Wenzel, L. Hamelin, J. Munksgaard, P. Karnoe, and M. Lind. Coherent Energy and Environmental System Analysis. Department of Development and Planning, Aalborg, 2011. www.ceesa.plan.aau.dk/digitalAssets/32/32603_ceesa_final_report_samlet_ 02112011.pdf. Accessed at 12-2-2014.

[43] Redpoint Energy. ENA Gas Future Scenarios Project. ENA, 2010. www.energynetworks.org/modx/assets/files/news/publications/ ena_gas_future_scenarios_report.pdf. Accessed at 12-2-2014.

[44] Massachusetts Institute of Technology (MIT). The Future of natural Gas. MIT, Boston, 2010. http://mitei.mit.edu/system/files/NaturalGas_ Report.pdf. Accessed at 12-2-2014.

[45] Department of Energy and Climate Change (DECC). $205^{\circ}$ Pathways Analysis. DECC, United Kindom, 2010. www.gov.uk/government/uploads/system/uploads/attachment_data/file/ 42562/216-2050-pathways-analysis-report.pdf. Accessed at 12-2-2014.

[46] Wetenschappelijke en Technologische Commissie voor de Biobased Economy. Naar groene chemie en groene materialen. The Hague, 2011. http://edepot.wur.nl/165546. Accessed at 12-2-2014.

[47] DVGW. Mit Gas-Innovationen in die Zukunft! Bonn, 2011. www.dvgw.de/fileadmin/dvgw/angebote/forschung/broschuere_innovati onsoffensive11.pdf. Accessed at 12-2-2014.

[48] G. Linke. Power storage in smart natural gas grids: fiction or fact? In International Gas Union Research conference, Seoul, 2011.

[49] H. Krause and G. Müller-Syring. Das Erdgasnetz als Speicher für regenerative Energie. gwf-Gas/Erdgas, (November):764-770, 2010.

[5o] S. Bajohr, M. Götz, F. Graf, and F. Ortloff. Speicherung von regenerativ erzeugter elektrischer Energie in der Erdgasinfrastruktur. gwf-Gas/Erdgas, (April):200-211, 2011.

[51] D. C. North. Institutions, Institutional Change and Economic Performance (Political Economy of Institutions and Decisions). Cambridge University Press, Cambridge, 1990.

[52] N. A. Owen, O. R. Inderwildi, and D. A. King. The status of conventional world oil reserves - Hype or cause for concern? Energy Policy, 38(8):47434749, 2010.

[53] CBS. Energie balans. statline.cbs.nl. Accessed at 16-4-2011. 
[54] J. M. Jauregui-Becker, H. Tragter, and F. van Houten. Structure and models of artifactual routine design problems for computational synthesis. CIRP Journal of Manufacturing Science and Technology, 1(3):120-125, 2009.

[55] R. Madlener and C. Schmid. Spatial diffusion of biogas technology in Switzerland: a GIS-based multi-agent simulation approach. International Journal of Environment and Pollution, 39(1/2):28-43, 2009.

[56] C. Walla and W. Schneeberger. The optimal size for biogas plants. Biomass and Bioenergy, 32(6):551-557, 2008.

[57] M. Börjesson and E. O. Ahlgren. Cost-effective biogas utilisation - A modelling assessment of gas infrastructural options in a regional energy system. Energy, 48(1):212-226, 2012.

[58] Y. N. Blokhina, A. Prochnow, M. Plöchl, C. Luckhaus, and M. Heiermann. Concepts and profitability of biogas production from landscape management grass. Bioresource technology, 102(2):2086-92, 2011.

[59] M. Berglund and P. Börjesson. Assessment of energy performance in the life-cycle of biogas production. Biomass and Bioenergy, 30(3):254-266, 2006.

[6o] AgentschapNL. Bio-energie - Output - Groen Gas. AgentschapNL, 2011. www.biogas.nl/downloads/o432bio-energie-output-groen-gas.pdf. Accessed at 12-2-2014.

[61] S. M. Lensink, J. A. Wassenaar, M. Mozaffarian, S. L. Luxembourg, and C. J. Faasen. Basisbedragen in de SDE+ 2012. ECN, 2011. www.ecn.nl/docs/library/report/2011/e11046.pdf. Accessed at 122-2014.

[62] W. G. Sullivan, E. M. Wicks, and J. T. Luxhoj. Engineering Economy. Pearson Education, New Jersey, 13th edition, 2006.

[63] AgentschapNL. Voorlopige Corrrectiebedragen stimulering duurzame energieproductie 2012 ten behoeve van voorschotverlening $2012 . \quad$ AgentschapNL, 2012. www.accountancynieuws.nl/Uploads/Files/Voorlopige-Correctie bedragen-2012.pdf. Accessed at 12-2-2014.

[64] SenterNovem. Cijfers en tabellen 2007. SenterNovem, Utrecht, 2007. www.rijksoverheid.nl/documenten-en-publicaties/brochures/2010/ o8/23/cijfers-en-tabellen-2007. Accessed at 12-2-2014.

[65] H. Levinsky and M. van Rij. Gaskwaliteit voor de toekomst. KEMA Nederland B.V., Groningen, 2011. www.rijksoverheid.nl/documenten-enpublicaties/rapporten/2011/o3/28/gaskwaliteit-voor-de-toekomst-1. Accessed at 12-2-2014. 
[66] MilieuCentraal. Energieprijzen. http://www.milieucentraal.nl/themas/energie-besparen/energieprijzen. Accessed at 8-2-2013.

[67] P. Forster, V. Ramaswarmy, P. Artaxo, T. Berntsen, R. Betts, D. Fahey, J. Haywood, J. Lean, D. Lowe, G. Myhre, J. Nganga, R. Prinn, G. Raga, M. Schulz, and R. Van Dorland. Changes in Atmosperic Constituents and in Radiative Forcing. In S. Solomon, D. Qin, M. Manning, Z. Chen, M. Marquis, K. Averyt, M. Tignor, and H. Miller, editors, Climate change 2007: The Physical Science Basis. Contribution of Working Group I to the Fourth Assessment Report of the Intergovernmental Panel on Climate Change, chapter 2. Cambridge University Press, Cambridge, 2007.

[68] P. Weiland. Biogas production: current state and perspectives. Applied microbiology and biotechnology, 85(4):849-60, 2010.

[69] C. N. Hamelinck, R. A. Suurs, and A. P. Faaij. International bioenergy transport costs and energy balance. Biomass and Bioenergy, 29(2):114-134, 2005 .

[70] TLN. Dieselprijs. www.tln.nl/BM_diesel_nl.html. Accessed at 19-8-2013.

[71] M. Ball, M. Wietschel, and O. Rentz. Integration of a hydrogen economy into the German energy system: an optimising modelling approach. International Journal of Hydrogen Energy, 32(10-11):1355-1368, 2007.

[72] W. Urban, K. Girod, and H. Lohmann. Technologien und Kosten der Biogasaufbereitung und Einspeisung in das Erdgasnetz. Ergebnisse der Markterhebung 2007-2008. Fraunhofer UMSICHT, Oberhausen, 2009. http://publica.fraunhofer.de/dokumente/N-94887.html. Accessed at 142-2014.

[73] G. Häring, M. Sonnleitner, W. Zörner, E. Brügging, C. Bücker, C. Wetter, and R. Vogt. Handreichung zur optimierung von biogasanlagen. Hochschule Ingolstadt, Fachhochschule Münster, IFEU Heibdelberg, 2010. www.thi.de/fileadmin/daten/forschung/Kompetenzfeld/Hand reichung_Biogas.pdf. Accessed at 12-2-2014.

[74] J. Holstein, R. Bakker, L. Grond, and M. Vos. Overstort van het distributienet naar het landelijke transportnet - Verkenning generiek raamwerk ontwikkeling van een overstortregeling ten behoeve van groengas accommodatie. KEMA Nederland B.V., Groningen, 2011. http://groengas.nl/report/overstortvan-het-distributienet-naar-het-landelijk-transportnet. Accessed at 12-22014.

[75] H. A. Zondag, M. de Rooij, and R. de Boer. Compact $\mathrm{CH}_{4}$ storage with solid sorbents and gas hydrates: Materials and techno-economic evaluation. ECN, 2012. 
[76] G. Cerbe, M. Dehli, J. E. Kätelhön, T. Kleiber, J. Lehmann, B. Lendt, J. Mischner, B. Mundus, H. Pietsch, D. Spohn, and W. Thielen. Grundlagen der Gastechnik. Carl Hanser Verlag, München, 6th edition, 2004.

[77] J. te Riele, G. Hendriks, and A. Schwartz. GWW Kosten. Leidingwerk, gas en water. H.J.M. Klein Gunnewiek, Doetinchem, $7^{\text {th }}$ edition, 2004.

[78] F. Bauer, T. Persson, C. Hulteberg, and D. Tamm. Biogas upgrading - technology overview, comparison and perspectives for the future. Biofuels, Bioproducts and Biorefining, 7(5):499-511, 2013.

[79] TU-Wien. Biogas to biomethane technology review. TU-Wien, Vienna, 2012. www.severnwye.org.uk/BiomethaneRegions/downloads/BiogasUpgradingTechnologyReview_EN.pdf. Accessed at 12-2-2014.

[8o] J. Bärnthaler, H. Bergman, D. Hornbachner, G. Konrad, V. Kryvoruchko, L. Targyik-Kumer, C. Pinter, and C. Wartha. Gasversorgung mittels lokaler Biogas-Mikronetze. Bundesministerium für Verkehr, Innovation und Technologie, Vienna, 2009. www.biogasnetzeinspeisung.at/downloads/20080930_endbericht_mikronetze.pdf. Accessed at 12-2-2014.

[81] N. Keyaerts, M. Hallack, J.-M. Glachant, and W. D’haeseleer. Gas market distorting effects of imbalanced gas balancing rules: Inefficient regulation of pipeline flexibility. Energy Policy, 39(2):865-876, 2011.

[82] J. M. Jauregui-Becker, W. W. Wits, and F. J. A. M. van Houten. Modeling Complexity in Engineering Routine Design. In CIRP Design Conference, 2011.

[83] A. Hugo, P. Rutter, S. Pistikopoulos, A. Amorelli, and G. Zoia. Hydrogen infrastructure strategic planning using multi-objective optimization. International Journal of Hydrogen Energy, 30(15):1523-1534, 2005.

[84] M. Kuby, L. Lines, R. Schultz, Z. Xie, J.-G. Kim, and S. Lim. Optimization of hydrogen stations in Florida using the Flow-Refueling Location Model. International Journal of Hydrogen Energy, 34(15):6045-6064, 2009.

[85] R. Bapna, L. S. Thakur, and S. K. Nair. Infrastructure development for conversion to environmentally friendly fuel. European Journal of Operational Research, 142(3):480-496, 2002.

[86] A. Zamboni, F. Bezzo, and N. Shah. Spatially Explicit Static Model for the Strategic Design of Future Bioethanol Production Systems. 2. MultiObjective Environmental Optimization. Energy \& Fuels, 23(10):51345143,2009 . 
[87] A. Molyneaux, G. Leyland, and D. Favrat. Environomic multi-objective optimisation of a district heating network considering centralized and decentralized heat pumps. Energy, 35(2):751-758, 2010.

[88] P. Voll, M. Hennen, C. Klaffke, M. Lampe, and A. Bardow. Exploring the Near-Optimal Solution Space for the Synthesis of Distributed Energy Supply Systems. Chemical Engineering Transactions, 35:277-282, 2013.

[89] G. Celli, E. Ghiani, S. Mocci, and F. Pilo. A Multiobjective Evolutionary Algorithm for the Sizing and Siting of Distributed Generation. IEEE Transactions on Power Systems, 20(2):750-757, 2005.

[9o] E. Carrano, L. Soares, R. Takahashi, R. Saldanha, and O. Neto. Electric Distribution Network Multiobjective Design Using a Problem-Specific Genetic Algorithm. IEEE Transactions on Power Delivery, 21(2):995-1005, 2006.

[91] N. Johnson and J. Ogden. A spatially-explicit optimization model for longterm hydrogen pipeline planning. International Journal of Hydrogen Energy, 37(6):5421-5433, 2012.

[92] H. Y. Lee and T. H. Cho. $A^{*}$-based layout design for gratings allocation. Computer-Aided Design, 40(4):455-464, 2008.

[93] K. Deb. Multi-Objective Optimization using Evolutionary Algorithms. John Wiley \& Sons, 1st edition, 2009.

[94] Microsoft. Visual C\# 2010 Express. http://www.visualstudio.com/ downloads/download-visual-studio-vs\#DownloadFamilies_4. Accessed at 11-2-2014.

[95] T. D. Weidenaar, E. Bekkering, J. M. Jaurequi Becker, S. Hoekstra, and M. Wolters. Finding robust investments for the Dutch gas distribution infrastructure in 2050 by a scenario study. In Proceedings of ECOS 2013 The 26th International Conference on Efficiency, Cost, Optimization, Simulation and Environmental Impact of Energy Systems, Guilin, 2013.

[96] CBS. COROP-gebieden. www.cbs.nl/nl-NL/menu/methoden/ toelichtingen/alfabet/c/coropgebieden.htm. Accessed at 21-6-2013.

[97] CBS. Statline. statline.cbs.nl/StatWeb/carto/?LA=NL. Accessed at 26-82013 .

[98] J. Koppejan, W. Elbersen, M. Meeusen, and P. Bindraban. Beschikbaarheid van Nederlandse biomassa voor elektriciteit en warmte in 2020. SenterNovem, Utrecht, 2009. http://edepot.wur.nl/51989. Accessed at 12-2-2014. 
[99] R. Zwart. Synthetic Natural Gas (SNG) Large-scale introduction of green natural gas in existing gas grids. ECN, 2007. www.ecn.nl/docs/library/report/2007/lo7069.pdf. Accessed at 12-22014.

[100] CBS. Dierlijke mest en mineralen; productie, transport en gebruik per regio. statline.cbs.nl/StatWeb/selection/ default.aspx?DM=SLNL\&PA=7311SLMI\&VW=T. Accessed at 1-8-2013.

[101] H. van den Boom. Benchmark (co-)vergisting boekjaar 2010: Rendement door markt in verdrukking! Rabobank, 2011. http://groengas.nl/report/benchmark-co-vergisting-boekjaar-2010. Accessed at 12-2-2014.

[102] Wikipedia. Erneuerbare-Energien-Gesetz. de.wikipedia.org/wiki/Erneuerbare-Energien-Gesetz. Accessed at 15-82013. 


\section{Part V}

\section{Appendices}





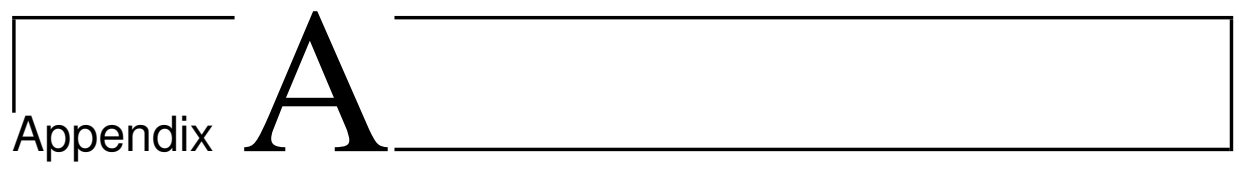

\section{Scenario dependent variables}

This chapter lists the values for the scenario dependent variables in each scenario, and it describes how these values were determined. The values for the scenario dependent variables are listed in Table A.1. The remainder of this chapter describes how these values were derived.

\begin{tabular}{llllll}
\hline & $\begin{array}{l}\text { Nominal } \\
\text { value }\end{array}$ & $\begin{array}{l}\text { Business } \\
\text { as usual }\end{array}$ & $\begin{array}{l}\text { Carbon } \\
\text { Con- } \\
\text { straints }\end{array}$ & $\begin{array}{l}\text { Tight } \\
\text { Market }\end{array}$ & $\begin{array}{l}\text { Rene- } \\
\text { wable } \\
\text { Self-suf- } \\
\text { ficiency }\end{array}$ \\
\hline $\begin{array}{l}\text { Biomass avail- } \\
\text { ability factor }\end{array}$ & 1 & 0.25 & 1 & 1 & 2 \\
$\begin{array}{l}\text { Gas demand fac- } \\
\text { tor }\end{array}$ & 1 & 0.83 & 0.67 & 0.67 & 0.5 \\
$\begin{array}{l}\text { Biomethane sub- } \\
\text { sidy [€ct/m }{ }^{3} \text { (n)] }\end{array}$ & 47.3 & 0 & 47.3 & 47.3 & 94.6 \\
$\begin{array}{l}\text { Gas retail price } \\
{\left[€ c t / m^{3}(\mathrm{n})\right]}\end{array}$ & 24.7 & 24.7 & 24.7 & 49.4 & 49.4 \\
$\begin{array}{l}\text { Electricity price } \\
{[€ c t / k W h]}\end{array}$ & 7 & 7 & 7 & 14 & 14 \\
$\begin{array}{l}\text { Transport fuel } \\
\text { price [€ct/kWh] }\end{array}$ & 12.6 & 2.53 & 2.53 & 5.06 & 5.06 \\
\hline
\end{tabular}

Table A.1: Values of the scenario dependent variables 


\section{Biomass availability}

The biomethane potential that was defined per scenario in Chapter 2 (see Table 2.7) was used to derive the biomass availability for this analysis.

Since the biomethane potential in the Carbon Constraint and Tight Market scenarios is equal to the nominal biomethane potential, the biomass availability of these scenarios is also equal to the nominal biomass availability.

In the Business as Usual scenario, biomass availability is only $25 \%$ of the nominal situation. We assumed that in this scenario only one fourth of the farmers that have biomass available in the nominal situation want to use their biomass for biomethane production. This was achieved by omitting 3 out of 4 biomass locations from the nominal start configuration, which was done randomly.

Furthermore, biomass availability in the Renewable Self-sufficiency scenario is double that of the nominal situation. Since energy crops are allowed in this scenario, this availability was achieved by letting the farmers have $25 \%$ extra biomass available. The remaining $75 \%$ extra biomass came from 1 or 2 biomass centers that have imported biomass available. These were located near harbors.

\section{Gas demand factor}

The extent to which the hourly gas demand will change in the year 2050 compared to the nominal situation was based on the low value heat demand determined for each scenario in Chapter 2 (see Table 2.4). We considered this a good measure for the future hourly gas demand, since low value heat is the energy required for space heating and hot water supply, which is currently for the largest part satisfied by natural gas. The hourly gas demand in 2050 was found by multiplying the nominal hourly gas demand by the gas demand factor. The gas demand factor was found by dividing the low value heat demand in the scenario by the demand in 2008 :

$$
\text { Gas demand factor }=\frac{\text { low value heat } 2050}{\text { low value heat } 2008}
$$

\section{Transport fuel}

A trend in the future scenarios is that there is no cheap oil left in 2050. Instead of oil, natural gas will be used as transport fuel in each scenario. Therefore, the price of $1 \mathrm{kWh}$ of fuel is equal to $1 \mathrm{kWh}$ of natural gas. The higher heating value of natural gas is $9.77 \mathrm{kWh} / \mathrm{m}^{3}(\mathrm{n})$. So the price for transport fuel could be derived from the natural gas price. The same holds for the $\mathrm{CO}_{2}$ emission of transport fuel, which in this study was the same as for natural gas, namely: 0.182 $\mathrm{kg} / \mathrm{kWh}$. 


\section{Electricity and gas price:}

In the Business as Usual and Carbon Constraint scenarios there is no perceived scarcity of energy resources. This means that there will be no significant increase in the electricity and natural gas price. We chose to set the price of $1 \mathrm{kWh}$ of electricity and $1 \mathrm{~m}^{3}(\mathrm{n})$ of natural gas equal to the 2012 value.

In the Tight Market and Renewable Self-sufficiency scenario there is a perceived scarcity of energy resources. Due to this scarcity, energy prices will rise compared to today's prices. We assumed that the price for electricity and natural gas doubles in these scenarios compared to today.

\section{Biomethane subsidy}

In the Business as Usual scenario, the market determines the energy mix. There is no willingness to reduce $\mathrm{CO}_{2}$ emission and no necessity to secure energy supply. Therefore, biomethane will only be produced when it can compete with natural gas, and the subsidy for biomethane was set to zero in this scenario. Note that from a subsidy perspective, the name Business as Usual is a bit strange, since at the moment biomethane production is subsidized. Business as Usual, however, refers more to the design of the gas grid, to which momentarily only limited volumes of biomethane are injected. With the subsidy regime defined in this scenario, this situation is not likely to change much.

In the Carbon Constraints scenario, biomethane is stimulated to reduce $\mathrm{CO}_{2}$ emissions. Since biomethane is preferred over natural gas, the producers of biomethane will be awarded with a certain amount of subsidy. The biomethane subsidy was set at the current level.

In the Tight Market scenario, there is no incentive to reduce $\mathrm{CO}_{2}$ emissions. However, due to the perceived energy scarcity, biomethane will be stimulated in order to diversify energy sources and reduce dependency on foreign energy sources. Biomethane subsidy was set at the current level.

In the Renewable Self-sufficiency scenario, biomethane is stimulated in order to reduce $\mathrm{CO}_{2}$ emissions and to reduce dependency on foreign energy sources. Due to the combination of these two factors, biomethane will receive a higher subsidy than in the Carbon Constraints and Tight Market scenarios. Biomethane subsidy in this scenario was set at twice that of today's value.

\section{Biomethane quality}

In Carbon constraints and Renewable Self-sufficiency the gas grid is adjusted to biogas quality. So no upgrading of the biogas is needed. In the DST this was simulated by setting the cost for upgrading to zero. 



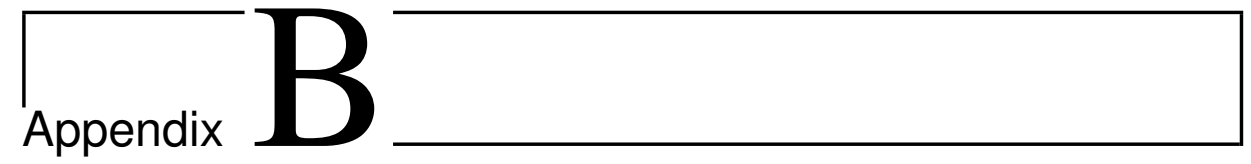

\section{Sensitivity analysis}

This chapter describes some parts of the sensitivity analysis in more detail. First in section B.1 the factors and their values are described in more detail. Secondly, section B.2 gives the results of the sensitivity analysis done for the intermediate region.

\section{B.1 Factors}

This section describes the factors that were varied in the sensitivity analysis, why they are likely to vary, and why they have an impact on the performance of the three biomethane supply chain design types. Table B.1 lists all the factors that have been varied, including their nominal, low, and high value. The variation of each factor is symmetrical, and the absolute value of the variation was determined by evaluating what a realistic variation would be. Therefore, in terms of percentage the variation of the factor values was not the same for all factors.

In the remainder of this section, the chosen factors and their values are described.

\section{Biomass cost (A)}

The cost of biomass fluctuates strongly. To give an example, the price of maize increased with $50 \%$ in the year 2011 compared to the year 2010 [61]. In addition, one of the main funders of biogas projects, Rabobank, expressed its concerns regarding the increasing biomass prices [101]. Rabobank expects that biomass prices will rise further and this will likely lead to a further reduction in profits among the different digester installations in the Netherlands. Hence, the costs for biomass is one of the main concerns within the field of biomethane production. 


\begin{tabular}{lllll}
\hline & Factor & $\begin{array}{l}\text { Nominal } \\
\text { value }\end{array}$ & $\begin{array}{l}\text { Low } \\
\text { value }\end{array}$ & $\begin{array}{l}\text { High } \\
\text { value }\end{array}$ \\
\hline A & Biomass cost $[€ \mathrm{ct} / \mathrm{kg}]$ & 3.1 & 1.5 & 4.5 \\
$\mathrm{~B}$ & Biogas yield $\left[\mathrm{m}^{3}(\mathrm{n}) / \mathrm{kg}\right]$ & 0.16 & 0.08 & 0.24 \\
$\mathrm{C}$ & Economic life of project [years] & 12 & 9 & 15 \\
$\mathrm{D}$ & Pipeline costs & 1 & 0.8 & 1.2 \\
E & Natural gas price + subsidy [€ct $\left./ \mathrm{m}^{3}(\mathrm{n})\right]$ & 72 & 64.8 & 79.2 \\
$\mathrm{~F}$ & Electricity price [€ct $/ \mathrm{kWh}]$ & 7 & 5 & 9 \\
$\mathrm{G}$ & Biomass transport costs & 1 & 0.8 & 1.2 \\
$\mathrm{H}$ & Digester installation costs & 1 & 0.8 & 1.2 \\
$\mathrm{I}$ & Upgrading plant costs & 1 & 0.8 & 1.2 \\
\hline
\end{tabular}

Table B.1: Factors that were varied and their nominal, low, and high value

We let the cost of biomass vary with $50 \%$. With a nominal value of $3.1 € \mathrm{ct} / \mathrm{kg}$, this resulted in a low value of $1.5 € \mathrm{ct} / \mathrm{kg}$, and a high value of $4.5 € \mathrm{ct} / \mathrm{kg}$.

\section{Biogas yield (B)}

The model uses one standard biomass type. As a consequence, the biogas yield is the same for all biomass. In practice, however, the biomass type and biogas yield vary strongly. For instance, when digesting only cow manure, biogas yields are very low, about $0.024 \mathrm{~m}^{3}(\mathrm{n}) / \mathrm{kg}[22]$. Maize on the other hand has a much higher biogas yield, namely $0.202 \mathrm{~m}^{3}(\mathrm{n}) / \mathrm{kg}[22]$.

In this analysis, we let the biogas yield vary with $50 \%$ compared to its nominal value of $0.16 \mathrm{~m}^{3}(\mathrm{n}) / \mathrm{kg}$. Resulting in a low value of $0.08 \mathrm{~m}^{3}(\mathrm{n}) / \mathrm{kg}$, and a high value of $0.24 \mathrm{~m}^{3}(\mathrm{n}) / \mathrm{kg}$.

\section{Economic life of project $(C)$}

At the moment, in the Netherlands, subsidies for renewable energy are granted for 12 years [61]. As a consequence, it is logical to use a depreciation period of 12 years for investments in a biomethane project. However, a longer economic life could also be possible. In Germany, for instance, subsidies are granted for 20 years [102]. The opposite could also be the case, when due to economic uncertainties a shorter economic life is used to evaluate the project. A longer subsidy period and economic life benefits a project economically. Furthermore, a longer economic life favors building blocks with higher capital costs over components with high operational costs, and vice versa.

For the high value we used 15 years, and for the low value 9 years. The biomethane subsidy period in this analysis was equal to the economic life of the project. 


\section{Pipeline costs (D)}

Although the model already uses different pipeline laying costs for urban and rural areas, in practice the costs will fluctuate even more. When crossing rivers, roads, or junctions, for example, the costs will rise significantly. Since a biomethane supply chain consists of a number of gas pipelines, the pipeline costs are an important factor to take into account.

The pipeline costs, both material and laying costs, were varied with $20 \%$ compared to their nominal value.

\section{Natural gas price \& subsidy (E)}

In biomethane projects, a financial compensation is given for each cubic meter of biomethane that is injected into the gas grid. This compensation is composed of (1) the natural gas price and (2) subsidy for biomethane. The natural gas price and biomethane subsidy determine to a large extent whether a project will be profitable or not.

In this analysis, we let the combined value of the natural gas price and biomethane subsidy vary with $10 \%$. How the compensation is broken down in biomethane subsidy and natural gas price is not of interest for the biomethane producer. We chose to vary the subsidy and keep the natural gas price fixed. The low value for subsidy was $40.1 € \mathrm{ct} / \mathrm{m}^{3}(\mathrm{n})$ and the high value was $54.5 € \mathrm{ct} / \mathrm{m}^{3}(\mathrm{n})$. When adding the biomethane subsidy and natural gas price, a low value is obtained of $64.8 € \mathrm{ct} / \mathrm{m}^{3}(\mathrm{n})$ and a high value of $79.2 € \mathrm{ct} / \mathrm{m}^{3}(\mathrm{n})$.

\section{Electricity price (F)}

Electricity is required to power digester installations, upgrading plants, compressors, and gas storages. Therefore, its price affects the economic performance of biomethane projects.

We let the electricity price vary with $20 \%$. With a nominal price of $7 € \mathrm{ct} / \mathrm{kWh}$, this resulted in a low value of $5 € \mathrm{ct} / \mathrm{kWh}$ and a high value of $9 € \mathrm{ct} / \mathrm{kWh}$.

\section{Biomass transport costs $(\mathrm{G})$}

Fuel prices tend to vary. To give an indication: between 2008 and mid-2013 prices of diesel have varied between $0.82 €$ and $1.30 €[70]$. The costs of biomass transport might determine whether central digestion or local digestion with a central upgrading plant is preferred. Higher transport costs will deteriorate the economic performance of the design with central digestion compared to the designs with local digestion.

The biomass transport costs - which includes flat kilometer cost, loading/unloading cost, and transport fuel cost - were varied with $20 \%$ compared to its nominal value. 


\section{Digester installation costs $(\mathrm{H})$}

The digester installation forms one of the largest expenses within a biomethane project. Hence, a fluctuation in digester installation costs will have a strong impact on the project's economic performance.

The capital and operational cost of the different digester installations in the model were varied with $20 \%$ compared to their nominal values.

\section{Upgrading plant costs (I)}

Just as the digester installation, the upgrading plant also forms one of the larger expenses within a biomethane project.

The capital and operational cost of the upgrading plants in the model have been varied with $20 \%$ compared to their nominal values.

\section{B.2 Sensitivity analysis on the intermediate region}

The sensitivity analysis presented in section 6.1 was also done for the intermediate region. The results of this analysis are listed here.

\section{B.2.1 Biomethane supply chain design types}

The three design types are shown in Figures B.1 - B.3. The NPV and biomethane cost for these three designs for the nominal values are shown in Table B.2. As can be seen, in the nominal situation, the Biomass transport has the highest NPV as well as the lowest biomethane cost. The Biogas hub design ranks second, and the Local for local design scores worst. These findings are similar to the findings for the urban region in chapter 6.

The breakdown of the biomethane cost for the three design types is shown in Table B.3. Although, these values are not entirely similar to the values found for the urban region, the main findings are comparable. That is, the cost for biomass and digestion contribute significantly to the biomethane cost of each design. Furthermore, the digestion cost for the Biomass transport design is significantly lower than the digestion cost for the other two designs. And the cost for upgrading, injection, and biomethane pipelines is significantly higher for the Local for local design than for the other two designs.

\section{B.2.2 Results}

The NPV values for each design for the high and low values of each factor are listed in Table B.4, and are graphically displayed in Figure B.4. The biomethane costs for each design and each factor are listed in Table B.5, and are also graphically displayed in Figure B.5. 


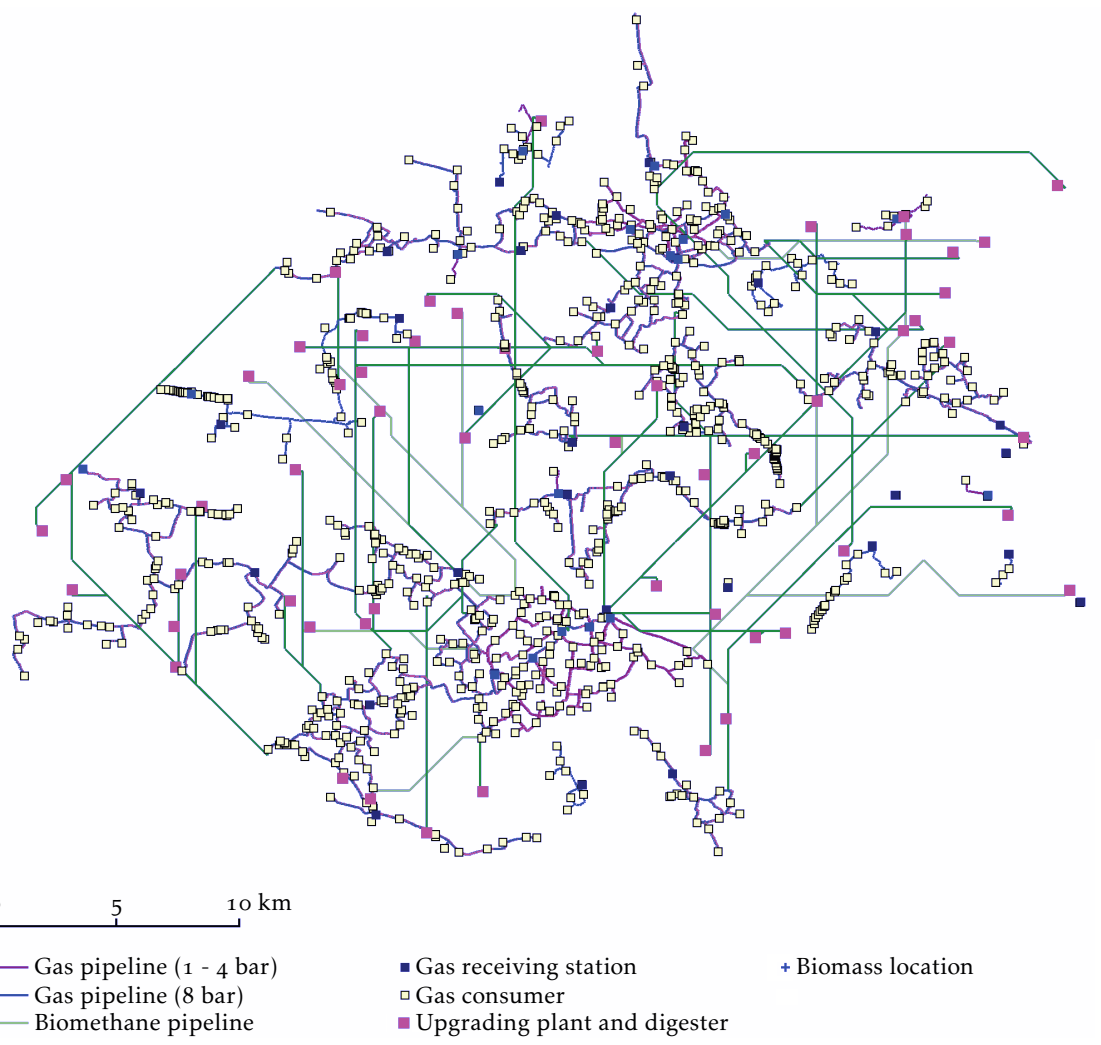

Figure B.1: The Local for local design, which is characterized by local digestion and local upgrading. (Intermediate region)

\begin{tabular}{llll}
\hline & Local for local & Biogas hub & Biomass transport \\
\hline NPV $[\mathrm{M} €]$ & $-95 \cdot 3$ & -42.7 & 27.1 \\
Biomethane cost $\left[€ / \mathrm{m}^{3}(\mathrm{n})\right]$ & 1.11 & 0.89 & 0.61 \\
\hline
\end{tabular}

Table B.2: Performance indicators for the tree biomethane supply chain designs with nominal values. (Intermediate region) 


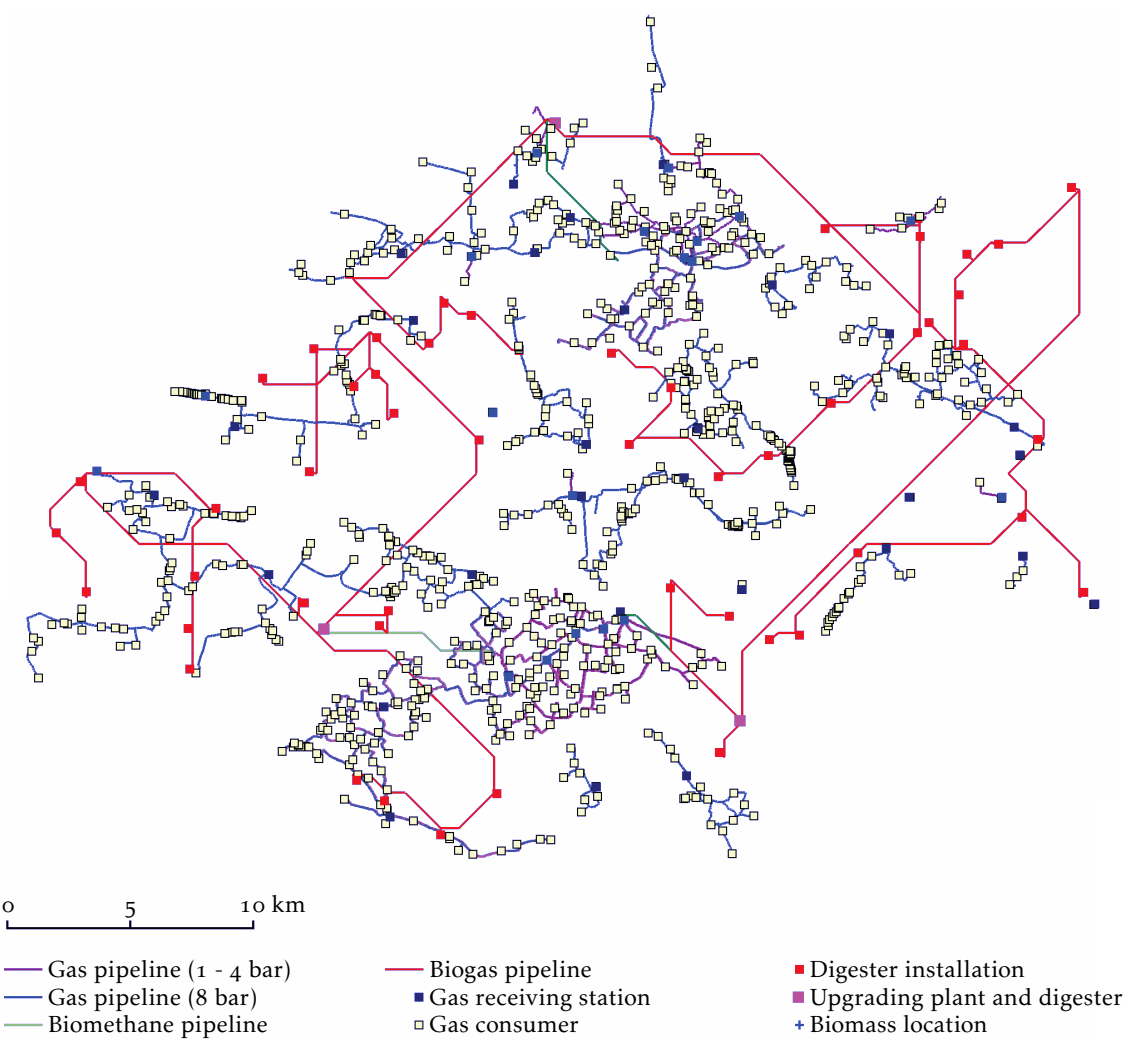

Figure B.2: The Biogas hub design, which is characterized by local digestion and central upgrading. (Intermediate region)

As can be seen in Figure B.4 and Figure B.5, the biomass cost and biogas yield strongly vary the NPV and biomethane cost of the three designs. Furthermore, an increase in the economic life of the project slightly increases NPV and decreases biomethane cost. The pipeline cost have no effect on the NPV and biomethane cost of the Biomass transport design, and only a minor effect on the other two designs. The electricity price and biomass transport costs have hardly any impact on the economic performance of the three designs. Whereas, the gas retail price \& subsidy, digester installation cost and upgrading cost have a larger impact on the economic impact. These findings are all in line with the findings in section 6.1. 


\begin{tabular}{llll}
\hline & Local for local & Biogas hub & Biomass transport \\
\hline Biomass & 32.9 & 32.9 & 32.9 \\
Biomass transport & o & 0 & 2.3 \\
Digestion & 31.7 & 31.7 & 17.2 \\
Biogas treatment & $\mathrm{O}$ & 2.1 & 0 \\
Compression & $\mathrm{O}$ & 3.9 & $\mathrm{O}$ \\
Biogas pipelines & $\mathrm{O}$ & 10.0 & 0 \\
Upgrading & 25.3 & 7.8 & $7 \cdot 5$ \\
Injection & 4.1 & 0.2 & 0.2 \\
Biomethane pipelines & 17.0 & 0.8 & 0.8 \\
\hline Capital cost & 56.1 & 37.1 & 15.9 \\
Operational cost & 54.7 & 52.3 & 45.1 \\
\hline Total & 110.9 & 89.4 & 60.9 \\
\hline
\end{tabular}

Table B.3: Breakdown of the biomethane cost for the three biomethane supply chain designs $\left[€ c t / \mathrm{m}^{3}(\mathrm{n})\right]$. (Intermediate region)

\begin{tabular}{|c|c|c|c|c|c|c|c|}
\hline \multicolumn{2}{|c|}{ Factor } & \multicolumn{2}{|c|}{ Local for local } & \multicolumn{2}{|c|}{ Biogas hub } & \multicolumn{2}{|c|}{$\begin{array}{l}\text { Biomass } \\
\text { transport }\end{array}$} \\
\hline & & low & high & low & high & low & high \\
\hline A & Biomass cost & -54 & -132 & -1 & -79 & 6.9 & -9 \\
\hline $\mathrm{B}$ & Biomass yield & -153 & -48 & -95 & -3 & -37 & 81 \\
\hline $\mathrm{C}$ & Economic life of project & -103 & -89 & -51 & -36 & 16 & 36 \\
\hline $\mathrm{D}$ & Pipeline costs & -88 & -103 & -39 & -46 & 27 & 27 \\
\hline $\mathrm{E}$ & Gas retail price \& subsidy & -113 & -78 & -60 & -25 & 9 & 45 \\
\hline $\mathrm{F}$ & Electricity price & -92 & -98 & -39 & -46 & 30 & 24 \\
\hline G & Biomass transport costs & -95 & -95 & -43 & -43 & 28 & 26 \\
\hline $\mathrm{H}$ & Digester installation costs & -80 & -110 & -28 & -58 & 35 & 19 \\
\hline I & Upgrading plant costs & -84 & -106 & -40 & -45 & 29 & 25 \\
\hline
\end{tabular}

Table B.4: NPV [M€] of the 3 designs for the high and low values of the factors. (Intermediate region) 


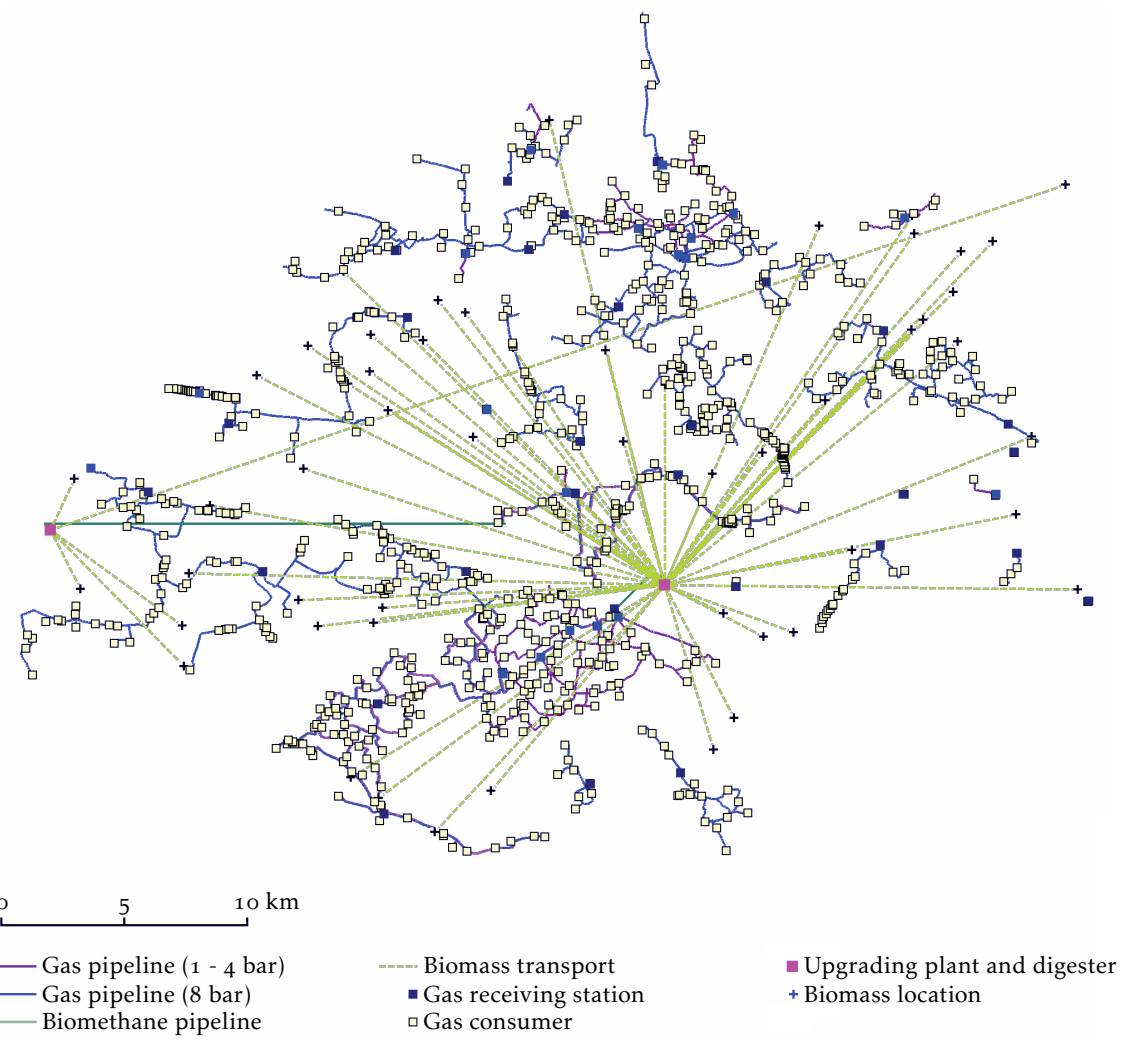

Figure B.3: The Biomass transport design, which is characterized by central digestion and central upgrading. (Intermediate region) 


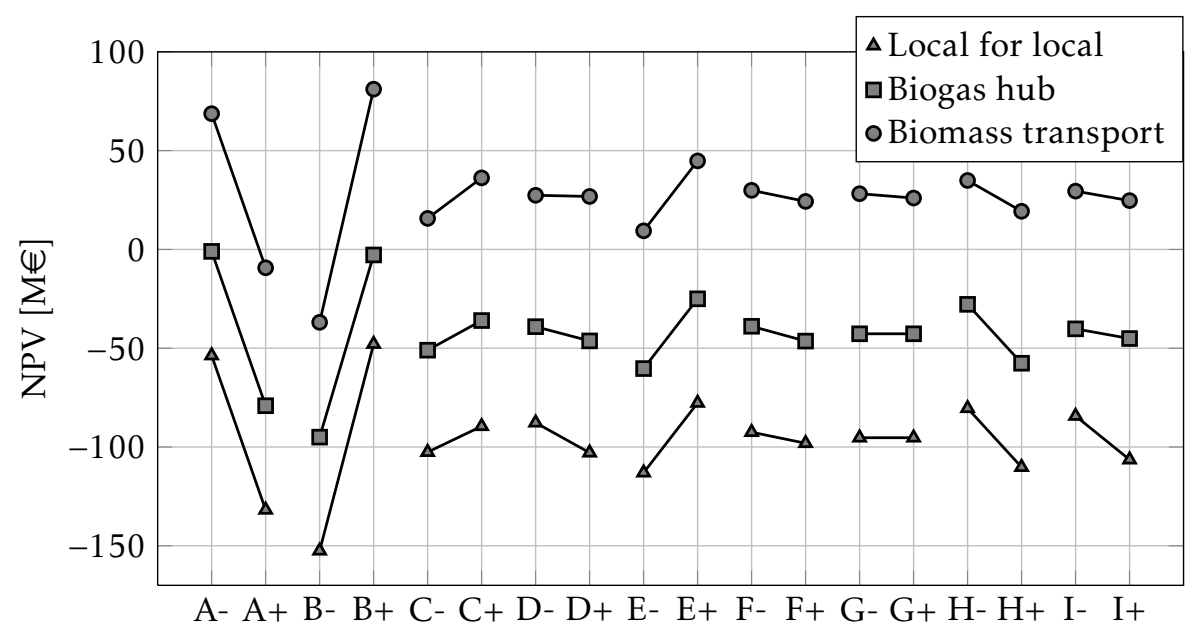

Figure B.4: NPV for the low and high values of the factors. (Intermediate region)

\begin{tabular}{llllllll}
\hline Factor & \multicolumn{2}{c}{ Local for local } & \multicolumn{2}{c}{ Biogas hub } & \multicolumn{2}{c}{ Biomass } \\
& & low & high & low & high & low & high \\
\hline A & Biomass cost & 0.94 & 1.26 & 0.72 & 1.04 & 0.44 & 0.76 \\
B & Biomass yield & 1.96 & 0.85 & 1.49 & 0.73 & 1.02 & 0.50 \\
C & Economic life of project & 1.23 & 1.04 & 0.97 & 0.85 & 0.64 & 0.59 \\
D & Pipeline costs & 1.08 & 1.14 & 0.88 & 0.91 & 0.61 & 0.61 \\
E & Gas retail price \& subsidy & 1.11 & 1.11 & 0.89 & 0.89 & 0.61 & 0.61 \\
F & Electricity price & 1.10 & 1.12 & 0.88 & 0.91 & 0.60 & 0.62 \\
G & Biomass transport costs & 1.11 & 1.11 & 0.89 & 0.89 & 0.60 & 0.61 \\
H & Digester installation costs & 1.05 & 1.17 & 0.83 & 0.95 & 0.58 & 0.64 \\
I & Upgrading plant costs & 1.06 & 1.15 & 0.88 & 0.90 & 0.60 & 0.62 \\
\hline
\end{tabular}

Table B.5: Biomethane cost $\left[€ / \mathrm{m}^{3}(\mathrm{n})\right]$ of the 3 designs for the high and low values of the factors. (Intermediate region) 


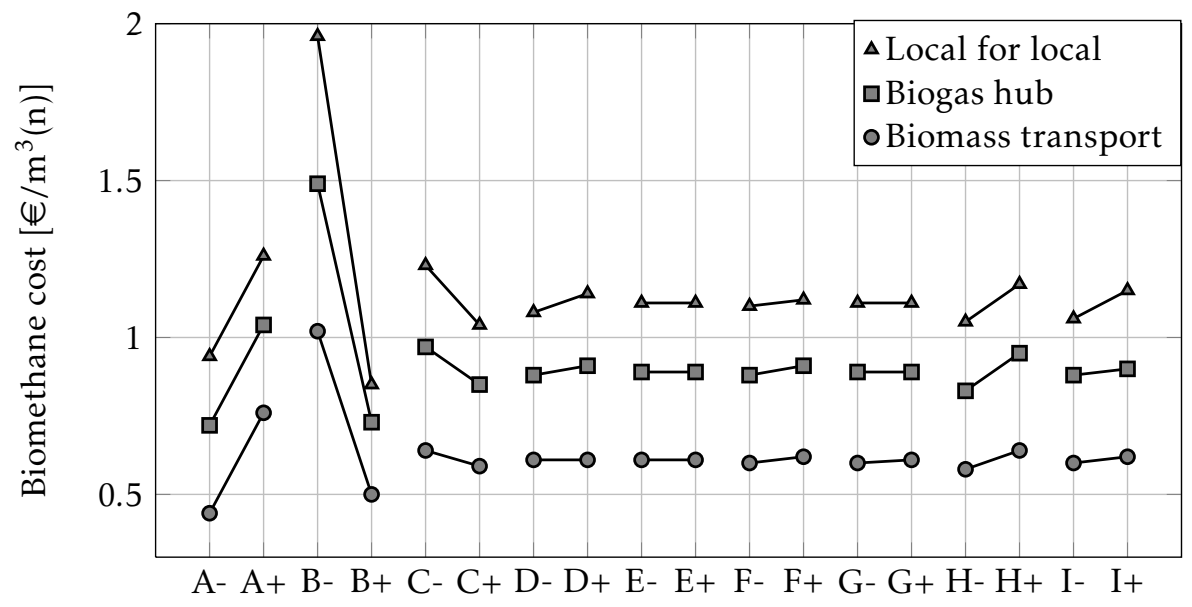

Figure B.5: Biomethane cost for the low and high values of the factors. (Intermediate region) 